\title{
VIABILIDADE AGRONÔMICO-AMBIENTAL DA DISPOSIÇÃO DE EFLUENTE DE ESGOTO TRATADO EM UM \\ SISTEMA SOLO-PASTAGEM
}

\section{ADRIEL FERREIRA DA FONSECA}

\author{
Tese apresentada à Escola Superior de Agricultura \\ "Luiz de Queiroz", Universidade de São Paulo, para \\ obtenção do título de Doutor em Agronomia, Área \\ de Concentração: Solos e Nutrição de Plantas.
}

\author{
P I R A C I C A B A
}

Estado de São Paulo - Brasil

Maio - 2005 


\section{VIABILIDADE AGRONÔMICO-AMBIENTAL DA DISPOSIÇÃO DE EFLUENTE DE ESGOTO TRATADO EM UM SISTEMA SOLO-PASTAGEM}

\section{ADRIEL FERREIRA DA FONSECA}

Engenheiro Agrônomo

Orientador: Prof. Dr. ADOLPHO JOSÉ MELFI

\footnotetext{
Tese apresentada à Escola Superior de Agricultura "Luiz de Queiroz", Universidade de São Paulo, para obtenção do título de Doutor em Agronomia, Área de Concentração: Solos e Nutrição de Plantas.
}

P I R A C I C A B A

Estado de São Paulo - Brasil

Maio - 2005 
Dados I nt er naci onai s de Cat al ogação na Publ i cação ( $C I P$ ) DI VI SÃO DE BI BLI OTECA E DOCUMENTAÇÃO - ESALQI USP

\section{Fonseca, Adriel Ferreira da}

Viabilidade agronômico-ambiental da disposição de efluente de esgoto tratado em um sistema solo-pastagem / Adriel Ferreira da Fonseca. - - Piracicaba, 2005.

174 p. : il.

Tese (doutorado) - - Escola Superior de Agricultura Luiz de Queiroz, 2005. Bibliografia.

1. Água residuária 2. Desenvolvimento sustentável 3. Nitrogênio 4. Pastagem 5. Química do solo 6. Salinidade do solo 7. Sódio 8. Solo tropical I. Título

CDD 631.41

"Permi tida a cópi a tot al ou parcial deste documento, desde que citada a f ont e - O aut or" 
Aos meus familiares

OFEREÇO

À minha esposa

Fabiana

a minha homenagem

À minha querida filha Lauane Vitória DEDICO 


\section{AGRADECIMENTOS}

O autor expressa seus agradecimentos às seguintes pessoas e instituições, sem o apoio das quais não teria sido possível a realização do presente trabalho:

Ao Prof. Adolpho José Melfi, pelo estímulo, confiança e orientação.

Ao Prof. Francisco Antonio Monteiro e à Prof ${ }^{\mathrm{a}}$. Célia Regina Montes, pelo apoio, sugestões e valiosas críticas em todas as etapas deste trabalho.

Ao Prof. Carlos Tadeu dos Santos Dias pelo auxílio nas análises estatísticas.

À Coordenação do Programa de Pós-Graduação em Solos e Nutrição de Plantas da Escola Superior de Agricultura Luiz de Queiroz (ESALQ) - Universidade de São Paulo (USP) por possibilitar a realização do Mestrado e do Doutorado.

Aos funcionários Clotilde, Dorival, James, Luís Silva, Lurdes, Paulo e Sérgio, pela amizade e auxílio nas diferentes etapas de pesquisa de campo e de laboratório.

Aos demais professores e funcionários do Departamento de Solos e Nutrição de Plantas da ESALQ/USP, do Núcleo de Pesquisa em Geoquímica e Geofísica da Litosfera (Nupegel/USP) e dos Laboratórios de Biogeoquímica Ambiental, Ecologia Isotópica e Fertilidade do Solo do Centro de Energia Nuclear na Agricultura (CENA/USP), principalmente, ao Prof. Takashi Muraoka.

Aos colegas da Pós-Graduação Alex, Alexandre, Débora, Sandra e Uwe.

Aos alunos Carlo, Filipe, Leonardo, Luiz Fernando, Thiago e Vagner pelo auxílio nos trabalhos de campo e nas análises laboratoriais.

À Fundação de Amparo à Pesquisa do Estado de São Paulo e à Companhia de Saneamento Básico do Estado de São Paulo pelo apoio financeiro e logístico. 


\section{SUMÁRIO}

\section{Página}

LISTA DE FIGURAS................................................................................ vii

LISTA DE TABELAS.................................................................................... viii

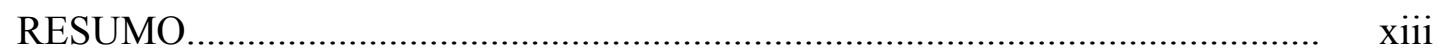

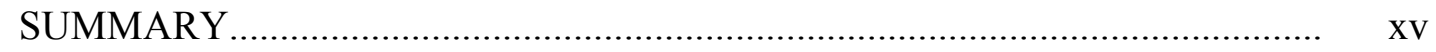

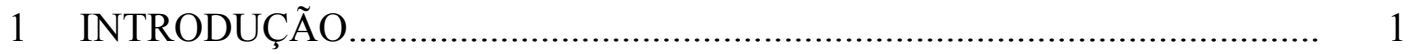

2 REVISÃO DE LITERATURA................................................................... 3

2.1 Disposição de efluente de esgoto tratado no solo e seu potencial de utilização nas plantas forrageiras................................................................. 3

2.2 Alterações no sistema solo-planta-ambiente devido à irrigação com efluente de esgoto tratado............................................................................ 6

3 MATERIAL E MÉTODOS.................................................................. 12

3.1 Localização e condução do experimento........................................................... 12

3.2 Amostragens e análises de água e efluente................................................ 15

3.3 Amostragens e análises de solo................................................................ 16

3.4 Amostragens e análises de solução no solo................................................. 18

3.5 Determinação da massa seca e análise química de plantas............................ 19

3.6 Análises estatísticas............................................................................... 20

4 RESULTADOS E DISCUSSÃO............................................................ 21

4.1 Condição do solo por ocasião da instalação do experimento......................... 21

4.2 Qualidade e quantidade de irrigação.................................................................. 23

4.3 Rendimento do capim............................................................................ 29

4.4 Acidez do solo..................................................................................... 32

4.5 Cálcio, magnésio e potássio.......................................................................... 46 


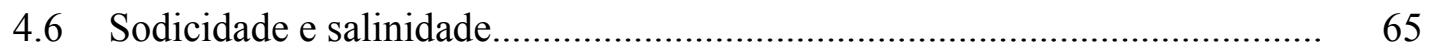

4.7 Fósforo, enxofre, carbono e nitrogênio....................................................... 90

4.8 Micronutrientes e elementos tóxicos........................................................... 116

5 CONCLUSÕES...................................................................................... 147

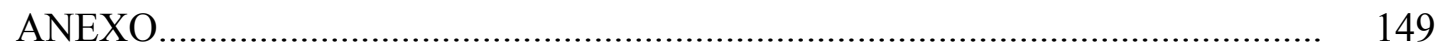

REFERÊNCIAS BIBLIOGRÁFICAS........................................................ 157 


\section{LISTA DE FIGURAS}

Página

1 Estação de tratamento de esgoto de origem predominantemente doméstico do município de Lins (SP) mediante o emprego de lagoas de estabilização (lagoa anaeróbia seguida de lagoa facultativa).

2 Lâminas mensais (início dia 15 e término dia 14) de precipitação pluvial (Pp) e de irrigação ocorridas no experimento de 15/01/2003 a 14/01/2005. T1 (controle): irrigação com água potável e aplicação de $520 \mathrm{~kg} \mathrm{ha}^{-1} \mathrm{ano}^{-1}$ de nitrogênio via fertilizante mineral (NFM); T2, T3, T4 e T5: irrigação com efluente secundário de esgoto tratado (ESET) e aplicação de 0, 171,6; 343,2 e $520 \mathrm{~kg} \mathrm{ha}^{-1} \mathrm{ano}^{-1}$ de NFM.

3 Influência de doses de nitrogênio via fertilizante mineral no rendimento acumulado anual de massa seca do capim-Bermuda Tifton 85 , submetido à irrigação com efluente secundário de esgoto tratado, no (o) primeiro e no $(\Delta)$ segundo ano. ${ }^{*} * \mathrm{P}<0,01$. 


\section{LISTA DE TABELAS}

Página

1 Histórico de fertilização mineral do experimento.......................................... 15

2 Características químicas e físicas do solo por ocasião da instalação do

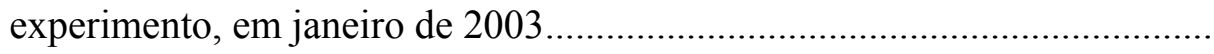

3 Resultados de análises (média de 24 amostras, coletadas mensalmente) da água potável e do efluente secundário de esgoto tratado (ESET), que foram empregados na irrigação do experimento e comparação dos valores médios dos constituintes do ESET com médias apresentadas em revisões bibliográficas internacionais.

4 Aporte médio anual dos principais elementos e compostos devido à irrigação

5 Efeitos da irrigação (água e efluente secundário de esgoto tratado - ESET) e de doses de nitrogênio via fertilizante mineral (NFM), aplicadas via solo, no rendimento anual de massa seca (MS) do capim-Bermuda Tifton $85(\mathrm{CV}=5,07 \%)$.

6 Efeitos da irrigação (água e efluente) e de doses de nitrogênio mineral no $\mathrm{pH}(\mathrm{CaCl} 2)$ do solo.

7 Efeitos da irrigação (água e efluente) e de doses de nitrogênio mineral no pH da solução no solo (extrato de saturação).

8 Coeficientes de correlação entre os parâmetros $\mathrm{pH}$ do solo $(\mathrm{em} \mathrm{CaCl} 2)$ e da solução no solo, Al trocável (mmolc kg-1) e solúvel (mmol L-1) e o acúmulo de Al (kg ha-1 semestre-1) na parte aérea do capim-Bermuda Tifton 85 
9 Efeitos da irrigação (água e efluente) e de doses de nitrogênio mineral nas concentrações de $\mathrm{H}+\mathrm{Al}$ do solo.

10 Efeitos da irrigação (água e efluente) e de doses de nitrogênio mineral nas concentrações de Al trocável no solo.

11 Efeitos da irrigação (água e efluente) e de doses de nitrogênio mineral na concentração de Al na solução no solo (extrato de saturação).

12 Efeitos da irrigação (água e efluente) e de doses de nitrogênio mineral no acúmulo semestral (somatório de três cortes bimestrais) de $\mathrm{Al}, \mathrm{Ca}, \mathrm{Mg}$ e $\mathrm{K}$ na parte aérea (folhas + colmos + bainhas) do capim-Bermuda Tifton $85 \ldots$

13 Efeitos da irrigação (água e efluente) e de doses de nitrogênio mineral nas concentrações de Ca trocável no solo.

14 Efeitos da irrigação (água e efluente) e de doses de nitrogênio mineral na concentração de Ca na solução no solo (extrato de saturação).

15 Efeitos da irrigação (água e efluente) e de doses de nitrogênio mineral na concentração de Ca na solução no solo (extrato de saturação).

16 Efeitos da irrigação (água e efluente) e de doses de nitrogênio mineral nas concentrações de Mg trocável no solo.

17 Efeitos da irrigação (água e efluente) e de doses de nitrogênio mineral na concentração de $\mathrm{Mg}$ na solução no solo (extrato de saturação)...

18 Efeitos da irrigação (água e efluente) e de doses de nitrogênio mineral nas concentrações de K trocável no solo

19 Efeitos da irrigação (água e efluente) e de doses de nitrogênio mineral na concentração de K na solução no solo (extrato de saturação)...

20 Efeitos da irrigação (água e efluente) e de doses de nitrogênio mineral nas concentrações de Na trocável no solo.

21 Efeitos da irrigação (água e efluente) e de doses de nitrogênio mineral no percentual de sódio trocável (PST) ${ }^{(1)}$ no solo.

22 Efeitos da irrigação (água e efluente) e de doses de nitrogênio mineral no acúmulo semestral (somatório de três cortes bimestrais) de $\mathrm{Na}, \mathrm{P}, \mathrm{S}$ e $\mathrm{N}$ na parte aérea (folhas + colmos + bainhas) do capim-Bermuda Tifton $85 \ldots . . . .$. 
23 Efeitos da irrigação (água e efluente) e de doses de nitrogênio mineral nas concentrações de Na na solução no solo (extrato de saturação).

24 Coeficientes de correlação entre os parâmetros concentração de $\mathrm{Na}$ trocável $\left(\mathrm{mmol}_{\mathrm{c}} \mathrm{kg}^{-1}\right)$ e solúvel $\left(\mathrm{mmol} \mathrm{L}^{-1}\right)$, percentual de sódio trocável (PST, em \%), razão de adsorção de sódio (RAS, em $\left.\left(\mathrm{mmol} \mathrm{L}^{-1}\right)^{0,5}\right)$, concentração de argila dispersa em água (ADA, em $\mathrm{g} \mathrm{kg}^{-1}$ ), grau de dispersão das argilas (GDA, em \%) e acúmulo de $\mathrm{Na}\left(\mathrm{kg} \mathrm{ha}^{-1}\right.$ semestre $\left.^{-1}\right)$ na parte aérea do capim-Bermuda Tifton 85 .

25 Efeitos da irrigação (água e efluente) e de doses de nitrogênio mineral na razão de adsorção de sódio no extrato de saturação.

26 Efeitos da irrigação (água e efluente) e de doses de nitrogênio mineral no grau de dispersão de argilas

27 Efeitos da irrigação (água e efluente) e de doses de nitrogênio mineral na condutividade elétrica no extrato de saturação

28 Efeitos da irrigação (água e efluente) e de doses de nitrogênio mineral nas concentrações de $\mathrm{P}$ disponível no solo.

29 Efeitos da irrigação (água e efluente) e de doses de nitrogênio mineral nas concentrações de $\mathrm{S}$ disponível no solo

30 Efeitos da irrigação (água e efluente) e de doses de nitrogênio mineral nas concentrações de $\mathrm{S}$ na solução no solo.

31 Efeitos da irrigação (água e efluente) e de doses de nitrogênio mineral nas concentrações de carbono total (CT) no solo.

32 Efeitos da irrigação (água e efluente) e de doses de nitrogênio mineral nas concentrações de nitrogênio total (NT) no solo

33 Efeitos da irrigação (água e efluente) e de doses de nitrogênio mineral nas concentrações de $\mathrm{N}-\mathrm{NO}_{3}{ }^{-}+\mathrm{N}^{-} \mathrm{NO}_{2}{ }^{-}$na solução no solo.

34 Efeitos da irrigação (água e efluente) e de doses de nitrogênio mineral nas concentrações de $\mathrm{N}^{-\mathrm{NH}_{4}}{ }^{+}$na solução no solo. 
35 Efeitos da irrigação (água e efluente) e de doses de nitrogênio mineral nas concentrações de $\mathrm{N}$-mineral $\left(\mathrm{N}-\mathrm{NO}_{3}{ }^{-}+\mathrm{N}^{-} \mathrm{NO}_{2}{ }^{-}+\mathrm{N}^{-\mathrm{NH}_{4}}{ }^{+}\right)$na solução no solo.

36 Efeitos da irrigação (água e efluente) e de doses de nitrogênio mineral nas concentrações de B disponível no solo

37 Efeitos da irrigação (água e efluente) e de doses de nitrogênio mineral no acúmulo semestral (somatório de três cortes bimestrais) dos micronutrientes $\mathrm{B}, \mathrm{Cu}, \mathrm{Zn}, \mathrm{Fe}$ e $\mathrm{Mn}$ na parte aérea (folhas + colmos + bainhas) do capim-Bermuda Tifton 85

38 Efeitos da irrigação (água e efluente) e de doses de nitrogênio mineral nas concentrações de B na solução no solo

39 Efeitos da irrigação (água e efluente) e de doses de nitrogênio mineral nas concentrações de $\mathrm{Cu}$ disponível no solo

40 Efeitos da irrigação (água e efluente) e de doses de nitrogênio mineral nas concentrações de $\mathrm{Cu}$ na solução no solo

41 Efeitos da irrigação (água e efluente) e de doses de nitrogênio mineral nas concentrações de Fe disponível no solo.

42 Efeitos da irrigação (água e efluente) e de doses de nitrogênio mineral nas concentrações de Fe na solução no solo.

43 Efeitos da irrigação (água e efluente) e de doses de nitrogênio mineral nas concentrações de Mn disponível no solo

44 Efeitos da irrigação (água e efluente) e de doses de nitrogênio mineral nas concentrações de Mn na solução no solo......

45 Efeitos da irrigação (água e efluente) e de doses de nitrogênio mineral nas concentrações de Zn disponível no solo.

46 Efeitos da irrigação (água e efluente) e de doses de nitrogênio mineral nas concentrações de $\mathrm{Zn}$ na solução no solo 
47 Coeficientes de correlação entre os resultados de análises químicas das soluções extraídas pelas cápsulas de cerâmica porosa e das pastas de saturação (extratos de saturação) com os resultados de análises químicas de solo para fins de fertilidade ${ }^{(\S)}$ 


\section{VIABILIDADE AGRONÔMICO-AMBIENTAL DA DISPOSIÇÃO DE EFLUENTE DE ESGOTO TRATADO EM UM SISTEMA SOLO-PASTAGEM}

Autor: ADRIEL FERREIRA DA FONSECA

Orientador: Prof. Dr. ADOLPHO JOSÉ MELFI

\section{RESUMO}

A utilização de efluentes de esgoto tratado (EET) na irrigação, ao invés de realizar a disposição deste subproduto nos cursos d'água tem sido uma alternativa antiga, popular e atrativa, com triplo propósito: tratamento complementar do efluente, fonte de água e de nutrientes ao sistema solo-planta. Entretanto, no Brasil, há falta de tradição na reciclagem de águas residuárias, particularmente, do EET e, conseqüentemente, poucos têm sido as pesquisas relacionadas a este tema. Um experimento foi conduzido em Lins (SP), durante dois anos, com os objetivos principais de (i) testar a possibilidade de uso do efluente secundário de esgoto tratado (ESET) como uma fonte alternativa de água e de nitrogênio ao capim-Tifton 85; (ii) determinar as concentrações de nutrientes e elementos tóxicos em amostras de água potável (AP), ESET, plantas, solo e solução no solo; (iii) verificar o comportamento das argilas dispersas em água. O delineamento experimental foi o de blocos completos casualizados, com quatro repetições. Os cinco tratamentos estudados foram: (i) T1 (controle) - irrigação com AP e adição de $520 \mathrm{~kg} \mathrm{ha}^{-1}$ ano $^{-1}$ de nitrogênio via fertilizante mineral (NFM); (ii) T2, T3, T4 e T5 - irrigação com ESET e adição de 0, 171,6; 343,2 e $520 \mathrm{~kg} \mathrm{ha}^{-1}$ ano $^{-1}$ de NFM, respectivamente. As características da água e do efluente foram monitoradas mensalmente e o rendimento de massa seca (MS) do capim foi 
determinado bimestralmente. Durante 18 meses, foram realizadas análises para monitoramento das concentrações dos elementos nas plantas (folhas e colmos + bainhas), no solo e na solução no solo (até $100 \mathrm{~cm}$ de profundidade). Foi verificado que o ESET pode substituir eficientemente a AP de irrigação em sistema de produção de feno, proporcionando benefícios econômicos e aumento de qualidade do capim. Ainda, o ESET pode atuar como amenizador da acidez do solo. A magnitude de resposta do capim ao ESET, bem como da economia de NFM é dependente da precipitação pluvial e da lâmina de irrigação empregada. A substituição da AP pelo ESET, na irrigação do capim, pode levar à economia de 32,2 a 81,0\% na dose de NFM necessária à obtenção de altos rendimentos, sem ocasionar alterações negativas no conteúdo de nutrientes nas plantas e na fertilidade do solo. Por outro lado, se os nutrientes presentes no ESET não forem computados no manejo da fertilização da pastagem, podem ocorrer incrementos no rendimento de MS e no acúmulo de elementos (inclusive de sódio), promovendo aumento de qualidade da forragem sem ocasionar efeitos deletérios no ambiente. As altas concentrações de sódio na AP (utilizada no tratamento controle), bem como no ESET indicam que o sistema solo-pastagem não suportará o elevado aporte deste elemento e pode ser necessário o uso de condicionador de solo. $\mathrm{O}$ aporte de nutrientes no sistema associado à manutenção de tensão hídrica adequada ao capim, pode promover mineralização da matéria orgânica do solo, reduzindo os estoques de carbono e nitrogênio. Ao que parece, a irrigação com ESET doméstico não proporcionará, em curto e médio prazo, excesso de boro e de metais pesados no sistema solo-pastagem. 


\title{
AGRONOMICAL-ENVIRONMENTAL VIABILITY OF TREATED SEWAGE EFFLUENT DISPOSAL IN A SOIL-PASTURE SYSTEM
}

\author{
Author: ADRIEL FERREIRA DA FONSECA \\ Adviser: Prof. Dr. ADOLPHO JOSÉ MELFI
}

\section{SUMMARY}

Treated sewage effluent (TSE) utilization for irrigation represents an antique, popular and attractive alternative to the common disposal of effluent to watercourses and includes three main purposes: effluent complementary treatment, water and nutrient source to the soil-plant system. However, because in Brazil no experiences in wastewater recycling exists consequently few scientific studies were carried out despite the importance of the subject. For this study an experiment was conducted for two years in Lins (São Paulo State, Brazil). The main objectives were (i) to test the feasibility of secondary-treated sewage effluent (STSE) utilization as an alternative water and nitrogen source for Tifton 85 Bermudagrass; (ii) to evaluate concentrations of nutrients and toxic elements in potable water (PW), STSE, plant, soil and soil solution samples; (iii) to verify the behavior of dispersed clays in water. A randomized complete block design was used with four replications. Five treatments were applied: (i) T1 (control) irrigation with PW plus $520 \mathrm{~kg} \mathrm{ha}^{-1}$ year $^{-1}$ nitrogen as mineral fertilizer (NMF); (ii) T2, T3, T4 and T5 - irrigation with STSE plus 0, 171.6, 343.2 and $520 \mathrm{~kg} \mathrm{ha}^{-1}$ year $^{-1}$ of NMF, respectively. Water and effluent characteristics were monthly monitored, and aboveground dry matter (DM) was measured bimonthly. Plant (leaves and culms + sheaths), soil and soil solution (up to $100 \mathrm{~cm}$ ) were analyzed during 18 months, to 
monitor elements concentrations over the experimental period. It was verified that STSE can replace efficiently the PW used for irrigation for the production of hay. This replacement can provide economical benefits, enhancement of forage quality, and mitigation of soil acidity. The magnitude of grass productivity as well as of NMF economy is dependent on rain and the used irrigation rates. Considering the complete substitution of PW for irrigation by STSE, the necessary dose of NFM for obtaining high yields could be reduce by 32.2 to $81.0 \%$ without negative effects on nutrient contents in the grass and soil fertility. On the other hand, also by non-consideration the effluent nutrients in pasture fertilization management, it may occur increasing dry matter yields and element contents (inclusive sodium), enhancement of forage quality, and, moreover without deleterious environmental effects. Because of high sodium concentrations in PW (control) and the STSE, it is suggested that the pasture-soil system will not tolerate the high sodium input, a future conditioning of the soil will be necessary. The nutrient inputs to the system associated with an adequate soil moisture tension to the grass may increase soil organic matter mineralization followed by decrease of carbon and nitrogen stocks. In short and medium term periods it is assumed that the irrigation with domestic TSE will not negatively influence the soil-pasture system by high concentrations of boron and heavy metals. 


\section{INTRODUÇÃO}

O tratamento de esgoto mediante o emprego de lagoas de estabilização, amplamente utilizado nas cidades de pequeno a médio porte (Feigin et al., 1991), sobretudo, no interior do Estado de São Paulo, gera dois subprodutos: (i) o lodo de lagoa, que não será objeto de estudo neste trabalho e (ii) o efluente de esgoto tratado (EET). Este último subproduto, apesar das concentrações de nutrientes e matéria orgânica serem fortemente reduzidas durante o processo de tratamento, apresenta concentrações, sobretudo, de nitrogênio $(\mathrm{N})$ e fósforo $(\mathrm{P})$ acima do permitido pela Resolução do Conselho Nacional do Meio Ambiente (Conama) no 20, 18/06/86 (Von Sperling, 1995). Assim, a colocação dos EET nos cursos d'água pode ocasionar eutroficação e, evidentemente, tem sido condenada devido fatores de ordem ambiental, legal e social (Bouwer \& Chaney, 1974; Bond, 1998). Portanto, a busca de alternativas visando resolver esse problema ambiental tem sido alvo de vários trabalhos (Bouwer $\&$ Chaney, 1974; Feigin et al., 1991; Cameron et al., 1997).

Estudos realizados em outros países têm mostrado que a colocação de EET no solo através da irrigação de plantas cultivadas tem sido uma das alternativas de mais baixo custo para a disposição deste subproduto no ambiente (Asano et al., 1996) e tem sido comumente empregada tanto em regiões secas quanto em regiões úmidas (Bouwer \& Chaney, 1974). Os efluentes que causam impacto negativo ao ambiente, quando lançados diretamente nos corpos d'água, podem ser utilizados como fonte de água e, segundo suas características químicas, como fonte de nutrientes para o sistema soloplanta. Desse modo, a colocação de EET no sistema solo-planta (que atua como verdadeiro "filtro vivo") se constitui numa das alternativas mais fáceis para mitigar a problemática emergente de escassez de água (Pollice et al., 2004), proporcionando 
benefícios econômicos (Darwish et al., 1999), principalmente, devido à economia de fertilizantes minerais para obtenção de alta produção vegetal (Smith \& Peterson, 1982; Feigin et al., 1991).

As plantas forrageiras, pelo fato de cobrirem quase a metade da superfície do Estado de São Paulo, apresentam potencialidade de uso como receptor de EET. A aplicação de efluentes em plantas forrageiras se justifica pelo fato delas apresentarem longa estação de crescimento, elevado acúmulo de nutrientes e pela sua capacidade de recobrimento do solo (Bole \& Bell, 1978). No entanto, a irrigação com EET tem ocasionado alterações nas características químicas (Bond, 1998), físicas (Balks et al., 1998) e microbiológicas do solo (Friedel et al., 2000), bem como no ambiente (AlNakshabandi et al., 1997). A magnitude dessas alterações depende das condições locais de solo, planta, fonte de água e ambiente (Shahalam et al., 1998). Portanto, para a disposição sustentável de EET no sistema solo-planta, é crucial o monitoramento do solo, da solução no solo, da nutrição e do rendimento das plantas, bem como o estudo da viabilidade econômica e ambiental desta técnica (Cameron et al., 1997; Bond, 1998). Desse modo, torna-se evidente a importância de se estudar o impacto da deposição de EET no sistema solo-planta-ambiente, notadamente nos solos tropicais com carga variável, baixa capacidade de troca de cátions (CTC) e baixa fertilidade natural, como é o caso da maioria dos solos paulistas e brasileiros.

Objetivou-se neste trabalho (i) monitorar as concentrações de nutrientes e elementos tóxicos presentes no efluente secundário de esgoto tratado (ESET), visando o aumento de sua eficiência como fonte de nutrientes, sobretudo, de N; (ii) avaliar as mudanças nas principais características químicas e físicas do solo devido à irrigação com ESET, estudando, inclusive, a dinâmica do carbono (C) e do N-mineral $\left(\mathrm{N}^{-\mathrm{NO}_{3}}{ }^{-}\right.$, $\mathrm{N}-\mathrm{NO}_{2}{ }^{-}$e $\mathrm{N}-\mathrm{NH}_{4}{ }^{+}$), a condutividade elétrica (CE) e as concentrações de $\mathrm{Na}$, metais pesados disponíveis e argila dispersa em água (ADA); (iii) verificar a economia de fertilizante nitrogenado mineral e o impacto da disposição de ESET em um sistema solopastagem, bem como as alterações no acúmulo de elementos e no rendimento do capimBermuda Tifton 85. 


\section{REVISÃO DE LITERATURA}

\subsection{Disposição de efluente de esgoto tratado no solo e seu potencial de utilização nas plantas forrageiras}

Dentre os vários métodos empregados no tratamento dos esgotos, os sistemas biológicos, sobretudo o de lagoas de estabilização (lagoa anaeróbia - tratamento primário e lagoa facultativa - tratamento secundário) tem sido amplamente empregado no Brasil, dado o baixo custo de operação e manutenção (Von Sperling, 1996). Porém, o subproduto líquido originário deste tratamento, denominado ESET, normalmente não apresenta padrões de qualidade para lançamento dos cursos d'água (Von Sperling, 1995). Uma das alternativas para solucionar este problema seria o emprego de tratamento terciário, não recomendável do ponto de vista econômico, pois seu custo poderia facilmente ultrapassar a casa de um milhão de dólares, dependendo do volume de esgoto tratado. Assim, seria utopia o tratamento terciário devido às circunstâncias preponderantes de (i) ausência de políticas nacionais, em longo prazo, para o tratamento de esgoto nos países em desenvolvimento (Von Sperling, 1995), particularmente no Brasil; (ii) inexistência de pelo menos um dos ítens de saneamento (rede geral, esgotamento sanitário e coleta de lixo) em 43,5\% dos domicílios brasileiros particulares permanentes (Brasil, 2001).

Antigamente, os cursos d'água eram capazes de suportar os efeitos negativos no ambiente advindo da disposição de dejetos antrópicos. Porém, devido ao aumento populacional e a concentração de pessoas nos centros urbanos, a capacidade assimilativa do ambiente tornou-se mais limitada (Feigin et al., 1991). Conseqüentemente, houve necessidade de conscientização da sociedade, sobretudo nas últimas décadas, o que levou a rejeição de práticas insustentáveis para o destino de resíduos antrópicos (Agenda 
21, 1996), corroborando para que a colocação de efluentes ricos em nutrientes/poluentes seja realizada no solo e não nos cursos d'água (Bond, 1998). Portanto, o solo se tornou um meio alternativo para disposição de resíduos antrópicos (Cameron et al., 1997), sobretudo, de EET (Bond, 1998).

A colocação de EET no solo tem sido realizada, principalmente, via irrigação de plantas cultivadas (Feigin et al., 1991), com triplo propósito: (i) realizar o tratamento complementar do efluente (Bouwer \& Chaney, 1974); (ii) valorizar este subproduto (um tipo de água marginal) como um recurso hídrico disponível para agricultura (Bouwer \& Idelovitch, 1987; Al-Jaloud et al., 1995; Tanji, 1997) - que é o setor de maior demanda por água (Agenda 21, 1996), notadamente nas regiões com severo déficit hídrico (Pescod, 1992); (iii) aproveitar os nutrientes contidos nos efluentes, visando sua utilização no crescimento e desenvolvimento das plantas (Bouwer \& Chaney, 1974; Vazquez-Montiel et al., 1996), além de promover economia de fertilizantes minerais e manutenção de alta produção vegetal (Smith \& Peterson, 1982; Feigin et al., 1991). O sistema solo-planta, desde que manejado adequadamente, promove absorção e "retenção" dos constituintes dos EET, ocasionando diminuição na concentração de elementos nas águas subterrâneas e superficiais (Feigin et al., 1978; Vaisman et al., 1981). O corte das plantas, bem como a remoção dos nutrientes acumulados nas mesmas tem tido papel fundamental na sustentabilidade do sistema solo-planta em promover o polimento do EET (Jordan et al., 1997). Portanto, o uso dos EET como fonte alternativa de água e de nutrientes, se manejado eficientemente, pode retornar benefícios econômicos e ambientais (Darwish et al., 1999; Sumner, 2000) para diversas situações de culturas, clima e solo (Feigin et al., 1991; Cameron et al., 1997; Bond, 1998). Ainda, o uso de EET na irrigação caracteriza-se por ser uma prática que atende algumas questões essenciais (problemática dos esgotos nos cursos d'água, nutrição sustentável das plantas e alívio da demanda de água doce para fins agrícolas) abordadas na Conferência das Nações Unidas sobre Meio Ambiente e Desenvolvimento no Rio de Janeiro, em 1992 (Agenda 21, 1996) e, conseqüentemente, contribui para o desenvolvimento sustentável. 
A prática de irrigação de lavouras com EET, apesar de pouco pesquisada no Brasil, caracteriza-se por ser antiga, atrativa, popular e usual em diversas partes do mundo (Bouwer \& Idelovitch, 1987; Feigin et al., 1991; Pescod, 1992), como por exemplo, (i) as chamadas "sewage farms" na Alemanha, Austrália e França, que se encontram em operação por mais de um século (Chang et al., 2002); (ii) as áreas agrícolas e/ou de paisagem nos EUA (Wang et al., 2003), Israel (Feigin et al., 1991) e México (Friedel et al., 2000), que vêm recebendo este subproduto em substituição à água de irrigação por mais de 50 anos. A lâmina de aplicação de EET, bem como a seleção de culturas pare receber este subproduto tem sido umas das principais questões no tocante a sustentabilidade do sistema solo-planta (Mohammad \& Ayadi, 2004).

As plantas receptoras de EET devem satisfazer a maioria dos critérios estabelecidos por Segarra et al. (1996), que são (i) alta absorção de N, (ii) elevado consumo d'água, (iii) possibilidade de processamento; (iv) potencial de mercado; (v) viabilidade econômica. Levando-se em consideração esses critérios, bem como os resultados do censo agropecuário mais recente (Brasil, 1998), os agrossistemas de pastagens apresentam elevado potencial para receberem irrigação com EET pelo fato de representarem aproximadamente 50\% das terras utilizadas no Estado de São Paulo e no Brasil. Neste aspecto, o capim-Bermuda Tifton 85 (Cynodon spp.) se destaca, dentre as pastagens cultivadas, por apresentar grande potencialidade para receber irrigação com EET, devido ao fato de ser (i) um híbrido $F_{1}$ do gênero Cynodon (Burton, 2001), caracterizado pelo alto potencial produtivo tanto do ponto de vista quantitativo como qualitativo (Hill et al., 1993); (ii) uma gramínea que chega a apresentar concentração de proteína bruta de 120-160 $\mathrm{g} \mathrm{kg}^{-1}$ e potencial para fenação (Hill et al., 1993); (iii) um capim que responde a doses elevadas de N (Alvim et al., 1999), apresentando estreita relação com a tensão hídrica (Marcelino et al., 2003); (iv) uma forrageira que se destaca pela elevada taxa de absorção de água e nutrientes (Fageria et al., 1997) e tolerância à salinidade (Grattan et al., 2004) e à sodicidade (Grieve et al., 2004), que tem sido algumas das principais preocupações nos agrossistemas irrigados com EET (Bond, 1998); (v) e, portanto, uma cultura que atende a maior parte dos critérios estabelecidos por Segarra et al. (1996). 
Resultados favoráveis à colocação dos EET no sistema solo-planta têm sido comuns na literatura internacional, incluindo aumento no rendimento de massa seca (MS) e/ou de proteína bruta em pastagens de alfafa (Medicago sativa L.) (Bole \& Bell, 1978; Day et al., 1982; Darwish et al., 1999; Grattan et al., 2004), azevém-perene (Lolium perenne L.) (Quin \& Woods, 1978), capim-Bermuda (Cynodon dactylon) (Hayes et al., 1990b; Grattan et al., 2004), capim-de-Rhodes (Chloris gayana Kunth) (Feigin et al., 1978; Vaisman et al., 1981), capim-Kikuyu (Pennisetum cladestinum Chiov) (Grattan et al., 2004), capim-Napier (Pennisetum purpureum) (Jeyaraman, 1988) e no milho forrageiro (Zea mays L.) (Overman \& Nguy, 1975; Overman, 1981; Adekalu \& Okunade, 2002; Mohammad \& Ayadi, 2004). Pelo fato de os EET, normalmente, apresentarem concentrações de $\mathrm{Na}$ mais elevadas, quando comparados às águas comumente empregadas na irrigação (Feigin et al., 1991; Pescod, 1992), tem sido observadas melhores respostas, em termos de rendimento quali-quantitativo nas plantas $\mathrm{C}_{4}$ natrófílas irrigadas com este subproduto (Grieve et al., 2004).

\subsection{Alterações no sistema solo-planta-ambiente devido à irrigação com efluente de esgoto tratado}

A irrigação de plantas cultivadas com EET, não obstante aos possíveis problemas de aceite público (Pollice et al., 2004), também tem ocasionado alterações nas características bioquímicas (Speir, 2002), físicas (Balks et al., 1998), microbiológicas (Friedel et al., 2000) e químicas do solo (Bond, 1998), bem como no ambiente (AlNakshabandi et al., 1997). Em síntese, a magnitude das alterações no sistema soloplanta-água-homem-ambiente depende das condições locais, sobretudo, tipo de solo, planta, clima, fonte de água, qualidade e quantidade de efluente empregado no sistema de produção (Hayes et al, 1990b; Cameron et al., 1997; Bond, 1998; Shahalam et al., 1998; Mohammad \& Ayadi, 2004).

A prática de irrigação com EET não é isenta de riscos e tem potencial de transmissão de doenças, pois patógenos presentes neste subproduto podem sobreviver no sistema solo-planta. Porém, fatores agronômicos, como crescimento da planta, método de irrigação empregado, práticas culturais e de colheita controlam a transmissão de 
doenças (Westcot, 1997). Os maiores riscos de contaminação por patógenos entéricos estão associados, normalmente, ao emprego de efluentes de esgotos não tratados na irrigação de lavouras, levando a ocorrência de riscos aos trabalhadores rurais, bem como aos consumidores (Santamaría \& Toranzos, 2003). Medidas de proteção de saúde pública incluem não apenas um segmento isolado, mas a integração de alternativas de controle, tais como: (i) restrições de cultivo (Pescod, 1992); (ii) tratamento secundário dos efluentes (Feigin et al., 1991) e, na seqüência, realização do processo de cloração (Bouwer \& Idelovitch, 1987); (iii) controle da aplicação de efluentes, exposição humana e higiene (Pescod, 1992); (iv) nas pastagens irrigadas com EET, os riscos de contaminação podem ser reduzidos drasticamente mediante o consumo de forragens que foram colhidas e secadas ao sol (Westcot, 1997), como num sistema de produção de feno. Portanto, para utilização sustentável dos EET nos agrossistemas há necessidade, acima de tudo, de monitoramento da qualidade deste subproduto (Bouwer \& Chaney, 1974; Tanji, 1997) e, principalmente, da qualidade microbiológica (Westcot, 1997).

As principais alterações nos solos irrigados com EET, principalmente, aqueles sob pastagens, têm sido confinadas aos efeitos de (i) carbono total (CT), nitrogênio total (NT), atividade microbiana e N-mineral (na solução no solo); (ii) cálcio (Ca) e magnésio $(\mathrm{Mg})$ trocáveis; (iii) salinidade (medida pela $\mathrm{CE}$ ), sodicidade, dispersão de argilas e condutividade hidráulica. Os outros parâmetros de solo normalmente não tem sido alterados ou as alterações têm sido de pequena magnitude, sem implicações agronômicas.

Normalmente a água de irrigação (ou o efluente) não tem tido efeitos sobre o pH do solo, por causa de seu poder tampão (Bouwer \& Idelovitch, 1987). No entanto, tem sido observado pequeno aumento no valor de $\mathrm{pH}$ de solos ácidos mediante irrigação com EET (Quin \& Woods, 1978) que, certamente tem ocorrido devido (i) ao alto $\mathrm{pH}$ do efluente (Stewart et al., 1990); (ii) à adição de cátions trocáveis e de ânions oriundos do efluente (Falkiner \& Smith, 1997); (iii) à alteração na ciclagem de nutrientes mediante adição deste subproduto, ocasionando incremento na redução do $\mathrm{NO}_{3}{ }^{-}$para $\mathrm{NH}_{4}{ }^{+} \mathrm{e}$ desnitrificação do $\mathrm{NO}_{3}^{-}$, produzindo íons $\mathrm{OH}^{-}$(Schipper et al., 1996). Porém, essas alterações de pH normalmente são de pequena magnitude (menor que uma unidade), 
sendo desprezíveis e de pouca importância prática com relação à disponibilidade de nutrientes (Speir et al., 1999), notadamente nos solos ácidos e de baixa fertilidade natural (Fonseca, 2001).

Quanto às concentrações de CT, NT e à atividade microbiana no solo, ora tem ocorrido aumento destes parâmetros, devido ao aporte de N e C oriundos do EET (Quin \& Woods, 1978; Mancino \& Pepper, 1992; Friedel et al., 2000), ora tem havido diminuição, principalmente, das concentrações de CT e NT, pelo aumento na atividade microbiana incrementando a decomposição da matéria orgânica do solo (MOS) (Polglase et al., 1995). Normalmente, o aumento nas concentrações de CT e NT, bem como na atividade microbiana tem sido observado em experimentos que vem recebendo EET por longo período, como relatado nos trabalhos de Quin \& Woods (1978), Friedel et al. (2000) e Ramirez-Ruentes et al. (2002). Porém, também tem sido observado, em solos sob pastagens irrigadas com EET, diminuição nas concentrações de CT e NT. Essa diminuição pode estar direta ou indiretamente relacionada ao fato de (i) o C-orgânico e o $\mathrm{N}$-orgânico do EET, principalmente algas mortas, quando adicionados no solo passam a fazer parte da MOS fresca, que apresenta rápida velocidade de decomposição (Snow et al., 1999); (ii) a umidade ideal constante ao longo do ano potencializa o processo de mineralização (Myers et al., 1982) e, principalmente, a interação água de irrigação (com EET) com altas temperaturas locais, promovendo rápida degradação do resíduo aplicado (Artiola \& Pepper, 1992); (iii) o EET, por apresentar estreita relação C/N, constitui-se numa importante fonte de energia ao meio (Bouwer \& Chaney, 1974; Feigin et al., 1991).

Nas pastagens irrigadas com EET tem sido comum, na solução no solo, aumento nas concentrações de N-NH${ }_{4}^{+}$e, principalmente, de N-NO${ }_{3}^{-}$(Quin \& Forsythe, 1978; Linden et al., 1981). Assim, o monitoramento de $\mathrm{N}^{-N_{3}}{ }_{3}^{-}$na solução no solo é crucial para sustentabilidade do sistema solo-planta-efluente-ambiente (Bond, 1998).

A quantidade de $\mathrm{P}$ adicionado no solo pela irrigação com EET, normalmente não tem sido excessiva e quando há aumento na disponibilidade deste nutriente, geralmente este ocorre na camada superficial (Hortenstine, 1976; Quin \& Woods, 1978). As plantas forrageiras, uma vez colhidas do local têm sido eficazes em remover o P- 
efluente (Kardos \& Hook, 1976; Hook, 1981). Ainda, a capacidade do solo em reter P tem contribuído para prevenir que este nutriente seja lixiviado para fora da zona radicular (Ryden \& Pratt, 1980), podendo determinar a sustentabilidade dos cultivos que utilizem irrigação com efluentes (Falkiner \& Polglase, 1997). No entanto, têm sido observadas evidências de migração de $\mathrm{P}$ em solos arenosos submetidos à irrigação com EET (Hook, 1981; Bond, 1998). Além do mais, existe carência de informações concernentes aos mecanismos que governam a migração e a retenção de $\mathrm{P}$ nos locais receptores de EET (Falkiner \& Polglase, 1997).

Pastagens submetidas à irrigação com EET têm levado às alterações nas concentrações trocáveis de $\mathrm{Ca}, \mathrm{Mg}$, potássio $(\mathrm{K})$ e sódio $(\mathrm{Na})$. Após longo período de irrigação com EET, tem sido observados pequeno acréscimo nas concentrações de Ca trocável (Quin \& Woods, 1978) e ligeiro decréscimo nas concentrações de Mg trocável (Wang et al., 2003). Os resultados têm sido divergentes com relação ao K, enquanto que o aumento na concentração de $\mathrm{Na}$ têm ocorrido em diferentes sistemas de cultivos (Karlen et al., 1976; Feigin et al., 1991). Evidentemente, o monitoramento nas concentrações de Na nos locais receptores de EET é essencial (Cameron et al., 1997; Bond, 1998) e se o EET for pobre em K e rico em Na, para que sua utilização seja sustentável, torna-se necessária suplementação potássica para manter adequada a absorção de nutrientes e a produtividade das culturas (Karlen et al., 1976).

Poucos têm sido os estudos relatando os efeitos da irrigação com EET na dinâmica do enxofre (S) e do boro (B). Normalmente, a disponibilidade de S não tem sido alterada pela irrigação com EET (Quin \& Woods, 1978; Fonseca, 2001). Quanto ao B, não tem sido observado alterações nas concentrações deste nutriente em estudo de curto prazo, como observado por Fonseca (2001), mas tem sido verificado aumento na disponibilidade de B em experimento de longo prazo, como relatado em El-Nennah et al. (1982).

Os EET normalmente apresentam baixas concentrações de metais pesados, sobretudo, efluentes domésticos (Bouwer \& Chaney, 1974; Feigin et al., 1991). Porém, despejos industriais no sistema de coleta e tratamento de esgoto doméstico podem levar ao aumento na concentração de metais pesados no EET. Nesse subproduto, os metais 
pesados podem estar associados (i) na fração líquida, formando complexos organometálicos que penetram no solo junto à água de irrigação; (ii) na fração constituída por sólidos suspensos, que se acumulam, principalmente, na camada superficial do solo (Feigin et al., 1991). Porém, os solos, normalmente apresentam alta capacidade em reter metais pesados que, em síntese, é devido aos fatores de (i) baixa solubilidade e alta adsorção específica destes elementos, levando a ocorrência de baixas concentrações em solução; (ii) presença da MOS, que afeta a solubilidade dos metais pesados, por causa da capacidade da MOS formar complexos estáveis com íons metálicos (complexos organometálicos), ocasionando diminuição da biodisponibilidade destes metais (McBride, 1989; Stevenson, 1986).

Todavia, a colocação dos EET no sistema solo-planta pode não alterar, bem como diminuir ou aumentar as concentrações disponíveis dos metais pesados cádmio $(\mathrm{Cd})$, cromo $(\mathrm{Cr})$, cobre $(\mathrm{Cu})$, ferro $(\mathrm{Fe})$, manganês $(\mathrm{Mn})$, níquel $(\mathrm{Ni})$, chumbo $(\mathrm{Pb})$ e zinco (Zn). Mohammad \& Mazahreh (2003) não observaram efeito da irrigação com EET na disponibilidade de $\mathrm{Cd}, \mathrm{Cr}, \mathrm{Cu}, \mathrm{Ni}, \mathrm{Pb}$ e $\mathrm{Zn}$ (extraídos por solução DTPA-TEA a pH 7,3). Efeitos similares foram observados por (i) Hayes et al. (1990a) para Cu; (ii) Inglés et al. (1992) para Cd, Ni e Pb; (iii) Johns \& McConchie (1994b) para Cu, Cd, Cr e $\mathrm{Pb}$; (iv) Al-Jaloud et al. (1995) para Ni; (v) Smith et al. (1996) para Cr, Ni, Pb e Zn; (vi) Ramirez-Fuentes et al. (2002) para Cr, Fe e Ni (extraídos em água régia); (vii) Wang et al. (2003) para $\mathrm{Cd}, \mathrm{Cr}, \mathrm{Cu}, \mathrm{Ni}$ e $\mathrm{Zn}$ (extraídos em água-régia) em solo irrigado por mais de 80 anos com EET. Também, tem sido observada diminuição na disponibilidade de metais pesados devido ao aumento de $\mathrm{pH}$ do solo mediante irrigação com EET (Falkiner \& Smith, 1997), incluindo estudos com Ni (Johns \& McConchie, 1994b), Cu, Mn, Zn (Al-Jaloud et al., 1995) e Pb (Paliwal et al., 1998).

Por outro lado, Quin \& Syers (1978) verificaram que solos sob pastagens submetidas à irrigação com EET por 16 anos apresentaram pequeno incremento nas concentrações de $\mathrm{Cu}, \mathrm{Mn}$ e $\mathrm{Zn}$ (disponíveis em solução $\mathrm{HCl}$ 0,1 mol L $\mathrm{m}^{-1}$ ). Siebe (1995) verificou pequeno aumento nas concentrações de $\mathrm{Cd}, \mathrm{Cu}$ e $\mathrm{Zn}$ (extraídos em água-régia) em solo cultivado com alfafa submetida à irrigação com EET por mais de 80 anos. AlNakshabandi et al. (1997) observaram aumento nas concentrações de $\mathrm{Cd}, \mathrm{Cu}, \mathrm{Fe}, \mathrm{Mn}$, 
$\mathrm{Pb}$ e $\mathrm{Zn}$ no solo (extraídos por solução DTPA-TEA a pH 7,3) devido às altas concentrações destes elementos no EET. No entanto, o incremento nas concentrações de metais pesados, sobretudo, das concentrações totais, nem sempre tem alterado a qualidade microbiológica do solo (Friedel et al., 2000; Yadav et al., 2002). Portanto, é de fundamental importância o monitoramento das concentrações de metais pesados ao longo do tempo nos solos destinados à disposição de EET (Cameron et al., 1997; Bond, 1998; Yadav et al., 2002), sobretudo, experimentação em longo prazo (Quin \& Syers, 1978; El-Nennah et al., 1982).

Aumento da CE do solo, bem como do percentual de sódio trocável (PST) tem sido relatado em solos sob pastagens irrigadas com EET (Hortenstine, 1976; Feigin et al., 1991; Bond, 1998). O incremento na concentração de Na no solo, bem como do PST pode (Bond, 1998) ou não (Balks et al., 1998) ocasionar alterações na condutividade hidráulica. A magnitude dos efeitos do $\mathrm{Na}$ em promover dispersão de argilas e, consequentemente, deterioração na estrutura, alteração da porosidade e diminuição na condutividade hidráulica do solo tem sido dependente da eficiência das chuvas em ocasionar lixiviação deste elemento (Mancino \& Pepper, 1992; Speir et al., 1999). Desse modo, o monitoramento das concentrações de $\mathrm{Na}$ no sistema solo-planta-efluenteambiente tem sido tão importante quanto o de $\mathrm{N}^{-\mathrm{NO}_{3}}{ }^{-}$(Bond, 1998).

Diante do exposto acima, não há dúvidas da importância do entendimento das alterações químicas e físicas de solos irrigados com EET, bem como do monitoramento da solução no solo e da nutrição e produção vegetal, visando a recomendação segura deste tipo de resíduo antrópico nos agrossistemas (Cameron et al., 1997; Bond, 1998), sobretudo, em condições de cultivos sob solos tropicais de baixa fertilidade natural, com cargas variáveis e de baixa CTC. 


\section{MATERIAL E MÉTODOS}

\subsection{Localização e condução do experimento}

O experimento foi instalado no município de Lins, Estado de São Paulo, com longitude $49^{\circ} 50^{\prime} \mathrm{W}$, latitude $22^{\circ} 21^{\prime} \mathrm{S}$ e altitude média de $440 \mathrm{~m}$, situado ao lado direito da estação de tratamento de esgoto (ETE) (Figura 1) operada pela Sabesp (Companhia de Saneamento Básico do Estado de São Paulo), na Unidade de Negócios do Baixo Tietê e Grande.

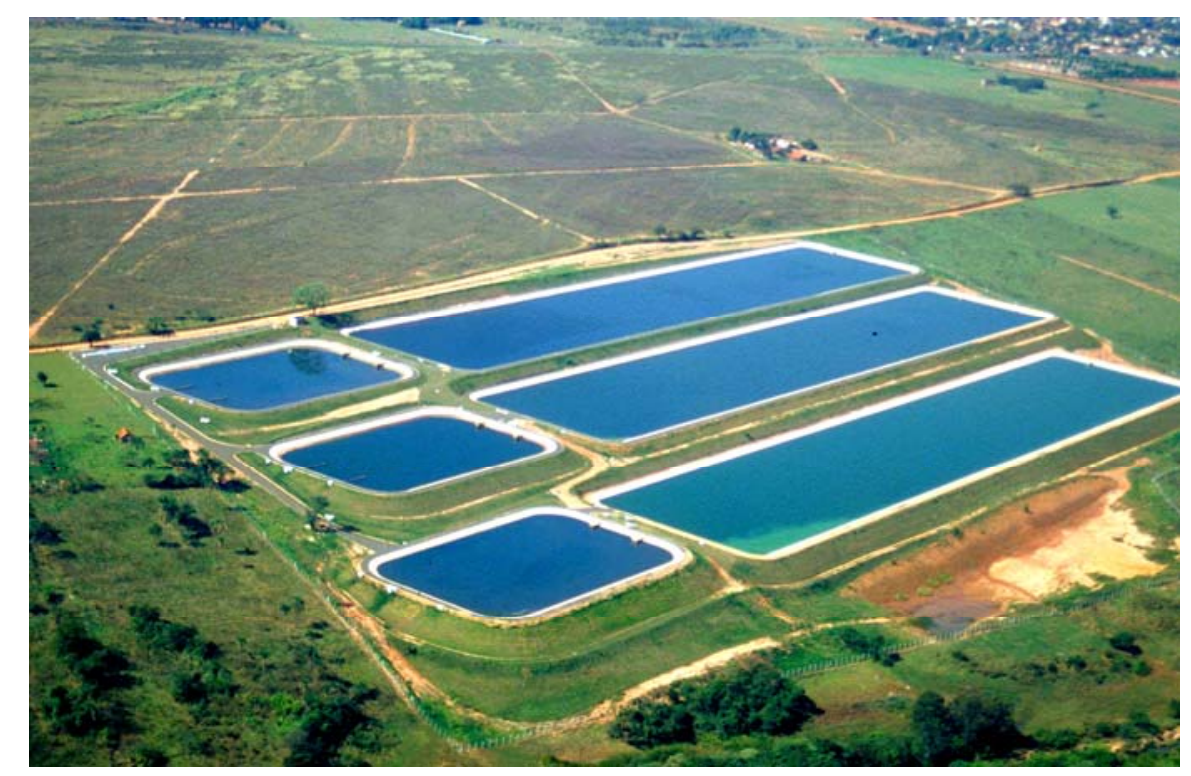

Figura 1 - Estação de tratamento de esgoto de origem predominantemente doméstico do município de Lins (SP) mediante o emprego de lagoas de estabilização (lagoa anaeróbia seguida de lagoa facultativa) 
A área experimental foi estudada por Ibrahim (2002). Geologicamente a área se insere na Formação Adamantina (Cretáceo Superior) do Grupo Bauru, pertencente à Bacia sedimentar do Paraná, localmente caracterizada por um banco de arenito de granulação fina a muito fina, moderadamente selecionado, com espessura superior a três metros, conforme Ibrahim (2002). O clima do local foi classificado como Cwa, caracterizado como mesotérmico de inverno seco, segundo a classificação de Koppen. A temperatura média tem sido de $22^{\circ} \mathrm{C}$ no mês mais quente e de $18^{\circ} \mathrm{C}$ no mês mais frio e a precipitação anual tem variado de 1.100 a $1.300 \mathrm{~mm}$.

O solo da área experimental é um Argissolo Vermelho distrófico Latossólico, de textura média-argilosa (Embrapa, 1999), cultivado com capim-Bermuda Tifton 85. Anteriormente ao capim, a área não era cultivada e encontrava-se em pousio. O plantio do capim foi realizado em janeiro de 2002, quatro meses após a aplicação de aproximadamente 2,0 $\mathrm{t} \mathrm{ha}^{-1}$ de calcário dolomítico (contendo 30,8\% de $\mathrm{CaO}$ e 19,8\% de $\mathrm{MgO}$ ), visando a elevação da saturação por bases a 60\% na camada 0-20 cm (Werner et al., 1996). Após o plantio não foi realizada correção da acidez, bem como fertilização do solo até a instalação do experimento, que ocorreu em 15 de janeiro de 2003.

O delineamento experimental foi o de blocos completos casualizados, com quatro repetições. Os cinco tratamentos empregados foram: (i) T1 (controle) - irrigação com água potável e adição de $520 \mathrm{~kg} \mathrm{ha}^{-1} \mathrm{ano}^{-1}$ de nitrogênio via fertilizante mineral (NFM); (ii) T2, T3, T4 e T5 - irrigação com ESET e adição de 0, 171,6; 343,2 e 520 kg $\mathrm{ha}^{-1}$ ano $^{-1}$ de NFM, respectivamente. As parcelas, distantes entre si $10 \mathrm{~m}$, apresentavam tamanho de $10 \times 10 \mathrm{~m}$, perfazendo uma área total de $100 \mathrm{~m}^{2}$. A área útil por unidade experimental foi de $48 \mathrm{~m}^{2}$, após ter sido desprezado 1,0 $\mathrm{m}$ de cada lado (bordadura) e 16 $\mathrm{m}^{2}$ centrais da parcela (área cuja precipitação dos aspersores não era uniforme). $\mathrm{O}$ sistema de irrigação empregado foi o de aspersão convencional, cujos aspersores localizavam-se no centro das parcelas, a uma altura de $90 \mathrm{~cm}$.

O manejo da irrigação foi realizado com base na umidade crítica do solo na camada 0 a $60 \mathrm{~cm}$. A cada dois dias, no período da manhã, foi realizada a leitura do potencial mátrico $\left(\psi_{m}\right)$ fornecida pelos tensiômetros, que se encontravam instalados no meio das camadas $0-20,20-40$ e $40-60 \mathrm{~cm}$, em cada uma das parcelas. A partir dos 
valores de $\psi_{m}$ e da curva de retenção, foi aplicado o modelo de van Genuchten (1980) para a obtenção da umidade atual do solo e, conseqüentemente, saber a necessidade de irrigação. Desse modo, conforme o tratamento empregado, água potável ou ESET foram aplicados no sistema solo-planta. Devido à alta razão de adsorção de sódio (RAS) tanto da água, como do ESET, foi necessário aplicar uma lâmina excedente de irrigação de aproximadamente 16\% (Ayers \& Westcot, 1985).

A precipitação pluvial no período experimental (15/01/2003 a 14/01/2005), bem como as lâminas de irrigação empregadas foram computadas. A água empregada na irrigação do tratamento T1 foi convencionalmente tratada pela Sabesp. O ESET, empregado na irrigação dos demais tratamentos, foi gerado na ETE adjacente ao experimento (Figura 1). Os esgotos, nessa ETE, são tratados por processos biológicos (lagoas de estabilização), passando por lagoas anaeróbia e facultativa, com tempo de retenção hidráulica de aproximadamente cinco e 15 dias, respectivamente.

A fertilização do experimento, considerando um sistema de produção de forragem para fenação, foi baseada nas sugestões apresentadas em Werner et al. (1996). Todas as parcelas receberam anualmente as mesmas quantidades de fertilizante mineral potássico (na forma de cloreto de potássio) e fosfatado (na forma de superfosfato simples). Somente as doses NFM (na forma de nitrato de amônio) variaram de 0 a 520 $\mathrm{kg} \mathrm{ha}{ }^{-1} \mathrm{ano}^{-1}$, conforme o tratamento. A fertilização potássica nos tratamentos T1 e T5 consistiu da relação anual $\mathrm{K}_{2} \mathrm{O} / \mathrm{N}$ de 0,8 , conforme empregada nos experimentos de fertilização de gramíneas do gênero Cynodon conduzidos por Alvim et al. (1998, 1999 e 2000). As épocas e as quantidades de fertilizantes minerais aplicados no decorrer do período experimental são apresentadas na Tabela 1 . Todos fertilizantes minerais foram distribuídos manualmente, imediatamente após os cortes do capim, conforme Premazzi et al. (2003).

Os tratos culturais foram realizados de modo a permitir o adequado crescimento e desenvolvimento das plantas. 
Tabela 1. Histórico de fertilização mineral do experimento

\begin{tabular}{|c|c|c|c|}
\hline \multirow{2}{*}{ Época de corte e fertilização } & \multicolumn{3}{|c|}{ Fertilizante } \\
\hline & $\mathbf{N}^{(1)}$ & $\mathbf{P}_{2} \mathbf{O}_{5}$ & $\mathbf{K}_{2} \mathbf{O}$ \\
\hline & \multicolumn{3}{|c|}{ kg ha $^{-1}$} \\
\hline Instalação do experimento (15/01/2003) & 60 & 100 & 40 \\
\hline $1^{\circ}$ corte do capim $(15 / 03 / 2003)$ & 60 & - & 40 \\
\hline $2^{\circ}$ corte do capim (15/05/2003) & 120 & - & 100 \\
\hline $3^{\circ}$ corte do capim (18/07/2003) & 100 & 50 & 75 \\
\hline $4^{\circ}$ corte do capim (15/09/2003) & 80 & - & 80 \\
\hline $5^{\circ}$ corte do capim (13/11/2003) & 100 & - & 80 \\
\hline $6^{\circ}$ corte do capim (14/01/2004) & 120 & 50 & 95 \\
\hline $7^{\circ}$ corte do capim (16/03/2004) & 120 & - & 80 \\
\hline $8^{\circ}$ corte do capim (16/05/2004) & 80 & - & 60 \\
\hline $9^{\circ}$ corte do capim (13/07/2004) & 80 & 50 & 60 \\
\hline $10^{\circ}$ corte do capim (13/09/2004) & 60 & - & 60 \\
\hline $11^{\circ}$ corte do capim (15/11/2004) & 60 & - & 60 \\
\hline
\end{tabular}

(1) Essas quantidades de nitrogênio via fertilizante mineral (NFM) foram aplicadas no tratamento T1 (controle), que recebeu irrigação com água. Os tratamentos T2, T3, T4 e T5 receberam 0, 33, 66 e $100 \%$ da dose de NFM aplicada no tratamento controle, respectivamente e foram irrigados com efluente secundário de esgoto tratado.

\subsection{Amostragens e análises de água e efluente}

Amostras de água e ESET foram coletadas mensalmente, antes da entrada na tubulação do sistema de irrigação. Depois de coletadas, as amostras foram mantidas em baixa temperatura (aproximadamente $4^{\circ} \mathrm{C}$ ) e, no laboratório, cada amostra foi dividida em três subamostras: (A) não filtrada; (B) filtrada em microfibra de vidro com poro de $0,45 \mu \mathrm{m}$ de diâmetro; (C) filtrada em membrana de éster-celulose com poro de 0,22 $\mu \mathrm{m}$ de diâmetro.

Nas subamostras (A) foram determinados os valores de $\mathrm{pH}, \mathrm{CE}$, sólidos totais (ST), demanda bioquímica de oxigênio (DBO) e demanda química de oxigênio (DQO), conforme APHA (1994). As subamostras (B) foram preservadas com solução de cloreto de mercúrio $30 \mathrm{mmol} \mathrm{L}^{-1}$ e mantidas em refrigeração até a determinação da concentração de carbono orgânico dissolvido (COD), mediante o uso do equipamento Shimadzu TOC5000A. O material particulado retido pela microfibra de vidro no processo de filtragem das subamostras (B) foi destinado à análise das concentrações de carbono total (CT) e nitrogênio total (NT), por combustão a seco (Nelson \& Sommers, 1996). As 
concentrações de CT e NT correspondem às de C-orgânico e N-orgânico não dissolvidas. As subamostras $(\mathrm{C})$ foram preservadas e mantidas de forma similar às subamostras (B), porém, foram destinadas às determinações analíticas de (i) $\mathrm{K} \mathrm{e} \mathrm{Na}$, por espectrofotometria de emissão em chama (EEC); (ii) $\mathrm{B}, \mathrm{Al}, \mathrm{Ca}, \mathrm{Mg}, \mathrm{Cu}, \mathrm{Fe}, \mathrm{Mn}, \mathrm{Zn}, \mathrm{Cd}$, $\mathrm{Cr}$, Ni e $\mathrm{Pb}$ por espectrometria de emissão óptica com plasma de argônio acoplado indutivamente (ICP-OES); (iii) $\mathrm{P}_{-} \mathrm{H}_{2} \mathrm{PO}_{4}^{-}, \mathrm{S}_{-} \mathrm{SO}_{4}{ }^{2-}, \mathrm{N}-\mathrm{NO}_{3}{ }^{-}, \mathrm{N}-\mathrm{NO}_{2}{ }^{-}, \mathrm{Cl}^{-}$e $\mathrm{F}^{-}$por cromatografia líquida (CL); (iv) alcalinidade (como $\mathrm{HCO}_{3}{ }^{-}$) por titulação com solução padronizada de $\mathrm{H}_{2} \mathrm{SO}_{4} 0,025 \mathrm{~mol} \mathrm{~L}^{-1}$; (v) $\mathrm{N}^{-\mathrm{NH}_{4}}{ }^{+}$por $\mathrm{CE}$ mediante o emprego de sistema de análise de injeção em fluxo contínuo, conforme Ruzicka \& Hansen (1975).

\subsection{Amostragens e análises de solo}

Para fins de caracterização da área experimental foram coletadas, meses antes da instalação do experimento, amostras de solo indeformadas (três repetições) nas camadas 0-20, 20-40 e 40-60 cm, com anéis volumétricos de 5,0 cm de altura por 5,0 cm de diâmetro. Essas amostras foram destinadas à obtenção das curvas características de umidade, conforme método sugerido por Camargo et al. (1986). Este procedimento foi necessário para estabelecer o manejo de irrigação.

No mês de dezembro/2002 foram coletadas aleatoriamente amostras compostas de solo das camadas superficiais (0-10 e 10-20 cm) e subsuperficiais (20-40, 40-60, 6080 e $80-100 \mathrm{~cm}$ ) na área experimental, mediante o emprego de trado tipo "holandês". Foram coletadas 12 e seis subamostras para formar uma amostra composta para cada uma das camadas superficiais e subsuperficiais, respectivamente. Após a instalação do experimento, os mesmos procedimentos de amostragens foram empregados em cada unidade experimental aos três (abril/2003), seis (julho/2003), nove (outubro/2003), 12 (janeiro/2004), 15 meses (abril/2004) e 18 meses (julho/2004). As amostras compostas de solo, após serem coletadas, foram secadas ao ar e peneiradas em peneira de malha de 2,0 mm e então, foram obtidas amostras de terra fina seca ao ar (TFSA).

Amostras de TFSA da amostragem do mês de dezembro/2002 foram analisadas fisicamente, visando determinar as frações areia, silte e argila, incluindo as concentrações ADA pelo método da pipeta. Amostras de TFSA das demais épocas 
também foram destinadas à determinação das concentrações de ADA. Para a realização dessas análises foram empregados os métodos sugeridos por Camargo et al. (1986).

Foi realizada investigação mineralógica de TFSA (amostras totais em pó e orientadas da fração argila separada) referentes às amostras coletadas no mês de dezembro/2002, mediante o emprego de difratometria de raios-X (DRX). Após as análises das amostras em pó, visando caracterizar os minerais das diferentes frações granulométricas (areia, silte e argila), as amostras de TFSA foram submetidas a diferentes procedimentos: (i) remoção da matéria orgânica (com $\mathrm{H}_{2} \mathrm{O}_{2} 30 \%$ em placa aquecida a $70^{\circ} \mathrm{C}$ ); (ii) remoção dos óxidos de $\mathrm{Fe}$ (por ditionito-bicarbonato-citrato) e (iii) separações das frações areia, silte e argila. Amostras separadas da fração argila natural (sem tratamento) e saturada (com $\mathrm{K}$ e com $\mathrm{Mg}$ ) foram submetidas à DRX. Adicionalmente, as amostras saturadas com $\mathrm{K}$ e com $\mathrm{Mg}$ receberam tratamentos térmicos $\left(110^{\circ}, 350^{\circ}\right.$ e $\left.550^{\circ} \mathrm{C}\right)$ e etilenoglicol, respectivamente. As amostras das frações areia e silte foram posteriormente analisadas por DRX. A partir do espaçamento interplanar dos minerais, fornecido pelos difratogramas, foi determinada a composição mineralógica das amostras (Embrapa, 1997).

Foram feitas análises químicas de TFSA em todas épocas de amostragens, com exceção das análises de CT e NT, que não foram realizadas aos 15 meses após a instalação do experimento. $\mathrm{O} \mathrm{pH}$ (acidez atual) foi determinado por potenciometria, em solução de $\mathrm{CaCl}_{2}$ 0,01 mol L $\mathrm{L}^{-1}$. As concentrações de $\mathrm{H}+\mathrm{Al}$ (acidez total) foram determinadas por titulação com solução padronizada de $\mathrm{NaOH} 0,025 \mathrm{~mol} \mathrm{~L}^{-1}$ de extratos de TFSA obtidos com solução de $\mathrm{Ca}\left(\mathrm{CH}_{3}-\mathrm{COO}\right)_{2}$ 0,5 mol $\mathrm{L}^{-1}$ a pH 7,0. As concentrações trocáveis de $\mathrm{Al}$ (acidez trocável), $\mathrm{Ca}$ e $\mathrm{Mg}$ foram determinadas em extratos de TFSA obtidos com solução de $\mathrm{KCl}$ 1,0 mol L $\mathrm{L}^{-1}$. Foram determinadas as concentrações de Al trocável por titulação com solução padronizada de $\mathrm{NaOH} \mathrm{0,025} \mathrm{mol}$ $\mathrm{L}^{-1}$ e as concentrações de $\mathrm{Ca}$ e $\mathrm{Mg}$ foram obtidas mediante leitura por espectrometria de absorção atômica com atomização em chama (EAA-chama). As concentrações de $\mathrm{Na}, \mathrm{K}$ e P foram determinadas em extratos de TFSA obtidos com solução de Mehlich-1 ( $\mathrm{HCl}$ $0,05 \mathrm{~mol} \mathrm{~L}^{-1}+\mathrm{H}_{2} \mathrm{SO}_{4} 0,0125 \mathrm{~mol} \mathrm{~L}^{-1}$ ), mediante leitura por EEC para $\mathrm{Na}$ e $\mathrm{K}$ e por espectrofotometria de absorção molecular (EAM) para P. As concentrações de S 
disponível foram extraídas por solução de fosfato monocálcico $0,01 \mathrm{~mol} \mathrm{~L}^{-1} \mathrm{e}$ as determinações foram realizadas por turbidimetria (Fox et al., 1987). As concentrações de $\mathrm{B}$ disponível foram extraídas por solução de $\mathrm{BaCl}_{2} 0,006 \mathrm{~mol} \mathrm{~L}^{-1}$ aquecido em microonda e as determinações foram realizadas por ICP-OES (Abreu et al., 1994). As concentrações disponíveis de metais pesados ( $\mathrm{Cd}, \mathrm{Cr}, \mathrm{Cu}, \mathrm{Fe}, \mathrm{Mn}, \mathrm{Ni}, \mathrm{Pb}$ e $\mathrm{Zn}$ ) foram determinadas em extratos de TFSA obtidos com solução de DTPA-TEA (ácido dietilenotriaminopentaacético $0,005 \mathrm{~mol} \mathrm{~L}^{-1}+$ trietanolamina $0,1 \mathrm{~mol} \mathrm{~L}^{-1}+\mathrm{CaCl}_{2} 0,01$ mol L ${ }^{-1}$ ) a pH 7,3 (Lindsay \& Norvell, 1978), mediante leitura por ICP-OES. As concentrações de CT e NT foram obtidas por combustão a seco (Nelson \& Sommers, 1996), após as amostras de TFSA serem moídas e peneiradas em peneira de malha de 0,15 mm. Nas amostras de TFSA do mês de dezembro/2003 também foram determinados, por potenciometria, o pH em água e em solução de $\mathrm{KCl} 1,0 \mathrm{~mol} \mathrm{~L}^{-1}$. Foram empregadas relações solo:solução de (i) 1:10 (m:v) para as determinações analíticas de $\mathrm{H}+\mathrm{Al}, \mathrm{Al}, \mathrm{Ca}, \mathrm{Mg}, \mathrm{K}, \mathrm{Na}$ e P; (ii) 1:2,5 (m:v) para as determinações de $\mathrm{pH}$ e S; (iii) 1:2 (m:v) para as determinações de B e metais pesados.

\subsection{Amostragens e análises de solução no solo}

Bimestralmente foram coletadas amostras de solução no solo mediante o emprego de cápsulas de cerâmica porosa (Wagner, 1962), nas ocasiões do primeiro ao nono corte do capim (Tabela 1), conforme procedimento adaptado de Ahmed et al. (2001) e Menéndez et al. (2003). As cápsulas foram assentadas em pó de sílica no meio das camadas 0-20, 20-40, 40-60, 60-80 e 80-100 cm. Foi empregado selo de bentonita para delimitação das camadas. Ao lado das cápsulas, aproximadamente $50 \mathrm{~cm}$, foram instalados tensiômetros para o monitoramento do $\psi_{m}$. Catorze e sete dias antes da data prevista para amostragem de solução no solo, as cápsulas foram submetidas a vácuo de $80,0 \mathrm{kPa}$, com utilização de bomba manual.

Apesar da cápsula de porcelana ser o extrator de solução no solo mais utilizado (Ahmed et al., 2001), o volume de solução coletado normalmente não tem sido semelhante para uma mesma situação de $\psi_{m}$ (Wagner, 1962; Menéndez et al., 2003). Isso implica na impossibilidade de coleta de amostra em quantidade suficiente para 
realização das análises, conforme relatado em Hansen \& Harris (1975). Visando contornar o problema "falta de amostra de solução", foi utilizado um método alternativo para obtenção de solução no solo, que consistiu no emprego de extratos de saturação a partir de pastas de saturação das amostras de TFSA, conforme Rhoades (1996).

Foram utilizados, para as amostras de solução no solo obtidas pelos dois métodos (cápsula de cerâmica porosa e extrato de saturação), os mesmos procedimentos de preparo, conservação e determinações analíticas empregados nas amostras de efluente (item 3.2), exceto determinações de ST, DBO, DQO, COD, CT, $\mathrm{NT}, \mathrm{Cl}^{-}, \mathrm{F}^{-}$e $\mathrm{HCO}_{3}^{-}$.

\subsection{Determinação da massa seca e análise química de plantas}

O capim foi cortado bimestralmente (12 cortes), à altura de aproximadamente 5,0 cm, mediante o emprego de roçadora costal mecanizada. Para determinar a massa seca (MS), foi cortado manualmente o capim localizado dentro de um quadrado de 1,0 $\mathrm{x}$ 1,0 $\mathrm{m}$ disposto aleatoriamente na área útil da parcela. A secagem do capim foi realizada em estufa com circulação forçada de ar, a $60^{\circ} \mathrm{C}$ até atingir massa constante e então, foi determinada a MS.

Subamostras do material vegetal foram retiradas, antes de serem levadas à estufa, visando à lavagem com água deionizada e à separação manual de folhas (F) e de colmos+bainhas $(\mathrm{C}+\mathrm{B})$. Essas subamostras foram secadas do mesmo modo que o restante do material vegetal, moídas em moinho tipo "Wiley", equipado com malha de $0,85 \mathrm{~mm}$ e armazenadas em recipientes plásticos tampados até a realização das análises químicas. Foram determinadas as concentrações de N, P, K, Ca, Mg, S, Na, B, Al, Cd, $\mathrm{Cr}, \mathrm{Cu}, \mathrm{Fe}, \mathrm{Mn}, \mathrm{Ni}, \mathrm{Pb}$ e Zn segundo os métodos descritos em Malavolta et al. (1997). Por meio de digestão sulfúrica e leitura pelo método semi-micro-Kjeldahl foram determinadas as concentrações de N. A determinação das concentrações de P, K, Ca, $\mathrm{Mg}, \mathrm{S}, \mathrm{Na}, \mathrm{Al}, \mathrm{Cd}, \mathrm{Cr}, \mathrm{Cu}, \mathrm{Fe}, \mathrm{Mn}, \mathrm{Ni}, \mathrm{Pb}$ e $\mathrm{Zn}$ foram realizadas mediante digestão nítrico-perclórica e leitura por EEC para $\mathrm{K}$ e Na; EAA-chama para Ca e Mg; ICP-OES para $\mathrm{P}, \mathrm{Cu}, \mathrm{Fe}, \mathrm{Mn}, \mathrm{Zn}, \mathrm{Al}, \mathrm{Cd}, \mathrm{Cr}, \mathrm{Ni}$ e $\mathrm{Pb}$; e turbidimetria para S. As concentrações de B foram determinadas por meio de digestão via seca (incineração) e leitura por ICPOES. 
$\mathrm{O}$ produto da concentração de elementos presentes nas subamostras (F) e $(\mathrm{C}+\mathrm{B})$ pela respectiva MS resultou na quantidade de elementos acumulados na parte aérea das plantas por ocasião do corte de capim.

\subsection{Análises estatísticas}

Médias e desvios padrão dos resultados de análises de água e ESET foram calculados para os 24 meses de amostragem. Os resultados de rendimento MS acumulada anualmente, elementos acumulados semestralmente e de análises de solo e solução no solo (extrato de saturação) foram submetidos a testes estatísticos para verificar a esfericidade dos dados. Pelo fato de ter sido observada uniformidade na matriz de covariância, atendendo à condição Huynh-Feldt (H-F), esses resultados foram submetidos à análise estatística univariada de acordo com o modelo de experimento em blocos, considerando o tempo (época de avaliação) como subparcela. Nos casos de F significativo $(P<0,05)$ foi aplicado o teste de Tukey.

Os tratamentos irrigados com ESET (T2, T3, T4 e T5) também foram analisados separadamente para os resultados de MS acumulada anualmente. Após a observação de $\mathrm{F}$ significativo $(P<0,05)$, foram ajustados aos modelos linear e quadrático os efeitos da variável preditora (dose de NFM) para a variável de resposta (rendimento de MS).

Foram realizadas, para épocas comuns de amostragens (julho/2003, janeiro/2004 e julho/2004), análises de correlações entre parâmetros de solo, solução no solo, acúmulo de elementos nas plantas, bem como entre métodos de obtenção da solução no solo (cápsulas de cerâmica porosa e extratos de saturação). Todas as análises estatísticas foram realizadas mediante o emprego do programa de computador SAS Versão 8.02 (SAS, 1999). 


\section{RESULTADOS E DISCUSSÃO}

\subsection{Condição do solo por ocasião da instalação do experimento}

O solo da área experimental apresenta mineralogia simples, predominantemente, quartzo e caulinita e, subordinadamente, ilita, hematita, magnetita e/ou maghemita. Na fração argila deferrificada a caulinita é o mineral dominante.

Por ocasião da instalação do experimento, o solo apresentava baixa fertilidade natural, sobretudo em P; baixa saturação por bases (V) nas camadas 20-100 cm; baixas concentrações de CT e NT; cargas elétricas predominantemente negativas (valor de $\Delta p H$ negativo); baixas concentrações de micronutrientes e elementos tóxicos; concentrações de Na abaixo de limite de deteç̧ão; baixas concentrações de sais (baixa CE); alto grau de floculação das argilas (GFA) (Tabela 2). Essas características são intrínsecas a solos altamente intemperizados, sobretudo aos Argissolos (Embrapa, 1999). As concentrações de $\mathrm{Cd}$, Ni e $\mathrm{Pb}$ encontravam-se abaixo do limite de detecção ${ }^{\S}$ do método empregado, cujos valores foram 0,$03 ; 0,06$ e $0,13 \mathrm{mg} \mathrm{kg}^{-1}$, respectivamente. As concentrações de $\mathrm{Cr}$ nas camadas 0-10 e 10-20 cm foram 0,04 e 0,03 $\mathrm{mg} \mathrm{kg}^{-1}$, respectivamente; porém, nas camadas 20-40, 40-60, 60-80 e 80-100 cm as concentrações deste elemento encontravam-se abaixo do limite de detecção $\left(0,01 \mathrm{mg} \mathrm{kg}^{-1}\right)$.

Os resultados das curvas de retenção de água no solo são apresentados na Tabela 2. Devido à textura média-arenosa a média-argilosa, bem como das baixas concentrações de CT (Tabela 2), a capacidade de armazenamento de água do solo é pequena, o que implica na necessidade de maior freqüência de irrigação (Libardi, 2000).

\footnotetext{
${ }^{\S}$ Limite de detecção $(L D) \rightarrow L D=3 * s$

Desvio Padrão $(s)$ referente à média de dez leituras do branco
} 
Tabela 2. Características químicas e físicas do solo por ocasião da instalação do experimento, em janeiro de 2003

\begin{tabular}{|c|c|c|c|c|c|c|c|c|c|c|}
\hline Camada & $\mathrm{H}_{2} \mathrm{O}$ & $\begin{array}{c}\mathbf{p H} \\
\mathbf{K C l}\end{array}$ & $\mathrm{CaCl}_{2}$ & $\underset{(1)}{\Delta p H}$ & $\mathbf{H}+\mathbf{A l}$ & Al & Ca & Mg & $\mathbf{K}$ & $\mathrm{Na}$ \\
\hline $\mathbf{c m}$ & & & & & \multicolumn{6}{|c|}{$\mathbf{m m o l}_{\mathrm{c}} \mathbf{k g}^{-1}$} \\
\hline $0-10$ & 5,65 & 4,70 & 4,90 & $-0,95$ & 15,17 & 1,00 & 10,26 & 5,61 & 1,45 & $\mathrm{ND}^{(2)}$ \\
\hline $10-20$ & 5,36 & 4,57 & 4,56 & $-0,79$ & 16,97 & 1,80 & 10,54 & 5,97 & 0,79 & ND \\
\hline $20-40$ & 5,06 & 4,53 & 4,32 & $-0,53$ & 17,47 & 4,10 & 7,36 & 5,52 & 0,53 & ND \\
\hline $40-60$ & 5,03 & 4,20 & 4,04 & $-0,83$ & 22,67 & 8,50 & 3,79 & 2,72 & 0,43 & ND \\
\hline $60-80$ & 5,03 & 4,19 & 4,20 & $-0,84$ & 24,57 & 6,80 & 5,71 & 4,34 & 0,45 & ND \\
\hline \multirow[t]{2}{*}{ 80-100 } & 4,91 & 4,25 & 4,18 & $-0,66$ & 17,97 & 5,70 & 3,90 & 4,71 & 0,76 & ND \\
\hline & $\mathbf{m m o l}_{\mathrm{c}} \mathbf{k g}^{-1}$ & $\begin{array}{l}\text { CTC } \\
\mathbf{k g}^{-1}\end{array}$ & $\begin{array}{l}\mathrm{V} \\
\%\end{array}$ & \multicolumn{6}{|c|}{$\mathrm{mg} \mathrm{kg}^{-1}$} & Zn \\
\hline $0-10$ & 18,32 & 32,49 & 53,31 & 6,23 & 2,33 & 0,38 & 0,24 & 13,22 & 3,80 & 0,23 \\
\hline $10-20$ & 19,10 & 32,27 & 50,48 & 1,35 & 3,10 & 0,34 & 0,25 & 14,12 & 4,71 & 0,19 \\
\hline $20-40$ & 17,51 & 30,88 & 43,43 & 1,57 & 8,91 & 0,24 & 0,30 & 13,68 & 4,07 & 0,25 \\
\hline $40-60$ & 15,44 & 29,61 & 23,44 & 0,71 & 2,20 & 0,33 & 0,37 & 9,11 & 2,02 & 0,22 \\
\hline $60-80$ & 17,30 & 35,07 & 29,94 & 0,71 & 17,35 & 0,20 & 0,27 & 7,64 & 2,23 & 0,20 \\
\hline \multirow[t]{3}{*}{ 80-100 } & 15,07 & 27,34 & 34,27 & 0,44 & 1,55 & 0,25 & 0,21 & 4,24 & 2,56 & 0,16 \\
\hline & $\mathbf{C T}{ }^{(3)}$ & $\underset{(4)}{\mathbf{N T}}$ & $\mathrm{CE}^{(5)}$ & Areia & Silte & $\begin{array}{r}A \\
\text { Tota }\end{array}$ & $\begin{array}{l}\text { Argila } \\
\text { l Água }\end{array}$ & $\underset{(6)}{\mathbf{G F}}$ & & $\begin{array}{l}\text { Clas. } \\
\text { Text. }{ }^{(7)}\end{array}$ \\
\hline & \multicolumn{2}{|c|}{$\mathrm{g} \mathrm{kg}^{-1}$} & dS $m^{-1}$ & & \multicolumn{3}{|c|}{$\mathrm{g} \mathrm{kg}^{-1}$} & \multicolumn{2}{|l|}{$\%$} & \\
\hline $0-10$ & 5,97 & 0,46 & 0,07 & 740 & 60 & 200 & 21 & 89,5 & & MAre \\
\hline $10-20$ & 5,84 & 0,46 & 0,08 & 740 & 40 & 220 & 19 & 91, & & Mare \\
\hline $20-40$ & 5,68 & 0,43 & 0,07 & 720 & 60 & 220 & 20 & 90, & & MAre \\
\hline $40-60$ & 5,28 & 0,41 & 0,04 & 660 & 80 & 260 & 22 & 91,5 & & MArg \\
\hline $60-80$ & 4,26 & 0,32 & 0,02 & 680 & 40 & 280 & 0 & 100, & & MArg \\
\hline \multirow[t]{4}{*}{ 80-100 } & 3,04 & 0,23 & 0,06 & 640 & 80 & 280 & 0 & 100 & & MArg \\
\hline & \multicolumn{10}{|c|}{ Tensão (kPa) } \\
\hline & $\mathbf{0 , 0 0}$ & 0,98 & 1,96 & 3,92 & 5,88 & 9,81 & 32,36 & 78,45 & 98,07 & 147,10 \\
\hline & \multicolumn{10}{|c|}{ Umidade volumétrica $\left(\mathrm{m}^{3} \mathrm{~m}^{-3}\right)$} \\
\hline $0-20$ & 0,389 & 0,343 & 0,330 & 0,304 & 0,283 & 0,257 & 0,213 & 0,181 & 0,156 & 0,151 \\
\hline $20-40$ & 0,436 & 0,358 & 0,333 & 0,297 & 0,279 & 0,247 & 0,210 & 0,195 & 0,151 & 0,137 \\
\hline $40-60$ & 0,419 & 0,351 & 0,334 & 0,307 & 0,289 & 0,260 & 0,218 & 0,182 & 0,172 & 0,163 \\
\hline \multicolumn{11}{|c|}{$\Delta p H=p H_{K C l}-p H_{H_{2} O}$} \\
\hline $\begin{array}{l}\text { 2) ND: elen } \\
{ }^{3)} \text { CT: carb } \\
{ }^{4)} \text { NT: nitro } \\
{ }^{5)} \text { CE: cond } \\
{ }^{6)} \text { GFA: gra } \\
{ }^{7)} \text { Clas. Tex }\end{array}$ & $\begin{array}{l}\text { ento quí } \\
\text { no total } \\
\text { gênio tot } \\
\text { dtividad } \\
\text { u de floc }\end{array}$ & mico nã & detect & 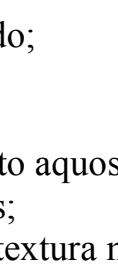 & $1.1 \mathrm{~m}$ & . Wl cont & forme $C$ ar & 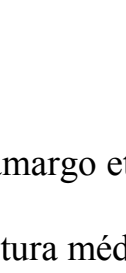 & 1 & 986); \\
\hline
\end{tabular}




\subsection{Qualidade e quantidade de irrigação}

As características da água e do ESET empregados na irrigação do capim podem ser observadas na Tabela 3. Os constituintes analisados nas amostras de água apresentaram menor variação quando comparados aos constituintes do ESET. As características químicas do ESET são dependentes, principalmente, do tipo de fonte de abastecimento de água, sistema de coleta e tratamento de esgoto e natureza de descarga de esgoto industrial na ETE (Feigin et al., 1991). Os constituintes do ESET, no presente estudo, variaram ao longo do ano, sobretudo na estação chuvosa (verão). Este fato concorda com as observações de Singh \& Bhati (2003), que verificaram diminuição nos parâmetros do ESET durante a estação chuvosa devido aos efeitos de diluição.

Os padrões de qualidade da água potável empregada na irrigação do tratamento T1 estão de acordo com a Resolução do Conama n. ${ }^{\circ}$ 20, enquadrando-se para uso de abastecimento doméstico, segundo Von Sperling (1995). Quanto ao ESET (que foi empregado na irrigação dos tratamentos T2, T3, T4 e T5), seus constituintes foram comparados às médias apresentadas em extensas revisões internacionais e/ou trabalhos em longo prazo apresentados em Bouwer \& Chaney (1974), Feigin et al. (1978), Asano \& Pettygrove (1987); Feigin et al. (1991) e Pescod (1992), cujos valores também são mostrados na Tabela 3.

As concentrações médias de ST, DBO, alcalinidade, $\mathrm{NT}, \mathrm{N}_{-} \mathrm{NH}_{4}^{+}, \mathrm{N}^{-\mathrm{NO}_{3}}{ }^{-}, \mathrm{N}-$ $\mathrm{NO}_{2}^{-}$, N-total $\left(\mathrm{NT}+\mathrm{N}_{-} \mathrm{NH}_{4}{ }^{+}+\mathrm{N}^{-\mathrm{NO}_{3}}{ }^{-}+\mathrm{N}_{-} \mathrm{NO}_{2}{ }^{-}\right), \mathrm{P}_{-} \mathrm{H}_{2} \mathrm{PO}_{4}{ }^{-}, \mathrm{Cl}^{-}, \mathrm{K}, \mathrm{Na}$ e B são consideradas normais para este subproduto (Tabela 3). Porém, as concentrações de DQO, COD, CT, bem como a RAS se encontram acima do normal para o ESET (Tabela 3). As concentrações de $\mathrm{S}_{-} \mathrm{SO}_{4}{ }^{2-}, \mathrm{Ca}, \mathrm{Mg}, \mathrm{Mn}$, bem como os valores de $\mathrm{pH}$ e $\mathrm{CE}$ deste subproduto se encontram abaixo da média mundial (Tabela 3). As concentrações de $\mathrm{F}^{-}$, $\mathrm{Cu}, \mathrm{Fe}$ e $\mathrm{Zn}$ se encontravam abaixo do valor de referência (Tabela 3). Os metais $\mathrm{Cd}, \mathrm{Cr}$, $\mathrm{Ni}$ e $\mathrm{Pb}$ se encontravam em concentrações inferiores ao limite de detecção do método empregado (Tabela 3).

Os limites apresentados em Ayers \& Westcot (1985) para concentrações de Al, $\mathrm{B}, \mathrm{Cd}, \mathrm{Cr}, \mathrm{Cu}, \mathrm{F}^{-}, \mathrm{Fe}, \mathrm{Mn}, \mathrm{Ni}, \mathrm{Pb}$ e Zn na água de irrigação são 5,0; 0,70;0,01;0,10; 
Tabela 3. Resultados de análises (média de 24 amostras, coletadas mensalmente) da água potável e do efluente secundário de esgoto tratado (ESET), que foram empregados na irrigação do experimento e comparação dos valores médios dos constituintes do ESET com médias apresentadas em revisões bibliográficas internacionais

\begin{tabular}{|c|c|c|c|c|}
\hline Constituinte & Água & ESET & Concentração normal $^{(1)}$ & Referência \\
\hline \multicolumn{5}{|c|}{$\mathrm{mg} \mathrm{L}^{-1}$} \\
\hline Sólidos totais (ST) & - & $571,00 \pm 52,51$ & 400 a 1200 & Feigin et al. (1991) \\
\hline DBO ${ }^{(2)}$ & - & $77,80 \pm 46,75$ & 10 a 80 & Feigin et al. (1991) \\
\hline DQO ${ }^{(3)}$ & - & $180,50 \pm 91,68$ & 30 a 160 & Feigin et al. (1991) \\
\hline $\mathrm{CT}^{(4)}$ & - & $49,44 \pm 7,95$ & 10 a 30 & Bouwer \& Chaney (1974) \\
\hline $\operatorname{COD}^{(5)}$ & $3,12 \pm 1,72$ & $65,28 \pm 57,41$ & 30 a 60 & Bouwer \& Chaney (1974) \\
\hline $\mathrm{NT}^{(6)}$ & - & $8,85 \pm 1,62$ & $1-23$ & Feigin et al. (1978) \\
\hline Alcalinidade como $\mathrm{HCO}_{3}^{-}$ & $224,50 \pm 41,88$ & $301,41 \pm 60,75$ & 200 a 700 & Feigin et al. (1991) \\
\hline $\mathrm{N}-\mathrm{NH}_{4}^{+}$ & $0,04 \pm 0,03$ & $22,37 \pm 3,52$ & 1 a 40 & Feigin et al. (1991) \\
\hline $\mathrm{N}-\mathrm{NO}_{3}^{-}$ & $0,18 \pm 0,06$ & $0,61 \pm 0,53$ & $0-10$ & Feigin et al. (1991) \\
\hline $\mathrm{N}-\mathrm{NO}_{2}^{-}$ & $0,02 \pm 0,07$ & $0,02 \pm 0,08$ & $0,02^{(8)}$ & Pescod (1992) \\
\hline N-total ${ }^{(7)}$ & $0,24 \pm 0,16$ & $31,85 \pm 5,75$ & 10 a 50 & Feigin et al. (1991) \\
\hline $\mathbf{P}-\mathrm{H}_{2} \mathbf{P O}_{4}^{-}$ & $<\mathrm{LD}^{(9)}$ & $4,30 \pm 1,11$ & 4,2 a 9,7 & Bouwer \& Chaney (1974) \\
\hline $\mathrm{S}-S O_{4}{ }^{2-}$ & $4,55 \pm 0,99$ & $4,93 \pm 1,36$ & $62^{(8)}$ & Asano \& Pettygrove (1987) \\
\hline $\mathrm{Cl}^{-}$ & $11,07 \pm 7,07$ & $59,07 \pm 15,36$ & 40 a 200 & Feigin et al. (1991) \\
\hline $\mathbf{F}^{-}$ & $0,70 \pm 0,14$ & $0,48 \pm 0,32$ & $1,2^{(8)}$ & Pescod (1992) \\
\hline Ca & $0,83 \pm 0,33$ & $8,06 \pm 1,07$ & 20 a 120 & Feigin et al. (1991) \\
\hline Mg & $0,17 \pm 0,04$ & $1,89 \pm 0,46$ & 10 a 50 & Feigin et al. (1991) \\
\hline $\mathbf{K}$ & $0,92 \pm 0,22$ & $16,62 \pm 1,81$ & 10 a 40 & Feigin et al. (1991) \\
\hline $\mathbf{N a}$ & $120,79 \pm 36,93$ & $145,79 \pm 31,33$ & 50 a 250 & Feigin et al. (1991) \\
\hline $\mathbf{B}$ & $0,148 \pm 0,045$ & $0,170 \pm 0,088$ & 0 a 1 & Feigin et al. (1991) \\
\hline Al & $0,040 \pm 0,024$ & $0,032 \pm 0,023$ & - & - \\
\hline Cd & $<\mathrm{LD}$ & $<\mathrm{LD}$ & $<0,002^{(8)}$ & Asano \& Pettygrove (1987) \\
\hline $\mathrm{Cr}$ & $<\mathrm{LD}$ & $<\mathrm{LD}$ & $<0,020^{(8)}$ & Asano \& Pettygrove (1987) \\
\hline $\mathbf{C u}$ & $0,001 \pm 0,001$ & $0,002 \pm 0,001$ & $0,040^{(8)}$ & Feigin et al. (1991) \\
\hline
\end{tabular}


Tabela 3. Resultados de análises (média de 24 amostras, coletadas mensalmente) da água potável e do efluente secundário de esgoto tratado (ESET), que foram empregados na irrigação do experimento e comparação dos valores médios dos constituintes do ESET com médias apresentadas em revisões bibliográficas internacionais

\begin{tabular}{|c|c|c|c|c|}
\hline Constituinte & Água & ESET & Concentração normal $^{(1)}$ & Referência \\
\hline \multicolumn{5}{|c|}{$\mathrm{mg} \mathrm{L}^{-1}$} \\
\hline $\mathbf{F e}$ & $<\mathrm{LD}$ & $0,082 \pm 0,061$ & $0,330^{(8)}$ & Pescod (1992) \\
\hline Mn & $0,002 \pm 0,002$ & $0,015 \pm 0,006$ & 0,200 a 0,700 & Pescod (1992) \\
\hline $\mathbf{N i}$ & $<\mathrm{LD}$ & $<\mathrm{LD}$ & $0,007^{(8)}$ & Feigin et al. (1991) \\
\hline $\mathbf{P b}$ & $<\mathrm{LD}$ & $<\mathrm{LD}$ & $<0,050^{(8)}$ & Asano \& Pettygrove (1987) \\
\hline Zn & $<\mathrm{LD}$ & $0,015 \pm 0,003$ & $0,040^{(8)}$ & Feigin et al. (1991) \\
\hline $\mathbf{p H}$ & $9,65 \pm 0,26$ & $7,51 \pm 0,34$ & 7,8 a 8,1 & Feigin et al. (1991) \\
\hline Relação DQO:DBO & - & $2,73 \pm 1,58$ & $2,4^{(8)}$ & Pescod (1992) \\
\hline Relação CT:NT & - & $5,63 \pm 0,54$ & $5: 1^{(8)}$ & Feigin et al. (1991) \\
\hline Relação molar Ca:Mg & $2,75 \pm 1,47$ & $2,70 \pm 0,89$ & - & - \\
\hline CE, em dS m ${ }^{-1}$ & $0,49 \pm 0,11$ & $0,86 \pm 0,12$ & 1,0 a 3,1 & Pescod (1992) \\
\hline RAS, em $\left(\mathrm{mmol} \mathrm{L}^{-1}\right)^{1 / 2}$ & $32,18 \pm 10,11$ & $11,94 \pm 2,91$ & 4,5 a 7,9 & Feigin et al. (1991) \\
\hline $\begin{array}{l}\text { (1) Faixa de concentração consid } \\
\text { (2) DBO: demanda bioquímica d } \\
\text { (3) DQO: demanda química de o } \\
\text { (4) CT: carbono total no material } \\
\text { (5) COD: carbono orgânico disso } \\
\text { (6) NT: nitrogênio total no mater } \\
\text { (7) N-total: nitrogênio total prese } \\
\text { (8) Valor de referência, uma vez } \\
\text { (9) LD: limite de detecção, cujos }\end{array}$ & $\begin{array}{l}\text { nal para os con } \\
\text { lo; } \\
\text { lado; } \\
\text { ET } \rightarrow N \text {-total }= \\
\text { onstituinte não } \\
\text { ram: } 25,7,3,3\end{array}$ & $\begin{array}{l}+N-N_{4}^{+}+\Lambda \\
\text { do rotineirame } \\
2 \text { e } 12 \mu \mathrm{g} \mathrm{L}^{-1}\end{array}$ & $\begin{array}{l}\left.+N-\mathrm{NO}_{2}^{-}\right) \\
\text {halisado nas amostras de } \mathrm{I}\end{array}$ & ET; \\
\hline
\end{tabular}


0,$20 ; 1,0 ; 5,0 ; 0,20 ; 0,20 ; 5,0$ e $2,0 \mathrm{mg} \mathrm{L}^{-1}$, respectivamente. Comparando-se esses limites com os valores médios apresentados na Tabela 3, conclui-se que, devido ao fato do ESET de Lins ser predominantemente doméstico, não há contaminação significativa dos esgotos com $\mathrm{Al}, \mathrm{B}, \mathrm{Cd}, \mathrm{Cr}, \mathrm{Cu}, \mathrm{F}^{-}, \mathrm{Fe}, \mathrm{Mn}, \mathrm{Ni}, \mathrm{Pb}$ e Zn. Portanto, baixas concentrações de elementos tais como $\mathrm{B}, \mathrm{F}^{-}$e metais pesados no ESET, associadas às concentrações desejáveis de N-mineral, $\mathrm{P}$ e outros nutrientes, constitui-se num fator determinante para a utilização deste subproduto na irrigação de plantas, segundo Pescod (1992) e Mohammad \& Mazahreh (2003). Ainda, as relações DQO:DBO e CT:NT no ESET, além de serem correlacionáveis aos valores de referência internacional (Tabela 3), são próximas entre si. Baixa relação DQO:DBO (Lambais, 1992) e baixa relação C:N (Mengel, 1996) são fatores que implicam em alta biodegradabilidade do material e, conseqüentemente, em disponibilidade dos nutrientes contidos no ESET.

No presente estudo, do ponto de vista agronômico, as altas concentrações de $\mathrm{Na}$ tanto na água como no ESET e, sobretudo, alta RAS associada à baixa $\mathrm{CE}$ e à baixa relação Ca:Mg, constituem-se nos principais fatores limitantes à sua aplicabilidade no solo (Paliwal \& Gandhi, 1976). Desse modo, o ESET pelo fato de apresentar menor e maior RAS e CE, respectivamente, apresenta menor risco de sodicidade quando comparado à água potável (Tabela 3).

A precipitação pluvial, bem como as lâminas de irrigação aplicadas nos tratamentos durante os 24 meses de experimento podem ser visualizadas na Figura 2. A necessidade de irrigação não foi semelhante para todos os tratamentos devido ao fato de as doses de NFM terem sido diferentes e a aplicação de ESET ter proporcionado aporte de N-mineral e outros elementos (Tabela 4). Assim, para cada tratamento empregado, as plantas apresentaram crescimento e desenvolvimento diferenciados e, portanto, para manter todas as parcelas com valores de $\psi_{m}$ semelhantes, foi necessária a aplicação de diferentes lâminas de irrigação.

Não há dúvidas do potencial do ESET em promover aporte de macro e micronutrientes, conforme apresentado na Tabela 4. No entanto, para cada 1,0 kg de Ntotal que entrou no sistema via irrigação com ESET, houve aporte de $0,72 \mathrm{~kg}$ de Nmineral e, indesejavelmente, de 4,6 kg de $\mathrm{Na}$. 


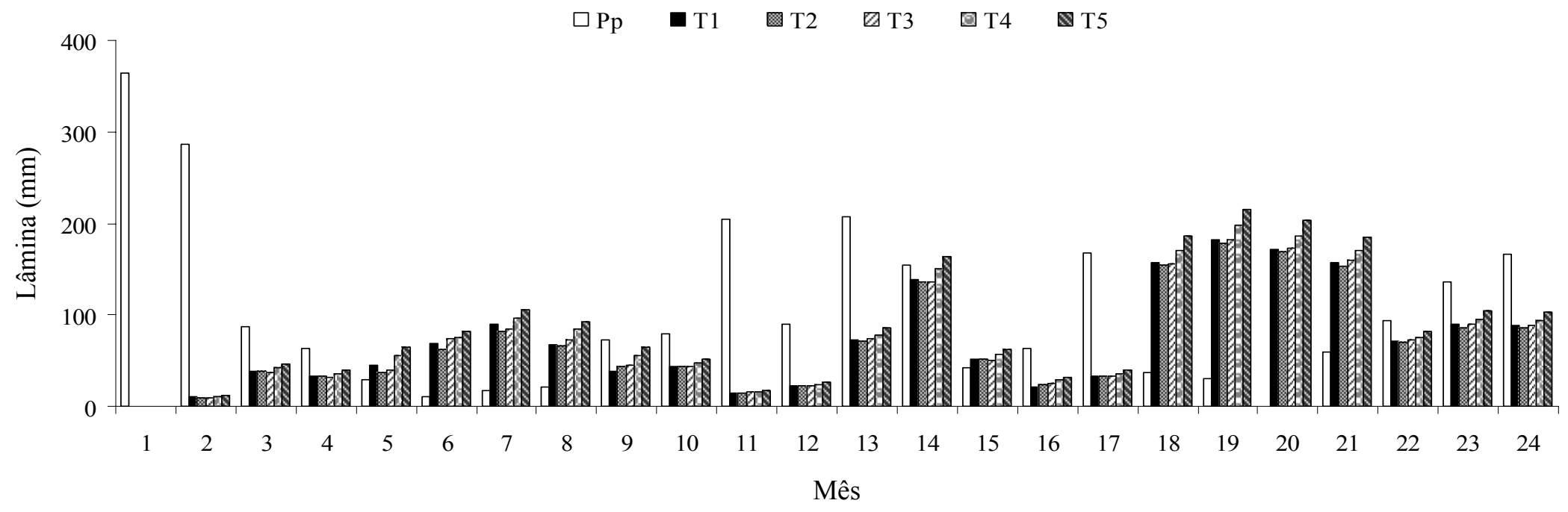

Figura 2 - Lâminas mensais (início dia 15 e término dia 14) de precipitação pluvial (Pp) e de irrigação ocorridas no experimento de 15/01/2003 a 14/01/2005. T1 (controle): irrigação com água potável e adição de $520 \mathrm{~kg} \mathrm{ha}^{-1} \mathrm{ano}^{-1}$ de nitrogênio via fertilizante mineral (NFM); T2, T3, T4 e T5: irrigação com efluente secundário de esgoto tratado (ESET) e adição de $0,171,6 ; 343,2$ e $520 \mathrm{~kg} \mathrm{ha}^{-1}$ ano $^{-1}$ de NFM 
Tabela 4. Aporte médio anual dos principais elementos e compostos devido à irrigação

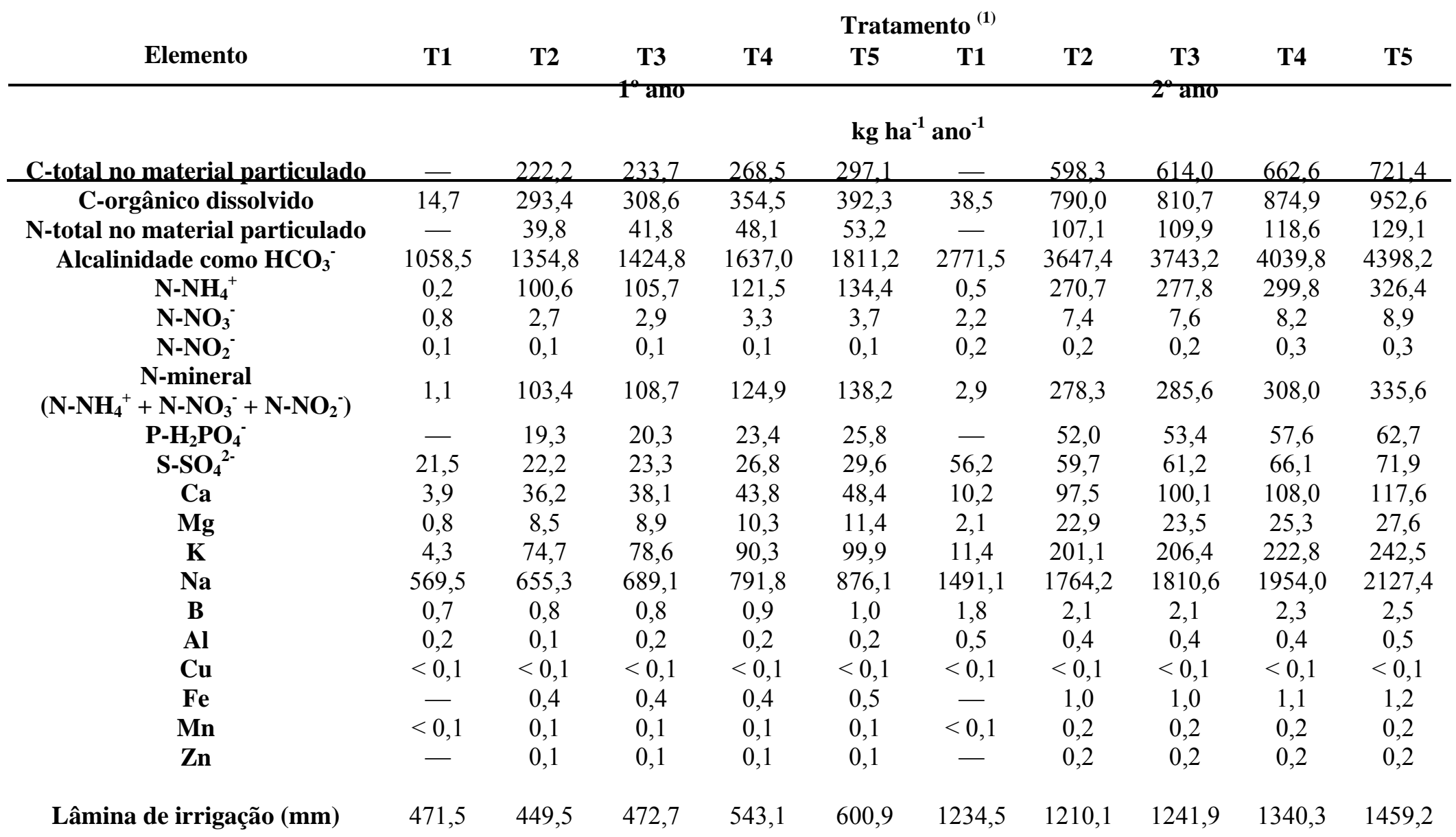

(1) T1 recebeu aplicação de $520 \mathrm{~kg} \mathrm{ha}^{-1}$ ano $^{-1}$ de nitrogênio via fertilizante mineral (NFM) e foi irrigado com água; T2, T3, T4 e T5 receberam $0,171,6 ; 343,3$ e $520 \mathrm{~kg} \mathrm{ha}^{-1}$ ano $^{-1}$ de NFM, respectivamente e foram irrigados com efluente secundário de esgoto tratado. 


\subsection{Rendimento do capim}

$\mathrm{O}$ uso de doses mais elevadas de NFM associadas à irrigação com ESET ocasionaram maiores rendimentos de MS (Tabela 5 e Figura 3). Isso foi devido ao fato de (i) o capim-Bermuda Tifton 85 responder linearmente até $600 \mathrm{~kg} \mathrm{ha}^{-1} \mathrm{ano}^{-1}$ de NFM, conforme resultados apresentados em Alvim et al. (1999); (ii) a irrigação com ESET ter proporcionado não somente aporte médio de $\mathrm{N}$-mineral de até $335,6 \mathrm{~kg} \mathrm{ha}^{-1} \mathrm{ano}^{-1}$, mas também de outros nutrientes (Tabela 4), os quais podem ter mascarado o efeito deletério do Na, conforme assinalado por Al-Jaloud et al. (1995) em seus estudos e promovido incremento na produção, concordando com os resultados de pesquisas realizadas com outras gramíneas forrageiras sob irrigação com EET, entre os quais azevém-perene (Quin \& Woods, 1978), capim-de-Rhodes (Feigin et al., 1978; Vaisman et al., 1981), capim-Kikuyu (Grattan et al., 2004); capim-Napier (Jeyaraman, 1988) e milho forrageiro (Overman \& Nguy, 1975; Overman, 1981; Adekalu \& Okunade, 2002; Mohammad \& Ayadi, 2004). Desse modo, tanto o NFM como o N-efluente foram importantes fontes de $\mathrm{N}$ para o sistema solo-pastagem. Ainda, o ESET, considerado um tipo de água marginal e que, muitas das vezes, não tem sido computada no balanço global (Bouwer, 2000), substituiu eficientemente a água convencional (potável) empregada na irrigação do capim.

Os altos rendimentos de MS observados no presente estudo foram devidos à associação dos fatores (i) irrigação, (ii) interação da irrigação com a fertilização nitrogenada, (iii) fonte de $\mathrm{N}$ mineral empregada e (iv) intervalo estabelecido entre cortes. O fator irrigação pode ter sido o mais importante, uma vez que o capim-Tifton 85 normalmente tem tido a sua produção limitada na Região Sudeste Brasileira pela ocorrência de seca (Alvim et al., 1999). A baixa tensão da água no solo, ocasionada pela freqüente irrigação (Figura 2), tem levado ao aumento da eficiência de uso do $\mathrm{N}$ e favorecido a obtenção de maior rendimento do capim, corroborando com os estudos de Marcelino et al. (2003). A fonte de $\mathrm{N}$ mineral empregada (nitrato de amônio), se comparada a mais utilizada no país (uréia), tem se destacado pelas baixíssimas perdas por volatilização e alta recuperação aparente de N pela parte aérea do capim (Primavesi et al., 2004). O intervalo entre cortes fixado em 60 dias, devido à logística deste estudo, 
Tabela 5. Efeitos da irrigação (água e efluente secundário de esgoto tratado - ESET) e de doses de nitrogênio via fertilizante mineral (NFM), aplicadas via solo, no rendimento anual de massa seca (MS) do capim-Bermuda Tifton $85(\mathrm{CV}=$ $5,07 \%)$

\begin{tabular}{|c|c|c|c|}
\hline Tratamento & $1^{\circ}$ ano & $\begin{array}{c}\text { MS } \\
2^{\circ} \text { ano } \\
\end{array}$ & Média \\
\hline & \multicolumn{3}{|c|}{ t ha ${ }^{-1}$ ano $^{-1}$} \\
\hline $\mathrm{T} 1$ - irrigação com água + NFM $\left(520 \mathrm{~kg} \mathrm{ha}^{-1} \mathrm{ano}^{-1}\right)$ & 32,91 & 32,62 & $32,76^{\text {bc }(1)}$ \\
\hline $\mathrm{T} 2$ - irrigação com ESET, sem NFM & 19,85 & 28,89 & $24,37^{\mathrm{d}}$ \\
\hline T3 - irrigação com ESET + NFM $\left(171,6 \mathrm{~kg} \mathrm{ha}^{-1}\right.$ ano $\left.^{-1}\right)$ & 28,36 & 35,93 & $32,15^{\mathrm{c}}$ \\
\hline $\mathrm{T} 4$ - irrigação com ESET + NFM $\left(343,2 \mathrm{~kg} \mathrm{ha}^{-1} \mathrm{ano}^{-1}\right)$ & 32,43 & 37,02 & $34,73^{b}$ \\
\hline T5 - irrigação com ESET + NFM $\left(520 \mathrm{~kg} \mathrm{ha}^{-1} \mathrm{ano}^{-1}\right)$ & 37,82 & 39,29 & $38,55^{\mathrm{a}}$ \\
\hline Média & $30,27^{\mathrm{B}}$ & $34,75^{\mathrm{A}}$ & \\
\hline
\end{tabular}

(1) Letras iguais maiúsculas ou minúsculas nas linhas e nas colunas, respectivamente, não diferem estatisticamente pelo teste de Tukey $(P<0,05)$.

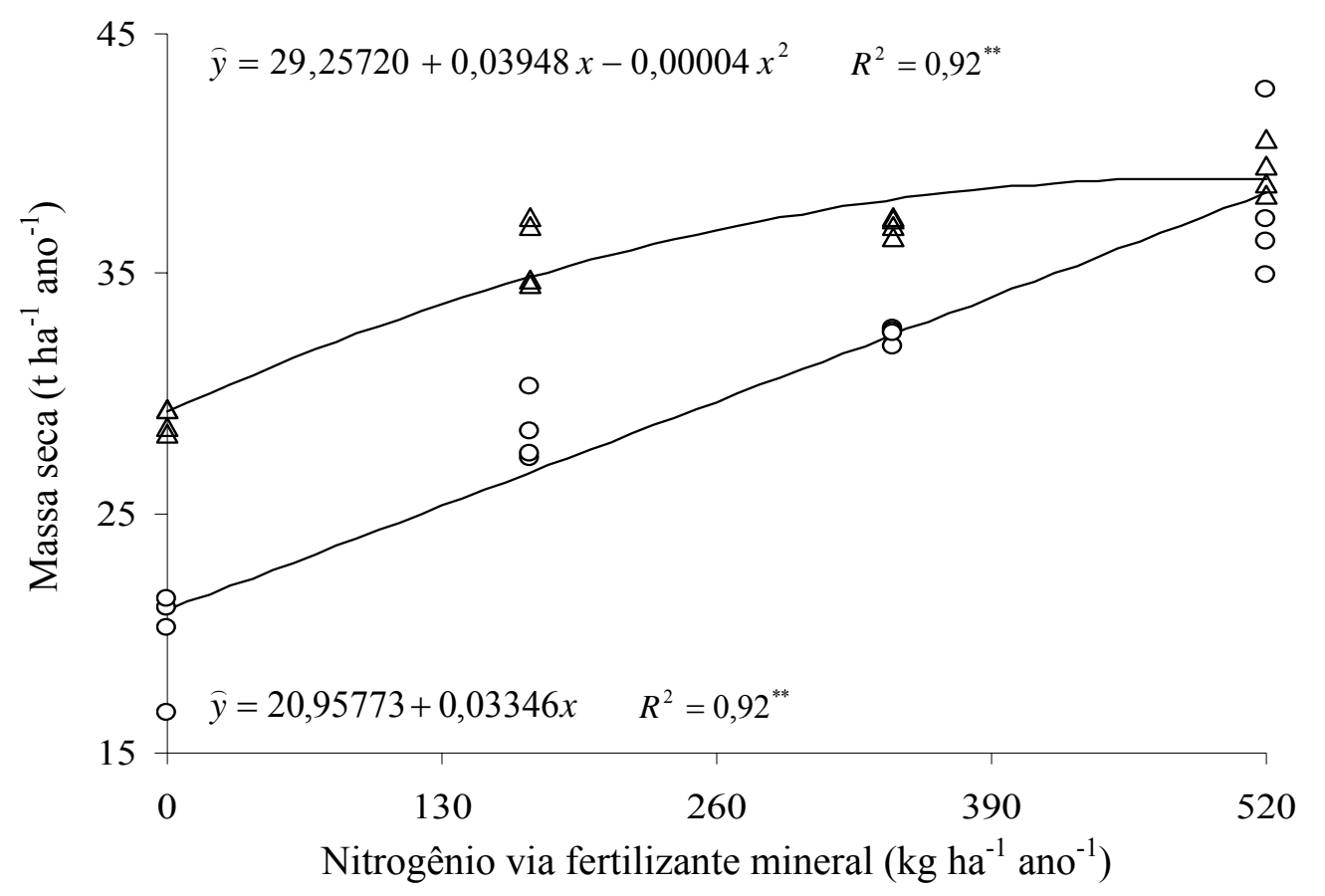

Figura 3 - Influência de doses de nitrogênio via fertilizante mineral no rendimento acumulado anual de massa seca do capim-Bermuda Tifton 85 , submetido à irrigação com efluente secundário de esgoto tratado, no (o) primeiro e no $(\Delta)$ segundo ano. ${ }^{* *} P<0,01$ 
pode ter influenciado o rendimento de MS. Segundo Alvim et al. (1999), a mudança do intervalo entre cortes de duas para seis semanas (no período das chuvas) e de quatro para oito semanas (no período da seca) tem ocasionado aumento no rendimento de MS do capim-Tifton 85 , porém, levando à diminuição de sua qualidade para alimentação animal.

$\mathrm{O}$ efluente não supriu toda a necessidade de $\mathrm{N}$ do capim, ocasionando, na ausência de NFM menor rendimento de MS (Tabela 5 e Figura 3). O fato do ESET se constituir como fonte eficiente de água e, ao mesmo tempo, nutrir parcialmente as plantas em $\mathrm{N}$ tem sido comum em várias situações de clima, solo e cultura (Smith \& Peterson, 1982; Feigin et al., 1991), inclusive em experimento com Cynodon (Hayes et al., 1990b). Isso freqüentemente se repete, pois (i) as curvas de requerimento/acúmulo de $\mathrm{N}$ não coincidem, para a maioria das plantas, com a curva de demanda por água (Bouwer \& Idelovitch, 1987); (ii) o aporte de N-efluente no sistema solo-pastagem é dependente da qualidade do efluente e da lâmina de irrigação empregada (Hayes et al., 1990b), que normalmente não são constantes ao longo do ano (Feigin et al., 1991).

Analisando isoladamente os tratamentos irrigados com ESET, foi observado incremento linear (no primeiro ano) e quadrático (no segundo ano) no rendimento de MS em resposta ao aumento da dose de NFM (Figura 3). No primeiro ano, a necessidade de irrigação foi menor pelo fato de ter ocorrido maior precipitação pluvial (1323 mm) (Figura 2) e conseqüentemente, o capim apresentou menor resposta à aplicação de ESET. No segundo ano, a precipitação pluvial foi menor (1160 mm), tornando-se necessária irrigação mais freqüente, com aplicação de lâminas mais elevadas (Figura 2) e, portanto, foi mais pronunciada a resposta do capim ao ESET (Figura 3). O rendimento máximo de MS (39,0 t ha ${ }^{-1}$ ano $\left.^{-1}\right)$ ocorreria no segundo ano mediante o uso de NFM de 493,5 $\mathrm{kg} \mathrm{ha}^{-1}$ ano $^{-1}$ acompanhado de irrigação com ESET.

O tratamento T1 (controle) pode ser considerado um padrão de comparação entre os tratamentos empregados, uma vez que seu rendimento anual foi superior ou semelhante aos resultados observados por Alvim et al. (1999) e Marcelino et al. (2003), que também estudaram a resposta do capim-Bermuda Tifton 85 às doses de NFM. A partir das equações apresentadas na Figura 3 e, admitindo-se o rendimento médio do 
tratamento T1 como referencial (Tabela 5), foram calculadas quais doses de NFM que, se submetidas à irrigação com ESET, poderiam ocasionar rendimento médio de 32,76 $\mathrm{t}$ $\mathrm{ha}^{-1}$ ano $^{-1}$ de MS. Assim, foi verificado que as doses de NFM de 352,7 e 98,7 kg ha ${ }^{-1}$ ano $^{-1}$ para o primeiro e segundo anos, respectivamente, conjuntamente à irrigação com ESET, seriam o suficiente para obtenção do mesmo rendimento de MS na condição de irrigação com água potável e fornecimento de NFM de $520 \mathrm{~kg} \mathrm{ha}^{-1} \mathrm{ano}^{-1}$. Isso representaria economia de NFM de $167,3(32,2 \%)$ e 421,2 (81,0\%) kg ha ${ }^{-1}$ ano $^{-1}$ para o primeiro e segundo anos, respectivamente, sem comprometer o rendimento do capim. Essa redução na dose de NFM empregada no capim para obtenção de alta produção de pastagem, mediante a substituição da água convencional pelo ESET, concordou com os resultados obtidos anteriormente por Feigin et al., (1978), Vaisman et al. (1981) e Feigin et al. (1991), em condições diferentes de solo, clima e cultura. Em alguns casos, o uso de EET na irrigação ocasionou economia de 50-75\% da dose de NFM, como observado por Hussain \& Al-Jaloud (1998) em experimento com cevada.

\subsection{Acidez do solo}

Os tratamentos empregados ocasionaram efeitos no $\mathrm{pH}$ (solo e solução no solo) somente na camada $0-10 \mathrm{~cm}$ (Tabelas 6 e 7). Maiores valores de $\mathrm{pH}$ foram verificados no tratamento $\mathrm{T} 2$ e menores valores de $\mathrm{pH}$ foram observados nos tratamentos $\mathrm{T} 1$, T4 e T5. O tratamento T2, pelo fato de ter recebido somente N-efluente, apresentou menor rendimento de MS (Tabela 5 e Figura 3), que certamente implicou em menor absorção e acúmulo de nutrientes, restando maior concentração de cátions alcalinos no meio (maior reserva alcalina). Menores valores de $\mathrm{pH}$ foram observados mediante o uso de doses mais elevadas de NFM, principalmente no tratamento T5 (Tabelas 6 e 7). Durante o processo de nitrificação, realizado pelos microrganismos Nitrosomonas e Nitrobacter, ocorre liberação de quatro prótons $\left(\mathrm{H}^{+}\right)$para cada mol de $\mathrm{NH}_{4}{ }^{+}$oxidado a $\mathrm{NO}_{3}{ }^{-}$(Bolan et al., 1991), contribuindo para diminuição do $\mathrm{pH}$ do meio. O tratamento T1 apresentou, na camada 0-10 cm, valor de $\mathrm{pH}$ da solução no solo mais elevado que o tratamento T5 (Tabela 7). Isso pode ser devido ao fato de o $\mathrm{pH}$ da água potável empregada na irrigação do tratamento $\mathrm{T} 1$ ser maior que $\mathrm{o} \mathrm{pH}$ do ESET utilizado nos demais tratamentos 
Tabela 6. Efeitos da irrigação (água e efluente) e de doses de nitrogênio mineral no pH $\left(\mathrm{CaCl}_{2}\right)$ do solo

\begin{tabular}{|c|c|c|c|c|c|c|c|}
\hline \multirow{2}{*}{ Tratamento } & \multicolumn{7}{|c|}{ Época de avaliação } \\
\hline & Abr/03 & Jul/03 & Out/03 & Jan/04 & Abr $/ 04$ & Jul/04 & Média \\
\hline \multicolumn{8}{|c|}{ Camada 0-10 cm (CV = 3,48\%) } \\
\hline $\mathrm{T1}^{(\mathbf{1})}$ & 4,90 & 5,15 & 5,25 & 4,99 & 4,99 & 4,98 & $5,04^{\text {bc }(6)}$ \\
\hline $\mathbf{T} 2^{(2)}$ & 5,08 & 5,08 & 5,73 & 5,44 & 5,88 & 5,28 & $5,41^{\mathrm{a}}$ \\
\hline $\mathbf{T} 3^{(3)}$ & 4,68 & 4,70 & 5,27 & 5,32 & 5,55 & 5,37 & $5,15^{a b}$ \\
\hline$T 4^{(4)}$ & 4,63 & 4,60 & 5,14 & 4,91 & 5,22 & 5,02 & $4,92^{b c}$ \\
\hline $\mathbf{T} 5^{(5)}$ & 4,78 & 4,60 & 5,14 & 4,82 & 4,75 & 4,82 & $4,82^{\mathrm{c}}$ \\
\hline Média & $4,81^{\mathrm{C}}$ & $4,83^{\mathrm{C}}$ & $5,31^{\mathrm{A}}$ & $5,09^{\mathrm{B}}$ & $5,28^{\mathrm{A}}$ & $5,09^{\mathrm{B}}$ & \\
\hline \multicolumn{8}{|c|}{ Camada $10-20 \mathrm{~cm}(C V=4,17 \%)$} \\
\hline T1 & 4,88 & 4,90 & 5,17 & 5,30 & 5,01 & 5,16 & $5,07^{\mathrm{a}}$ \\
\hline T2 & 5,03 & 5,00 & 5,44 & 5,34 & 5,28 & 5,29 & $5,23^{\mathrm{a}}$ \\
\hline T3 & 4,73 & 4,50 & 4,99 & 5,01 & 5,35 & 4,97 & $4,92^{\mathrm{a}}$ \\
\hline T4 & 4,70 & 4,50 & 5,06 & 4,97 & 4,86 & 4,85 & $4,82^{\mathrm{a}}$ \\
\hline T5 & 4,78 & 4,75 & 5,18 & 4,80 & 4,83 & 4,91 & $4,87^{\mathrm{a}}$ \\
\hline Média & $4,82^{\mathrm{B}}$ & $4,73^{\mathrm{B}}$ & $5,17^{\mathrm{A}}$ & $5,08^{\mathrm{A}}$ & $5,07^{\mathrm{A}}$ & $5,04^{\mathrm{A}}$ & \\
\hline \multicolumn{8}{|c|}{ Camada $20-40 \mathrm{~cm}(C V=4,49 \%)$} \\
\hline $\mathrm{T1}$ & 4,58 & 4,63 & 4,41 & 4,80 & 4,90 & 4,59 & $4,65^{\mathrm{a}}$ \\
\hline $\mathbf{T} 2$ & 4,70 & 4,45 & 4,70 & 4,69 & 5,03 & 4,69 & $4,71^{\mathrm{a}}$ \\
\hline T3 & 4,30 & 4,13 & 4,38 & 4,30 & 4,48 & 4,35 & $4,32^{\mathrm{a}}$ \\
\hline T4 & 4,35 & 4,10 & 4,32 & 4,30 & 4,55 & 4,42 & $4,34^{\mathrm{a}}$ \\
\hline T5 & 4,50 & 4,18 & 4,41 & 4,52 & 4,68 & 4,51 & $4,47^{\mathrm{a}}$ \\
\hline Média & $4,49^{\mathrm{B}}$ & $4,30^{\mathrm{C}}$ & $4,44^{\mathrm{BC}}$ & $4,52^{\mathrm{B}}$ & $4,73^{\mathrm{A}}$ & $4,51^{\mathrm{B}}$ & \\
\hline \multicolumn{8}{|c|}{ Camada $40-60 \mathrm{~cm}(\mathrm{CV}=3,59 \%)$} \\
\hline T1 & 4,45 & 4,53 & 4,41 & 4,31 & 4,36 & 4,24 & $4,38^{\mathrm{a}}$ \\
\hline $\mathbf{T 2}$ & 4,33 & 4,28 & 4,34 & 4,32 & 4,49 & 4,46 & $4,37^{\mathrm{a}}$ \\
\hline T3 & 4,18 & 4,08 & 4,12 & 4,15 & 4,35 & 4,29 & $4,19^{\mathrm{a}}$ \\
\hline T4 & 4,25 & 4,10 & 4,17 & 4,16 & 4,24 & 4,16 & $4,18^{\mathrm{a}}$ \\
\hline T5 & 4,28 & 4,15 & 4,36 & 4,20 & 4,26 & 4,17 & $4,24^{\mathrm{a}}$ \\
\hline Média & $4,30^{\mathrm{A}}$ & $4,23^{\mathrm{A}}$ & $4,28^{\mathrm{A}}$ & $4,23^{\mathrm{A}}$ & $4,34^{\mathrm{A}}$ & $4,26^{\mathrm{A}}$ & \\
\hline \multicolumn{8}{|c|}{ Camada $60-80 \mathrm{~cm}(\mathrm{CV}=2,90 \%)$} \\
\hline T1 & 4,58 & 4,38 & 4,38 & 4,23 & 4,42 & 4,22 & $4,37^{\mathrm{a}}$ \\
\hline $\mathbf{T} 2$ & 4,33 & 4,20 & 4,30 & 4,27 & 4,49 & 4,31 & $4,31^{\mathrm{a}}$ \\
\hline T3 & 4,23 & 4,08 & 4,14 & 4,13 & 4,38 & 4,09 & $4,17^{\mathrm{a}}$ \\
\hline T4 & 4,23 & 4,23 & 4,21 & 4,21 & 4,31 & 4,14 & $4,22^{\mathrm{a}}$ \\
\hline T5 & 4,23 & 4,15 & 4,26 & 4,26 & 4,30 & 4,15 & $4,22^{\mathrm{a}}$ \\
\hline Média & $4,32^{\mathrm{AB}}$ & $4,21^{\mathrm{BC}}$ & $4,26^{\mathrm{BC}}$ & $4,22^{\mathrm{BC}}$ & $4,32^{\mathrm{A}}$ & $4,18^{\mathrm{C}}$ & \\
\hline
\end{tabular}


Tabela 6. Efeitos da irrigação (água e efluente) e de doses de nitrogênio mineral no pH $\left(\mathrm{CaCl}_{2}\right)$ do solo

\begin{tabular}{|c|c|c|c|c|c|c|c|}
\hline \multirow{2}{*}{ Tratamento } & \multicolumn{7}{|c|}{ Época de avaliação } \\
\hline & Abr/03 & $\mathbf{J u l} / \mathbf{0 3}$ & Out/03 & Jan/04 & Abr/04 & Jul/04 & Média \\
\hline \multicolumn{8}{|c|}{ Camada 80-100 cm (CV = 3,75\%) } \\
\hline $\mathrm{T1}$ & 4,45 & 4,35 & 4,34 & 4,26 & 4,31 & 4,21 & $4,32^{\mathrm{a}}$ \\
\hline T2 & 4,35 & 4,25 & 4,28 & 4,52 & 4,38 & 4,30 & $4,35^{\mathrm{a}}$ \\
\hline T3 & 4,23 & 4,13 & 4,15 & 4,11 & 4,30 & 4,07 & $4,16^{\mathrm{a}}$ \\
\hline T4 & 4,25 & 4,15 & 4,21 & 4,22 & 4,23 & 4,15 & $4,20^{\mathrm{a}}$ \\
\hline T5 & 4,30 & 4,13 & 4,27 & 4,24 & 4,23 & 4,13 & $4,22^{\mathrm{a}}$ \\
\hline Média & $4,32^{\mathrm{A}}$ & $4,20^{\mathrm{A}}$ & $4,25^{\mathrm{A}}$ & $4,27^{\mathrm{A}}$ & $4,29^{\mathrm{A}}$ & $4,17^{\mathrm{A}}$ & \\
\hline \multicolumn{8}{|c|}{$\begin{array}{l}\text { (1) T1: irrigação com água }+520 \mathrm{~kg} \mathrm{ha}^{-1} \text { ano }{ }^{-1} \text { de nitrogênio via fertilizante mineral (NFM); } \\
\text { (2) T2: irrigação com efluente secundário de esgoto tratado (ESET), sem NFM; } \\
\text { (3) T3: irrigação com ESET + } 171,6 \mathrm{~kg} \mathrm{ha}^{-1} \mathrm{ano}^{-1} \text { de NFM; } \\
\text { (4) T4: irrigação com ESET }+343,3 \mathrm{~kg} \mathrm{ha}^{-1} \mathrm{ano}^{-1} \text { de NFM; } \\
\text { (5) T5: irrigação com ESET + 520 } \mathrm{kg} \mathrm{ha}^{-1} \text { ano }^{-1} \text { de NFM; } \\
\text { (6) Letras iguais maiúsculas ou minúsculas nas linhas e nas colunas, respectivamente, nã }\end{array}$} \\
\hline
\end{tabular}

(Tabela 3). Quando se procede a comparação de ambos tratamentos, T1 e T5, pode se verificar que, apesar destes tratamentos terem recebido as mesmas doses de NFM, o tratamento T5 ainda recebeu aporte de até $335,6 \mathrm{~kg} \mathrm{ha}^{-1} \mathrm{ano}^{-1}$ de $\mathrm{N}$-mineral oriundo do ESET (Tabela 4). Portanto, seria de se esperar menor valor de $\mathrm{pH}$ no solo do tratamento T5. Porém, graças ao efeito do ESET como amenizador da acidez do solo, o pH de T1 e T5 não diferiram estatisticamente (Tabela 6).

$\mathrm{O}$ fato de o ESET exercer efeito na acidez do solo tem sido relatado em diferentes situações de clima, solo e cultura, sobretudo em agrossistemas de pastagens (Quin \& Woods, 1978) e este efeito tem sido devido aos fatores (i) alto $\mathrm{pH}$ do efluente (Stewart et al.,1990); (ii) adição de cátions trocáveis e de ânions oriundos deste subproduto (Falkiner \& Smith, 1997), contribuindo para aumento da reserva alcalina (Zekri \& Koo, 1994); (iii) alteração na ciclagem de nutrientes mediante irrigação com EET, ocasionando incremento na redução de $\mathrm{NO}_{3}^{-}$a $\mathrm{NH}_{4}{ }^{+}$e desnitrificação do $\mathrm{NO}_{3}^{-}$, produzindo íons $\mathrm{OH}^{-}$(Schipper et al., 1996); (iv) e, principalmente, devido ao aporte significativo de $\mathrm{HCO}_{3}{ }^{-}$(Tabela 4). 
Tabela 7. Efeitos da irrigação (água e efluente) e de doses de nitrogênio mineral no pH da solução no solo (extrato de saturação)

\begin{tabular}{|c|c|c|c|c|c|c|c|}
\hline \multirow{2}{*}{ Tratamento } & \multicolumn{7}{|c|}{ Época de avaliação } \\
\hline & Abr/03 & Jul/03 & Out/03 & Jan/04 & Abr/04 & Jul/04 & Média \\
\hline \multicolumn{8}{|c|}{ Camada 0-10 cm $(C V=4,28 \%)$} \\
\hline$T 1^{(1)}$ & 6,53 & 6,55 & 7,11 & 6,81 & 5,37 & 7,50 & $6,64^{\mathrm{b}(6)}$ \\
\hline$T 2^{(2)}$ & 6,60 & 6,60 & 7,44 & 7,07 & 6,99 & 7,56 & $7,04^{\mathrm{a}}$ \\
\hline $\mathrm{T}^{(3)}$ & 6,15 & 6,04 & 7,32 & 7,19 & 6,71 & 7,55 & $6,83^{a b}$ \\
\hline$T 4^{(4)}$ & 5,81 & 5,78 & 7,33 & 6,77 & 6,53 & 7,26 & $6,58^{\mathrm{bc}}$ \\
\hline $\mathbf{T} 5^{(5)}$ & 6,14 & 6,44 & 7,06 & 6,16 & 5,05 & 6,86 & $6,28^{c}$ \\
\hline Média & $6,25^{\mathrm{C}}$ & $6,28^{\mathrm{C}}$ & $7,25^{\mathrm{A}}$ & $6,80^{\mathrm{B}}$ & $6,13^{\mathrm{C}}$ & $7,34^{\mathrm{A}}$ & \\
\hline \multicolumn{8}{|c|}{ Camada $10-20 \mathrm{~cm}(C V=6,36 \%)$} \\
\hline T1 & 6,54 & 6,31 & 6,97 & 6,90 & 5,15 & 6,58 & $6,41^{\mathrm{a}}$ \\
\hline T2 & 6,33 & 5,56 & 7,27 & 7,06 & 6,52 & 7,18 & $6,65^{\mathrm{a}}$ \\
\hline T3 & 6,37 & 5,50 & 6,49 & 6,40 & 6,19 & 7,28 & $6,37^{\mathrm{a}}$ \\
\hline T4 & 6,15 & 5,02 & 6,79 & 6,71 & 5,83 & 6,54 & $6,17^{\mathrm{a}}$ \\
\hline T5 & 6,40 & 5,71 & 6,99 & 6,29 & 4,92 & 6,91 & $6,20^{\mathrm{a}}$ \\
\hline Média & $6,36^{\mathrm{B}}$ & $5,62^{\mathrm{C}}$ & $6,90^{\mathrm{A}}$ & $6,67^{\mathrm{AB}}$ & $5,72^{\mathrm{C}}$ & $6,90^{\mathrm{A}}$ & \\
\hline \multicolumn{8}{|c|}{ Camada $20-40 \mathrm{~cm}(C V=5,84 \%)$} \\
\hline T1 & $5, \grave{54}$ & 5,17 & 5,52 & 6,01 & 5,08 & 6,61 & $5,65^{\mathrm{a}}$ \\
\hline T2 & 5,43 & 5,08 & 5,52 & 5,85 & 5,55 & 5,85 & $5,55^{\mathrm{a}}$ \\
\hline T3 & 5,39 & 4,77 & 4,79 & 5,07 & 5,13 & 6,51 & $5,28^{\mathrm{a}}$ \\
\hline T4 & 5,31 & 4,68 & 4,88 & 5,36 & 5,12 & 6,67 & $5,34^{\mathrm{a}}$ \\
\hline T5 & 5,35 & 5,03 & 5,26 & 5,64 & 4,65 & 6,27 & $5,37^{\mathrm{a}}$ \\
\hline Média & $5,40^{\mathrm{BC}}$ & $4,94^{\mathrm{D}}$ & $5,19^{\mathrm{CD}}$ & $5,59^{\mathrm{B}}$ & $5,11^{\mathrm{D}}$ & $6,38^{\mathrm{A}}$ & \\
\hline \multicolumn{8}{|c|}{ Camada $40-60 \mathrm{~cm}(C V=6,64 \%)$} \\
\hline T1 & 5,29 & 5,02 & 4,95 & 5,46 & 4,94 & 6,35 & $5,33^{\mathrm{a}}$ \\
\hline $\mathbf{T} 2$ & 5,53 & 5,44 & 4,86 & 5,00 & 4,84 & 5,68 & $5,23^{\mathrm{a}}$ \\
\hline T3 & 5,33 & 4,81 & 4,53 & 4,82 & 4,90 & 6,34 & $5,12^{\mathrm{a}}$ \\
\hline T4 & 5,70 & 4,94 & 4,69 & 5,02 & 4,91 & 6,02 & $5,21^{\mathrm{a}}$ \\
\hline T5 & 5,63 & 4,77 & 5,27 & 5,00 & 4,77 & 5,56 & $5,17^{\mathrm{a}}$ \\
\hline Média & $5,50^{\mathrm{B}}$ & $5,00^{\mathrm{C}}$ & $4,86^{\mathrm{C}}$ & $5,06^{\mathrm{C}}$ & $4,87^{\mathrm{C}}$ & $5,99^{\mathrm{A}}$ & \\
\hline \multicolumn{8}{|c|}{ Camada $60-80 \mathrm{~cm}(C V=6,29 \%)$} \\
\hline $\mathrm{T} 1$ & 5,30 & 5,20 & 4,65 & 4,73 & 5,03 & 6,24 & $5,19^{\mathrm{a}}$ \\
\hline T2 & 5,79 & 5,43 & 5,11 & 4,55 & 4,71 & 5,51 & $5,18^{\mathrm{a}}$ \\
\hline T3 & 5,80 & 5,14 & 4,89 & 4,62 & 4,77 & 5,51 & $5,12^{\mathrm{a}}$ \\
\hline T4 & 5,48 & 5,32 & 4,80 & 4,79 & 4,82 & 5,96 & $5,19^{\mathrm{a}}$ \\
\hline T5 & 5,63 & 4,91 & 5,05 & 4,63 & 4,74 & 5,58 & $5,09^{\mathrm{a}}$ \\
\hline Média & $5,60^{\mathrm{A}}$ & $5,20^{\mathrm{B}}$ & $4,90^{\mathrm{BC}}$ & $4,66^{\mathrm{C}}$ & $4,81^{\mathrm{C}}$ & $5,76^{\mathrm{A}}$ & \\
\hline
\end{tabular}


Tabela 7. Efeitos da irrigação (água e efluente) e de doses de nitrogênio mineral no pH da solução no solo (extrato de saturação)

\begin{tabular}{|c|c|c|c|c|c|c|c|}
\hline \multirow{2}{*}{ Tratamento } & \multicolumn{7}{|c|}{ Época de avaliação } \\
\hline & Abr/03 & $\mathrm{Jul} / 03$ & Out/03 & Jan/04 & Abr/04 & Jul/04 & Média \\
\hline \multicolumn{8}{|c|}{ Camada $80-100 \mathrm{~cm}(\mathrm{CV}=7,06 \%)$} \\
\hline T1 & 5,86 & 5,29 & 5,57 & 4,45 & 4,81 & 5,82 & $5,30^{\mathrm{a}}$ \\
\hline T2 & 5,83 & 5,54 & 5,13 & 4,73 & 4,62 & 5,22 & $5,18^{\mathrm{a}}$ \\
\hline T3 & 5,42 & 5,18 & 5,01 & 4,36 & 4,72 & 5,32 & $5,00^{\mathrm{a}}$ \\
\hline T4 & 5,51 & 5,17 & 5,20 & 4,78 & 4,67 & 5,88 & $5,20^{\mathrm{a}}$ \\
\hline T5 & 5,87 & 5,07 & 5,21 & 4,71 & 4,72 & 5,39 & $5,16^{\mathrm{a}}$ \\
\hline Média & $5,70^{\mathrm{A}}$ & $5,25^{\mathrm{B}}$ & $5,22^{\mathrm{B}}$ & $4,60^{\mathrm{C}}$ & $4,71^{\mathrm{C}}$ & $5,53^{\mathrm{AB}}$ & \\
\hline \multicolumn{8}{|c|}{$\begin{array}{l}\text { (1) T1: irrigação com água }+520 \mathrm{~kg} \mathrm{ha}^{-1} \text { ano }^{-1} \text { de nitrogênio via fertilizante mineral (NFM); } \\
\text { (2) T2: irrigação com efluente secundário de esgoto tratado (ESET), sem NFM; } \\
\text { (3) T3: irrigação com ESET + } 171,6 \mathrm{~kg} \mathrm{ha}^{-1} \mathrm{ano}^{-1} \text { de NFM; } \\
\text { (4) T4: irrigação com ESET + 343,3 kg ha } \mathrm{ano}^{-1} \text { de NFM; } \\
\text { (5) T5: irrigação com ESET + } 520 \mathrm{~kg} \mathrm{ha}^{-1} \text { ano }^{-1} \text { de NFM; } \\
\text { (6) Letras iguais maiúsculas ou minúsculas nas linhas e nas colunas, respectivamente, nã } \\
\text { diferem estatisticamente pelo teste de Tukey }(P<0,05) \text {. }\end{array}$} \\
\hline
\end{tabular}

Foram observadas alterações no pH do solo, exceto nas camadas 40-60 e 80$100 \mathrm{~cm}$ (Tabela 6) e no pH da solução no solo (Tabela 7) devido à época de amostragem. Os valores de $\mathrm{pH}$ (solo e solução no solo) das camadas superficiais (0-10 e 10-20 cm) foram maiores na última amostragem quando comparados aos valores da primeira amostragem de solo (Tabelas 6 e 7). Ainda, foi observada pequena acidificação do solo na camada 60-80 cm no decorrer do experimento (Tabela 6). A solução no solo, pelo fato dela ser resultante de interações das fases sólida, líquida e gasosa e que apresenta alta atividade biológica, é um dos componentes do solo que mais rapidamente se modifica frente às condições do meio (Wolt, 1994). Desse modo, a solução no solo, bem como o solo, sofreram alterações sazonais de $\mathrm{pH}$ durante este estudo na maior parte das camadas. Essas alterações sazonais na reação do solo foram devido aos fatores (i) microrganismos atuantes no ciclo do N (Bolan et al., 1991) e na degradação da MOS (Fassbender \& Bornemisza, 1987), que promovem liberação de prótons $\left(\mathrm{H}^{+}\right)$; (ii) efeito das chuvas, principalmente no verão (Figura 2), que podem ocasionar lixiviação de íons e acidificação do solo; (iii) ao aporte de $\mathrm{HCO}_{3}^{-}$(Tabela 4), que pode consumir $\mathrm{H}^{+}$, sobretudo, nas épocas onde a amostragem de solo foi realizada logo após longo período 
de irrigação e baixa precipitação pluvial (Figura 2); (iv) ao baixo poder tampão do solo estudado (baixa CTC - Tabela 2), que o torna mais susceptível às alterações de $\mathrm{pH}$, principalmente, àquelas relacionadas à água de irrigação (Bouwer \& Idelovitch, 1987). Num estudo envolvendo dez solos neozelandeses sob pastagens irrigadas com EET durante 16 meses, com lâminas entre 1700 a 2400 mm, Ross et al. (1978) observaram alterações de $\mathrm{pH}$ somente em três solos (diminuição e aumento de $\mathrm{pH}$ em um e dois solos, respectivamente).

Normalmente, os agrossistemas irrigados com EET tendem apresentar, com o tempo de irrigação, $\mathrm{pH}$ do solo semelhante ao do EET. Desse modo, solos ácidos tendem a ter o pH aumentado (Mancino \& Pepper, 1992; Allhands et al., 1995) enquanto que solos alcalinos tendem a ter o pH diminuído (Hayes et al., 1990a; Shahalam et al., 1998; Mohammad \& Mazahreh, 2003). No trabalho de Allhands et al. (1995), a irrigação de pastagens de capim-Bermuda Coastal com EET por 16 anos ocasionou elevação de $\mathrm{pH}$ de solos arenosos da Florida (EUA), cujos valores aumentaram, na camada 0-15 cm, de 5,2 para 7,0, próximo ao $\mathrm{pH}$ do efluente $(7,5)$.

Contudo, as alterações de $\mathrm{pH}$ observadas no presente estudo foram de pequena magnitude (menor que uma unidade), sendo desprezíveis e de pouca importância prática com relação à disponibilidade de nutrientes (Speir et al., 1999), notadamente por se tratar de solo ácido e de baixa fertilidade natural (Fonseca, 2001). Ainda, os resultados obtidos neste trabalho, quanto às alterações na reação do solo, concordaram com as observações realizadas por Quin \& Woods (1978), Ross et al. (1978), Smith et al. (1996), Al-Nakshabandi et al. (1997), Dawes \& Goonetilleke (2003). Também, houve correlação entre $\mathrm{pH}\left(\mathrm{CaCl}_{2}\right)$ e $\mathrm{pH}$ da solução no solo (extrato de saturação) somente para as camadas 0-10 e 10-20 cm (Tabela 8).

Com relação à acidez potencial do solo $(\mathrm{H}+\mathrm{Al})$, os tratamentos ocasionaram alterações somente nas camadas 0-10, 20-40 e 40-60 cm (Tabela 9). No tratamento T2 foram observados as menores concentrações de $\mathrm{H}+\mathrm{Al}$ e este fato se deve a não adição de NFM, que provocou menor acidificação do solo e, conseqüentemente, a explicação para este fato é a mesma apresentada anteriormente para acidez atual do solo. 
Tabela 8. Coeficientes de correlação entre os parâmetros $\mathrm{pH}$ do solo $\left(\mathrm{em}^{\mathrm{CaCl}}{ }_{2}\right)$ e da solução no solo, $\mathrm{Al}$ trocável $\left(\mathrm{mmol}_{\mathrm{c}} \mathrm{kg}^{-1}\right)$ e solúvel $\left(\mathrm{mmol} \mathrm{L}^{-1}\right)$ e o acúmulo de $\mathrm{Al}\left(\mathrm{kg} \mathrm{ha}^{-1}\right.$ semestre $\left.^{-1}\right)$ na parte aérea do capim-Bermuda Tifton 85

\begin{tabular}{|c|c|c|c|c|c|c|}
\hline \multirow{2}{*}{ Parâmetro } & \multicolumn{6}{|c|}{ Camada (cm) } \\
\hline & 0-10 & $10-20$ & $20-40$ & 40-60 & $60-80$ & $80-100$ \\
\hline \multicolumn{7}{|c|}{ pH $\left(\mathrm{CaCl}_{2}\right)$ do solo } \\
\hline pH da solução no solo & $0,63^{* *}$ & $0,62^{* *}$ & $0,27^{\mathrm{NS}}$ & $0,10^{\mathrm{NS}}$ & $-0,19^{\mathrm{NS}}$ & $0,04^{\mathrm{NS}}$ \\
\hline Al trocável & $-0,55^{* *}$ & $-0,47^{* *}$ & $-0,80^{* *}$ & $-0,67^{* *}$ & $-0,43^{*}$ & $-0,46^{*}$ \\
\hline Al solúvel & $0,45^{*}$ & $0,47^{* *}$ & $0,23^{\mathrm{NS}}$ & $0,08^{\mathrm{NS}}$ & $-0,05^{\mathrm{NS}}$ & $-0,25^{\mathrm{NS}}$ \\
\hline Acúmulo de Al & $-0,53^{*}$ & $-0,64^{*}$ & $-0,56^{*}$ & $-0,46^{\mathrm{NS}}$ & $-0,22^{\mathrm{NS}}$ & $-0,23^{\mathrm{NS}}$ \\
\hline \multicolumn{7}{|c|}{ pH da solução no solo } \\
\hline Al trocável & $-0,43^{*}$ & $-0,31^{\mathrm{NS}}$ & $-0,34^{\mathrm{NS}}$ & $-0,50^{* *}$ & $-0,41^{*}$ & $-0,35^{\mathrm{NS}}$ \\
\hline Al solúvel & $0,58^{* *}$ & $0,51^{* *}$ & $0,61^{* *}$ & $0,62^{* *}$ & $-0,12^{\mathrm{NS}}$ & $-0,40^{*}$ \\
\hline Acúmulo de Al & $-0,79^{* *}$ & $-0,73^{* *}$ & $-0,72^{* *}$ & $-0,59^{*}$ & $-0,39^{\mathrm{NS}}$ & $-0,22^{\mathrm{NS}}$ \\
\hline \multicolumn{7}{|c|}{ Al trocável } \\
\hline Al solúvel & $0,06^{\mathrm{NS}}$ & $-0,50^{* *}$ & $-0,25^{\mathrm{NS}}$ & $-0,36^{\mathrm{NS}}$ & $-0,01^{\mathrm{NS}}$ & $-0,00^{\mathrm{NS}}$ \\
\hline Acúmulo de Al & $0,55^{*}$ & $0,57^{*}$ & $0,59^{*}$ & $0,59^{*}$ & $0,28^{\mathrm{NS}}$ & $-0,24^{\mathrm{NS}}$ \\
\hline \multicolumn{7}{|c|}{ Al solúvel } \\
\hline Acúmulo de Al & $-0,30^{\mathrm{NS}}$ & $-0,52^{*}$ & $-0,37^{\mathrm{NS}}$ & $-0,50^{\mathrm{NS}}$ & $-0,21^{\mathrm{NS}}$ & $-0,36^{\mathrm{NS}}$ \\
\hline
\end{tabular}

NS: Não significativo. ${ }^{*} P<0,05 .{ }^{* *} P<0,01$.

Comparando-se o tratamento controle (T1) e os tratamentos T4 e T5, que receberam maiores doses de NFM acrescidos de maiores lâminas de irrigação com ESET (Figura 2), nota-se que a acidez potencial não foi diferente (Tabela 9). É evidente que nos tratamentos T4 e T5 houve aporte de N-efluente (predominantemente como N$\mathrm{NH}_{4}{ }^{+}$) (Tabela 4), que provoca liberação de prótons durante o processo de nitrificação (Bolan et al., 1991). No entanto, houve efeito do ESET como amenizador da acidez do solo e desse modo, não foi observado maior acidez potencial do solo nas parcelas que receberam maiores doses de NFM $+\mathrm{N}$-efluente, concordando com os trabalhos de Falkiner \& Smith (1997) e Fonseca (2001). Ainda, Allhands et al. (1995) verificaram que a concentração de $\mathrm{H}+\mathrm{Al}$ na camada $0-15 \mathrm{~cm}$ de solos arenosos ácidos, sob pastagem de capim-Bermuda Coastal, foi diminuída mediante irrigação com EET. 
Tabela 9. Efeitos da irrigação (água e efluente) e de doses de nitrogênio mineral nas concentrações de $\mathrm{H}+\mathrm{Al}$ do solo

\begin{tabular}{|c|c|c|c|c|c|c|c|}
\hline \multirow{2}{*}{ Tratamento } & \multicolumn{7}{|c|}{ Época de avaliação } \\
\hline & Abr/03 & Jul/03 & Out/03 & Jan/04 & Abr/04 & Jul/04 & Média \\
\hline & \multicolumn{7}{|c|}{$\mathrm{mmol}_{\mathrm{c}} \mathrm{kg}^{-1}$} \\
\hline \multicolumn{8}{|c|}{ Camada 0-10 cm (CV = 13,24\%) } \\
\hline$T 1^{(1)}$ & 15,55 & 17,80 & 11,04 & 13,04 & 11,28 & 15,20 & $13,99^{\mathrm{ab}}$ \\
\hline $\mathbf{T} 2^{(2)}$ & 14,53 & 22,93 & 9,05 & 11,58 & 9,43 & 15,38 & $13,82^{b}$ \\
\hline T3 ${ }^{(3)}$ & 17,63 & 17,31 & 10,39 & 11,81 & 10,45 & 16,10 & $13,95^{\mathrm{ab}}$ \\
\hline$T 4^{(4)}$ & 17,13 & 20,76 & 11,19 & 14,19 & 13,60 & 14,60 & $15,25^{\mathrm{ab}}$ \\
\hline $\mathbf{T} 5^{(5)}$ & 15,80 & 18,33 & 11,57 & 15,22 & 15,68 & 18,30 & $15,82^{a}$ \\
\hline Média & $16,13^{\mathrm{B}}$ & $19,42^{\mathrm{A}}$ & $10,65^{\mathrm{D}}$ & $13,17^{\mathrm{C}}$ & $12,09^{\mathrm{CD}}$ & $15,92^{\mathrm{B}}$ & \\
\hline \multicolumn{8}{|c|}{ Camada $10-20 \mathrm{~cm}(C V=13,81 \%)$} \\
\hline $\mathrm{T1}^{(1)}$ & 15,15 & 15,51 & 13,21 & 12,00 & 12,40 & 13,40 & $13,61^{\mathrm{a}}$ \\
\hline $\mathbf{T} 2^{(2)}$ & 15,74 & 22,12 & 11,08 & 13,05 & 8,03 & 14,13 & $14,02^{\mathrm{a}}$ \\
\hline T3 ${ }^{(3)}$ & 17,23 & 21,01 & 12,19 & 12,97 & 11,15 & 17,78 & $15,39^{\mathrm{a}}$ \\
\hline$T 4^{(4)}$ & 17,13 & 19,38 & 10,44 & 14,14 & 12,90 & 15,25 & $14,87^{\mathrm{a}}$ \\
\hline $\mathbf{T} 5^{(5)}$ & 16,55 & 18,52 & 11,45 & 14,40 & 13,65 & 15,55 & $15,02^{\mathrm{a}}$ \\
\hline Média & $13,36^{\mathrm{B}}$ & $19,31^{\mathrm{A}}$ & $11,68^{\mathrm{C}}$ & $13,31^{\mathrm{C}}$ & $11,63^{\mathrm{C}}$ & $15,22^{\mathrm{B}}$ & \\
\hline \multicolumn{8}{|c|}{ Camada $20-40 \mathrm{~cm}(C V=9,73 \%)$} \\
\hline T1 & 18,65 & 24,69 & 14,93 & 14,68 & 11,83 & 20,73 & $17,58^{a b}$ \\
\hline $\mathbf{T 2}$ & 16,60 & 23,94 & 14,57 & 14,53 & 9,43 & 17,25 & $16,05^{b}$ \\
\hline T3 & 21,90 & 25,58 & 16,97 & 18,17 & 16,98 & 23,23 & $20,47^{\text {a }}$ \\
\hline T4 & 20,10 & 26,16 & 17,69 & 20,22 & 17,03 & 18,40 & $19,93^{\text {a }}$ \\
\hline T5 & 17,92 & 23,62 & 15,59 & 17,24 & 16,58 & 18,98 & $18,32^{a b}$ \\
\hline Média & $19,03^{\mathrm{B}}$ & $24,80^{\mathrm{A}}$ & $15,95^{\mathrm{CD}}$ & $16,97^{\mathrm{C}}$ & $14,37^{\mathrm{D}}$ & $19,72^{\mathrm{B}}$ & \\
\hline \multicolumn{8}{|c|}{ Camada $40-60 \mathrm{~cm}(C V=9,85 \%)$} \\
\hline T1 & 18,20 & 22,95 & 16,97 & 17,87 & 16,18 & 20,85 & $18,84^{a b}$ \\
\hline T2 & 19,43 & 21,45 & 16,42 & 15,48 & 13,68 & 17,83 & $17,38^{\mathrm{b}}$ \\
\hline T3 & 23,18 & 24,63 & 17,79 & 20,49 & 16,78 & 22,90 & $20,96^{\mathrm{a}}$ \\
\hline T4 & 21,05 & 25,11 & 17,77 & 20,97 & 17,85 & 22,08 & $20,80^{\mathrm{a}}$ \\
\hline T5 & 22,25 & 24,34 & 16,37 & 19,47 & 18,95 & 19,40 & $20,13^{\mathrm{a}}$ \\
\hline Média & $20,82^{\mathrm{B}}$ & $23,69^{\mathrm{A}}$ & $17,07^{\mathrm{D}}$ & $18,86^{\mathrm{CD}}$ & $16,69^{\mathrm{D}}$ & $20,61^{\mathrm{BC}}$ & \\
\hline \multicolumn{8}{|c|}{ Camada $60-80 \mathrm{~cm}(\mathrm{CV}=9,91 \%)$} \\
\hline T1 & 17,68 & 22,16 & 14,64 & 17,32 & 14,78 & 19,00 & $17,60^{\mathrm{a}}$ \\
\hline T2 & 19,20 & 17,95 & 16,89 & 13,88 & 13,78 & 19,88 & $16,93^{\mathrm{a}}$ \\
\hline T3 & 19,28 & 22,53 & 16,53 & 18,22 & 15,35 & 19,45 & $18,56^{\mathrm{a}}$ \\
\hline T4 & 19,83 & 22,28 & 16,04 & 18,64 & 15,08 & 18,18 & $18,34^{\mathrm{a}}$ \\
\hline T5 & 18,85 & 23,17 & 15,02 & 17,42 & 15,73 & 18,40 & $18,10^{\mathrm{a}}$ \\
\hline Média & $19,97^{\text {B }}$ & $21,62^{\mathrm{A}}$ & $15,83^{\mathrm{CD}}$ & $17,10^{\mathrm{C}}$ & $14,94^{\mathrm{D}}$ & $18,98^{\mathrm{B}}$ & \\
\hline
\end{tabular}


Tabela 9. Efeitos da irrigação (água e efluente) e de doses de nitrogênio mineral nas concentrações de $\mathrm{H}+\mathrm{Al}$ do solo

\begin{tabular}{|c|c|c|c|c|c|c|c|}
\hline \multirow{2}{*}{ Tratamento } & \multicolumn{7}{|c|}{ Época de avaliação } \\
\hline & Abr/03 & Jul/03 & Out/03 & Jan/04 & Abr/04 & Jul/04 & Média \\
\hline & \multicolumn{7}{|c|}{$\operatorname{mmol}_{\mathrm{c}} \mathrm{kg}^{-1}$} \\
\hline \multicolumn{8}{|c|}{ Camada $80-100 \mathrm{~cm}(C V=10,88 \%)$} \\
\hline T1 & 16,30 & 22,27 & 13,02 & 17,00 & 14,98 & 16,63 & $16,70^{\mathrm{a}}$ \\
\hline $\mathbf{T 2}$ & 16,93 & 16,52 & 14,69 & 17,03 & 13,33 & 16,93 & $15,90^{\mathrm{a}}$ \\
\hline T3 & 19,23 & 22,31 & 15,59 & 17,78 & 12,73 & 18,50 & $17,69^{\mathrm{a}}$ \\
\hline T4 & 16,38 & 21,38 & 16,75 & 17,25 & 15,65 & 17,70 & $17,52^{\mathrm{a}}$ \\
\hline T5 & 19,38 & 21,79 & 14,87 & 17,27 & 15,40 & 17,88 & $17,76^{\mathrm{a}}$ \\
\hline Média & $17,64^{\mathrm{B}}$ & $20,85^{\mathrm{A}}$ & $14,99^{\mathrm{C}}$ & $17,27^{\mathrm{B}}$ & $14,42^{\mathrm{C}}$ & $17,53^{\mathrm{B}}$ & \\
\hline
\end{tabular}

(1) T1: irrigação com água $+520 \mathrm{~kg} \mathrm{ha}^{-1}$ ano $^{-1}$ de nitrogênio via fertilizante mineral (NFM);

(2) T2: irrigação com efluente secundário de esgoto tratado (ESET), sem NFM;

(3) T3: irrigação com ESET + 171,6 kg ha ${ }^{-1} \mathrm{ano}^{-1}$ de NFM;

(4) T4: irrigação com ESET + 343,3 $\mathrm{kg} \mathrm{ha}^{-1} \mathrm{ano}^{-1}$ de NFM;

${ }^{(5)}$ T5: irrigação com ESET + $520 \mathrm{~kg} \mathrm{ha}^{-1}$ ano $^{-1}$ de NFM;

(6) Letras iguais maiúsculas ou minúsculas nas linhas e nas colunas, respectivamente, não diferem estatisticamente pelo teste de Tukey $(P<0,05)$.

Os valores de $\mathrm{H}+\mathrm{Al}$ aumentaram, aos seis meses após a instalação do experimento e diminuíram ou tornaram-se estáveis durante as demais épocas de amostragens (Tabela 9). Comparando-se os valores médios dos tratamentos, não foram diferentes as concentrações de $\mathrm{H}+\mathrm{Al}$ observadas aos três e aos 18 meses de experimento (Tabela 9). Isso indica que, mesmo após intensa adição de NFM e elevado rendimento de MS (Figura 2), a acidez potencial do solo não foi alterada e, certamente, foi mantida devido à adição de cátions e de ânions, principalmente, $\mathrm{HCO}_{3}{ }^{-}$oriundos do efluente (Falkiner \& Smith, 1997) e da água de irrigação. Salienta-se que a água empregada na irrigação do tratamento controle foi caracterizada como alcalina, rica em $\mathrm{HCO}_{3}{ }^{-}$, cujas características foram apresentadas e discutidas no item 4.2.

Os tratamentos ocasionaram alterações nas concentrações de Al trocável somente nas camadas 0-10 e 20-40 cm (Tabela 10). O tratamento T2 apresentou menores concentrações de Al trocável, condizente com maiores valores de $\mathrm{pH}$ (Tabela 6) e menores valores de $\mathrm{H}+\mathrm{Al}$ (Tabela 9). Porém, os tratamentos que receberam maiores doses de NFM apresentaram menores valores de $\mathrm{pH}$ e maiores concentrações de $\mathrm{H}+\mathrm{Al}$ 
Tabela 10. Efeitos da irrigação (água e efluente) e de doses de nitrogênio mineral nas concentrações de $\mathrm{Al}$ trocável no solo

\begin{tabular}{|c|c|c|c|c|c|c|c|}
\hline \multirow{2}{*}{ Tratamento } & \multicolumn{7}{|c|}{ Época de avaliação } \\
\hline & Abr/03 & Jul/03 & Out/03 & Jan/04 & Abr/04 & Jul/04 & Média \\
\hline & \multicolumn{7}{|c|}{$\mathrm{mmol}_{\mathrm{c}} \mathrm{kg}^{-1}$} \\
\hline \multicolumn{8}{|c|}{ Camada 0-10 cm (CV = 52,03\%) } \\
\hline $\mathrm{T1}^{(1)}$ & 1,18 & 0,11 & 1,50 & 0,53 & 1,15 & 0,38 & $0,81^{\mathrm{ab}}$ \\
\hline $\mathbf{T}^{(2)}$ & 0,48 & 0,56 & 0,50 & 0,08 & 0,20 & 0,10 & $0,32^{b}$ \\
\hline $\mathbf{T} 3^{(3)}$ & 1,08 & 1,08 & 1,63 & 0,38 & 0,30 & 0,33 & $0,80^{\mathrm{ab}}$ \\
\hline$T 4^{(4)}$ & 1,33 & 1,66 & 1,53 & 0,83 & 0,53 & 0,60 & $1,08^{\mathrm{a}}$ \\
\hline $\mathbf{T} 5^{(5)}$ & 0,95 & 1,09 & 1,58 & 0,80 & 1,60 & 1,08 & $1,18^{\mathrm{a}}$ \\
\hline Média & $1,00^{\mathrm{AB}}$ & $0,90^{\mathrm{BC}}$ & $1,35^{\mathrm{A}}$ & $0,52^{\mathrm{CD}}$ & $0,76^{\mathrm{BCD}}$ & $0,50^{\mathrm{D}}$ & \\
\hline \multicolumn{8}{|c|}{ Camada $10-20 \mathrm{~cm}(C V=55,02 \%)$} \\
\hline T1 & 0,75 & 0,77 & 1,63 & 0,73 & 0,63 & 0,30 & $0,80^{\mathrm{a}}$ \\
\hline $\mathbf{T 2}$ & 0,93 & 0,55 & 1,05 & 0,08 & 0,20 & 0,20 & $0,50^{\mathrm{a}}$ \\
\hline T3 & 1,15 & 1,96 & 1,98 & 0,70 & 0,43 & 0,38 & $1,10^{\mathrm{a}}$ \\
\hline T4 & 1,45 & 2,33 & 1,95 & 0,48 & 0,80 & 0,60 & $1,27^{\mathrm{a}}$ \\
\hline T5 & 0,63 & 1,09 & 1,43 & 0,73 & 1,05 & 0,48 & $0,90^{\mathrm{a}}$ \\
\hline Média & $0,98^{\mathrm{BC}}$ & $1,34^{\mathrm{AB}}$ & $1,61^{\mathrm{A}}$ & $0,54^{\mathrm{CD}}$ & $0,62^{\mathrm{CD}}$ & $0,39^{\mathrm{D}}$ & \\
\hline \multicolumn{8}{|c|}{ Camada $20-40 \mathrm{~cm}(C V=38,59 \%)$} \\
\hline $\mathrm{T1}$ & 2,20 & 3,80 & 7,13 & 3,95 & 1,33 & 2,30 & $3,45^{b c}$ \\
\hline T2 & 2,65 & 3,89 & 1,80 & 2,63 & 1,30 & 0,45 & $2,12^{\mathrm{c}}$ \\
\hline T3 & 4,35 & 7,83 & 6,00 & 5,00 & 5,10 & 5,30 & $5,60^{\mathrm{a}}$ \\
\hline T4 & 4,60 & 7,51 & 6,55 & 3,43 & 4,33 & 3,43 & $4,97^{\mathrm{ab}}$ \\
\hline T5 & 2,38 & 5,44 & 4,28 & 3,60 & 1,63 & 4,03 & $3,56^{\mathrm{bc}}$ \\
\hline Média & $3,24^{\mathrm{B}}$ & $5,69^{\mathrm{A}}$ & $5,15^{\mathrm{A}}$ & $3,72^{\mathrm{B}}$ & $2,74^{\mathrm{B}}$ & $3,10^{\mathrm{B}}$ & \\
\hline \multicolumn{8}{|c|}{ Camada $40-60 \mathrm{~cm}(C V=25,98 \%)$} \\
\hline $\mathrm{T} 1$ & 3,98 & 5,60 & 6,70 & 5,95 & 4,43 & 5,05 & $5,28^{\mathrm{a}}$ \\
\hline T2 & 5,38 & 5,10 & 6,23 & 5,78 & 5,43 & 0,85 & $4,79^{\mathrm{a}}$ \\
\hline T3 & 6,38 & 9,43 & 8,60 & 7,73 & 5,65 & 6,25 & $7,34^{\mathrm{a}}$ \\
\hline T4 & 5,95 & 7,21 & 8,40 & 6,33 & 7,10 & 5,70 & $6,78^{a}$ \\
\hline T5 & 5,38 & 7,63 & 5,93 & 6,35 & 6,45 & 5,55 & $6,21^{\mathrm{a}}$ \\
\hline Média & $5,41^{\mathrm{BC}}$ & $6,99^{\mathrm{A}}$ & $7,17^{\mathrm{A}}$ & $6,43^{\mathrm{AB}}$ & $5,81 \mathrm{ABC}$ & $4,68^{\mathrm{C}}$ & \\
\hline \multicolumn{8}{|c|}{ Camada $60-80 \mathrm{~cm}(C V=21,43 \%)$} \\
\hline $\mathrm{T1}$ & 3,78 & 6,68 & 8,30 & 6,20 & 5,43 & 4,88 & $5,88^{\mathrm{a}}$ \\
\hline $\mathbf{T 2}$ & 4,73 & 4,58 & 7,53 & 5,68 & 6,25 & 6,50 & $5,88^{\mathrm{a}}$ \\
\hline T3 & 6,40 & 8,90 & 8,38 & 7,75 & 5,53 & 7,08 & $7,34^{\mathrm{a}}$ \\
\hline T4 & 5,63 & 8,04 & 7,60 & 6,15 & 6,70 & 5,68 & $6,63^{\mathrm{a}}$ \\
\hline T5 & 5,60 & 8,53 & 6,10 & 6,05 & 6,80 & 5,35 & $6,40^{\mathrm{a}}$ \\
\hline Média & $5,23^{\mathrm{C}}$ & $7,34^{\mathrm{AB}}$ & $7,58^{\mathrm{A}}$ & $6,37^{\mathrm{ABC}}$ & $6,14^{\mathrm{BC}}$ & $5,90^{\mathrm{C}}$ & \\
\hline
\end{tabular}


Tabela 10. Efeitos da irrigação (água e efluente) e de doses de nitrogênio mineral nas concentrações de $\mathrm{Al}$ trocável no solo

\begin{tabular}{|c|c|c|c|c|c|c|c|}
\hline \multirow{2}{*}{ Tratamento } & \multicolumn{7}{|c|}{ Época de avaliação } \\
\hline & Abr/03 & Jul/03 & Out/03 & Jan/04 & Abr/04 & Jul/04 & Média \\
\hline & \multicolumn{7}{|c|}{$\mathrm{mmol}_{\mathrm{c}} \mathbf{k g}^{-1}$} \\
\hline \multicolumn{8}{|c|}{ Camada $80-100 \mathrm{~cm}(C V=22,36 \%)$} \\
\hline T1 & 3,95 & 6,55 & 8,18 & 6,30 & 5,60 & 4,73 & $5,88^{\mathrm{a}}$ \\
\hline $\mathbf{T 2}$ & 4,03 & 5,10 & 7,18 & 5,58 & 4,43 & 5,88 & $5,36^{\mathrm{a}}$ \\
\hline T3 & 6,48 & 7,08 & 8,15 & 7,48 & 6,03 & 6,93 & $7,02^{\mathrm{a}}$ \\
\hline T4 & 4,95 & 6,21 & 7,70 & 5,80 & 6,20 & 4,73 & $5,93^{\mathrm{a}}$ \\
\hline T5 & 5,75 & 8,83 & 6,73 & 6,25 & 6,68 & 5,75 & $6,66^{\mathrm{a}}$ \\
\hline Média & $5,03^{\mathrm{C}}$ & $6,75^{\mathrm{AB}}$ & $7,59^{\mathrm{A}}$ & $6,28^{\mathrm{BC}}$ & $5,79^{\mathrm{BC}}$ & $5,60^{\mathrm{BC}}$ & \\
\hline
\end{tabular}

(1) T1: irrigação com água $+520 \mathrm{~kg} \mathrm{ha}^{-1}$ ano $^{-1}$ de nitrogênio via fertilizante mineral (NFM);

(2) T2: irrigação com efluente secundário de esgoto tratado (ESET), sem NFM;

(3) T3: irrigação com ESET + 171,6 kg ha-1 ano $^{-1}$ de NFM;

(4) T4: irrigação com ESET + 343,3 $\mathrm{kg} \mathrm{ha}^{-1} \mathrm{ano}^{-1}$ de NFM;

(5) T5: irrigação com ESET $+520 \mathrm{~kg} \mathrm{ha}^{-1} \mathrm{ano}^{-1}$ de NFM;

(6) Letras iguais maiúsculas ou minúsculas nas linhas e nas colunas, respectivamente, não diferem estatisticamente pelo teste de Tukey $(P<0,05)$.

(Tabela 9) e Al trocável (Tabela 10). Ainda, houve correlação negativa para todas as camadas entre $\mathrm{pH}\left(\mathrm{CaCl}_{2}\right)$ e $\mathrm{Al}$ trocável (Tabela 8). No entanto, correlação negativa entre $\mathrm{pH}$ da solução no solo e Al trocável somente ocorreu nas camadas 0-10, 40-60 e 60-80 cm (Tabela 8). A diminuição de uma unidade de $\mathrm{pH}$ ocasiona aumento na atividade do $\mathrm{Al}^{3+}$ na solução em 42 vezes quando este cátion se encontra em equilíbrio com $\mathrm{Al}(\mathrm{OH})_{3}$ amorfo (Lindsay, 1979). Portanto, a grande variação na atividade do $\mathrm{Al}$ devido a pequenas alterações no $\mathrm{pH}$ pode explicar os altos coeficientes de variação nas concentrações deste elemento no solo (Tabela 10), bem como na solução no solo (Tabela 11).

Baixa correlação $(r<0,70)$ ou ausência de correlação foi observada entre os parâmetros $\mathrm{Al}$ solúvel e pH (do solo e da solução no solo). Ao que parece, o método de laboratório empregado para obtenção da solução no solo (extrato de saturação) foi limitante para estudo do comportamento de Al. Moss (1963) estudou o efeito do tempo de equilíbrio, após a reumidificação de amostras de TFSA, nas concentrações de cátions na solução no solo. $\mathrm{O}$ autor verificou que cátions de maior valência demandavam maior 
Tabela 11. Efeitos da irrigação (água e efluente) e de doses de nitrogênio mineral na concentração de Al na solução no solo (extrato de saturação)

\begin{tabular}{|c|c|c|c|c|c|c|c|}
\hline \multirow{2}{*}{ Tratamento } & \multicolumn{7}{|c|}{ Época de avaliação } \\
\hline & Abr/03 & Jul/03 & Out/03 & Jan/04 & Abr/04 & Jul/04 & Média \\
\hline & \multicolumn{7}{|c|}{$\mu \mathrm{mol} \mathrm{L} \mathrm{L}^{-1}$} \\
\hline \multicolumn{8}{|c|}{ Camada 0-10 cm (CV = 59,03\%) } \\
\hline T1 & 17,38 & 21,67 & 310,75 & 153,08 & 6,47 & 269,91 & $129,88^{b(6)}$ \\
\hline T2 & 11,21 & $<\mathrm{LD}^{(7)}$ & 435,01 & 246,63 & 35,47 & 81,10 & $134,90^{b}$ \\
\hline T3 & 46,06 & 0,68 & 307,34 & 489,75 & 428,16 & 117,95 & $231,66^{\mathrm{a}}$ \\
\hline T4 & 18,11 & 15,20 & 708,05 & 206,80 & 92,21 & 179,34 & $203,29^{a b}$ \\
\hline T5 & 5,17 & $<\mathrm{LD}$ & 461,80 & 208,29 & 22,38 & 142,57 & $140,03^{\mathrm{b}}$ \\
\hline Média & $19,59^{\mathrm{D}}$ & $7,51^{\mathrm{D}}$ & $444,59^{\mathrm{A}}$ & $260,91^{\mathrm{B}}$ & $116,94^{\mathrm{C}}$ & $158,17^{\mathrm{C}}$ & \\
\hline \multicolumn{8}{|c|}{ Camada $10-20 \mathrm{~cm}(\mathrm{CV}=122,48 \%)$} \\
\hline T1 & 14,76 & $<\mathrm{LD}$ & 75,97 & 380,33 & 3,48 & 417,79 & $148,72^{\mathrm{a}}$ \\
\hline $\mathbf{T} 2$ & 11,44 & $<\mathrm{LD}$ & 73,35 & 219,49 & 103,93 & 364,63 & $128,81^{\mathrm{a}}$ \\
\hline T3 & 2,86 & $<\mathrm{LD}$ & 9,81 & 326,37 & 107,73 & 268,98 & $119,29^{\mathrm{a}}$ \\
\hline T4 & 5,29 & $<\mathrm{LD}$ & 122,35 & 311,10 & 31,48 & 117,16 & $97,90^{\mathrm{a}}$ \\
\hline T5 & 0,38 & $<\mathrm{LD}$ & 75,71 & 243,06 & 71,67 & 122,32 & $85,52^{\text {a }}$ \\
\hline Média & $6,95^{\mathrm{B}}$ & $<\mathrm{LD}$ & $71,44^{\text {B }}$ & $296,07^{\mathrm{A}}$ & $63,66^{\mathrm{B}}$ & $258,18^{\mathrm{A}}$ & \\
\hline \multicolumn{8}{|c|}{ Camada $20-40 \mathrm{~cm}(C V=210,57 \%)$} \\
\hline $\mathrm{T} 1$ & $<\mathrm{LD}$ & $<\mathrm{LD}$ & $<\mathrm{LD}$ & 142,36 & 10,51 & 87,54 & $40,07^{\mathrm{a}}$ \\
\hline T2 & $<\mathrm{LD}$ & $<\mathrm{LD}$ & $<\mathrm{LD}$ & 74,60 & 10,95 & 47,42 & $22,16^{\mathrm{a}}$ \\
\hline T3 & $<\mathrm{LD}$ & $<\mathrm{LD}$ & $<\mathrm{LD}$ & 3,46 & 4,32 & 26,59 & $5,73^{\mathrm{a}}$ \\
\hline T4 & $<\mathrm{LD}$ & $<\mathrm{LD}$ & $<\mathrm{LD}$ & 102,37 & 3,09 & 69,46 & $29,15^{\text {a }}$ \\
\hline T5 & $<\mathrm{LD}$ & $<\mathrm{LD}$ & $<\mathrm{LD}$ & 35,29 & 2,48 & 25,57 & $10,56^{\mathrm{a}}$ \\
\hline Média & $<\mathrm{LD}$ & $<\mathrm{LD}$ & $<\mathrm{LD}$ & $71,61^{\mathrm{A}}$ & $6,27^{\mathrm{B}}$ & $51,32^{\mathrm{A}}$ & \\
\hline \multicolumn{8}{|c|}{ Camada $40-60 \mathrm{~cm}(\mathrm{CV}=451,90 \%)$} \\
\hline T1 & $<\mathrm{LD}$ & $<\mathrm{LD}$ & $<\mathrm{LD}$ & 3,29 & 7,44 & 4,22 & $2,49^{\mathrm{a}}$ \\
\hline $\mathbf{T} 2$ & $<\mathrm{LD}$ & $<\mathrm{LD}$ & $<\mathrm{LD}$ & $<\mathrm{LD}$ & 0,77 & 18,14 & $3,15^{\mathrm{a}}$ \\
\hline T3 & $<\mathrm{LD}$ & $<\mathrm{LD}$ & $<\mathrm{LD}$ & $<\mathrm{LD}$ & 2,31 & 27,54 & $4,98^{\mathrm{a}}$ \\
\hline T4 & $<\mathrm{LD}$ & $<\mathrm{LD}$ & $<\mathrm{LD}$ & $<\mathrm{LD}$ & 0,62 & 24,83 & $4,24^{\mathrm{a}}$ \\
\hline T5 & $<\mathrm{LD}$ & $<\mathrm{LD}$ & $<\mathrm{LD}$ & $<\mathrm{LD}$ & 2,98 & 1,00 & $0,66^{\mathrm{a}}$ \\
\hline Média & $<\mathrm{LD}$ & $<\mathrm{LD}$ & $<\mathrm{LD}$ & $0,66^{\mathrm{B}}$ & $2,82^{\mathrm{AB}}$ & $15,15^{\mathrm{A}}$ & \\
\hline \multicolumn{8}{|c|}{ Camada $60-80 \mathrm{~cm}(\mathrm{CV}=179,03 \%)$} \\
\hline T1 & $<\mathrm{LD}$ & $<\mathrm{LD}$ & $<\mathrm{LD}$ & $<\mathrm{LD}$ & 0,89 & 0,84 & $0,29^{b}$ \\
\hline $\mathbf{T} 2$ & $<\mathrm{LD}$ & $<\mathrm{LD}$ & $<\mathrm{LD}$ & $<\mathrm{LD}$ & 1,13 & 0,39 & $0,25^{\mathrm{b}}$ \\
\hline T3 & $<\mathrm{LD}$ & $<\mathrm{LD}$ & $<\mathrm{LD}$ & 4,17 & 2,84 & 0,74 & $1,29^{\mathrm{a}}$ \\
\hline T4 & $<\mathrm{LD}$ & $<\mathrm{LD}$ & $<\mathrm{LD}$ & $<\mathrm{LD}$ & 0,90 & 1,70 & $0,43^{b}$ \\
\hline T5 & $<\mathrm{LD}$ & $<\mathrm{LD}$ & $<\mathrm{LD}$ & $<\mathrm{LD}$ & 0,67 & 0,63 & $0,22^{b}$ \\
\hline Média & $<\mathrm{LD}$ & $<\mathrm{LD}$ & $0,00^{\mathrm{B}}$ & $0,83^{\mathrm{A}}$ & $1,28^{\mathrm{A}}$ & $0,86^{\mathrm{A}}$ & \\
\hline
\end{tabular}


Tabela 11. Efeitos da irrigação (água e efluente) e de doses de nitrogênio mineral na concentração de Al na solução no solo (extrato de saturação)

\begin{tabular}{|c|c|c|c|c|c|c|c|}
\hline \multirow{2}{*}{ Tratamento } & \multicolumn{7}{|c|}{ Época de avaliação } \\
\hline & Abr/03 & Jul/03 & Out/03 & Jan/04 & Abr/04 & Jul/04 & Média \\
\hline & \multicolumn{7}{|c|}{$\mu \mathrm{mol} \mathrm{L}^{-1}$} \\
\hline \multicolumn{8}{|c|}{ Camada $80-100 \mathrm{~cm}(C V=184,49 \%)$} \\
\hline T1 & $<\mathrm{LD}$ & $<\mathrm{LD}$ & $<\mathrm{LD}$ & $<\mathrm{LD}$ & 0,84 & 0,56 & $0,23^{\mathrm{b}}$ \\
\hline $\mathbf{T} 2$ & $<\mathrm{LD}$ & $<\mathrm{LD}$ & $<\mathrm{LD}$ & $<\mathrm{LD}$ & 1,06 & 1,15 & $0,37^{\mathrm{ab}}$ \\
\hline T3 & $<\mathrm{LD}$ & $<\mathrm{LD}$ & $<\mathrm{LD}$ & 2,72 & 0,84 & 1,01 & $0,76^{\mathrm{a}}$ \\
\hline T4 & $<\mathrm{LD}$ & $<\mathrm{LD}$ & $<\mathrm{LD}$ & $<\mathrm{LD}$ & 0,98 & 0,86 & $0,31^{\mathrm{ab}}$ \\
\hline T5 & $<\mathrm{LD}$ & $<\mathrm{LD}$ & $<\mathrm{LD}$ & $<\mathrm{LD}$ & 1,36 & 0,53 & $0,32^{a b}$ \\
\hline Média & $<\mathrm{LD}$ & $<\mathrm{LD}$ & $<\mathrm{LD}$ & $0,54^{\mathrm{AB}}$ & $1,02^{\mathrm{A}}$ & $0,82^{\mathrm{A}}$ & \\
\hline
\end{tabular}

(1) T1: irrigação com água $+520 \mathrm{~kg} \mathrm{ha}^{-1}$ ano $^{-1}$ de nitrogênio via fertilizante mineral (NFM);

(2) T2: irrigação com efluente secundário de esgoto tratado (ESET), sem NFM;

(3) T3: irrigação com ESET + 171,6 $\mathrm{kg} \mathrm{ha}^{-1} \mathrm{ano}^{-1}$ de NFM;

(4) T4: irrigação com ESET + 343,3 $\mathrm{kg} \mathrm{ha}^{-1} \mathrm{ano}^{-1}$ de NFM;

(5) T5: irrigação com ESET $+520 \mathrm{~kg} \mathrm{ha}^{-1} \mathrm{ano}^{-1}$ de NFM;

(6) Letras iguais maiúsculas ou minúsculas nas linhas e nas colunas, respectivamente, não diferem estatisticamente pelo teste de Tukey $(P<0,05)$;

(7) LD: limite de detecção $\left(0,22 \mu \mathrm{mol} \mathrm{L} \mathrm{L}^{-1}\right)$. Para fins de análises estatísticas esses valores foram considerados iguais a zero.

período para atingir o equilíbrio. No presente trabalho as pastas de saturação foram deixadas em equilíbrio por 24 horas, conforme metodologia de Rhoades (1996). Provavelmente, este período de repouso não foi tempo suficiente para se obter $\mathrm{Al} \mathrm{em}$ equilíbrio na solução, mediante emprego desta metodologia. Portanto, tornam-se necessários estudos para identificar o tempo de equilíbrio necessário para obtenção da solução de solos tropicais mediante o emprego do método da pasta de saturação. Certamente, problemas do ponto de vista metodológico têm limitado os estudos do comportamento de $\mathrm{Al}$ na solução de solos irrigados com EET.

No presente estudo, as plantas do tratamento T1 e T2 acumularam menor quantidade de Al quando comparadas às plantas dos tratamentos T3, T4 e T5 (Tabela 12). No decorrer do experimento, a quantidade de Al acumulada nos tratamentos diminuiu (Tabela 12). Essas alterações no acúmulo de Al não foram influenciadas pelo ESET, uma vez que o aporte deste elemento foi aproximadamente constante para todos os tratamentos (Tabela 4). O fato das plantas do primeiro semestre, bem como das 
Tabela 12. Efeitos da irrigação (água e efluente) e de doses de nitrogênio mineral no acúmulo semestral (somatório de três cortes bimestrais) de $\mathrm{Al}, \mathrm{Ca}, \mathrm{Mg}$ e $\mathrm{K}$ na parte aérea (folhas + colmos + bainhas) do capim-Bermuda Tifton 85

\begin{tabular}{|c|c|c|c|c|}
\hline Tratamento & $1^{\circ}$ semestre & $\begin{array}{c}\text { Época } \\
2^{\mathbf{o}} \text { semestre } \\
\end{array}$ & $3^{\circ}$ semestre & Média \\
\hline & \multicolumn{4}{|c|}{ kg ha $^{-1}$} \\
\hline \multicolumn{5}{|c|}{ Acúmulo de Al (CV = 13,04\%) } \\
\hline$T 1^{(1)}$ & 1,46 & 1,38 & 0,84 & $1,23^{b(6)}$ \\
\hline $\mathbf{T} 2^{(2)}$ & 2,36 & 0,97 & 0,71 & $1,35^{\mathrm{b}}$ \\
\hline T3 ${ }^{(3)}$ & 2,27 & 1,56 & 1,14 & $1,66^{\mathrm{a}}$ \\
\hline T4 ${ }^{(4)}$ & 1,89 & 2,01 & 1,21 & $1,71^{\mathrm{a}}$ \\
\hline $\mathbf{T} 5^{(5)}$ & 1,66 & 2,18 & 1,13 & $1,66^{\mathrm{a}}$ \\
\hline Média & $1,93^{\mathrm{A}}$ & $1,62^{\mathrm{B}}$ & $1,01^{\mathrm{C}}$ & \\
\hline \multicolumn{5}{|c|}{ Acúmulo de Ca (CV = 11,29\%) } \\
\hline $\mathrm{T} 1$ & 48,42 & 77,98 & 67,22 & $64,54^{\mathrm{b}}$ \\
\hline $\mathbf{T} 2$ & 33,41 & 39,69 & 41,92 & $38,34^{\mathrm{d}}$ \\
\hline T3 & 37,98 & 70,35 & 57,62 & $55,32^{\mathrm{c}}$ \\
\hline T4 & 39,88 & 83,07 & 64,26 & $62,40^{\mathrm{b}}$ \\
\hline T5 & 46,85 & 96,56 & 73,05 & $72,15^{\mathrm{a}}$ \\
\hline Média & $41,31^{\mathrm{C}}$ & $73,53^{\mathrm{A}}$ & $60,81^{\text {B }}$ & \\
\hline \multicolumn{5}{|c|}{ Acúmulo de $\mathrm{Mg}(\mathrm{CV}=9,59 \%)$} \\
\hline T1 & 29,12 & 36,01 & 32,18 & $32,44^{\mathrm{b}}$ \\
\hline $\mathbf{T 2}$ & 19,71 & 17,28 & 18,31 & $18,43^{\mathrm{d}}$ \\
\hline T3 & 20,05 & 29,29 & 23,92 & $24,42^{\mathrm{c}}$ \\
\hline T4 & 21,55 & 38,43 & 33,67 & $31,22^{\mathrm{b}}$ \\
\hline T5 & 27,28 & 49,32 & 46,10 & $40,90^{\mathrm{a}}$ \\
\hline Média & $23,54^{\mathrm{C}}$ & $34,07^{\mathrm{A}}$ & $30,84^{\mathrm{B}}$ & \\
\hline \multicolumn{5}{|c|}{ Acúmulo de $K(C V=10,70 \%)$} \\
\hline $\mathrm{T} 1$ & 209,00 & 317,37 & 252,53 & $259,56^{\mathrm{a}}$ \\
\hline $\mathbf{T} 2$ & 160,38 & 177,91 & 227,14 & $188,48^{\mathrm{b}}$ \\
\hline T3 & 181,04 & 294,51 & 297,13 & $257,56^{\mathrm{a}}$ \\
\hline T4 & 193,99 & 354,90 & 295,34 & $281,41^{\text {a }}$ \\
\hline T5 & 229,96 & 363,38 & 282,83 & $292,06^{\mathrm{a}}$ \\
\hline Média & $194,87^{\mathrm{C}}$ & $301,61^{\mathrm{A}}$ & $270,99^{\mathrm{B}}$ & \\
\hline
\end{tabular}

(1) T1: irrigação com água $+520 \mathrm{~kg} \mathrm{ha}^{-1}$ ano $^{-1}$ de nitrogênio via fertilizante mineral (NFM);

(2) T2: irrigação com efluente secundário de esgoto tratado (ESET), sem NFM;

(3) T3: irrigação com ESET + 171,6 $\mathrm{kg} \mathrm{ha}^{-1}$ ano $^{-1}$ de NFM;

(4) T4: irrigação com ESET + 343,3 $\mathrm{kg} \mathrm{ha}^{-1} \mathrm{ano}^{-1}$ de NFM;

${ }^{(5)}$ T5: irrigação com ESET $+520 \mathrm{~kg} \mathrm{ha}^{-1}$ ano $^{-1}$ de NFM;

(6) Letras iguais maiúsculas ou minúsculas nas linhas e nas colunas, respectivamente, não diferem estatisticamente pelo teste de Tukey $(P<0,05)$. 
plantas dos tratamentos $\mathrm{T} 3, \mathrm{~T} 4$ e $\mathrm{T} 5$ terem acumulado mais $\mathrm{Al}$ está relacionado à disponibilidade deste elemento no solo (Tabela 10). Houve correlação positiva entre a concentração de Al trocável no solo (camadas 0-10, 10-20, 20-40 e 40-60 cm) e o acúmulo deste elemento nas plantas (Tabela 8). Foi observada correlação negativa entre o pH (do solo e da solução) nas camadas 0-10, 10-20 e 20-40 com o acúmulo de Al no capim (Tabela 8). E ainda, o Al solúvel na solução no solo não se correlacionou ou correlacionou-se inversamente ao esperado com o acúmulo deste elemento no capim (Tabela 8). Portanto, a falta de correlação entre Al na solução no solo com a concentração trocável deste elemento, bem como com a quantidade de Al acumulada no capim (Tabela 8), torna-se um forte indicativo que o método da pasta de saturação não é sustentável para estudo de Al.

\subsection{Cálcio, magnésio e potássio}

Os tratamentos alteraram as concentrações de Ca trocável no solo, exceto na camada 60-80 cm (Tabela 13). Maiores concentrações de Ca foram observadas no tratamento T2, onde a ausência de NFM ocasionou menor crescimento e desenvolvimento vegetal, levando a ocorrência de baixo rendimento de MS (Tabela 5 e Figura 3), que implicou em menor acúmulo e exportação de Ca (Tabela 12), restando maior quantidade deste nutriente no complexo de troca (Tabela 13). Em situação de baixo rendimento de MS (tratamento T2) o aporte de $\mathrm{Ca}$ via fertilizante mineral fosfatado (superfosfato simples, que contém 18 a $21 \%$ de $\mathrm{Ca}$, conforme Tisdale et al. (1985)) e, principalmente, via irrigação com ESET (Tabela 4) contribuíram para manutenção da concentração deste nutriente no perfil do solo. Isso pode ser afirmado, pois as concentrações médias de Ca trocável no tratamento $\mathrm{T} 2$, no decorrer do experimento (Tabela 13), foram semelhantes ou superiores às observadas por ocasião da instalação do experimento (Tabela 2). Em sistemas de produção menos intensivos, frente às limitações de recursos técnico-econômicos, o uso de EET como fonte de água para irrigação tem ocasionado aumento na concentração de Ca trocável no solo, conforme assinalado por Agunwamba (2001). Porém, em sistema intensivo de produção, como no presente estudo, que apresentou alto rendimento de MS (Tabela 5) e elevada exportação 
Tabela 13. Efeitos da irrigação (água e efluente) e de doses de nitrogênio mineral nas concentrações de Ca trocável no solo

\begin{tabular}{|c|c|c|c|c|c|c|c|}
\hline \multirow{2}{*}{ Tratamento } & \multicolumn{7}{|c|}{ Época de avaliação } \\
\hline & Abr/03 & Jul/03 & Out/03 & Jan/04 & Abr $/ 04$ & Jul/04 & Média \\
\hline & \multicolumn{7}{|c|}{$\mathrm{mmol}_{\mathrm{c}} \mathbf{k g}^{-1}$} \\
\hline \multicolumn{8}{|c|}{ Camada $0-10 \mathrm{~cm}(C V=10,07 \%)$} \\
\hline $\mathrm{T1}^{(1)}$ & 11,43 & 11,51 & 10,55 & 9,62 & 9,06 & 8,58 & $10,13^{b(6)}$ \\
\hline$T 2^{(2)}$ & 12,74 & 12,21 & 15,19 & 10,67 & 12,41 & 11,93 & $12,52^{\mathrm{a}}$ \\
\hline $\mathbf{T} 3^{(3)}$ & 9,95 & 10,05 & 10,69 & 10,54 & 9,87 & 11,40 & $10,42^{b}$ \\
\hline$T 4^{(4)}$ & 9,11 & 8,63 & 9,70 & 7,83 & 8,78 & 7,32 & $8,56^{\mathrm{c}}$ \\
\hline $\mathbf{T} 5^{(5)}$ & 11,29 & 11,17 & 11,06 & 8,51 & 10,33 & 7,80 & $10,03^{b}$ \\
\hline Média & $10,91^{\mathrm{AB}}$ & $10,72^{\mathrm{AB}}$ & $11,44^{\mathrm{A}}$ & $9,43^{\mathrm{C}}$ & $10,09^{\mathrm{BC}}$ & $9,41^{\mathrm{C}}$ & \\
\hline \multicolumn{8}{|c|}{ Camada $10-20 \mathrm{~cm}(C V=13,66 \%)$} \\
\hline $\mathrm{T} 1$ & 10,83 & 9,49 & 9,50 & 9,46 & 10,64 & 8,89 & $9,80^{\mathrm{ab}}$ \\
\hline T2 & 11,83 & 12,05 & 14,66 & 10,63 & 10,51 & 8,67 & $11,39^{\mathrm{a}}$ \\
\hline T3 & 9,50 & 8,81 & 9,96 & 7,76 & 8,99 & 7,48 & $8,75^{\mathrm{b}}$ \\
\hline T4 & 9,08 & 8,43 & 10,33 & 7,68 & 8,82 & 6,24 & $8,43^{b}$ \\
\hline $\mathbf{T 5}$ & 10,51 & 8,91 & 13,12 & 10,06 & 11,53 & 8,66 & $10,47^{\mathrm{ab}}$ \\
\hline Média & $10,35^{\mathrm{AB}}$ & $9,54^{\mathrm{B}}$ & $11,51^{\mathrm{A}}$ & $9,12^{\mathrm{BC}}$ & $10,10^{\mathrm{B}}$ & $7,99^{\mathrm{C}}$ & \\
\hline \multicolumn{8}{|c|}{ Camada $20-40 \mathrm{~cm}(\mathrm{CV}=16,00 \%)$} \\
\hline $\mathrm{T} 1$ & 9,72 & 7,26 & 5,93 & 7,81 & 7,99 & 6,97 & $7,61^{\mathrm{a}}$ \\
\hline T2 & 9,22 & 8,11 & 10,71 & 6,75 & 7,59 & 6,66 & $8,18^{\mathrm{a}}$ \\
\hline T3 & 6,64 & 5,21 & 6,02 & 5,34 & 5,27 & 4,64 & $5,52^{\mathrm{b}}$ \\
\hline T4 & 6,55 & 5,44 & 6,40 & 5,69 & 6,35 & 4,04 & $5,74^{\mathrm{b}}$ \\
\hline T5 & 8,51 & 6,42 & 9,08 & 6,09 & 7,66 & 6,11 & $7,31^{\mathrm{ab}}$ \\
\hline Média & $8,13^{\mathrm{A}}$ & $6,49^{\mathrm{CD}}$ & $7,63^{\mathrm{AB}}$ & $6,34^{\mathrm{CD}}$ & $6,97^{\mathrm{BC}}$ & $5,68^{\mathrm{D}}$ & \\
\hline \multicolumn{8}{|c|}{ Camada $40-60 \mathrm{~cm}(\mathrm{CV}=21,38 \%)$} \\
\hline $\mathrm{T} 1$ & 9,65 & 6,10 & 6,07 & 5,64 & 6,40 & 4,70 & $6,43^{\mathrm{ab}}$ \\
\hline T2 & 6,77 & 7,46 & 8,60 & 6,45 & 7,30 & 6,22 & $7,13^{a}$ \\
\hline T3 & 5,59 & 4,39 & 4,78 & 4,92 & 5,53 & 4,09 & $4,88^{\mathrm{b}}$ \\
\hline T4 & 5,64 & 5,85 & 6,02 & 3,93 & 3,97 & 4,47 & $4,98^{\mathrm{b}}$ \\
\hline T5 & 6,79 & 6,29 & 7,37 & 5,50 & 4,77 & 5,01 & $5,96^{\mathrm{ab}}$ \\
\hline Média & $6,89^{\mathrm{A}}$ & $6,02^{\mathrm{ABC}}$ & $6,57^{\mathrm{AB}}$ & $5,29^{\mathrm{C}}$ & $5,59^{\mathrm{BC}}$ & $4,90^{\mathrm{C}}$ & \\
\hline \multicolumn{8}{|c|}{ Camada $60-80 \mathrm{~cm}(\mathrm{CV}=22,40 \%)$} \\
\hline T1 & 7,29 & 5,35 & 4,53 & 5,25 & 6,04 & 3,73 & $5,36^{\mathrm{a}}$ \\
\hline $\mathbf{T 2}$ & 7,04 & 6,03 & 5,96 & 5,39 & 5,60 & 5,27 & $5,88^{\mathrm{a}}$ \\
\hline T3 & 4,60 & 3,98 & 4,42 & 4,05 & 4,61 & 3,58 & $4,21^{\mathrm{a}}$ \\
\hline T4 & 4,91 & 4,71 & 4,54 & 4,39 & 3,65 & 3,75 & $4,33^{\mathrm{a}}$ \\
\hline T5 & 5,67 & 5,94 & 5,45 & 4,94 & 3,77 & 4,43 & $5,03^{\mathrm{a}}$ \\
\hline Média & $5,90^{\mathrm{A}}$ & $5,20^{\mathrm{AB}}$ & $4,98^{\mathrm{ABC}}$ & $4,80^{\mathrm{BC}}$ & $4,73^{\mathrm{BC}}$ & $4,15^{\mathrm{C}}$ & \\
\hline
\end{tabular}


Tabela 13. Efeitos da irrigação (água e efluente) e de doses de nitrogênio mineral nas concentrações de Ca trocável no solo

\begin{tabular}{|c|c|c|c|c|c|c|c|}
\hline \multirow{2}{*}{ Tratamento } & \multicolumn{7}{|c|}{ Época de avaliação } \\
\hline & Abr/03 & Jul/03 & Out/03 & Jan/04 & Abr/04 & Jul/04 & Média \\
\hline & \multicolumn{7}{|c|}{$\mathrm{mmol}_{\mathrm{c}} \mathrm{kg}^{-1}$} \\
\hline \multicolumn{8}{|c|}{ Camada $80-100 \mathrm{~cm}(C V=20,35 \%)$} \\
\hline T1 & 5,93 & 3,12 & 3,57 & 4,39 & 4,13 & 3,86 & $4,17^{\mathrm{ab}}$ \\
\hline T2 & 5,11 & 3,67 & 4,47 & 5,13 & 5,67 & 4,36 & $4,73^{\text {a }}$ \\
\hline T3 & 3,49 & 2,68 & 3,50 & 2,50 & 2,65 & 2,80 & $2,93^{\mathrm{c}}$ \\
\hline T4 & 3,84 & 3,28 & 3,25 & 2,88 & 2,91 & 3,09 & $3,21^{\mathrm{c}}$ \\
\hline T5 & 4,09 & 3,02 & 4,20 & 3,51 & 3,04 & 3,65 & $3,58^{\mathrm{bc}}$ \\
\hline Média & $4,49^{\mathrm{A}}$ & $3,15^{\mathrm{B}}$ & $3,80^{\mathrm{AB}}$ & $3,68^{\mathrm{B}}$ & $3,68^{\mathrm{B}}$ & $3,55^{\mathrm{B}}$ & \\
\hline
\end{tabular}

(1) T1: irrigação com água $+520 \mathrm{~kg} \mathrm{ha}^{-1}$ ano $^{-1}$ de nitrogênio via fertilizante mineral (NFM);

(2) T2: irrigação com efluente secundário de esgoto tratado (ESET), sem NFM;

(3) T3: irrigação com ESET + 171,6 $\mathrm{kg} \mathrm{ha}^{-1} \mathrm{ano}^{-1}$ de NFM;

(4) T4: irrigação com ESET + 343,3 $\mathrm{kg} \mathrm{ha}^{-1} \mathrm{ano}^{-1}$ de NFM;

(5) T5: irrigação com ESET + $520 \mathrm{~kg} \mathrm{ha}^{-1} \mathrm{ano}^{-1}$ de NFM;

(6) Letras iguais maiúsculas ou minúsculas nas linhas e nas colunas, respectivamente, não diferem estatisticamente pelo teste de Tukey $(P<0,05)$.

de nutrientes, inclusive de Ca (Tabela 12), o aporte de Ca-efluente (Tabela 4) não foi o bastante para ocasionar aumento na concentração trocável deste nutriente no solo (Tabela 13), discordando de várias observações (Quin \& Woods, 1978; Cromer et al., 1984; Johns \& McConchie, 1994b; Zekri \& Koo, 1994; Falkiner \& Smith, 1997; Speir et al., 1999), porém concordando com os resultados de Paliwal et al. (1998).

Comparando-se os tratamentos irrigados com ESET (T2, T3, T4 e T5), foram verificadas que, com exceção das camadas 0-10 e 80-100 cm, maiores concentrações de Ca trocável ocorreram nos tratamentos T2 e/ou T5 (Tabela 13). Este fato foi devido, no caso do tratamento T2, à menor exportação de $\mathrm{Ca}$ (Tabela 12) e, no caso do tratamento T5, à maior necessidade de irrigação (Figura 2), que proporcionou aporte elevado de Caefluente (Tabela 4). Ainda, as concentrações de Ca trocável nos tratamentos T2 e T5 não foram diferentes, apesar de T5 ter tido maior exportação deste nutriente (Tabela 12), o que evidencia o papel do ESET na manutenção da concentração deste nutriente no solo. A discriminação dos efeitos do efluente nas concentrações de $\mathrm{Ca}$, no presente estudo, foi possível graças à baixa CTC do solo (Tabela 2). Wang et al. (2003) comentaram que 
muitas das vezes não é possível discriminar o efeito do Ca-efluente em solos de alta CTC, devido à elevada concentração deste cátion no complexo de troca.

Em condição semelhante de fertilização mineral (tratamentos T1 e T5) o tipo de água empregada na irrigação não ocasionou alterações nas concentrações de $\mathrm{Ca}$ trocável (Tabela 13), mas afetou o acúmulo deste nutriente na parte aérea do capim (Tabela 12). Este fato concorda com as informações obtidas por (i) Hayes et al. (1990a), onde o uso de EET na irrigação de capim-Bermuda proporcionou aumento na qualidade da pastagem, porém, sem ocasionar alterações significativas na concentração de Ca trocável no solo; (ii) Adekalu \& Okunade (2002), que verificaram maiores concentrações de Ca no milho submetido à irrigação com EET.

No decorrer do experimento as concentrações de $\mathrm{Ca}$ trocável variaram conforme a época de amostragem de solo (Tabela 13). As variações sazonais nas concentrações de $\mathrm{Ca}$, assim como no $\mathrm{pH}$ do solo (Tabela 6) e nas concentrações de H+Al (Tabela 9) e Al (Tabela 10) são atribuídas às variações das lâminas de irrigação (Figura 2). Comparando-se os valores médios da primeira e da última amostragem de solo, pode-se observar que as concentrações médias de Ca trocável diminuíram, concordando com as observações de (i) Hayes et al. (1990a), num estudo com solo sob pastagem de capim-Bermuda submetido à irrigação com EET por 16 meses; (ii) Dawes \& Goonetilleke (2003), que verificaram diminuição na concentração de Ca trocável com o tempo de disposição de EET no solo. Ainda, as alterações nas concentrações de Ca trocável obtidas no presente estudo podem estar associadas aos efeitos dos tratamentos nas concentrações de $\mathrm{Na}$ trocável, que serão discutidos no próximo item (4.6).

Quanto ao Ca solúvel no extrato de saturação (solução no solo), somente houve efeito dos tratamentos nas camadas 0-10, 10-20 e 60-80 cm (Tabela 14) e ainda, maiores concentrações deste nutriente na solução foram observadas nos tratamentos irrigados com ESET, ora T2 (camadas 0-10 e 60-80 cm), ora T3 (Camada 60-80 cm), ora T5 (camada 10-20 cm). Os efeitos dos tratamentos na concentração de Ca na solução no solo não foram similares aos ocorridos no complexo de troca. Este fato pode ser afirmado, pois foram observados baixos coeficientes de correlação ou inexistência de correlação entre os parâmetros Ca trocável e percentual de Ca trocável (PCT) com o Ca 
Tabela 14. Efeitos da irrigação (água e efluente) e de doses de nitrogênio mineral na concentração de Ca na solução no solo (extrato de saturação)

\begin{tabular}{|c|c|c|c|c|c|c|c|}
\hline \multirow{2}{*}{ Tratamento } & \multicolumn{7}{|c|}{ Época de avaliação } \\
\hline & Abr/03 & Jul/03 & Out/03 & Jan/04 & Abr/04 & Jul/04 & Média \\
\hline & \multicolumn{7}{|c|}{$\mu \mathrm{mol} \mathrm{L}^{-1}$} \\
\hline \multicolumn{8}{|c|}{ Camada 0-10 cm (CV = 40,33\%) } \\
\hline $\mathrm{T1}^{(1)}$ & 230,72 & 239,25 & 64,52 & 39,36 & 57,07 & 39,11 & $111,67^{\mathrm{b}(6)}$ \\
\hline $\mathbf{T} 2^{(2)}$ & 317,43 & 406,97 & 125,11 & 118,13 & 75,41 & 43,26 & $181,05^{\mathrm{a}}$ \\
\hline$T 3^{(3)}$ & 261,82 & 353,31 & 89,43 & 44,82 & 84,72 & 59,97 & $149,01^{\mathrm{ab}}$ \\
\hline T4 ${ }^{(4)}$ & 260,78 & 213,07 & 68,85 & 51,39 & 46,45 & 25,75 & $111,05^{b}$ \\
\hline$T 5^{(5)}$ & 324,93 & 273,51 & 55,49 & 38,13 & 107,91 & 32,80 & $138,80^{\mathrm{ab}}$ \\
\hline Média & $279,14^{\mathrm{A}}$ & $297,22^{\mathrm{A}}$ & $80,68^{\text {B }}$ & $58,37^{\text {В }}$ & $74,31^{\text {B }}$ & $40,18^{\mathrm{B}}$ & \\
\hline \multicolumn{8}{|c|}{ Camada $10-20 \mathrm{~cm}(C V=41,89 \%)$} \\
\hline T1 & 320,36 & 418,00 & 112,35 & 50,68 & 59,07 & 41,03 & $166,92^{\mathrm{c}}$ \\
\hline T2 & 395,76 & 707,84 & 171,01 & 75,64 & 102,48 & 64,22 & $252,82^{a b}$ \\
\hline T3 & 350,94 & 515,74 & 135,23 & 30,55 & 29,42 & 32,89 & $182,46^{\mathrm{abc}}$ \\
\hline T4 & 327,78 & 506,40 & 89,09 & 20,11 & 77,94 & 21,56 & $173,81^{b c}$ \\
\hline T5 & 522,11 & 788,71 & 119,77 & 24,72 & 73,49 & 33,26 & $260,34^{\mathrm{a}}$ \\
\hline Média & $383,39^{\mathrm{B}}$ & $587,34^{\mathrm{A}}$ & $125,49^{\mathrm{C}}$ & $40,34^{\mathrm{D}}$ & $68,48^{\mathrm{CD}}$ & $38,59^{\mathrm{D}}$ & \\
\hline \multicolumn{8}{|c|}{ Camada $20-40 \mathrm{~cm}(C V=34,52 \%)$} \\
\hline T1 & 479,53 & 191,06 & 273,31 & 28,15 & 37,59 & 31,33 & $173,49^{\mathrm{a}}$ \\
\hline T2 & 373,04 & 259,08 & 446,49 & 67,56 & 86,38 & 41,10 & $212,28^{\mathrm{a}}$ \\
\hline T3 & 300,48 & 179,30 & 216,98 & 36,39 & 20,19 & 27,53 & $130,15^{\mathrm{a}}$ \\
\hline T4 & 281,57 & 175,63 & 168,72 & 34,46 & 43,52 & 22,69 & $121,10^{\mathrm{a}}$ \\
\hline T5 & 305,94 & 207,95 & 189,21 & 17,57 & 52,91 & 22,93 & $132,75^{\mathrm{a}}$ \\
\hline Média & $348,12^{\mathrm{A}}$ & $202,60^{\mathrm{C}}$ & $258,94^{\mathrm{B}}$ & $36,83^{\mathrm{D}}$ & $48,12^{\mathrm{D}}$ & $29,11^{\mathrm{D}}$ & \\
\hline \multicolumn{8}{|c|}{ Camada $40-60 \mathrm{~cm}(C V=61,31 \%)$} \\
\hline $\mathrm{T1}$ & 295,04 & 93,71 & 306,31 & 38,16 & 21,04 & 50,05 & $134,05^{\mathrm{a}}$ \\
\hline T2 & 133,92 & 138,21 & 467,00 & 92,35 & 61,89 & 32,22 & $177,44^{\mathrm{a}}$ \\
\hline T3 & 87,42 & 72,44 & 322,36 & 105,50 & 34,07 & 22,34 & $107,36^{\mathrm{a}}$ \\
\hline T4 & 99,34 & 82,57 & 258,90 & 69,79 & 22,91 & 21,91 & $92,57^{\text {a }}$ \\
\hline T5 & 103,89 & 122,11 & 185,27 & 74,80 & 68,68 & 19,18 & $95,65^{\mathrm{a}}$ \\
\hline Média & $143,92^{\mathrm{B}}$ & $101,81^{\mathrm{BC}}$ & $307,97^{\mathrm{A}}$ & $76,12^{\mathrm{CD}}$ & $41,72^{\mathrm{CD}}$ & $29,14^{\mathrm{D}}$ & \\
\hline \multicolumn{8}{|c|}{ Camada $60-80 \mathrm{~cm}(C V=64,79 \%)$} \\
\hline T1 & 60,61 & 59,12 & 71,80 & 62,35 & 7,77 & 13,39 & $45,84^{b}$ \\
\hline T2 & 53,21 & 38,09 & 138,75 & 222,78 & 28,56 & 30,37 & $85,29^{\mathrm{a}}$ \\
\hline T3 & 45,35 & 22,18 & 128,72 & 268,90 & 48,87 & 19,13 & $88,86^{\mathrm{a}}$ \\
\hline T4 & 38,86 & 29,20 & 134,49 & 215,57 & 12,60 & 15,59 & $74,39^{\text {ab }}$ \\
\hline T5 & 33,54 & 26,87 & 93,30 & 152,59 & 42,69 & 25,28 & $62,38^{a b}$ \\
\hline Média & $46,32^{\mathrm{C}}$ & $35,09^{\mathrm{C}}$ & $113,41^{\mathrm{B}}$ & $184,44^{\mathrm{A}}$ & $28,10^{\mathrm{C}}$ & $20,75^{\mathrm{C}}$ & \\
\hline
\end{tabular}


Tabela 14. Efeitos da irrigação (água e efluente) e de doses de nitrogênio mineral na concentração de Ca na solução no solo (extrato de saturação)

\begin{tabular}{|c|c|c|c|c|c|c|c|}
\hline \multirow{2}{*}{ Tratamento } & \multicolumn{7}{|c|}{ Época de avaliação } \\
\hline & Abr/03 & Jul/03 & Out/03 & Jan/04 & Abr/04 & Jul/04 & Média \\
\hline & \multicolumn{7}{|c|}{$\mu \mathrm{mol} \mathrm{L}^{-1}$} \\
\hline \multicolumn{8}{|c|}{ Camada $80-100 \mathrm{~cm}(C V=83,03 \%)$} \\
\hline T1 & 36,99 & 15,20 & 33,83 & 55,46 & 22,89 & 13,33 & $29,61^{\mathrm{a}}$ \\
\hline T2 & 34,93 & 17,84 & 37,18 & 248,77 & 24,62 & 23,19 & $64,42^{\mathrm{a}}$ \\
\hline T3 & 31,59 & 17,61 & 26,43 & 191,63 & 50,52 & 22,41 & $56,70^{\mathrm{a}}$ \\
\hline T4 & 26,93 & 17,51 & 17,10 & 126,82 & 20,79 & 20,31 & $38,24^{\mathrm{a}}$ \\
\hline T5 & 37,54 & 18,80 & 52,08 & 102,67 & 30,11 & 32,52 & $45,62^{\mathrm{a}}$ \\
\hline Média & $33,60^{\mathrm{B}}$ & $17,39^{\mathrm{B}}$ & $33,32^{\mathrm{B}}$ & $145,07^{\mathrm{A}}$ & $29,78^{\mathrm{B}}$ & $22,35^{\mathrm{B}}$ & \\
\hline
\end{tabular}

(1) T1: irrigação com água $+520 \mathrm{~kg} \mathrm{ha}^{-1}$ ano $^{-1}$ de nitrogênio via fertilizante mineral (NFM);

(2) T2: irrigação com efluente secundário de esgoto tratado (ESET), sem NFM;

(3) T3: irrigação com ESET + 171,6 kg ha-1 $\mathrm{ano}^{-1}$ de NFM;

(4) T4: irrigação com ESET + 343,3 $\mathrm{kg} \mathrm{ha}^{-1} \mathrm{ano}^{-1}$ de NFM;

${ }^{(5)}$ T5: irrigação com ESET $+520 \mathrm{~kg} \mathrm{ha}^{-1}$ ano $^{-1}$ de NFM;

(6) Letras iguais maiúsculas ou minúsculas nas linhas e nas colunas, respectivamente, não diferem estatisticamente pelo teste de Tukey $(P<0,05)$.

solúvel (Tabela 15). Os resultados das concentrações de Ca na solução (Tabela 14) apresentaram maior variação que os resultados das concentrações deste elemento no complexo de troca (Tabela 13). Essa maior variabilidade nos resultados de $\mathrm{Ca}$ na solução associada aos baixos coeficientes de correlação com a fase trocável (Tabela 15), evidenciou que o extrato de saturação não ocasionou concentrações representativas de Ca solúvel. Portanto, o período de repouso (uma noite) empregado no preparo da pasta de saturação, conforme Rhoades (1996), não pareceu ser o suficiente para promover equilíbrio entre a concentração de cátions na fase sólida e fase líquida (solução no solo), sobretudo, para cátions que normalmente apresentam maior afinidade no complexo de troca, como é o caso do Al e do Ca (Meurer et al., 2004). Esta ausência de equilíbrio concorda com as observações de Moss (1963), onde foram necessários mais de 30 dias para que amostras de TFSA apresentassem, após o reumidecimento, concentração de Ca na solução em equilíbrio com a fase sólida.

$\mathrm{O}$ fato da água de irrigação não ter ocasionado grandes alterações na concentração de Ca trocável na maioria das camadas (Tabela 13), bem como na solução 
Tabela 15. Coeficientes de correlação entre os parâmetros concentração trocável $\left(\mathrm{mmol}_{\mathrm{c}}\right.$ $\left.\mathrm{kg}^{-1}\right)$ e solúvel $\left(\mathrm{mmol} \mathrm{L}^{-1}\right)$ e o acúmulo $\left(\mathrm{kg} \mathrm{ha}^{-1}\right.$ semestre $\left.^{-1}\right)$, na parte aérea do capim-Bermuda Tifton 85, dos nutrientes $\mathrm{Ca}, \mathrm{Mg}$ e K

\begin{tabular}{|c|c|c|c|c|c|c|}
\hline \multirow{2}{*}{ Parâmetro } & \multicolumn{6}{|c|}{ Camada (cm) } \\
\hline & 0 a 10 & 10 a 20 & 20 a 40 & 40 a 60 & 60 a 80 & 80 a 100 \\
\hline \multicolumn{7}{|c|}{ Ca trocável no solo } \\
\hline Ca solúvel & $0,37^{*}$ & $0,18^{\mathrm{NS}}$ & $0,62^{* *}$ & $0,56^{* *}$ & $-0,02^{\mathrm{NS}}$ & $0,06^{\mathrm{NS}}$ \\
\hline Acúmulo de Ca & $-0,63^{*}$ & $-0,29^{\mathrm{NS}}$ & $-0,15^{\mathrm{NS}}$ & $-0,52^{*}$ & $-0,34^{\mathrm{NS}}$ & $-0,13^{\mathrm{NS}}$ \\
\hline \multicolumn{7}{|c|}{ Mg trocável no solo } \\
\hline Mg solúvel & $0,77^{* *}$ & $0,58^{* * *}$ & $0,57^{* *}$ & $0,56^{* *}$ & $-0,02^{\mathrm{NS}}$ & $-0,06^{\mathrm{NS}}$ \\
\hline Acúmulo de Mg & $-0,71^{* *}$ & $-0,54^{*}$ & $-0,18^{\mathrm{NS}}$ & $-0,64^{* *}$ & $-0,49^{\mathrm{NS}}$ & $-0,29^{\mathrm{NS}}$ \\
\hline \multicolumn{7}{|c|}{ K trocável no solo } \\
\hline K solúvel & $0,58^{* *}$ & $0,67^{* *}$ & $0,82^{* *}$ & $0,40^{*}$ & $0,35^{\mathrm{NS}}$ & $0,40^{*}$ \\
\hline Acúmulo de $\mathrm{K}$ & $-0,53^{*}$ & $-0,19^{\mathrm{NS}}$ & $-0,76^{* *}$ & $-0,62^{*}$ & $-0,67^{* *}$ & $-0,49^{\mathrm{NS}}$ \\
\hline \multicolumn{7}{|c|}{ Percentual de Ca trocável $(P C T)^{(1)}$} \\
\hline Ca solúvel & $-0,05^{\mathrm{NS}}$ & $-0,23^{\mathrm{NS}}$ & $0,47^{* *}$ & $0,58^{* *}$ & $0,18^{\mathrm{NS}}$ & $0,06^{\mathrm{NS}}$ \\
\hline Acúmulo de Ca & $-0,00^{\mathrm{NS}}$ & $0,33^{\mathrm{NS}}$ & $0,18^{\mathrm{NS}}$ & $-0,27^{\mathrm{NS}}$ & $-0,06^{\mathrm{NS}}$ & $0,07^{\mathrm{NS}}$ \\
\hline \multicolumn{7}{|c|}{ Percentual de Mg trocável $(P M T)^{(2)}$} \\
\hline Mg solúvel & $0,65^{* *}$ & $0,38^{*}$ & $0,41^{*}$ & $0,60^{* *}$ & $0,15^{\mathrm{NS}}$ & $-0,05^{\mathrm{NS}}$ \\
\hline Acúmulo de Mg & $-0,67^{* *}$ & $-0,42^{\mathrm{NS}}$ & $-0,23^{\mathrm{NS}}$ & $-0,56^{*}$ & $-0,39^{\mathrm{NS}}$ & $-0,15^{\mathrm{NS}}$ \\
\hline \multicolumn{7}{|c|}{ Percentual de K trocável $(P K T)^{(3)}$} \\
\hline K solúvel & $0,41^{*}$ & $0,62^{* *}$ & $0,79^{* *}$ & $0,44^{*}$ & $0,53^{* *}$ & $0,43^{*}$ \\
\hline Acúmulo de $\mathrm{K}$ & $-0,33^{\mathrm{NS}}$ & $-0,24^{\mathrm{NS}}$ & $-0,55^{*}$ & $-0,50^{\mathrm{NS}}$ & $-0,62^{*}$ & $-0,39^{\mathrm{NS}}$ \\
\hline \multicolumn{7}{|c|}{ Ca solúvel na solução no solo } \\
\hline Acúmulo de Ca & $-0,72^{* *}$ & $-0,67^{* *}$ & $-0,73^{* *}$ & $-0,38^{\mathrm{NS}}$ & $0,36^{\mathrm{NS}}$ & $0,23^{\mathrm{NS}}$ \\
\hline \multicolumn{7}{|c|}{ Mg solúvel na solução no solo } \\
\hline Acúmulo de Mg & $-0,45^{\mathrm{NS}}$ & $-0,44^{\mathrm{NS}}$ & $-0,49^{\mathrm{NS}}$ & $-0,41^{\mathrm{NS}}$ & $0,25^{\mathrm{NS}}$ & $0,14^{\mathrm{NS}}$ \\
\hline \multicolumn{7}{|c|}{ K solúvel na solução no solo } \\
\hline Acúmulo de $\mathrm{K}$ & $-0,89^{* *}$ & $-0,80^{* *}$ & $-0,83^{* *}$ & $-0,50^{\mathrm{NS}}$ & $0,41^{\mathrm{NS}}$ & $0,16^{\mathrm{NS}}$ \\
\hline \multicolumn{7}{|c|}{ NS: Não significativo. ${ }^{*} P<0,05 . * * P<0,01$. } \\
\hline \multirow{2}{*}{ (1) $P C T=($} & \multicolumn{2}{|c|}{$\mathrm{Ca}$} & \multirow{2}{*}{ *100 } & & & \\
\hline & $+K+\Lambda$ & $H+A l$ & & & & \\
\hline \multirow{2}{*}{ (2) $P M T=$} & \multicolumn{2}{|l|}{$M g$} & \multirow{2}{*}{$* 100$} & & & \\
\hline & $+K+I$ & $H+A l$ & & & & \\
\hline \multirow{2}{*}{ (3) $P K T=$} & \multirow{2}{*}{\multicolumn{2}{|c|}{$\frac{K}{+K+N}$}} & \multirow{2}{*}{ *100 } & & & \\
\hline & & & & & & \\
\hline
\end{tabular}


no solo (Tabela 14), mas ter promovido alteração no acúmulo deste nutriente no capim (Tabela 12), pode estar relacionada à baixa CTC do solo (Tabela 2), que implica em baixo poder tampão. Essa afirmação pode ser suportada a partir dos resultados de análises de correlações (Tabela 15), onde foi observada (i) ausência de correlação (camadas 10-20, 20-40, 60-80 e 80-100 cm) e baixa correlação (camadas 0-10 e 40-60 $\mathrm{cm}$ ) entre os parâmetros Ca trocável no solo e Ca acumulado na parte aérea do capim; (ii) correlação negativa entre Ca solúvel nas camadas 0-10, 10-20 20-40 cm e ausência de correlação para as demais camadas com a quantidade de Ca acumulada no capim; (iii) ausência de correlação entre o PCT e o acúmulo de Ca no capim. Portanto, conclui-se que o capim-Bermuda Tifton 85 é uma excelente planta extratora de nutrientes do meio, constituindo-se num dreno eficiente dos constituintes (inclusive de $\mathrm{Ca}$ ) do ESET aplicado no sistema solo-planta.

As concentrações de $\mathrm{Mg}$ trocáveis foram alteradas pelos tratamentos, com exceção da camada 80-100 cm (Tabela 16). O tratamento T2, pelo fato de ter apresentado menor rendimento (Tabela 5 e Figura 3) e baixa extração de Mg (Tabela 12), proporcionou condições para ocorrência de maior concentração trocável deste nutriente (Tabela 16).

Os tratamentos T1 e T5 não apresentaram concentrações de Mg trocável diferentes (Tabela 16), porém as plantas do tratamento T5 acumularam maior quantidade deste nutriente devido ao aporte de Mg-efluente (Tabela 12). O fato do ESET não ter proporcionado alterações nas concentrações de $\mathrm{Mg}$ trocável no solo discorda das observações de (i) Stewart et al. (1990), Falkiner \& Smith (1997), Agunwamba (2001), Adekalu \& Okunade (2002), que observaram aumento na concentração deste nutriente no complexo de troca; (ii) Zekri \& Koo (1994), Ramirez-Fuentes et al. (2002) e Wang et al. (2003), que observaram diminuição na concentração de Mg trocável no solo. No entanto, os resultados do presente trabalho, com relação ao $\mathrm{Mg}$ trocável, concorda com as observações de Hayes et al. (1990a), Johns \& McConchie (1994b), Paliwal et al. (1998) e Fonseca (2001). Nos agrossistemas irrigados com ESET, normalmente tem sido observado aumento e diminuição nas concentrações de $\mathrm{Mg}$ trocável em sistemas de baixo e alto nível de produção, respectivamente. Ainda, o fato de as plantas do 
Tabela 16. Efeitos da irrigação (água e efluente) e de doses de nitrogênio mineral nas concentrações de Mg trocável no solo

\begin{tabular}{|c|c|c|c|c|c|c|c|}
\hline \multirow[b]{2}{*}{ Tratamento } & \multicolumn{7}{|c|}{ Época de avaliação } \\
\hline & Abr/03 & Jul/03 & Out/03 & Jan/04 & Abr $/ 04$ & Jul/04 & Média \\
\hline & \multicolumn{7}{|c|}{$\mathrm{mmol}_{\mathrm{c}} \mathrm{kg}^{-1}$} \\
\hline \multicolumn{8}{|c|}{ Camada 0-10 cm (CV = 12,91\%) } \\
\hline$T 1^{(1)}$ & 5,50 & 5,87 & 3,82 & 3,35 & 3,74 & 2,58 & $4,14^{\mathrm{b}(6)}$ \\
\hline$T 2^{(2)}$ & 7,15 & 6,77 & 6,38 & 4,53 & 5,43 & 5,04 & $5,88^{a}$ \\
\hline $\mathbf{T} 3^{(3)}$ & 5,91 & 5,77 & 4,45 & 4,41 & 4,37 & 3,96 & $4,81^{\mathrm{ab}}$ \\
\hline$T 4^{(4)}$ & 4,71 & 4,39 & 4,01 & 2,80 & 3,65 & 2,20 & $3,63^{b}$ \\
\hline$T 5^{(5)}$ & 5,07 & 5,69 & 4,31 & 3,24 & 3,50 & 1,99 & $3,97^{\mathrm{b}}$ \\
\hline Média & $5,67^{\mathrm{A}}$ & $5,70^{\mathrm{A}}$ & $4,60^{\mathrm{B}}$ & $3,67^{\mathrm{CD}}$ & $4,14^{\mathrm{BC}}$ & $3,15^{\mathrm{D}}$ & \\
\hline \multicolumn{8}{|c|}{ Camada $10-20 \mathrm{~cm}(C V=16,01 \%)$} \\
\hline T1 & 6,11 & 8,30 & 6,14 & 5,67 & 4,62 & 4,47 & $5,88^{a b}$ \\
\hline T2 & 8,03 & 7,58 & 8,75 & 6,03 & 5,93 & 5,25 & $6,93^{\mathrm{a}}$ \\
\hline T3 & 6,34 & 6,54 & 6,27 & 4,59 & 5,25 & 4,34 & $5,55^{\mathrm{ab}}$ \\
\hline T4 & 6,06 & 6,13 & 5,66 & 3,89 & 4,00 & 3,56 & $4,89^{\mathrm{b}}$ \\
\hline T5 & 6,29 & 7,77 & 8,66 & 4,30 & 4,03 & 3,71 & $5,79^{a b}$ \\
\hline Média & $6,57^{\mathrm{A}}$ & $7,27^{\mathrm{A}}$ & $7,09^{\mathrm{A}}$ & $4,90^{\mathrm{B}}$ & $4,77^{\mathrm{B}}$ & $4,27^{\mathrm{B}}$ & \\
\hline \multicolumn{8}{|c|}{ Camada $20-40 \mathrm{~cm}(C V=18,78 \%)$} \\
\hline T1 & 6,29 & 6,09 & 4,30 & 6,19 & 5,61 & 3,26 & $5,29^{a b}$ \\
\hline T2 & 7,44 & 6,90 & 7,17 & 5,97 & 7,42 & 4,43 & $6,56^{\mathrm{a}}$ \\
\hline T3 & 5,27 & 4,87 & 4,83 & 4,23 & 3,98 & 3,39 & $4,43^{b}$ \\
\hline T4 & 5,86 & 4,80 & 4,96 & 3,26 & 4,46 & 2,93 & $4,38^{\mathrm{b}}$ \\
\hline T5 & 6,40 & 5,75 & 8,09 & 4,64 & 4,98 & 3,71 & $5,59^{\mathrm{ab}}$ \\
\hline Média & $6,26^{\mathrm{A}}$ & $5,68^{\mathrm{ABC}}$ & $5,87^{\mathrm{AB}}$ & $4,86^{\mathrm{C}}$ & $5,29^{\mathrm{BC}}$ & $3,54^{\mathrm{D}}$ & \\
\hline \multicolumn{8}{|c|}{ Camada $40-60 \mathrm{~cm}(C V=13,61 \%)$} \\
\hline T1 & 5,45 & 4,41 & 4,04 & 4,01 & 3,82 & 2,78 & $4,09^{a b}$ \\
\hline T2 & 5,34 & 5,18 & 5,97 & 4,52 & 5,76 & 3,89 & $5,11^{\mathrm{a}}$ \\
\hline T3 & 4,12 & 4,25 & 3,69 & 2,87 & 3,50 & 2,75 & $3,53^{\mathrm{b}}$ \\
\hline T4 & 4,62 & 4,28 & 4,12 & 2,93 & 3,05 & 2,60 & $3,60^{\mathrm{b}}$ \\
\hline T5 & 4,89 & 4,39 & 5,13 & 3,24 & 2,90 & 2,11 & $3,78^{b}$ \\
\hline Média & $4,88^{\mathrm{A}}$ & $4,50^{\mathrm{A}}$ & $4,59^{\mathrm{A}}$ & $3,51^{\mathrm{B}}$ & $3,81^{\mathrm{B}}$ & $2,83^{\mathrm{C}}$ & \\
\hline \multicolumn{8}{|c|}{ Camada $60-80 \mathrm{~cm}(C V=16,54 \%)$} \\
\hline T1 & 5,39 & 4,04 & 3,91 & 3,55 & 3,65 & 2,62 & $3,86^{\mathrm{ab}}$ \\
\hline T2 & 5,07 & 4,66 & 4,64 & 3,95 & 5,79 & 4,28 & $4,73^{\mathrm{a}}$ \\
\hline T3 & 3,98 & 3,71 & 2,80 & 2,87 & 3,98 & 2,10 & $3,24^{\mathrm{b}}$ \\
\hline T4 & 4,71 & 4,10 & 4,03 & 3,71 & 3,39 & 2,60 & $3,76^{\mathrm{ab}}$ \\
\hline T5 & 3,98 & 3,85 & 3,98 & 3,44 & 3,50 & 2,02 & $3,46^{\mathrm{b}}$ \\
\hline Média & $4,62^{\mathrm{A}}$ & $4,07^{\mathrm{AB}}$ & $3,87^{\mathrm{B}}$ & $3,51^{\mathrm{B}}$ & $4,06^{\mathrm{AB}}$ & $2,73^{\mathrm{C}}$ & \\
\hline
\end{tabular}


Tabela 16. Efeitos da irrigação (água e efluente) e de doses de nitrogênio mineral nas concentrações de Mg trocável no solo

\begin{tabular}{|c|c|c|c|c|c|c|c|}
\hline \multirow{2}{*}{ Tratamento } & \multicolumn{7}{|c|}{ Época de avaliação } \\
\hline & Abr/03 & Jul/03 & Out/03 & Jan/04 & Abr/04 & Jul/04 & Média \\
\hline & \multicolumn{7}{|c|}{$\mathrm{mmol}_{\mathrm{c}} \mathrm{kg}^{-1}$} \\
\hline \multicolumn{8}{|c|}{ Camada $80-100 \mathrm{~cm}(C V=15,61 \%)$} \\
\hline $\mathrm{T1}$ & 5,52 & 3,89 & 3,23 & 3,69 & 3,85 & 2,85 & $3,84^{\mathrm{a}}$ \\
\hline T2 & 5,16 & 4,64 & 4,35 & 4,21 & 4,86 & 2,87 & $4,34^{\mathrm{a}}$ \\
\hline T3 & 3,82 & 3,57 & 3,28 & 2,62 & 4,10 & 2,15 & $3,25^{\mathrm{a}}$ \\
\hline T4 & 4,87 & 3,98 & 3,18 & 3,26 & 3,76 & 3,03 & $3,68^{\mathrm{a}}$ \\
\hline T5 & 3,78 & 3,96 & 3,96 & 3,85 & 3,77 & 2,23 & $3,59^{\mathrm{a}}$ \\
\hline Média & $4,63^{\mathrm{A}}$ & $4,01^{\mathrm{BC}}$ & $3,60^{\mathrm{BC}}$ & $3,53^{\mathrm{C}}$ & $4,07^{\mathrm{B}}$ & $2,63^{\mathrm{D}}$ & \\
\hline
\end{tabular}

(1) T1: irrigação com água $+520 \mathrm{~kg} \mathrm{ha}^{-1}$ ano $^{-1}$ de nitrogênio via fertilizante mineral (NFM);

(2) T2: irrigação com efluente secundário de esgoto tratado (ESET), sem NFM;

(3) T3: irrigação com ESET + 171,6 $\mathrm{kg} \mathrm{ha}^{-1} \mathrm{ano}^{-1}$ de NFM;

(4) T4: irrigação com ESET + 343,3 $\mathrm{kg} \mathrm{ha}^{-1} \mathrm{ano}^{-1}$ de NFM;

(5) T5: irrigação com ESET $+520 \mathrm{~kg} \mathrm{ha}^{-1} \mathrm{ano}^{-1}$ de NFM;

${ }^{(6)}$ Letras iguais maiúsculas ou minúsculas nas linhas e nas colunas, respectivamente, não diferem estatisticamente pelo teste de Tukey $(P<0,05)$.

tratamento $\mathrm{T} 5$ ter acumulado mais $\mathrm{Mg}$ que as plantas do tratamento $\mathrm{T} 1$, evidenciou que o ESET aumentou a qualidade do capim, concordando com as observações de Hayes et al. (1990b). Este aumento na quantidade de Mg nas plantas discordou das observações de Fonseca (2001), mas concordou com as informações obtidas por Adekalu \& Okunade (2002). Aumentos na concentração de Mg nas forrageiras cultivadas em sistemas intensivos são benéficos para a nutrição animal, por evitar hipomagnesemia (Mengel \& Kirkby, 2001).

As concentrações de $\mathrm{Mg}$ no perfil do solo diminuíram no decorrer do experimento (Tabela 16). No complexo de troca, as concentrações de $\mathrm{Mg}$ foram diminuídas a medida em que as plantas receberam maiores doses de NFM, que proporcionou maiores rendimentos de MS (Tabela 5 e Figura 3) e acúmulo de $\mathrm{Mg}$ (Tabela 12). Este fato pode ser afirmado, pois houve correlações negativas entre os parâmetros Mg trocável, nas camadas 0-10, 10-20 e 40-60 cm e percentual de $\mathrm{Mg}$ trocável (PMT), nas camadas 0-10 e 40-60 cm com o acúmulo deste nutriente nas plantas (Tabela 15). Apesar dos valores médios de $\mathrm{pH}$ do solo não terem sido muito 
diferentes entre a primeira e a última amostragem (Tabela 6), as concentrações de $\mathrm{Ca}$ (Tabela 13) e Mg (Tabela 16) diminuíram. Este fato se torna muito importante, pois os efeitos do ESET como amenizador da acidez do solo (Tabelas 6, 9 e 10) não implicaram em aumentos nas concentrações trocáveis de Ca (Tabela 13) e Mg (Tabela 16) e, portanto, não substitui a calagem, que tem sido a principal prática agronômica fonte de $\mathrm{Ca}$ e Mg às plantas (Raij, 1991). Salienta-se que, considerando a densidade deste solo de aproximadamente $1300 \mathrm{~kg} \mathrm{~m}^{-3}$, as concentrações trocáveis de Ca (Tabela 13) e de $\mathrm{Mg}$ (Tabela 16), em subsuperfície, estão muito próximas dos níveis críticos 5,0 e 4,0 $\mathrm{mmol}_{\mathrm{c}}$ $\mathrm{dm}^{-1}$, respectivamente, apresentados em Raij (1991).

As concentrações de $\mathrm{Mg}$ na solução no solo foram alteradas pelos tratamentos, exceto na camada 60-80 cm (Tabela 17). Maiores concentrações de Mg solúvel foram, normalmente, observadas no tratamento T2 (Tabela 17), ou seja, em situação de menor extração deste nutriente (Tabela 12), restando maior quantidade de Mg no complexo de troca (Tabela 16), que está em equilíbrio com a fase líquida do solo (Meurer \& Anghinoni, 2004). Na camada 0-10 cm, os efeitos dos tratamentos nas concentrações trocáveis (Tabela 16) e solúveis (Tabela 17) de Mg foram iguais e, desse modo, houve alta correlação $(r>0,70)$ entre estes parâmetros (Tabela 15).

Foram observadas, até $60 \mathrm{~cm}$, correlações positivas entre os parâmetros $\mathrm{Mg}$ trocável e PMT com as concentrações deste nutriente no extrato de saturação (Tabela 15). O fato de haver melhor correlação entre as concentrações solúveis e trocáveis de $\mathrm{Mg}$, quando comparadas às de $\mathrm{Ca}$ (Tabela 15) e de $\mathrm{Al}$ (Tabela 8 ), pode ser devido às diferenças nos coeficientes de seletividade, sobretudo, em condição de aumento da força iônica (Loyola Jr. \& Pavan, 1989). Portanto, cátions que apresentam maiores coeficientes de seletividade apresentam maior afinidade pelo complexo de troca e, portanto, menores concentrações em solução. Quando as amostras de TFSA foram reumidecidas, para elaboração da pasta de saturação, certamente o $\mathrm{Mg}$ atingiu um estádio de melhor equilíbrio entre a fase sólida e a fase solução quando comparados aos cátions de maior afinidade pelo complexo de troca (Al e Ca). Moss (1963) verificou que, após o reumidecimento da TFSA, as concentrações de $\mathrm{Mg}$ atingiram equilíbrio em tempo bem menor que as concentrações de Ca. 
Tabela 17. Efeitos da irrigação (água e efluente) e de doses de nitrogênio mineral na concentração de Mg na solução no solo (extrato de saturação)

\begin{tabular}{|c|c|c|c|c|c|c|c|}
\hline \multirow{2}{*}{ Tratamento } & \multicolumn{7}{|c|}{ Época de avaliação } \\
\hline & Abr/03 & Jul/03 & Out/03 & Jan/04 & Abr $/ 04$ & Jul/04 & Média \\
\hline & \multicolumn{7}{|c|}{$\mu \mathrm{mol} \mathrm{L} \mathrm{L}^{-1}$} \\
\hline \multicolumn{8}{|c|}{ Camada $0-10 \mathrm{~cm}(C V=48,45 \%)$} \\
\hline$T 1^{(1)}$ & 166,02 & 197,16 & 32,78 & 14,06 & 30,03 & 19,31 & $76,56^{\mathrm{b}(6)}$ \\
\hline$T 2^{(2)}$ & 280,82 & 390,44 & 45,05 & 22,31 & 95,82 & 28,31 & $143,79^{\mathrm{a}}$ \\
\hline T3 ${ }^{(3)}$ & 186,00 & 253,31 & 27,94 & 20,38 & 48,18 & 32,93 & $94,79^{a b}$ \\
\hline$T 4^{(4)}$ & 160,44 & 106,23 & 22,13 & 13,37 & 13,33 & 13,10 & $54,77^{\mathrm{b}}$ \\
\hline $\mathbf{T} 5^{(5)}$ & 190,35 & 202,75 & 14,88 & 15,65 & 42,68 & 23,24 & $81,59^{b}$ \\
\hline Média & $196,72^{\mathrm{A}}$ & $229,98^{\mathrm{A}}$ & $28,55^{\mathrm{B}}$ & $17,15^{\text {B }}$ & $46,01^{\text {B }}$ & $23,38^{\mathrm{B}}$ & \\
\hline \multicolumn{8}{|c|}{ Camada $10-20 \mathrm{~cm}(C V=32,19 \%)$} \\
\hline T1 & 226,64 & 431,48 & 60,51 & 16,49 & 27,96 & 28,23 & $131,89^{\mathrm{c}}$ \\
\hline T2 & 293,31 & 924,98 & 120,22 & 17,07 & 38,38 & 47,51 & $240,25^{\mathrm{a}}$ \\
\hline T3 & 298,58 & 522,48 & 104,52 & 15,56 & 8,80 & 22,00 & $161,99^{b c}$ \\
\hline T4 & 271,20 & 366,52 & 39,53 & 3,29 & 41,57 & 21,05 & $123,86^{\mathrm{c}}$ \\
\hline T5 & 266,89 & 690,95 & 80,70 & 8,44 & 138,45 & 21,17 & $201,10^{a b}$ \\
\hline Média & $271,32^{\mathrm{B}}$ & $587,28^{\mathrm{A}}$ & $81,10^{\mathrm{C}}$ & $12,17^{\mathrm{D}}$ & $51,03^{\mathrm{CD}}$ & $27,99^{\mathrm{D}}$ & \\
\hline \multicolumn{8}{|c|}{ Camada $20-40 \mathrm{~cm}(C V=40,52 \%)$} \\
\hline T1 & 155,61 & 225,56 & 251,43 & 16,58 & 30,97 & 16,13 & $116,05^{b}$ \\
\hline $\mathbf{T 2}$ & 288,10 & 332,56 & 347,56 & 65,08 & 94,82 & 25,75 & $192,31^{\mathrm{a}}$ \\
\hline T3 & 270,30 & 187,99 & 202,50 & 21,24 & 14,57 & 19,79 & $119,40^{\mathrm{b}}$ \\
\hline T4 & 271,58 & 167,47 & 149,26 & 11,29 & 38,10 & 14,40 & $108,68^{\mathrm{b}}$ \\
\hline T5 & 232,92 & 236,88 & 97,68 & 8,20 & 35,41 & 18,38 & $104,91^{\mathrm{b}}$ \\
\hline Média & $243,70^{\mathrm{A}}$ & $230,09^{\mathrm{A}}$ & $209,69^{\mathrm{A}}$ & $24,48^{\mathrm{B}}$ & $42,77^{\mathrm{B}}$ & $18,89^{\mathrm{B}}$ & \\
\hline \multicolumn{8}{|c|}{ Camada $40-60 \mathrm{~cm}(\mathrm{CV}=46,86 \%)$} \\
\hline $\mathrm{T} 1$ & 206,84 & 64,56 & 185,62 & 18,68 & 4,46 & 20,21 & $83,40^{\mathrm{ab}}$ \\
\hline $\mathbf{T 2}$ & 93,97 & 115,82 & 275,07 & 63,14 & 59,36 & 26,49 & $105,64^{\mathrm{a}}$ \\
\hline T3 & 58,73 & 47,24 & 231,67 & 57,22 & 15,46 & 15,13 & $70,91^{\mathrm{b}}$ \\
\hline T4 & 77,15 & 37,55 & 211,72 & 40,97 & 4,88 & 14,14 & $64,40^{\mathrm{b}}$ \\
\hline T5 & 79,69 & 58,04 & 137,85 & 38,26 & 49,77 & 16,83 & $63,41^{\mathrm{b}}$ \\
\hline Média & $103,28^{\mathrm{B}}$ & $64,64^{\mathrm{C}}$ & $208,39^{\mathrm{A}}$ & $43,66^{\mathrm{CD}}$ & $26,79^{\mathrm{D}}$ & $18,56^{\mathrm{D}}$ & \\
\hline \multicolumn{8}{|c|}{ Camada $60-80 \mathrm{~cm}(\mathrm{CV}=54,80 \%)$} \\
\hline T1 & 44,44 & 23,43 & 75,93 & 56,51 & 5,25 & 10,82 & $36,06^{\mathrm{a}}$ \\
\hline T2 & 33,75 & 22,18 & 116,12 & 169,60 & 17,84 & 31,33 & $65,14^{\mathrm{a}}$ \\
\hline T3 & 25,39 & 18,76 & 57,31 & 173,81 & 30,42 & 15,56 & $53,54^{\mathrm{a}}$ \\
\hline T4 & 30,56 & 18,03 & 152,76 & 205,09 & 7,44 & 13,25 & $71,19^{\mathrm{a}}$ \\
\hline T5 & 23,28 & 11,31 & 63,17 & 144,48 & 49,12 & 23,48 & $52,48^{\mathrm{a}}$ \\
\hline Média & $31,48^{\mathrm{C}}$ & $18,74^{\mathrm{C}}$ & $93,06^{\mathrm{B}}$ & $149,90^{\mathrm{A}}$ & $22,02^{\mathrm{C}}$ & $18,89^{\mathrm{C}}$ & \\
\hline
\end{tabular}


Tabela 17. Efeitos da irrigação (água e efluente) e de doses de nitrogênio mineral na concentração de Mg na solução no solo (extrato de saturação)

\begin{tabular}{|c|c|c|c|c|c|c|c|}
\hline \multirow{2}{*}{ Tratamento } & \multicolumn{7}{|c|}{ Época de avaliação } \\
\hline & Abr/03 & Jul/03 & Out/03 & Jan/04 & Abr/04 & Jul/04 & Média \\
\hline & \multicolumn{7}{|c|}{$\mu \mathrm{mol} \mathrm{L}^{-1}$} \\
\hline \multicolumn{8}{|c|}{ Camada $80-100 \mathrm{~cm}(C V=55,03 \%)$} \\
\hline $\mathrm{T} 1$ & 26,59 & 8,54 & 17,51 & 48,05 & 9,58 & 12,69 & $20,49^{\mathrm{b}}$ \\
\hline T2 & 32,60 & 12,99 & 23,07 & 241,12 & 17,47 & 27,84 & $59,18^{\mathrm{a}}$ \\
\hline T3 & 26,36 & 11,54 & 21,19 & 154,34 & 44,36 & 23,99 & $46,96^{\mathrm{a}}$ \\
\hline T4 & 27,30 & 10,63 & 14,57 & 161,98 & 19,22 & 15,16 & $41,48^{\mathrm{a}}$ \\
\hline T5 & 18,83 & 14,27 & 44,94 & 140,53 & 26,87 & 31,91 & $46,22^{\mathrm{a}}$ \\
\hline Média & $26,34^{\mathrm{B}}$ & $11,59^{\mathrm{B}}$ & $24,26^{\mathrm{B}}$ & $149,20^{\mathrm{A}}$ & $23,50^{\mathrm{B}}$ & $22,32^{\mathrm{B}}$ & \\
\hline
\end{tabular}

(1) T1: irrigação com água $+520 \mathrm{~kg} \mathrm{ha}^{-1}$ ano $^{-1}$ de nitrogênio via fertilizante mineral (NFM);

(2) T2: irrigação com efluente secundário de esgoto tratado (ESET), sem NFM;

(3) T3: irrigação com ESET + 171,6 $\mathrm{kg} \mathrm{ha}^{-1} \mathrm{ano}^{-1}$ de NFM;

(4) T4: irrigação com ESET + 343,3 $\mathrm{kg} \mathrm{ha}^{-1} \mathrm{ano}^{-1}$ de NFM;

${ }^{(5)}$ T5: irrigação com ESET + $520 \mathrm{~kg} \mathrm{ha}^{-1}$ ano $^{-1}$ de NFM;

${ }^{(6)}$ Letras iguais maiúsculas ou minúsculas nas linhas e nas colunas, respectivamente, não diferem estatisticamente pelo teste de Tukey $(P<0,05)$.

Não houve correlação entre $\mathrm{Mg}$ solúvel e o acúmulo deste nutriente no capim (Tabela 15). Foram obtidas correlações negativas entre as concentrações de Mg trocável nas camadas 0-10, 10-20 e 40-60 $\mathrm{cm}$ e do PMT nas camadas 0-10 e 40-60 $\mathrm{cm}$ com o acúmulo de $\mathrm{Mg}$ nas plantas (Tabela 15). A falta de correlação entre $\mathrm{Mg}$ solúvel e o acúmulo deste nutriente na parte aérea do capim, bem como as correlações negativas (e/ou inexistência de correlação) da concentração entre Mg trocável e PMT com Mg acumulado (Tabela 15), é um reflexo do baixo poder tampão do solo (Tabela 2). Todas as alterações que os tratamentos provocaram no solo refletiram diretamente, em um curto espaço de tempo, na nutrição e qualidade das plantas. Portanto, a qualidade da água de irrigação, neste caso, do ESET, tem o potencial de influenciar mais rapidamente as concentrações e o acúmulo de nutrientes nas plantas quando comparado aos experimentos de Quin \& Woods (1978), Mohammad \& Mazahreh (2003), Mohammad $\&$ Ayadi (2004), que foram realizados com plantas forrageiras estabelecidas sob solos de alta CTC. 
Tabela 18. Efeitos da irrigação (água e efluente) e de doses de nitrogênio mineral nas concentrações de K trocável no solo

\begin{tabular}{|c|c|c|c|c|c|c|c|}
\hline \multirow{2}{*}{ Tratamento } & \multicolumn{7}{|c|}{ Época de avaliação } \\
\hline & Abr/03 & $\mathbf{J u l} / \mathbf{0 3}$ & Out/03 & Jan/04 & Abr/04 & Jul/04 & Média \\
\hline & \multicolumn{7}{|c|}{$\mathrm{mmol}_{\mathrm{c}} \mathbf{k g}^{-1}$} \\
\hline \multicolumn{8}{|c|}{ Camada 0-10 cm (CV = 11,31\%) } \\
\hline $\mathrm{T1}^{(1)}$ & 2,07 & 2,39 & 2,31 & 2,01 & 1,90 & 1,27 & $1,99^{\mathrm{c}(6)}$ \\
\hline $\mathbf{T 2}^{(2)}$ & 2,02 & 2,65 & 3,99 & 4,86 & 4,67 & 3,18 & $3,56^{\mathrm{a}}$ \\
\hline T3 ${ }^{(3)}$ & 2,54 & 2,74 & 3,13 & 3,41 & 3,30 & 2,44 & $2,93^{\mathrm{b}}$ \\
\hline$T 4^{(4)}$ & 1,66 & 2,17 & 1,97 & 2,07 & 1,95 & 1,40 & $1,87^{\mathrm{c}}$ \\
\hline$T 5^{(5)}$ & 1,78 & 2,38 & 1,21 & 1,13 & 1,53 & 1,31 & $1,56^{\mathrm{c}}$ \\
\hline Média & $2,01^{\mathrm{B}}$ & $2,47^{\mathrm{A}}$ & $2,52^{\mathrm{A}}$ & $2,70^{\mathrm{A}}$ & $2,67^{\mathrm{A}}$ & $1,92^{\mathrm{B}}$ & \\
\hline \multicolumn{8}{|c|}{ Camada $10-20 \mathrm{~cm}(C V=14,34 \%)$} \\
\hline $\mathrm{T} 1$ & 1,23 & 0,82 & 0,97 & 0,94 & 1,14 & 0,86 & $0,99^{b c}$ \\
\hline T2 & 1,21 & 1,00 & 1,51 & 2,29 & 2,94 & 2,48 & $1,90^{\mathrm{a}}$ \\
\hline T3 & 1,24 & 0,88 & 0,86 & 1,24 & 1,58 & 1,23 & $1,17^{\mathrm{b}}$ \\
\hline T4 & 0,97 & 0,71 & 0,84 & 0,72 & 1,28 & 0,71 & $0,87^{\mathrm{cd}}$ \\
\hline T5 & 1,17 & 0,71 & 0,64 & 0,49 & 0,95 & 0,60 & $0,76^{\mathrm{d}}$ \\
\hline Média & $1,16^{\mathrm{B}}$ & $0,82^{\mathrm{C}}$ & $0,97^{\mathrm{C}}$ & $1,14^{\mathrm{B}}$ & $1,58^{\mathrm{A}}$ & $1,18^{\mathrm{B}}$ & \\
\hline \multicolumn{8}{|c|}{ Camada $20-40 \mathrm{~cm}(C V=17,78 \%)$} \\
\hline $\mathrm{T} 1$ & 0,69 & 0,50 & 0,50 & 0,38 & 0,50 & 0,36 & $0,49^{\mathrm{b}}$ \\
\hline T2 & 0,69 & 0,62 & 0,68 & 0,78 & 1,45 & 0,72 & $0,82^{\mathrm{a}}$ \\
\hline T3 & 0,77 & 0,64 & 0,60 & 0,52 & 0,61 & 0,44 & $0,60^{\mathrm{b}}$ \\
\hline T4 & 0,62 & 0,54 & 0,56 & 0,38 & 0,69 & 0,40 & $0,53^{\mathrm{b}}$ \\
\hline T5 & 0,76 & 0,54 & 0,52 & 0,36 & 0,50 & 0,29 & $0,49^{\mathrm{b}}$ \\
\hline Média & $0,71^{\mathrm{A}}$ & $0,57^{\mathrm{B}}$ & $0,57^{\mathrm{B}}$ & $0,48^{\mathrm{BC}}$ & $0,75^{\mathrm{A}}$ & $0,44^{\mathrm{C}}$ & \\
\hline \multicolumn{8}{|c|}{ Camada $40-60 \mathrm{~cm}(\mathrm{CV}=14,34 \%)$} \\
\hline $\mathrm{T} 1$ & 0,53 & 0,54 & 0,52 & 0,38 & 0,38 & 0,25 & $0,43^{\mathrm{b}}$ \\
\hline T2 & 0,52 & 0,52 & 0,53 & 0,47 & 0,64 & 0,61 & $0,55^{\mathrm{a}}$ \\
\hline T3 & 0,57 & 0,52 & 0,51 & 0,42 & 0,57 & 0,32 & $0,48^{\mathrm{ab}}$ \\
\hline T4 & 0,50 & 0,46 & 0,49 & 0,36 & 0,47 & 0,32 & $0,43^{\mathrm{b}}$ \\
\hline T5 & 0,53 & 0,49 & 0,47 & 0,37 & 0,33 & 0,23 & $0,40^{\mathrm{b}}$ \\
\hline Média & $0,53^{\mathrm{A}}$ & $0,50^{\mathrm{A}}$ & $0,50^{\mathrm{A}}$ & $0,40^{\mathrm{B}}$ & $0,48^{\mathrm{A}}$ & $0,35^{\mathrm{B}}$ & \\
\hline \multicolumn{8}{|c|}{ Camada $60-80 \mathrm{~cm}(C V=18,99 \%)$} \\
\hline $\mathrm{T} 1$ & 0,47 & 0,46 & 0,47 & 0,34 & 0,36 & 0,23 & $0,39^{\mathrm{a}}$ \\
\hline T2 & 0,47 & 0,47 & 0,50 & 0,41 & 0,50 & 0,45 & $0,47^{\mathrm{a}}$ \\
\hline T3 & 0,51 & 0,54 & 0,45 & 0,43 & 0,62 & 0,29 & $0,47^{\mathrm{a}}$ \\
\hline T4 & 0,46 & 0,48 & 0,54 & 0,34 & 0,29 & 0,32 & $0,40^{\mathrm{a}}$ \\
\hline T5 & 0,43 & 0,48 & 0,48 & 0,34 & 0,32 & 0,31 & $0,39^{\mathrm{a}}$ \\
\hline Média & $0,47^{\mathrm{A}}$ & $0,49^{\mathrm{A}}$ & $0,49^{\mathrm{A}}$ & $0,37^{\mathrm{BC}}$ & $0,42^{\mathrm{AB}}$ & $0,32^{\mathrm{C}}$ & \\
\hline
\end{tabular}


Tabela 18. Efeitos da irrigação (água e efluente) e de doses de nitrogênio mineral nas concentrações de K trocável no solo

\begin{tabular}{cccccccc}
\hline \multirow{2}{*}{ Tratamento } & \multicolumn{7}{c}{ Época de avaliação } \\
\cline { 2 - 7 } & Abr/03 & Jul/03 & Out/03 & Jan/04 & Abr/04 & Jul/04 & Média \\
\hline \multicolumn{7}{c}{ mmol $_{\mathbf{c}} \mathbf{~ k g}^{-1}$} \\
Camada & $\mathbf{7 0 - 1 0 0 ~} \mathbf{~ c m ~ ( C V ~ = ~ 2 4 , 4 5 \% ) ~}$ \\
T1 & 0,64 & 0,74 & 0,63 & 0,32 & 0,35 & 0,30 & $0,50^{\text {a }}$ \\
T2 & 0,46 & 0,43 & 0,61 & 0,41 & 0,42 & 0,47 & $0,47^{\text {a }}$ \\
T3 & 0,52 & 0,69 & 0,60 & 0,57 & 0,61 & 0,33 & $0,55^{\text {a }}$ \\
T4 & 0,54 & 0,53 & 0,80 & 0,44 & 0,34 & 0,34 & $0,50^{\text {a }}$ \\
T5 & 0,51 & 0,58 & 0,49 & 0,34 & 0,37 & 0,21 & $0,42^{\text {a }}$ \\
Média & $0,53^{\mathrm{A}}$ & $0,59^{\mathrm{A}}$ & $0,63^{\mathrm{A}}$ & $0,42^{\mathrm{B}}$ & $0,42^{\mathrm{B}}$ & $0,33^{\mathrm{B}}$ & \\
\hline
\end{tabular}

${ }^{(1)}$ T1: irrigação com água $+520 \mathrm{~kg} \mathrm{ha}^{-1}$ ano $^{-1}$ de nitrogênio via fertilizante mineral (NFM);

(2) T2: irrigação com efluente secundário de esgoto tratado (ESET), sem NFM;

(3) T3: irrigação com ESET + 171,6 $\mathrm{kg} \mathrm{ha}^{-1} \mathrm{ano}^{-1}$ de NFM;

(4) T4: irrigação com ESET + 343,3 $\mathrm{kg} \mathrm{ha}^{-1} \mathrm{ano}^{-1}$ de NFM;

(5) T5: irrigação com ESET $+520 \mathrm{~kg} \mathrm{ha}^{-1} \mathrm{ano}^{-1}$ de NFM;

${ }^{(6)}$ Letras iguais maiúsculas ou minúsculas nas linhas e nas colunas, respectivamente, não diferem estatisticamente pelo teste de Tukey $(P<0,05)$.

As concentrações trocáveis de $\mathrm{K}$ somente foram influenciadas pelos tratamentos até a profundidade de $60 \mathrm{~cm}$ (Tabela 18). Assim como para Ca (Tabela 13) e Mg (Tabela 16), maiores concentrações de $\mathrm{K}$ trocável ocorreram no tratamento T2 (Tabela 18). As explicações para este fato são as mesmas discutidas para $\mathrm{Ca}$ e $\mathrm{Mg}$, que estão relacionadas ao rendimento de MS (Tabela 5 e Figura 3) e ao acúmulo de nutrientes no capim, no caso, de K (Tabela 12).

Comparando-se os tratamentos T1 e T5, que receberam a mesma dose de NFM, o emprego de ESET na irrigação, apesar de ter ocasionado aporte médio de até $242,5 \mathrm{~kg}$ $\mathrm{ha}^{-1}$ ano $^{-1}$ de K (Tabela 4), não implicou em aumento no acúmulo deste nutriente no capim (Tabela 12), nem mesmo em incremento na concentração trocável (Tabela 18) ou solúvel (Tabela 19) deste nutriente. Em alguns casos, como na camada 10-20 cm, a concentração de $\mathrm{K}$ trocável no tratamento $\mathrm{T} 5$ foi até menor que no tratamento $\mathrm{T} 1$ (Tabela 18). Certamente, o K-efluente não foi drenado para as plantas (Tabela 12). Consumo de luxo de $\mathrm{K}$ pelas plantas irrigadas com EET tem sido observado em outros experimentos (Fonseca, 2001; Adekalu \& Okunade, 2002; Mohammad \& Ayad, 2004), 
Tabela 19. Efeitos da irrigação (água e efluente) e de doses de nitrogênio mineral na concentração de K na solução no solo (extrato de saturação)

\begin{tabular}{|c|c|c|c|c|c|c|c|}
\hline \multirow{2}{*}{ Tratamento } & \multicolumn{7}{|c|}{ Época de avaliação } \\
\hline & Abr/03 & Jul/03 & Out/03 & Jan/04 & Abr/04 & Jul/04 & Média \\
\hline & \multicolumn{7}{|c|}{$\mu \mathrm{mol} \mathrm{L}^{-1}$} \\
\hline \multicolumn{8}{|c|}{ Camada $0-10 \mathrm{~cm}(C V=23,23 \%)$} \\
\hline $\mathrm{T1}^{(1)}$ & 381,91 & 469,25 & 210,35 & 139,82 & 125,06 & 119,39 & $240,96^{\mathrm{c}(6)}$ \\
\hline $\mathbf{T} 2^{(2)}$ & 406,00 & 899,96 & 503,86 & 648,99 & 646,55 & 376,18 & $580,26^{\mathrm{a}}$ \\
\hline T3 ${ }^{(3)}$ & 565,04 & 825,62 & 353,63 & 233,70 & 315,32 & 232,67 & $421,00^{b}$ \\
\hline$T 4^{(4)}$ & 298,90 & 677,86 & 215,33 & 110,23 & 238,01 & 107,98 & $274,72^{c}$ \\
\hline$T 5^{(5)}$ & 408,67 & 596,41 & 123,93 & 94,67 & 187,25 & 100,68 & $251,94^{\mathrm{c}}$ \\
\hline Média & $412,10^{\mathrm{B}}$ & $693,82^{A}$ & $281,42^{\mathrm{C}}$ & $245,48^{\mathrm{CD}}$ & $302,44^{\mathrm{C}}$ & $187,38^{\mathrm{D}}$ & \\
\hline \multicolumn{8}{|c|}{ Camada $10-20 \mathrm{~cm}(C V=20,87 \%)$} \\
\hline T1 & 196,18 & 115,90 & 98,13 & 48,19 & 188,94 & 76,68 & $120,67^{\mathrm{bc}}$ \\
\hline $\mathbf{T 2}$ & 199,47 & 236,80 & 238,88 & 187,22 & 440,44 & 274,44 & $262,88^{\mathrm{a}}$ \\
\hline T3 & 253,81 & 195,74 & 158,29 & 57,11 & 140,53 & 64,35 & $144,97^{b}$ \\
\hline T4 & 160,23 & 172,72 & 84,41 & 37,86 & 133,46 & 52,81 & $106,92^{\mathrm{c}}$ \\
\hline T5 & 224,86 & 273,31 & 69,98 & 35,69 & 79,31 & 66,08 & $124,87^{\mathrm{bc}}$ \\
\hline Média & $206,91^{\mathrm{A}}$ & $198,89^{\mathrm{A}}$ & $129,94^{\mathrm{B}}$ & $73,21^{\mathrm{C}}$ & $196,53^{\mathrm{A}}$ & $106,87^{\mathrm{B}}$ & \\
\hline \multicolumn{8}{|c|}{ Camada $20-40 \mathrm{~cm}(\mathrm{CV}=36,17 \%)$} \\
\hline T1 & 86,76 & 59,34 & 105,80 & 28,70 & 33,77 & 44,09 & $59,74^{\mathrm{b}}$ \\
\hline $\mathbf{T} 2$ & 76,25 & 60,76 & 108,87 & 54,94 & 190,29 & 64,69 & $92,63^{\mathrm{a}}$ \\
\hline T3 & 114,84 & 87,08 & 94,36 & 35,83 & 51,32 & 33,22 & $69,44^{\mathrm{ab}}$ \\
\hline T4 & 88,40 & 73,09 & 80,15 & 41,38 & 65,04 & 28,58 & $62,77^{\mathrm{b}}$ \\
\hline T5 & 126,34 & 64,15 & 89,46 & 27,54 & 50,80 & 44,47 & $67,13^{a b}$ \\
\hline Média & $98,52^{\mathrm{A}}$ & $68,88^{\text {В }}$ & $95,73^{\mathrm{A}}$ & $37,68^{\mathrm{C}}$ & $78,24^{\mathrm{AB}}$ & $43,01^{\mathrm{C}}$ & \\
\hline \multicolumn{8}{|c|}{ Camada $40-60 \mathrm{~cm}(C V=31,90 \%)$} \\
\hline T1 & 54,25 & 47,85 & 82,02 & 21,65 & 35,56 & 49,05 & $48,40^{\mathrm{ab}}$ \\
\hline T2 & 41,12 & 43,85 & 139,43 & 37,46 & 73,89 & 53,97 & $64,95^{\text {a }}$ \\
\hline T3 & 52,94 & 43,17 & 93,32 & 43,98 & 49,39 & 39,86 & $53,78^{a b}$ \\
\hline T4 & 40,21 & 32,33 & 82,67 & 24,79 & 30,97 & 40,91 & $41,98^{\mathrm{a}}$ \\
\hline $\mathbf{T 5}$ & 38,92 & 52,67 & 64,75 & 34,76 & 52,10 & 32,52 & $45,96^{\mathrm{ab}}$ \\
\hline Média & $45,49^{\mathrm{BC}}$ & $43,97^{\mathrm{BC}}$ & $92,44^{\mathrm{A}}$ & $32,53^{\mathrm{C}}$ & $48,38^{\mathrm{B}}$ & $43,26^{\mathrm{BC}}$ & \\
\hline \multicolumn{8}{|c|}{ Camada $60-80 \mathrm{~cm}(\mathrm{CV}=36,16 \%)$} \\
\hline T1 & 27,30 & 32,10 & 48,49 & 31,79 & 25,06 & 23,32 & $31,35^{\mathrm{a}}$ \\
\hline $\mathbf{T 2}$ & 23,96 & 20,77 & 59,71 & 35,47 & 38,79 & 44,07 & $37,13^{\mathrm{a}}$ \\
\hline T3 & 30,71 & 23,44 & 56,48 & 70,24 & 59,37 & 37,23 & $46,24^{\mathrm{a}}$ \\
\hline T4 & 25,55 & 18,39 & 67,37 & 43,40 & 27,24 & 28,06 & $35,00^{\mathrm{a}}$ \\
\hline T5 & 22,97 & 44,04 & 43,98 & 38,09 & 35,79 & 28,72 & $35,60^{\mathrm{a}}$ \\
\hline Média & $26,10^{\mathrm{C}}$ & $27,75^{\mathrm{C}}$ & $55,21^{\mathrm{A}}$ & $43,80^{\mathrm{AB}}$ & $37,25^{\mathrm{BC}}$ & $32,28^{\mathrm{BC}}$ & \\
\hline
\end{tabular}


Tabela 19. Efeitos da irrigação (água e efluente) e de doses de nitrogênio mineral na concentração de K na solução no solo (extrato de saturação)

\begin{tabular}{|c|c|c|c|c|c|c|c|}
\hline \multirow{2}{*}{ Tratamento } & \multicolumn{7}{|c|}{ Época de avaliação } \\
\hline & Abr/03 & Jul/03 & Out/03 & Jan/04 & Abr/04 & Jul/04 & Média \\
\hline & \multicolumn{7}{|c|}{$\mu \mathrm{mol} \mathrm{L}^{-1}$} \\
\hline \multicolumn{8}{|c|}{ Camada $80-100 \mathrm{~cm}(C V=35,31 \%)$} \\
\hline T1 & 53,16 & 41,17 & 38,46 & 24,14 & 24,61 & 23,64 & $34,20^{\mathrm{b}}$ \\
\hline $\mathbf{T 2}$ & 22,75 & 18,57 & 40,70 & 42,32 & 35,25 & 54,00 & $35,60^{a b}$ \\
\hline T3 & 39,64 & 41,36 & 40,19 & 89,35 & 44,45 & 43,95 & $49,82^{\mathrm{a}}$ \\
\hline T4 & 27,07 & 29,31 & 55,43 & 35,87 & 34,85 & 35,03 & $36,26^{a b}$ \\
\hline T5 & 25,88 & 30,35 & 40,77 & 38,67 & 36,43 & 34,15 & $34,38^{\mathrm{b}}$ \\
\hline Média & $33,70^{\mathrm{AB}}$ & $32,15^{\mathrm{B}}$ & $43,11^{\mathrm{AB}}$ & $46,07^{\mathrm{A}}$ & $35,12^{\mathrm{AB}}$ & $38,16^{\mathrm{AB}}$ & \\
\hline
\end{tabular}

(1) T1: irrigação com água $+520 \mathrm{~kg} \mathrm{ha}^{-1}$ ano $^{-1}$ de nitrogênio via fertilizante mineral (NFM);

(2) T2: irrigação com efluente secundário de esgoto tratado (ESET), sem NFM;

(3) T3: irrigação com ESET + 171,6 kg ha ${ }^{-1} \mathrm{ano}^{-1}$ de NFM;

(4) T4: irrigação com ESET + 343,3 $\mathrm{kg} \mathrm{ha}^{-1} \mathrm{ano}^{-1}$ de NFM;

${ }^{(5)}$ T5: irrigação com ESET + $520 \mathrm{~kg} \mathrm{ha}^{-1} \mathrm{ano}^{-1}$ de NFM;

${ }^{(6)}$ Letras iguais maiúsculas ou minúsculas nas linhas e nas colunas, respectivamente, não diferem estatisticamente pelo teste de Tukey $(P<0,05)$.

porém, este fato não ocorreu no presente estudo (Tabela 12). O que pode ter acontecido seria perdas de $\mathrm{K}$ por lixiviação, que possivelmente ocorreram no período entre a fertilização potássica e a amostragem de solo, que foi realizada alternadamente aos 30 dias após o corte do capim e por ocasião do mesmo. Ainda, apesar de a afinidade de troca do K ser superior a do Na (Takachi \& Pavan, 1995), o elevado aporte de Naefluente (Tabela 4) pode ter favorecido o deslocamento do $\mathrm{K}$ no complexo de troca, diminuindo sua concentração, sobretudo, nos tratamentos T4 e T5 (Tabela 18), que receberam maiores lâminas de irrigação com ESET (Figura 2).

A complexidade no entendimento do K-efluente nos locais receptores de EET tem sido comentada em vários trabalhos, mas tem havido grandes divergências nos resultados publicados, devido à dinâmica deste nutriente no sistema solo-planta-efluente (Zekri \& Koo, 1994). Aumentos nas concentrações de K trocável, mediante irrigação com EET têm sido observados por Cromer et al. (1984), Mancino \& Pepper (1992), AlNakshabandi et al. (1997), Falkiner \& Smith (1997), Paliwal et al. (1998), Agunwamba (2001) e Adekalu \& Okunade (2002). Diminuições nas concentrações de K trocável 
devido a irrigação com EET tem sido verificadas nos estudos de Karlen et al. (1976), Stewart et al. (1990) e Mohammad \& Mazahreh (2003), na camada superficial do solo. No presente estudo, o fato de o ESET, para condição semelhante de fertilização mineral (tratamentos T1 e T5) não ter ocasionado alteração nas concentrações de $\mathrm{K}$ trocável, concordou com os resultados de Johns \& McConchie (1994b) e Hayes et al. (1990a).

Ao que parece, a concentração de K presente no ESET não necessita ser levada em consideração nos agrossistemas de pastagens sob solos tropicais de baixa CTC destinados à irrigação com este subproduto, pois o K-efluente, associado com a fertilização mineral potássica, atua como amenizador do efeito deletério do Na-efluente na nutrição vegetal. Karlen et al. (1976) assinalaram que, se o EET for rico em $\mathrm{Na}$ e pobre em K, para que sua disposição no solo seja sustentável, torna-se necessária suplementação potássica mineral para manter adequada a absorção de nutrientes e o rendimento das culturas. Este fato se torna ainda mais importante em solo com baixa CTC (Fonseca, 2001).

Dentre os elementos $\mathrm{Ca}, \mathrm{Mg}$ e $\mathrm{K}$, este último foi o único cujas concentrações médias não diferiram, para as camadas 0-10 e 10-20 cm, através de comparação entre a primeira e a última amostragem de solo (Tabela 18). Para as demais camadas, houve diminuição na concentração média de $\mathrm{K}$ trocável no solo, concordando com as observações de Mancino \& Pepper (1992).

As concentrações de $\mathrm{K}$ trocável (na camada $0-10 \mathrm{~cm}$ ) nos tratamentos T4 e T5 (Tabela 18), que foram os mais produtivos (Tabela 5 e Figura 3), encontram-se próximo do nível crítico $\left(1,4 \mathrm{mmol}_{\mathrm{c}} \mathrm{dm}^{-3}\right)$ sugerido por Coutinho et al. (2004). Isso evidencia que a relação $\mathrm{K}_{2} \mathrm{O} / \mathrm{N}$ de 0,8 empregada em vários estudos de fertilização mineral (Alvim et al., 1998; 1999 e 2000) e utilizada como parâmetro neste experimento, não parece ser sustentável para sistemas de alta produção de capim-Bermuda Tifton 85 .

Os efeitos dos tratamentos nas concentrações trocáveis (Tabela 18) e solúveis (Tabela 19) de $\mathrm{K}$ foram iguais para a camada 0-10 cm. Houve correlação entre os parâmetros K trocável e K solúvel no perfil do solo, com exceção da camada $60-80 \mathrm{~cm}$ (Tabela 15). Ainda, o percentual de K trocável (PKT) também se correlacionou com o K solúvel (Tabela 15). 
Para o $\mathrm{K}$, assim como para $\mathrm{Al}$, $\mathrm{Ca}$ e $\mathrm{Mg}$, foram observados maiores coeficientes de variação (CV) na solução no solo (Tabelas 11, 14, 17 e 19) que no complexo de troca (Tabelas 10, 13, 16 e 18). Porém, dentre os cátions $\mathrm{Al}^{3+}, \mathrm{Ca}^{2+}, \mathrm{Mg}^{2+} \mathrm{e}$ $\mathrm{K}^{+}$, este último foi o que apresentou resultados mais coerentes e mais correlações entre as concentrações trocável e solúvel nas diferentes camadas do solo (Tabela 15). Provavelmente, as concentrações de $\mathrm{K}^{+}$solúvel obtidas pelo método da pasta de saturação (Rhoades, 1996) se encontravam em melhores condições de equilíbrio que as concentrações dos cátions $\mathrm{Al}^{3+}, \mathrm{Ca}^{2+}, \mathrm{Mg}^{2+}$. Em um estudo de tempo de equilíbrio $(0 \mathrm{a}$ 40 dias) entre a fase sólida e a fase líquida, Moss (1963) verificou que o tempo de equilíbrio para $\mathrm{K}$ não foi afetado. Isso evidencia que este nutriente, devido à sua menor afinidade de troca catiônica quando comparado ao $\mathrm{Al}, \mathrm{Ca}$ e $\mathrm{Mg}$, atinge mais rapidamente o equilíbrio dinâmico entre a fase sólida e a fase líquida do solo.

Todavia, os extratos aquosos e de saturação podem induzir a erros significativos de peptizacão, hidrólise, troca catiônica e dissolução (Sonnevend et al., 1990; Rhoades, 1996) por serem obtidos a partir de TFSA. Através do processo de secagem (para a obtenção da TFSA) e re-hidratação do solo (para a obtenção da pasta de saturação), a qualidade da solução no solo é afetada por processos químicos e biológicos (Wolt, 1994) Ocorre aumento de doação de $\mathrm{H}^{+}$de moléculas de água altamente polarizadas que estão associadas às superfícies das argilas secas ao ar e, assim, contribui para o aumento da acidez de superfície e incremento na concentração de ácidos orgânicos solúveis em água, nos solos que foram secos e re-hidratados. Aumento na concentração de ácidos orgânicos solúveis também ocorre pelo fato de a microbiota não resistir ao processo de secagem do solo. Portanto, o efeito combinado de secagem e oxidação da matéria orgânica com o aumento da acidez, pode alterar os "pools" de cátions e ânions específicos, incluindo aqueles oriundos da biomassa microbiana sucumbida, ocasionando mudanças na capacidade de troca iônica e reações de redução (Wolt, 1994). Além do mais, o tempo necessário para que as concentrações totais dos cátions atingem o equilíbrio em amostras de solo re-hidratadas também são diferentes (Moss, 1963). Portanto, todos esses processos descritos anteriormente auxiliam na explicação dos altos CV obtidos para Al (Tabela 11), Ca (Tabela 14), Mg (Tabela 17) e 
K (Tabela 19) solúvel, bem como a falta de correlação, em muitas situações, entre as concentrações trocáveis e solúveis destes elementos (Tabelas 8 e 15).

\subsection{Sodicidade e salinidade}

Os tratamentos empregados somente ocasionaram alterações nas concentrações de Na trocável no solo (Tabela 20), bem como no PST (Tabela 21), nas camadas 0-10, 10-20 e 80-100 cm. Na camada 0-10 cm, o tratamento T3 apresentou maiores concentrações de Na trocável quando comparado aos tratamentos T2 e T5 (Tabela 20). Isso pode ser atribuído ao fato de (i) o tratamento T3 ter tido maior aporte de $\mathrm{Na}$ efluente que o tratamento T2 (Tabela 4); e ainda, (ii) o tratamento T3 ter acumulado menor quantidade de Na no capim que o tratamento T5 (Tabela 22), implicando em maiores quantidades de $\mathrm{Na}$ remanescente no complexo de troca (Tabela 20). Ainda, na camada 0-10 cm, os tratamentos T3 e T4 apresentaram PST mais elevado que o tratamento T2 (Tabela 21). Na camada $10-20 \mathrm{~cm}$, o tratamento T3 apresentou maior concentração de Na trocável (Tabela 20) e, por consequência, PST mais elevado (Tabela 21), quando comparado ao tratamento T2. Na camada $80-100 \mathrm{~cm}$, as concentrações de $\mathrm{Na}$ trocável e o PST não foram diferentes para os tratamentos irrigados com efluente (T2, T3, T4 e T5). Comparando-se os tratamentos T1 e T5, que receberam a mesma dose de NFM, não foram observadas diferenças nas concentrações de Na trocável (Tabela 20), no PST (Tabela 21) e no acúmulo de Na no capim (Tabela 22). Desse modo, o fato de a irrigação ter ocasionado aporte distinto de Na-efluente para cada tratamento (Tabela 4), não implicou em aumentos, nas mesmas proporções, das concentrações de $\mathrm{Na}$ trocável (Tabela 20), no PST (Tabela 21), bem como no acúmulo de Na no capim (Tabela 22).

Os resultados obtidos neste experimento evidenciam a dinâmica complexa do elemento Na no sistema solo-planta-efluente, sobretudo, em solo de baixa CTC (Tabela 2), altamente intemperizado, submetido às intensas chuvas no verão (Figura 2). Além do mais, as diferenças observadas nas quantidades de $\mathrm{Na}$ acumulado no capim (Tabela 22) não são suficientes para explicar os efeitos nas concentrações de Na trocável (Tabela 20), bem como no PST (Tabela 21). O aporte médio anual de Na, via irrigação, variou 
Tabela 20. Efeitos da irrigação (água e efluente) e de doses de nitrogênio mineral nas concentrações de Na trocável no solo

\begin{tabular}{|c|c|c|c|c|c|c|c|}
\hline \multirow{2}{*}{ Tratamento } & \multicolumn{7}{|c|}{ Época de avaliação } \\
\hline & Abr/03 & Jul/03 & Out/03 & Jan/04 & Abr/04 & Jul/04 & Média \\
\hline & \multicolumn{7}{|c|}{$\mathrm{mmol}_{\mathrm{c}} \mathbf{k g}^{-1}$} \\
\hline \multicolumn{8}{|c|}{ Camada 0-10 cm (CV = 11,98\%) } \\
\hline $\mathrm{T1}^{(1)}$ & 1,35 & 2,90 & 5,76 & 3,39 & 3,80 & 4,15 & $3,56^{\mathrm{ab}(6)}$ \\
\hline$T 2^{(2)}$ & 0,84 & 2,59 & 5,68 & 3,58 & 3,95 & 3,92 & $3,43^{\mathrm{b}}$ \\
\hline T3 ${ }^{(3)}$ & 0,83 & 2,88 & 6,36 & 4,28 & 4,48 & 5,81 & $4,11^{\mathrm{a}}$ \\
\hline$T 4^{(4)}$ & 0,81 & 2,62 & 6,97 & 4,10 & 3,98 & 4,36 & $3,81^{\mathrm{ab}}$ \\
\hline $\mathbf{T} 5^{(5)}$ & 0,80 & 2,71 & 6,20 & 3,36 & 3,32 & 4,24 & $3,44^{\mathrm{b}}$ \\
\hline Média & $0,93^{\mathrm{E}}$ & $2,74^{\mathrm{D}}$ & $6,19^{\mathrm{A}}$ & $3,74^{\mathrm{C}}$ & $3,91^{\mathrm{C}}$ & $4,50^{\mathrm{B}}$ & \\
\hline \multicolumn{8}{|c|}{ Camada $10-20 \mathrm{~cm}(C V=12,40 \%)$} \\
\hline $\mathrm{T} 1$ & 0,75 & 1,63 & 3,19 & 3,86 & 3,17 & 3,12 & $2,62^{\mathrm{ab}}$ \\
\hline T2 & 0,53 & 1,45 & 3,52 & 3,76 & 2,99 & 3,28 & $2,59^{\mathrm{b}}$ \\
\hline T3 & 0,62 & 1,67 & 3,55 & 4,13 & 4,42 & 4,30 & $3,12^{\mathrm{a}}$ \\
\hline T4 & 0,57 & 1,51 & 3,65 & 4,28 & 3,11 & 3,73 & $2,81^{\mathrm{ab}}$ \\
\hline T5 & 0,47 & 1,42 & 3,78 & 3,63 & 3,35 & 3,28 & $2,66^{\mathrm{ab}}$ \\
\hline Média & $0,59^{\mathrm{D}}$ & $1,54^{\mathrm{C}}$ & $3,53^{\mathrm{B}}$ & $3,93^{\mathrm{A}}$ & $3,41^{\mathrm{B}}$ & $3,54^{\mathrm{B}}$ & \\
\hline \multicolumn{8}{|c|}{ Camada $20-40 \mathrm{~cm}(C V=13,40 \%)$} \\
\hline $\mathrm{T} 1$ & 0,44 & 0,50 & 1,22 & 3,03 & 4,21 & 3,58 & $2,16^{\mathrm{a}}$ \\
\hline T2 & 0,25 & 0,59 & 2,36 & 3,20 & 2,94 & 3,84 & $2,20^{\mathrm{a}}$ \\
\hline T3 & 0,52 & 0,55 & 2,20 & 2,42 & 3,44 & 4,08 & $2,20^{\mathrm{a}}$ \\
\hline T4 & 0,27 & 0,48 & 1,97 & 2,60 & 3,65 & 4,05 & $2,17^{\mathrm{a}}$ \\
\hline T5 & 0,24 & 0,42 & 2,36 & 3,15 & 3,53 & 3,23 & $2,16^{\mathrm{a}}$ \\
\hline Média & $0,34^{\mathrm{D}}$ & $0,51^{\mathrm{D}}$ & $2,02^{\mathrm{C}}$ & $2,88^{\mathrm{B}}$ & $3,55^{\mathrm{A}}$ & $3,76^{\mathrm{A}}$ & \\
\hline \multicolumn{8}{|c|}{ Camada $40-60 \mathrm{~cm}(C V=21,31 \%)$} \\
\hline $\mathrm{T} 1$ & 0,24 & 0,26 & 0,63 & 2,06 & 2,39 & 2,67 & $1,38^{\mathrm{a}}$ \\
\hline T2 & 0,15 & 0,35 & 0,96 & 1,68 & 2,13 & 3,24 & $1,42^{\mathrm{a}}$ \\
\hline T3 & 0,15 & 0,28 & 0,84 & 1,42 & 2,61 & 3,02 & $1,39^{\mathrm{a}}$ \\
\hline T4 & 0,14 & 0,24 & 0,80 & 1,63 & 2,50 & 3,05 & $1,39^{\mathrm{a}}$ \\
\hline T5 & 0,15 & 0,26 & 1,13 & 1,47 & 2,25 & 2,89 & $1,36^{\mathrm{a}}$ \\
\hline Média & $0,17^{\mathrm{E}}$ & $0,28^{\mathrm{E}}$ & $0,87^{\mathrm{D}}$ & $1,65^{\mathrm{C}}$ & $2,38^{\mathrm{B}}$ & $2,97^{\mathrm{A}}$ & \\
\hline \multicolumn{8}{|c|}{ Camada $60-80 \mathrm{~cm}(C \mathrm{C}=19,84 \%)$} \\
\hline T1 & 0,18 & 0,22 & 0,30 & 0,59 & 1,45 & 2,25 & $0,83^{\mathrm{a}}$ \\
\hline T2 & 0,14 & 0,27 & 0,37 & 0,85 & 1,84 & 2,21 & $0,95^{\mathrm{a}}$ \\
\hline T3 & 0,24 & 0,25 & 0,27 & 0,83 & 1,81 & 2,29 & $0,95^{\mathrm{a}}$ \\
\hline T4 & 0,13 & 0,19 & 0,35 & 0,83 & 1,64 & 2,51 & $0,94^{\mathrm{a}}$ \\
\hline T5 & 0,12 & 0,20 & 0,40 & 0,68 & 1,57 & 2,18 & $0,86^{\mathrm{a}}$ \\
\hline Média & $0,16^{\mathrm{E}}$ & $0,23^{\mathrm{DE}}$ & $0,34^{\mathrm{D}}$ & $0,76^{\mathrm{C}}$ & $1,66^{\mathrm{B}}$ & $2,29^{\mathrm{A}}$ & \\
\hline
\end{tabular}


Tabela 20. Efeitos da irrigação (água e efluente) e de doses de nitrogênio mineral nas concentrações de Na trocável no solo

\begin{tabular}{cccccccc}
\hline \multirow{2}{*}{ Tratamento } & \multicolumn{7}{c}{ Época de avaliação } \\
& Abr/03 & Jul/03 & Out/03 & Jan/04 & Abr/04 & Jul/04 & Média \\
\hline \multicolumn{7}{c}{ mmol $_{\mathbf{c}} \mathbf{~ k g}^{-1}$} \\
Camada 80-100 \\
cm (CV = 19,87\%) \\
T1 & 0,17 & 0,16 & 0,20 & 0,30 & 0,77 & 1,84 & $0,57^{\mathrm{b}}$ \\
T2 & 0,12 & 0,20 & 0,33 & 0,90 & 1,21 & 1,96 & $0,79^{\mathrm{a}}$ \\
T3 & 0,26 & 0,22 & 0,17 & 0,73 & 1,18 & 1,91 & $0,75^{\mathrm{a}}$ \\
T4 & 0,14 & 0,16 & 0,18 & 0,52 & 1,15 & 2,18 & $0,72^{\mathrm{ab}}$ \\
T5 & 0,13 & 0,18 & 0,34 & 0,49 & 1,03 & 1,65 & $0,64^{\mathrm{ab}}$ \\
Média & $0,17^{\mathrm{D}}$ & $0,18^{\mathrm{D}}$ & $0,24^{\mathrm{D}}$ & $0,59^{\mathrm{C}}$ & $1,07^{\mathrm{B}}$ & $1,91^{\mathrm{A}}$ & \\
\hline
\end{tabular}

(1) T1: irrigação com água $+520 \mathrm{~kg} \mathrm{ha}^{-1}$ ano $^{-1}$ de nitrogênio via fertilizante mineral (NFM);

(2) T2: irrigação com efluente secundário de esgoto tratado (ESET), sem NFM;

(3) T3: irrigação com ESET + 171,6 $\mathrm{kg} \mathrm{ha}^{-1} \mathrm{ano}^{-1}$ de NFM;

(4) T4: irrigação com ESET $+343,3 \mathrm{~kg} \mathrm{ha}^{-1} \mathrm{ano}^{-1}$ de NFM;

(5) T5: irrigação com ESET $+520 \mathrm{~kg} \mathrm{ha}^{-1} \mathrm{ano}^{-1}$ de NFM;

(6) Letras iguais maiúsculas ou minúsculas nas linhas e nas colunas, respectivamente, não diferem estatisticamente pelo teste de Tukey $(P<0,05)$.

de 569,5 a 2127,4 $\mathrm{kg} \mathrm{ha}^{-1}$ e o acúmulo semestral deste elemento foi, independentemente do tratamento, inferior a $50 \mathrm{~kg} \mathrm{ha}^{-1}$ (Tabela 22). Desse modo, a maior parte do Naefluente que atingiu o solo foi perdida do sistema via lixiviação, devido à menor preferência de adsorção deste cátion no complexo de troca, quando comparado aos cátions $\mathrm{Al}^{3+}, \mathrm{Ca}^{2+}, \mathrm{Mg}^{2+}$ e $\mathrm{K}^{+}$. Essa menor afinidade do $\mathrm{Na}^{+}$pelos sítios de troca, quando

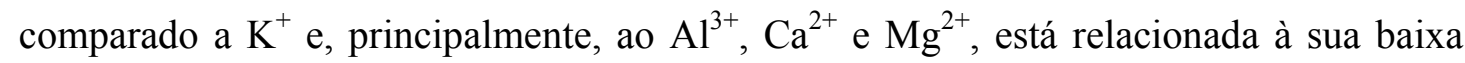
valência e grande raio iônico hidratado (Meurer et al., 2004). Assim que o $\mathrm{Na}^{+}$atinge o solo, a maior parte permanece em solução, devido ao forte grau de hidratação deste elemento (Takachi \& Pavan, 1995), tornando-o mais susceptível à lixiviação.

No decorrer do experimento as concentrações de Na trocável (Tabela 20), bem como do PST (Tabela 21) aumentaram, pois a quantidade de $\mathrm{Na}$ absorvida, acumulada e exportada pelo capim (Tabela 22) foi bem menor que o aporte de Na no sistema (Tabela 4). Hortenstine (1976), Quin \& Woods (1978), Feigin et al. (1991), Mancino \& Pepper (1992), Bond (1998) e Adekalu \& Okunade (2002) também verificaram aumento no 
Tabela 21. Efeitos da irrigação (água e efluente) e de doses de nitrogênio mineral no percentual de sódio trocável (PST) ${ }^{(1)}$ no solo

\begin{tabular}{|c|c|c|c|c|c|c|c|}
\hline \multirow{2}{*}{ Tratamento } & \multicolumn{7}{|c|}{ Época de avaliação } \\
\hline & Abr/03 & Jul/03 & Out/03 & Jan/04 & Abr/04 & Jul/04 & Média \\
\hline & \multicolumn{7}{|c|}{$\%$} \\
\hline \multicolumn{8}{|c|}{ Camada 0-10 cm (CV=12,18\%) } \\
\hline $\mathrm{T1}^{(2)}$ & 3,73 & 7,20 & 17,32 & 10,77 & 12,73 & 13,19 & $10,82^{a b(7}$ \\
\hline $\mathbf{T} 2^{(3)}$ & 2,29 & 5,56 & 14,10 & 10,16 & 11,12 & 9,95 & $8,86^{\mathrm{b}}$ \\
\hline$T 3^{(4)}$ & 2,27 & 7,42 & 18,16 & 12,43 & 13,88 & 14,59 & $11,46^{\mathrm{a}}$ \\
\hline$T 4^{(5)}$ & 2,37 & 6,82 & 20,60 & 13,24 & 12,58 & 14,60 & $11,70^{\mathrm{a}}$ \\
\hline$T 5^{(6)}$ & 2,27 & 6,65 & 18,00 & 10,71 & 9,66 & 12,68 & $10,00^{\mathrm{ab}}$ \\
\hline Média & $2,58^{\mathrm{E}}$ & $6,73^{\mathrm{D}}$ & $17,64^{\mathrm{A}}$ & $11,46^{\mathrm{C}}$ & $12,00^{\mathrm{BC}}$ & $13,00^{\mathrm{B}}$ & \\
\hline \multicolumn{8}{|c|}{ Camada $10-20 \mathrm{~cm}(C V=14,42 \%)$} \\
\hline T1 & 2,19 & 4,51 & 9,76 & 12,10 & 9,91 & 10,28 & $8,12^{a b}$ \\
\hline T2 & 1,43 & 3,34 & 8,91 & 10,54 & 9,82 & 9,78 & $7,31^{\mathrm{b}}$ \\
\hline T3 & 1,76 & 4,30 & 10,79 & 13,45 & 14,13 & 12,31 & $9,46^{\mathrm{a}}$ \\
\hline T4 & 1,67 & 4,14 & 11,81 & 13,97 & 10,47 & 12,69 & $9,12^{a b}$ \\
\hline T5 & 1,31 & 3,79 & 10,15 & 11,06 & 10,00 & 10,32 & $7,77^{\mathrm{ab}}$ \\
\hline Média & $1,67^{\mathrm{D}}$ & $4,01^{\mathrm{C}}$ & $10,28^{\mathrm{B}}$ & $12,23^{\mathrm{A}}$ & $10,87^{\mathrm{B}}$ & $11,08^{\mathrm{B}}$ & \\
\hline \multicolumn{8}{|c|}{ Camada $20-40 \mathrm{~cm}(\mathrm{CV}=14,26 \%)$} \\
\hline T1 & 1,21 & 1,28 & 4,46 & 9,48 & 13,98 & 10,35 & $6,79^{\mathrm{a}}$ \\
\hline T2 & 0,74 & 1,48 & 6,64 & 10,22 & 10,21 & 11,71 & $6,83^{\mathrm{a}}$ \\
\hline T3 & 1,48 & 1,49 & 7,31 & 7,92 & 11,44 & 11,43 & $6,84^{\mathrm{a}}$ \\
\hline T4 & 0,81 & 1,31 & 6,22 & 8,12 & 11,40 & 13,64 & $6,92^{\mathrm{a}}$ \\
\hline T5 & 0,71 & 1,14 & 6,66 & 10,02 & 10,67 & 10,02 & $6,54^{\mathrm{a}}$ \\
\hline Média & $0,99^{\mathrm{D}}$ & $1,34^{\mathrm{D}}$ & $6,26^{\mathrm{C}}$ & $9,15^{\mathrm{B}}$ & $11,54^{\mathrm{A}}$ & $11,43^{\mathrm{A}}$ & \\
\hline \multicolumn{8}{|c|}{ Camada $40-60 \mathrm{~cm}(C V=20,36 \%)$} \\
\hline $\mathrm{T1}$ & 0,68 & 0,76 & 2,22 & 6,89 & 8,22 & 8,61 & $4,56^{\mathrm{a}}$ \\
\hline T2 & 0,47 & 1,03 & 2,95 & 5,91 & 7,23 & 10,08 & $4,61^{\mathrm{a}}$ \\
\hline T3 & 0,45 & 0,84 & 3,02 & 4,71 & 9,01 & 9,17 & $4,53^{\mathrm{a}}$ \\
\hline T4 & 0,45 & 0,66 & 2,71 & 5,51 & 9,00 & 9,43 & $4,63^{\mathrm{a}}$ \\
\hline T5 & 0,44 & 0,72 & 3,71 & 4,92 & 7,71 & 9,76 & $4,54^{\mathrm{a}}$ \\
\hline Média & $0,50^{\mathrm{E}}$ & $0,80^{\mathrm{E}}$ & $2,92^{\mathrm{D}}$ & $5,59^{\mathrm{C}}$ & $8,23^{\text {В }}$ & $9,41^{\mathrm{A}}$ & \\
\hline \multicolumn{8}{|c|}{ Camada $60-80 \mathrm{~cm}(C V=21,38 \%)$} \\
\hline $\mathrm{T1}$ & 0,58 & 0,70 & 1,29 & 2,19 & 5,53 & 8,09 & $3,06^{\mathrm{a}}$ \\
\hline $\mathbf{T 2}$ & 0,43 & 0,96 & 1,31 & 3,48 & 6,70 & 6,89 & $3,30^{\mathrm{a}}$ \\
\hline T3 & 0,83 & 0,81 & 1,08 & 3,14 & 6,87 & 8,24 & $3,50^{\mathrm{a}}$ \\
\hline T4 & 0,45 & 0,60 & 1,38 & 2,96 & 6,84 & 9,14 & $3,56^{\mathrm{a}}$ \\
\hline T5 & 0,43 & 0,58 & 1,56 & 2,53 & 6,47 & 8,07 & $3,27^{\mathrm{a}}$ \\
\hline Média & $0,54^{\mathrm{E}}$ & $0,73^{\mathrm{DE}}$ & $1,32^{\mathrm{D}}$ & $2,86^{\mathrm{C}}$ & $6,48^{\mathrm{B}}$ & $8,09^{\mathrm{A}}$ & \\
\hline
\end{tabular}


Tabela 21. Efeitos da irrigação (água e efluente) e de doses de nitrogênio mineral no percentual de sódio trocável (PST) ${ }^{(1)}$ no solo

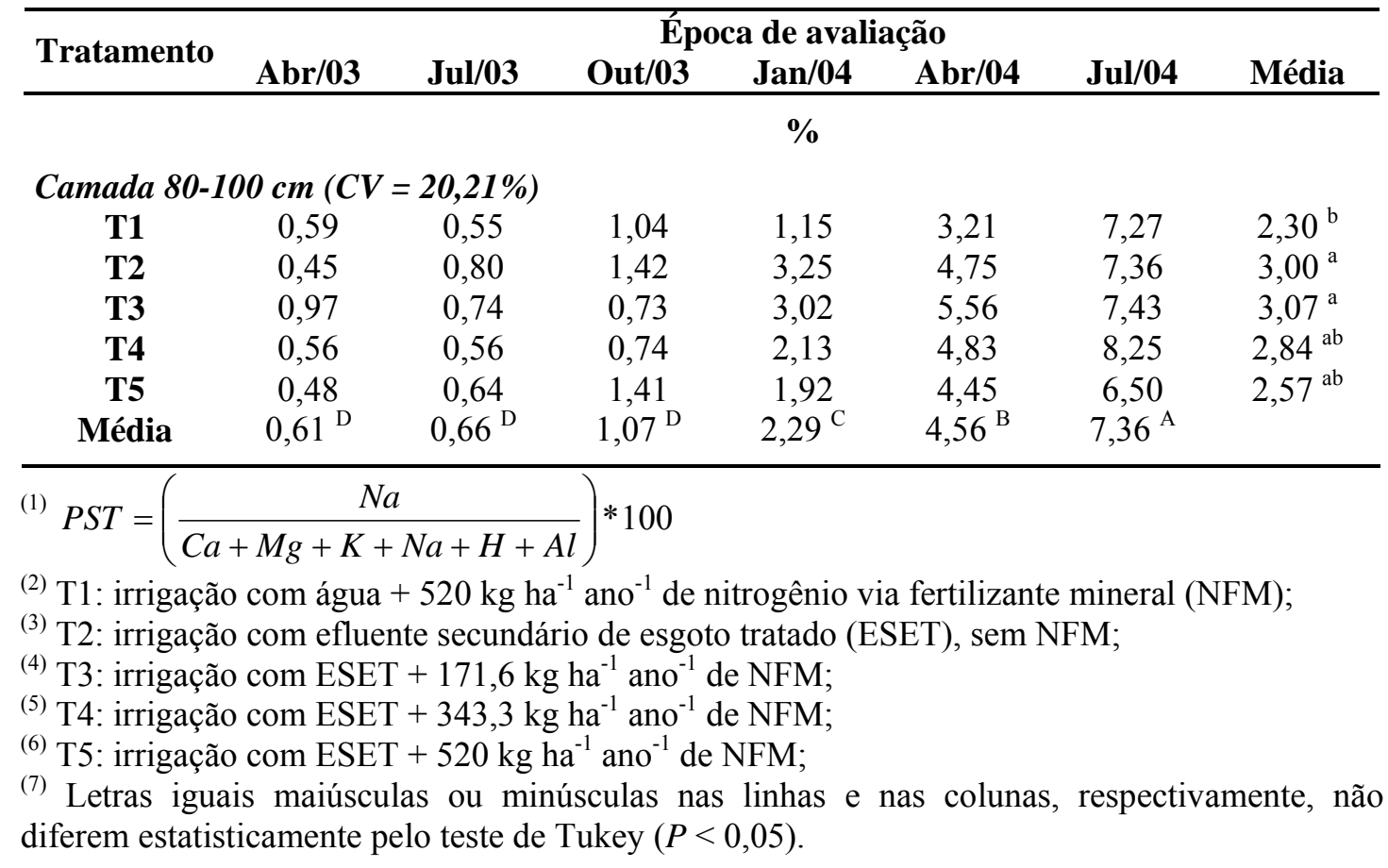

PST, na concentração de $\mathrm{Na}$ trocável e no conteúdo deste elemento nas forrageiras submetidas à irrigação com água rica em $\mathrm{Na}$, particularmente EET.

As chuvas decorrentes do verão e início de outono (Figura 2) promoveram, em algumas camadas, diminuição na concentração de Na trocável (Tabela 20), bem como no PST (Tabela 21). Na camada $0-10 \mathrm{~cm}$ os parâmetros concentração de $\mathrm{Na}$ trocável (Tabela 20) e PST (Tabela 21) aumentaram de abril/2003 até outubro/2003, período coincidente com baixa precipitação pluvial e alta demanda por irrigação (Figura 2); estes parâmetros diminuiram nos meses de jan/2004 e abril/2004, período coincidente com maior precipitação pluvial (Figura 2). A diminuição nas concentrações de $\mathrm{Na}$ trocável (Tabela 20) e no PST (Tabela 21) na camada 0-10 cm e, ao mesmo tempo, aumento destes parâmetros nas camadas subsuperficiais, no mês de janeiro/2004, mostra a lixiviação de $\mathrm{Na}$ promovida pelas chuvas intensas nesta época. A lixiviação de $\mathrm{Na}$ continuou após janeiro/2004, uma vez que no mês de julho/2004 foram observados, nas camadas subsuperficiais $(20-40,40-60,60-80$ e $80-100 \mathrm{~cm})$ os maiores valores de $\mathrm{Na}$ 
Tabela 22. Efeitos da irrigação (água e efluente) e de doses de nitrogênio mineral no acúmulo semestral (somatório de três cortes bimestrais) de $\mathrm{Na}, \mathrm{P}, \mathrm{S}$ e $\mathrm{N}$ na parte aérea (folhas + colmos + bainhas) do capim-Bermuda Tifton 85

\begin{tabular}{|c|c|c|c|c|}
\hline Tratamento & $1^{\circ}$ semestre & $\begin{array}{c}\text { Época } \\
2^{\mathbf{o}} \text { semestre } \\
\end{array}$ & $3^{\circ}$ semestre & Média \\
\hline & \multicolumn{4}{|c|}{ kg ha $^{-1}$} \\
\hline \multicolumn{5}{|c|}{ Acúmulo de Na (CV = 12,41\%) } \\
\hline$T 1^{(1)}$ & 13,45 & 33,16 & 32,00 & $26,20^{a b(6)}$ \\
\hline $\mathbf{T} 2^{(2)}$ & 12,19 & 13,03 & 25,30 & $16,84^{\mathrm{c}}$ \\
\hline T3 ${ }^{(3)}$ & 13,63 & 23,29 & 34,15 & $23,69^{\mathrm{bc}}$ \\
\hline T4 ${ }^{(4)}$ & 16,00 & 33,81 & 37,61 & $29,14^{\mathrm{ab}}$ \\
\hline $\mathbf{T} 5^{(5)}$ & 17,54 & 40,29 & 41,21 & $33,01^{\text {a }}$ \\
\hline Média & $14,57^{\mathrm{C}}$ & $28,72^{\text {B }}$ & $34,05^{\mathrm{A}}$ & \\
\hline \multicolumn{5}{|c|}{ Acúmulo de P (CV = 14,42\%) } \\
\hline $\mathrm{T} 1$ & 20,31 & 25,43 & 24,59 & $23,44^{\mathrm{c}}$ \\
\hline $\mathbf{T} 2$ & 16,27 & 21,65 & 27,38 & $21,77^{\mathrm{c}}$ \\
\hline T3 & 18,31 & 36,33 & 31,72 & $28,79^{\mathrm{b}}$ \\
\hline T4 & 19,17 & 36,73 & 30,53 & $28,81^{\mathrm{b}}$ \\
\hline T5 & 23,17 & 46,86 & 34,33 & $34,79^{\mathrm{a}}$ \\
\hline Média & $19,44^{\mathrm{C}}$ & $33,40^{\mathrm{A}}$ & $29,71^{\mathrm{B}}$ & \\
\hline \multicolumn{5}{|c|}{ Acúmulo de $S(C V=9,29 \%)$} \\
\hline T1 & 27,06 & 37,18 & 21,00 & $28,41^{\mathrm{b}}$ \\
\hline $\mathbf{T 2}$ & 20,12 & 21,16 & 17,65 & $19,64^{\mathrm{c}}$ \\
\hline T3 & 22,40 & 34,85 & 21,60 & $26,28^{\mathrm{b}}$ \\
\hline T4 & 24,12 & 41,21 & 20,88 & $28,74^{\mathrm{b}}$ \\
\hline T5 & 26,74 & 49,42 & 24,11 & $33,42^{\mathrm{a}}$ \\
\hline Média & $24,09^{\mathrm{B}}$ & $36,76^{\mathrm{A}}$ & $21,05^{\mathrm{C}}$ & \\
\hline \multicolumn{5}{|c|}{ Acúmulo de $N(C V=10,64 \%)$} \\
\hline T1 & 196,84 & 237,28 & 269,43 & $234,52^{b c}$ \\
\hline $\mathrm{T} 2$ & 149,10 & 125,91 & 191,81 & $155,61^{\mathrm{d}}$ \\
\hline T3 & 161,22 & 217,69 & 262,65 & $213,85^{\mathrm{c}}$ \\
\hline T4 & 172,77 & 269,24 & 298,47 & $246,82^{b}$ \\
\hline T5 & 204,40 & 332,39 & 320,74 & $285,84^{\mathrm{a}}$ \\
\hline Média & $176,87^{\mathrm{C}}$ & $236,50^{\mathrm{B}}$ & $268,62^{A}$ & \\
\hline
\end{tabular}

(1) T1: irrigação com água $+520 \mathrm{~kg} \mathrm{ha}^{-1}$ ano ${ }^{-1}$ de nitrogênio via fertilizante mineral (NFM);

(2) T2: irrigação com efluente secundário de esgoto tratado (ESET), sem NFM;

(3) T3: irrigação com ESET + 171,6 $\mathrm{kg} \mathrm{ha}^{-1}$ ano $^{-1}$ de NFM;

(4) T4: irrigação com ESET + 343,3 $\mathrm{kg} \mathrm{ha}^{-1} \mathrm{ano}^{-1}$ de NFM;

${ }^{(5)}$ T5: irrigação com ESET $+520 \mathrm{~kg} \mathrm{ha}^{-1}$ ano $^{-1}$ de NFM;

(6) Letras iguais maiúsculas ou minúsculas nas linhas e nas colunas, respectivamente, não diferem estatisticamente pelo teste de Tukey $(P<0,05)$. 
trocável (Tabela 20) e de PST (Tabela 21) no decorrer do experimento. Por ocasião do mês de julho/2004 a baixa precipitação pluvial levou ao aumento na demanda por irrigação (Figura 2), implicando, consequentemente em aporte de $\mathrm{Na}$; como resultado, foram observados incrementos nas concentrações de Na trocável (Tabela 20), bem como no PST (Tabela 21), sobretudo, nas camadas superficiais $(0-10$ e 10-20 cm). As variações sazonais nas concentrações de Na trocável (Tabela 20), bem como no PST (Tabela 21) concordaram com as observações de Mancino \& Pepper (1992). Esses autores verificaram, em um experimento de capim-Bermuda submetido à irrigação com EET por 16 meses, que as concentrações de Na trocável aumentaram com o tempo, mas, diminuíram por ocasião de períodos com chuvas intensas.

A precipitação pluvial intensa em determinados períodos do ano tem papel fundamental na sustentabilidade do sistema solo-planta receptor de EET rico em $\mathrm{Na}$, por promover lixiviação deste elemento do meio, conforme assinalado por Mancino \& Pepper (1992) e Speir et al. (1999). Porém, as observações realizadas no presente estudo não fornecem informações para prever se o sistema solo-planta suportará, em longo prazo, o elevado aporte de $\mathrm{Na}$ via irrigação. Apenas 24 meses de experimentação não são suficientes para prever se as chuvas de verão são capazes de lixiviar aproximadamente $2000 \mathrm{~kg} \mathrm{ha}^{-1}$ de $\mathrm{Na}$. Portanto, a resposta mais adequada para esses questionamentos demanda de estudos de campo em médio e/ou em longo prazo.

Com relação às plantas, maior acúmulo de $\mathrm{Na}$ no capim foi observado no tratamento T5 (Tabela 22), que recebeu doses mais elevadas de ESET (Tabela 4). Não houve diferenças entre o acúmulo de $\mathrm{Na}$ dos tratamentos T1, T4 e T5, porém, o tratamento T5 acumulou mais Na quando comparado aos tratamentos T2 e T3 (Tabela 22). Incremento no conteúdo de $\mathrm{Na}$ em plantas forrageiras tem sido desejável, por proporcionar aumento na qualidade deste produto à alimentação animal (Marschner, 1995).

O capim-Bermuda Tifton 85, no presente estudo, apresentou alto rendimento de MS (Tabela 4 e Figura 3), mesmo em condição de elevado PST (Tabela 21). A explicação para isso pode estar relacionada aos fatores discutidos no item 4.3, bem como ao fato de (i) o aporte de K no sistema solo-planta ter atendido ao mínimo requerido para 
propósito metabólico $\left(5,0 \mathrm{~g} \mathrm{~kg}^{-1}\right.$ de $\mathrm{K}$ na MS - valor de referência para o capim-deRhodes), segundo Smith (1974); (ii) as plantas pertencentes ao gênero Cynodon serem incluídas no grupo das natrofílicas (Marschner, 1995) e consideradas como tolerantes à sodicidade (Fageria et al., 1997); (iii) outros cultivares de capim-Bermuda, quando submetidos à irrigação com EET, terem apresentado altos rendimentos de MS em condições de PST de 6,0\% (Mancino \& Pepper, 1992) e 7,6\% (Hayes et al., 1990a); (iii) apesar de serem escassos estudos com o cultivar Tifton 85 submetido à condição de sodicidade ou salinidade-sódica, Grieve et al. (2004) verificaram que o capim-Bermuda submetido à irrigação com águas residuárias salino-sódicas com CE de 15 e $25 \mathrm{dS} \mathrm{m}^{-1} \mathrm{e}$ RAS de 24,6 e 39,1 (mmol L-1 $)^{0,5}$ apresentou forte preferência do $\mathrm{K}^{+}$sobre o $\mathrm{Na}^{+}$, mantendo adequada a concentração de $\mathrm{K}^{+}$na planta e obtendo alto rendimento de MS.

O fato de o sistema solo-planta, no presente estudo, ter se mantido eficiente para receber irrigação com ESET foi devido, principalmente, à associação das características do capim-Bermuda Tifton 85 com práticas agronômicas (fertilização e irrigação) adequadas. As propriedades intrínsicas do solo apresentaram menor contribuição para a sustentabilidade do sistema de reuso de água que as características inerentes do capim. Desse modo, a tolerância das plantas à salinidade e à sodicidade tornaram-se tão importantes quanto os demais critérios (alta absorção de $\mathrm{N}$, elevado consumo d'água, possibilidade de processamento, potencial de mercado e viabilidade econômica) estabelecidos por Segarra et al. (1996), com relação à escolha da cultura adequada para receber irrigação com EET.

As concentrações dos nutrientes $\mathrm{Ca}, \mathrm{Mg}$ e $\mathrm{K}$ no ESET, ao que parece, não devem ser consideradas quando se trata da aplicação deste subproduto (rico em $\mathrm{Na}$ ) nas pastagens sob solo de baixa CTC, como no presente estudo (Tabela 2). Esta afirmação se baseia no princípio de que os nutrientes $\mathrm{Ca}, \mathrm{Mg}$ e $\mathrm{K}$, presentes no ESET, irão atuar no sentido contrário ao efeito deletério do Na no sistema solo-planta (Al-Jaloud et al, 1995). Ainda, a afirmação explícita em diversos trabalhos (Day et al., 1981; Bielorai et al., 1984; Zekri \& Koo, 1994; Reboll et al., 2000; Agunwamba (2001); Singh \& Bhati, 2003) de que "o EET apresenta capacidade de nutrir adequadamente as plantas, principalmente em $\mathrm{Ca}, \mathrm{Mg}$ e K”, somente é válida em pelo menos uma das seguintes 
situações (i) sistemas de produção com baixo emprego de tecnologia; (ii) plantas cultivadas sob solos de alta fertilidade natural; (iii) sistemas de produção cujas culturas apresentam, se comparadas às plantas forrageiras e produtoras de grãos, baixa demanda por nutrientes e elevada eficiência de uso dos mesmos, como no caso de pomares em formação e plantações florestais.

Quanto ao $\mathrm{Na}$ solúvel, os tratamentos ocasionaram alterações nas concentrações deste elemento na solução no solo, exceto camada 10-20 cm (Tabela 23). Na camada 0-10 cm, o tratamento T3, apesar de não ter diferido do tratamento $\mathrm{T} 2$, apresentou maior concentração de $\mathrm{Na}$ solúvel; já os tratamentos $\mathrm{T} 4$ e T5, que não diferiram do tratamento $\mathrm{T} 1$, apresentaram menores concentrações deste elemento (Tabela 23). O fato dos tratamentos T4 e T5 terem apresentados menores concentrações de Na solúvel na camada 0-10 pode ser devido ao maior acúmulo deste elemento no capim (Tabela 22), pois houve correlação negativa entre a concentração de Na solúvel, nesta camada, com o acúmulo deste elemento no capim (Tabela 24). Na camada 20-40 $\mathrm{cm}$, o tratamento T3, que não diferiu dos tratamentos $\mathrm{T} 2$ e $\mathrm{T} 5$, apresentou maior concentração de Na solúvel, quando comparado aos tratamentos T1 e T4 (Tabela 23). Não foram diferentes as concentrações de $\mathrm{Na}$ solúvel nos tratamentos irrigados com ESET (T2, T3, T4 e T5) nas camadas 40-60 e 60-80 cm (Tabela 24). Nas camadas subsuperficiais (20-40, 40-60, 60-80 e 80-100 cm), normalmente foram observadas menores concentrações de Na solúvel no tratamento T1 (Tabela 24). Na camada 40-60 $\mathrm{cm}$, os tratamentos T2 e T5 apresentaram concentrações de Na solúvel tão alta quanto o tratamento T3; o mesmo fato se repetiu para o tratamento T5 na camada 60-80. No entanto, as concentrações de Na solúvel observadas no tratamento T1 não diferiram das encontradas nos tratamentos T2 (camadas 20-40 e 60-80 cm), T4 (camadas 20-40, 4060, 60-80 e 80-100 cm) e T5 (camada 20-40 cm) (Tabela 23). Na camada 80-100 cm, o tratamento T3 apresentou maior concentração de Na solúvel quando comparado ao tratamento T4. As concentrações de Na solúvel no tratamento T3 foram superiores às do tratamento T1 no perfil do solo, com exceção da camada 10-20 cm (Tabela 23). Essas diferentes quanto às concentrações de $\mathrm{Na}$ solúvel podem estar associadas ao aporte distinto de Na-efluente para cada tratamento (Tabela 4), à interação deste elemento no 
Tabela 23. Efeitos da irrigação (água e efluente) e de doses de nitrogênio mineral nas concentrações de Na na solução no solo (extrato de saturação)

\begin{tabular}{|c|c|c|c|c|c|c|c|}
\hline \multirow{2}{*}{ Tratamento } & \multicolumn{7}{|c|}{ Época de avaliação } \\
\hline & Abr/03 & Jul/03 & Out/03 & Jan/04 & Abr/04 & Jul/04 & Média \\
\hline & \multicolumn{7}{|c|}{$\mathrm{mmol} \mathrm{L}^{-1}$} \\
\hline \multicolumn{8}{|c|}{ Camada 0-10 cm (CV = 12,95\%) } \\
\hline $\mathrm{T1}^{(1)}$ & 2,69 & 4,78 & 3,39 & 2,18 & 1,40 & 2,70 & $2,86^{\text {bc (6) }}$ \\
\hline $\mathbf{T} 2^{(2)}$ & 2,32 & 4,22 & 4,20 & 2,25 & 1,44 & 3,49 & $2,99^{\mathrm{ab}}$ \\
\hline $\mathrm{T}^{(3)}$ & 2,41 & 5,07 & 4,24 & 2,29 & 1,69 & 3,68 & $3,23^{\text {a }}$ \\
\hline$T 4^{(4)}$ & 2,18 & 3,97 & 3,60 & 2,46 & 1,12 & 2,56 & $2,65^{\mathrm{c}}$ \\
\hline $\mathbf{T} 5^{(5)}$ & 2,35 & 4,20 & 3,26 & 2,48 & 1,44 & 2,29 & $2,67^{\mathrm{c}}$ \\
\hline Média & $2,39^{\mathrm{D}}$ & $4,45^{\mathrm{A}}$ & $3,74^{\mathrm{B}}$ & $2,33^{\mathrm{D}}$ & $1,42^{\mathrm{E}}$ & $2,94^{\mathrm{C}}$ & \\
\hline \multicolumn{8}{|c|}{ Camada $10-20 \mathrm{~cm}(C V=19,23 \%)$} \\
\hline $\mathrm{T1}$ & 2,07 & 2,43 & 2,74 & 1,62 & 1,97 & 1,60 & $2,07^{\mathrm{a}}$ \\
\hline $\mathbf{T 2}$ & 1,87 & 1,81 & 4,33 & 1,94 & 1,20 & 2,03 & $2,20^{\mathrm{a}}$ \\
\hline T3 & 2,34 & 2,93 & 3,92 & 1,91 & 1,13 & 1,94 & $2,36^{\mathrm{a}}$ \\
\hline T4 & 1,87 & 2,45 & 3,15 & 1,56 & 1,30 & 1,57 & $1,98^{\mathrm{a}}$ \\
\hline T5 & 1,86 & 2,47 & 3,67 & 1,56 & 1,51 & 1,90 & $2,16^{\mathrm{a}}$ \\
\hline Média & $2,00^{\mathrm{C}}$ & $2,42^{\mathrm{B}}$ & $3,56^{\mathrm{A}}$ & $1,72^{\mathrm{CD}}$ & $1,42^{\mathrm{D}}$ & $1,81^{\mathrm{C}}$ & \\
\hline \multicolumn{8}{|c|}{ Camada $20-40 \mathrm{~cm}(C V=25,59 \%)$} \\
\hline T1 & 1,70 & 0,61 & 1,85 & 1,40 & 1,09 & 1,13 & $1,30^{\mathrm{b}}$ \\
\hline T2 & 0,31 & 0,41 & 3,35 & 2,02 & 1,02 & 1,71 & $1,47^{\mathrm{ab}}$ \\
\hline T3 & 2,05 & 0,54 & 3,26 & 1,76 & 0,93 & 2,06 & $1,77^{\mathrm{a}}$ \\
\hline T4 & 0,34 & 0,44 & 2,56 & 1,69 & 1,25 & 1,75 & $1,34^{\mathrm{b}}$ \\
\hline T5 & 0,33 & 0,41 & 3,59 & 1,47 & 1,40 & 1,71 & $1,49^{a b}$ \\
\hline Média & $0,95^{\mathrm{C}}$ & $0,49^{\mathrm{D}}$ & $2,92^{\mathrm{A}}$ & $1,67^{\mathrm{B}}$ & $1,14^{\mathrm{C}}$ & $1,67^{\mathrm{B}}$ & \\
\hline \multicolumn{8}{|c|}{ Camada $40-60 \mathrm{~cm}(\mathrm{CV}=23,79 \%)$} \\
\hline $\mathrm{T1}$ & 0,31 & 0,30 & 0,76 & 1,09 & 0,45 & 1,22 & $0,69^{\mathrm{b}}$ \\
\hline T2 & 0,16 & 0,26 & 1,47 & 1,61 & 0,83 & 1,99 & $1,05^{\mathrm{a}}$ \\
\hline T3 & 0,29 & 0,20 & 1,28 & 1,64 & 0,72 & 1,77 & $0,98^{\mathrm{a}}$ \\
\hline T4 & 0,21 & 0,21 & 1,09 & 1,45 & 0,58 & 1,82 & $0,89^{a b}$ \\
\hline T5 & 0,17 & 0,20 & 1,79 & 1,48 & 0,93 & 1,84 & $1,07^{\mathrm{a}}$ \\
\hline Média & $0,23^{\mathrm{D}}$ & $0,24^{\mathrm{D}}$ & $1,28^{\mathrm{B}}$ & $1,45^{\mathrm{B}}$ & $0,70^{\mathrm{C}}$ & $1,73^{\mathrm{A}}$ & \\
\hline \multicolumn{8}{|c|}{ Camada $60-80 \mathrm{~cm}(\mathrm{CV}=58,82 \%)$} \\
\hline T1 & 0,20 & 0,19 & 0,34 & 0,79 & 0,30 & 1,07 & $0,48^{\mathrm{b}}$ \\
\hline T2 & 0,16 & 0,21 & 0,40 & 1,20 & 0,50 & 1,73 & $0,70^{\mathrm{ab}}$ \\
\hline T3 & 0,27 & 0,19 & 0,46 & 1,61 & 0,67 & 1,77 & $0,83^{\mathrm{a}}$ \\
\hline T4 & 0,13 & 0,16 & 0,52 & 1,43 & 0,35 & 1,84 & $0,74^{\mathrm{ab}}$ \\
\hline T5 & 0,14 & 0,12 & 0,34 & 1,27 & 1,49 & 1,68 & $0,84^{\mathrm{a}}$ \\
\hline Média & $0,18^{\mathrm{C}}$ & $0,18^{\mathrm{C}}$ & $0,41^{\mathrm{BC}}$ & $1,26^{\mathrm{A}}$ & $0,66^{\mathrm{B}}$ & $1,62^{\mathrm{A}}$ & \\
\hline
\end{tabular}


Tabela 23. Efeitos da irrigação (água e efluente) e de doses de nitrogênio mineral nas concentrações de Na na solução no solo (extrato de saturação)

\begin{tabular}{|c|c|c|c|c|c|c|c|}
\hline \multirow{2}{*}{ Tratamento } & \multicolumn{7}{|c|}{ Época de avaliação } \\
\hline & Abr/03 & Jul/03 & Out/03 & Jan/04 & Abr/04 & Jul/04 & Média \\
\hline & \multicolumn{7}{|c|}{$\mathrm{mmol} \mathrm{L}^{-1}$} \\
\hline \multicolumn{8}{|c|}{ Camada $80-100 \mathrm{~cm}(C V=29,61 \%)$} \\
\hline T1 & 0,25 & 0,08 & 0,26 & 0,47 & 0,33 & 1,10 & $0,42^{\mathrm{c}}$ \\
\hline T2 & 0,13 & 0,17 & 0,27 & 1,24 & 0,30 & 1,66 & $0,63^{a b}$ \\
\hline T3 & 0,28 & 0,14 & 0,27 & 1,38 & 0,58 & 1,68 & $0,72^{\mathrm{a}}$ \\
\hline T4 & 0,17 & 0,13 & 0,26 & 0,98 & 0,39 & 1,31 & $0,54^{\mathrm{bc}}$ \\
\hline T5 & 0,14 & 0,21 & 0,38 & 0,98 & 0,32 & 1,68 & $0,62^{a b}$ \\
\hline Média & $0,19^{\mathrm{D}}$ & $0,15^{\mathrm{D}}$ & $0,29^{\mathrm{CD}}$ & $1,01^{\mathrm{B}}$ & $0,38^{\mathrm{C}}$ & $1,49^{\mathrm{A}}$ & \\
\hline
\end{tabular}

(1) T1: irrigação com água $+520 \mathrm{~kg} \mathrm{ha}^{-1}$ ano $^{-1}$ de nitrogênio via fertilizante mineral (NFM);

(2) T2: irrigação com efluente secundário de esgoto tratado (ESET), sem NFM;

(3) T3: irrigação com ESET + 171,6 $\mathrm{kg} \mathrm{ha}^{-1} \mathrm{ano}^{-1}$ de NFM;

(4) T4: irrigação com ESET + 343,3 $\mathrm{kg} \mathrm{ha}^{-1} \mathrm{ano}^{-1}$ de NFM;

(5) T5: irrigação com ESET $+520 \mathrm{~kg} \mathrm{ha}^{-1} \mathrm{ano}^{-1}$ de NFM;

(6) Letras iguais maiúsculas ou minúsculas nas linhas e nas colunas, respectivamente, não diferem estatisticamente pelo teste de Tukey $(P<0,05)$.

complexo de troca com outros cátions trocáveis $\left(\mathrm{Al}^{3+}, \mathrm{Ca}^{2+}, \mathrm{Mg}^{2+}\right.$ e $\left.\mathrm{K}^{+}\right)$e ao acúmulo diferenciado de Na pelas plantas (Tabela 22).

As concentrações de $\mathrm{Na}$ solúvel (Tabela 23), assim como às de Na trocável (Tabela 20), foram influenciadas pela época de avaliação. As explicações para este fato são as mesmas discutidas anteriormente para $\mathrm{Na}$ trocável, podendo estar associadas (i) ao aporte de $\mathrm{Na}$ mais elevado em determinadas épocas do ano por causa da irrigação (Figura 2), (ii) à lixiviação deste elemento no perfil; (iii) ao acúmulo distinto de $\mathrm{Na} \mathrm{em}$ determinados períodos (Tabela 22).

Através da interpretação dos resultados das análises de correlações, conclui-se que as concentrações de $\mathrm{Na}$ solúvel, nas camadas superficiais, estão mais relacionadas à capacidade de extração deste elemento pelas plantas, pois foram obtidas correlações negativas entre as concentrações de Na solúvel e o acúmulo de Na no capim (Tabela 24). Ao que parece, devido à baixa CTC do solo (Tabela 2), ou seja, baixo poder tampão, as plantas governam grandemente as concentrações solúveis dos cátions $\mathrm{Ca}, \mathrm{Mg}, \mathrm{K}$ e $\mathrm{Na}$ nas camadas superficiais $(0-10$ e 10-20 cm). Isso porque na maioria das situações foram 
Tabela 24. Coeficientes de correlação entre os parâmetros concentração de Na trocável $\left(\mathrm{mmol}_{\mathrm{c}} \mathrm{kg}^{-1}\right)$ e solúvel $\left(\mathrm{mmol} \mathrm{L}^{-1}\right)$, percentual de sódio trocável (PST, em \%), razão de adsorção de sódio (RAS, em $\left.\left(\mathrm{mmol} \mathrm{L}^{-1}\right)^{0,5}\right)$, concentração de argila dispersa em água (ADA, em $\mathrm{g} \mathrm{kg}^{-1}$ ), grau de dispersão das argilas (GDA, em $\%)$ e acúmulo de $\mathrm{Na}\left(\mathrm{kg} \mathrm{ha}^{-1}\right.$ semestre $\left.^{-1}\right)$ na parte aérea do capim-Bermuda Tifton 85

\begin{tabular}{|c|c|c|c|c|c|c|}
\hline \multirow{2}{*}{ Parâmetro } & \multicolumn{6}{|c|}{ Camada (cm) } \\
\hline & 0-10 & $10-20$ & $20-40$ & $40-60$ & $60-80$ & 80-100 \\
\hline \multicolumn{7}{|c|}{ Na trocável no solo } \\
\hline Na solúvel & $0,19^{\mathrm{NS}}$ & $-0,02^{\mathrm{NS}}$ & $0,38^{*}$ & $0,68^{* *}$ & $0,73^{* *}$ & $0,79^{* *}$ \\
\hline RAS ${ }^{(1)}$ & $0,76^{* *}$ & $0,87^{* *}$ & $0,87^{* *}$ & $0,87^{* *}$ & $0,89^{* *}$ & $0,90^{* *}$ \\
\hline ADA & $0,66^{* *}$ & $0,82^{* *}$ & $0,88^{* *}$ & $0,93^{* *}$ & $0,87^{* *}$ & $0,89^{* *}$ \\
\hline GDA $^{(2)}$ & $0,62^{* *}$ & $0,81^{* *}$ & $0,81^{* *}$ & $0,90^{* *}$ & $0,84^{* *}$ & $0,90^{* *}$ \\
\hline Acúmulo de Na & $0,65^{* *}$ & $0,70^{* *}$ & $0,76^{* *}$ & $0,75^{* *}$ & $0,66^{* *}$ & $0,57^{*}$ \\
\hline \multicolumn{7}{|c|}{ Na solúvel no extrato de saturação } \\
\hline PST ${ }^{(3)}$ & $0,04^{\mathrm{NS}}$ & $-0,12^{\mathrm{NS}}$ & $0,35^{\mathrm{NS}}$ & $0,66^{* *}$ & $0,71^{\text {** }}$ & $0,77^{* *}$ \\
\hline ADA & $-0,16^{\mathrm{NS}}$ & $-0,20^{\mathrm{NS}}$ & $0,29^{\mathrm{NS}}$ & $0,70^{* *}$ & $0,50^{* *}$ & $0,66^{* *}$ \\
\hline GDA & $-0,20^{\mathrm{NS}}$ & $-0,21^{\mathrm{NS}}$ & $0,22^{\mathrm{NS}}$ & $0,63^{*}$ & $0,46^{*}$ & $0,66^{* *}$ \\
\hline Acúmulo de Na & $-0,70^{* *}$ & $-0,69^{* *}$ & $0,62^{*}$ & $0,70^{* *}$ & $0,73^{* *}$ & $0,64^{*}$ \\
\hline \multicolumn{7}{|c|}{ PST } \\
\hline RAS & $0,74^{* *}$ & $0,85^{* *}$ & $0,85^{* *}$ & $0,84^{* *}$ & $0,87^{* *}$ & $0,88^{* *}$ \\
\hline ADA & $0,67^{* *}$ & $0,83^{* *}$ & $0,86^{* *}$ & $0,92^{* *}$ & $0,86^{* *}$ & $0,88^{* *}$ \\
\hline GDA & $0,64^{* *}$ & $0,81^{* *}$ & $0,80^{* *}$ & $0,89^{* *}$ & $0,83^{* *}$ & $0,89^{* *}$ \\
\hline Acúmulo de $\mathrm{Na}$ & $0,81^{* *}$ & $0,75^{* *}$ & $0,76^{* *}$ & $0,76^{* *}$ & $0,68^{* *}$ & $0,59^{*}$ \\
\hline \multicolumn{7}{|c|}{ RAS } \\
\hline ADA & $0,60^{* *}$ & $0,79^{* *}$ & $0,82^{* *}$ & $0,86^{* *}$ & $0,77^{* *}$ & $0,88^{* *}$ \\
\hline GDA & $0,58^{* *}$ & $0,77^{* *}$ & $0,67^{* *}$ & $0,80^{* *}$ & $0,73^{* *}$ & $0,89^{* *}$ \\
\hline Acúmulo de Na & $0,79^{* *}$ & $0,77^{* *}$ & $0,75^{* *}$ & $0,78^{* *}$ & $0,67^{* *}$ & $0,64^{* *}$ \\
\hline
\end{tabular}

NS: Não significativo. ${ }^{*} P<0,05 .{ }^{* *} P<0,01$.

${ }^{(1)}$ Razão de adsorção de $\mathrm{Na} \rightarrow R A S=\frac{N a}{\sqrt{C a+M g}}$, onde $\mathrm{Na}$, Ca e Mg são dados em mmol L ${ }^{-1}$.

${ }^{(2)} G D A=100-G F A^{\S}$

${ }^{(3)} P S T=\left(\frac{N a}{C a+M g+K+N a+H+A l}\right) * 100$

$\S$ Grau de floculação das argilas $(G F A) \rightarrow G F A=\frac{A T-A D A}{A T} * 100$, no qual argila total $(A T)$ foi obtida mediante o emprego do dispersante hexametafosfato de sódio, conforme Camargo et al. (1986). 
obtidas correlaçõs negativas entre as concentrações solúveis destes cátions com seus respectivos acúmulos nas plantas (Tabelas 15 e 24). No caso do $\mathrm{Na}$, onde o aporte foi elevado (Tabela 4) e o acúmulo relativamente baixo (Tabela 22), os coeficientes de correlação foram positivos para as camadas subsuperficiais. No caso do $\mathrm{Ca}, \mathrm{Mg}$ e $\mathrm{K}$, que, se comparados ao $\mathrm{Na}$, apresentaram menor e maior aporte via irrigação (Tabela 4) e acúmulo nas plantas (Tabela 12), respectivamente, ou foram obtidos coeficientes de correlação negativos, ou não houve correlação entre as concentrações na solução (no perfil do solo) com seus respectivos acúmulos nas plantas (Tabela 15).

Analisando-se os resultados de correlações obtidas entre as concentrações solúveis e trocáveis, conclui-se que (i) o $\mathrm{Al}^{3+}$ não obteve correlação (Tabela 8); (ii) o $\mathrm{Ca}^{2+}$ somente obteve correlação nas camadas 0-10, 20-40 e 40-60 cm, mas os coeficientes de correlação foram baixos (Tabela 15); (iii) $\mathrm{o} \mathrm{Mg}^{2+}$ obteve correlação nas camadas 0-10, 10-20, 20-40 e 40-60 cm, mas somente apresentou alta correlação na camada 0-10 cm (Tabela 15); (iv) o $\mathrm{K}^{+}$apenas não obteve correlação na camada 60-80 $\mathrm{cm}$, porém, os coeficientes de correlação foram baixos, com excessão da camada 20-40 cm (Tabela 15); (v) o $\mathrm{Na}^{+}$, ao contrário do que se esperava, não obteve correlação nas camadas superficiais, apresentou baixa correlação nas camadas 20-40 e 40-60 cm e somente apresentou boa correlação nas camadas 60-80 e 80-100 cm (Tabela 24). Portanto, extrato de saturação obtido conforme Rhoades (1996), não parece ser o modo mais adequando para procedimentos de estudos envolvendo a fração solúvel dos cátions $\mathrm{Al}^{3+}, \mathrm{Ca}^{2+}, \mathrm{Mg}^{2+}, \mathrm{K}^{+}$e $\mathrm{Na}^{+}$em solo com baixa CTC.

Apesar de ter ocorrido diferenças entre as concentrações trocáveis (Tabela 20) e solúveis (Tabela 23) de $\mathrm{Na}$ e entre os valores de PST (Tabela 21), o risco de sodicidade do solo (Tabela 25), que pode ser avaliado pela RAS (Quirk \& Schofield, 1955), não foi diferente entre os tratamentos. Porém, foi observado aumento da RAS no decorrer do experimento, principalmente, nos períodos onde as lâminas de irrigação superaram a precipitação pluvial, ou seja, nos meses de outubro/2003 e julho/2004 (Tabela 25). Devido ao elevado valor da RAS da água e do ESET utilizados na irrigação (Tabela 3), o solo passou apresentar riscos de sodicidade por ter tido aumento nos parâmetros Na trocável (Tabela 20) e solúvel (Tabela 23), PST (Tabela 21) e RAS 
Tabela 25. Efeitos da irrigação (água e efluente) e de doses de nitrogênio mineral na razão de adsorção de sódio (RAS) no extrato de saturação

\begin{tabular}{|c|c|c|c|c|c|c|c|}
\hline \multirow{2}{*}{ Tratamento } & \multicolumn{7}{|c|}{ Época de avaliação } \\
\hline & Abr/03 & $\mathrm{Jul} / 03$ & Out/03 & Jan/04 & Abr/04 & Jul/04 & Média \\
\hline & \multicolumn{7}{|c|}{$\left(m m o l ~ L^{-1}\right)^{0,5}$} \\
\hline \multicolumn{8}{|c|}{ Camada 0-10 cm (CV = 19,66\%) } \\
\hline$T 1^{(1)}$ & 4,31 & 7,43 & 11,22 & 9,49 & 4,75 & 11,43 & $8,10^{\mathrm{a}}$ \\
\hline $\mathbf{T} 2^{(2)}$ & 3,19 & 4,82 & 10,69 & 7,50 & 3,99 & 13,38 & $7,26^{\mathrm{a}}$ \\
\hline $\mathrm{T}^{(3)}$ & 3,60 & 6,52 & 12,53 & 9,00 & 5,00 & 12,46 & $8,19^{a}$ \\
\hline$T 4^{(4)}$ & 3,69 & 7,05 & 12,02 & 10,53 & 4,67 & 13,28 & $8,54^{\mathrm{a}}$ \\
\hline $\mathbf{T} 5^{(5)}$ & 3,37 & 6,22 & 12,40 & 10,99 & 3,98 & 9,91 & $7,81^{a}$ \\
\hline Média & $3,64^{\mathrm{D}}$ & $6,41^{\mathrm{C}}$ & $11,77^{\mathrm{A}}$ & $9,50^{\mathrm{B}}$ & $4,48^{\mathrm{D}}$ & $12,09^{\mathrm{A}}$ & \\
\hline \multicolumn{8}{|c|}{ Camada $10-20 \mathrm{~cm}(C V=25,13 \%)$} \\
\hline $\mathrm{T1}$ & 2,85 & 2,63 & 6,99 & 6,50 & 6,68 & 6,75 & $5,40^{\mathrm{a}}$ \\
\hline $\mathbf{T 2}$ & 2,29 & 1,44 & 8,18 & 7,23 & 3,48 & 6,35 & $4,83^{\mathrm{a}}$ \\
\hline T3 & 2,91 & 2,91 & 8,05 & 9,22 & 6,20 & 8,92 & $6,37^{\mathrm{a}}$ \\
\hline T4 & 2,46 & 2,64 & 8,70 & 10,65 & 3,90 & 8,09 & $6,07^{\mathrm{a}}$ \\
\hline T5 & 2,14 & 2,03 & 8,24 & 8,80 & 3,94 & 8,41 & $5,59^{\mathrm{a}}$ \\
\hline Média & $2,53^{\mathrm{C}}$ & $2,33^{\mathrm{C}}$ & $8,03^{\mathrm{A}}$ & $8,48^{\mathrm{A}}$ & $4,84^{\mathrm{B}}$ & $7,71^{\mathrm{A}}$ & \\
\hline \multicolumn{8}{|c|}{ Camada $20-40 \mathrm{~cm}(C V=40,20 \%)$} \\
\hline T1 & 2,14 & 0,97 & 2,71 & 6,71 & 6,27 & 5,61 & $4,07^{\mathrm{a}}$ \\
\hline T2 & 0,39 & 0,54 & 3,98 & 5,71 & 2,77 & 7,48 & $3,48^{\mathrm{a}}$ \\
\hline T3 & 2,71 & 0,90 & 5,05 & 7,48 & 6,66 & 10,32 & $5,52^{\mathrm{a}}$ \\
\hline T4 & 0,47 & 0,77 & 4,61 & 7,91 & 5,51 & 9,74 & $4,83^{\mathrm{a}}$ \\
\hline T5 & 0,45 & 0,63 & 7,66 & 9,64 & 5,43 & 8,41 & $5,37^{\mathrm{a}}$ \\
\hline Média & $1,23^{\mathrm{C}}$ & $0,76^{\mathrm{C}}$ & $4,80^{\mathrm{B}}$ & $7,49^{\mathrm{A}}$ & $5,33^{\text {В }}$ & $8,31^{\mathrm{A}}$ & \\
\hline \multicolumn{8}{|c|}{ Camada $40-60 \mathrm{~cm}(\mathrm{CV}=39,01 \%)$} \\
\hline $\mathrm{T} 1$ & 0,45 & 0,77 & 1,13 & 5,36 & 3,07 & 5,00 & $2,63^{a}$ \\
\hline $\mathbf{T} 2$ & 0,34 & 0,54 & 1,66 & 4,15 & 2,51 & 8,93 & $3,02^{\mathrm{a}}$ \\
\hline T3 & 0,85 & 0,60 & 1,77 & 4,84 & 3,28 & 9,62 & $3,49^{\mathrm{a}}$ \\
\hline T4 & 0,51 & 0,64 & 1,57 & 4,86 & 3,90 & 9,80 & $3,55^{\mathrm{a}}$ \\
\hline T5 & 0,42 & 0,47 & 3,21 & 4,66 & 2,90 & 10,21 & $3,64^{\mathrm{a}}$ \\
\hline Média & $0,52^{\mathrm{E}}$ & $0,61^{\mathrm{E}}$ & $1,87^{\mathrm{D}}$ & $4,77^{\mathrm{B}}$ & $3,13^{\mathrm{C}}$ & $8,71^{\mathrm{A}}$ & \\
\hline \multicolumn{8}{|c|}{ Camada $60-80 \mathrm{~cm}(\mathrm{CV}=76,37 \%)$} \\
\hline T1 & 0,59 & 0,71 & 0,91 & 2,78 & 1,81 & 7,08 & $2,31^{\mathrm{a}}$ \\
\hline T2 & 0,61 & 1,00 & 0,91 & 1,94 & 2,46 & 8,39 & $2,55^{\mathrm{a}}$ \\
\hline T3 & 1,04 & 0,98 & 1,15 & 2,48 & 2,67 & 9,95 & $3,04^{\mathrm{a}}$ \\
\hline T4 & 0,50 & 0,75 & 0,98 & 2,33 & 3,44 & 11,06 & $3,18^{\mathrm{a}}$ \\
\hline T5 & 0,61 & 0,64 & 0,86 & 2,54 & 6,54 & 8,33 & $3,25^{\mathrm{a}}$ \\
\hline Média & $0,67^{\mathrm{C}}$ & $0,81^{\mathrm{C}}$ & $0,96^{\mathrm{C}}$ & $2,41^{\mathrm{BC}}$ & $3,38^{\mathrm{B}}$ & $8,96^{\mathrm{A}}$ & \\
\hline
\end{tabular}


Tabela 25. Efeitos da irrigação (água e efluente) e de doses de nitrogênio mineral na razão de adsorção de sódio (RAS) no extrato de saturação

\begin{tabular}{|c|c|c|c|c|c|c|c|}
\hline \multirow{2}{*}{ Tratamento } & \multicolumn{7}{|c|}{ Época de avaliação } \\
\hline & Abr/03 & Jul/03 & Out/03 & Jan/04 & Abr $/ 04$ & Jul/04 & Média \\
\hline & \multicolumn{7}{|c|}{$\left(\mathrm{mmol} \mathrm{L}^{-1}\right)^{0,5}$} \\
\hline \multicolumn{8}{|c|}{ Camada $80-100 \mathrm{~cm}(C V=55,61 \%)$} \\
\hline T1 & 1,04 & 0,54 & 1,28 & 2,53 & 2,83 & 7,31 & $2,59^{\mathrm{a}}$ \\
\hline T2 & 0,50 & 1,13 & 1,32 & 1,76 & 1,54 & 7,78 & $2,34^{\mathrm{a}}$ \\
\hline T3 & 1,22 & 0,89 & 1,26 & 2,42 & 2,26 & 8,74 & $2,80^{\mathrm{a}}$ \\
\hline T4 & 0,72 & 0,80 & 1,45 & 1,89 & 2,05 & 8,12 & $2,50^{\mathrm{a}}$ \\
\hline T5 & 0,57 & 1,34 & 1,28 & 2,09 & 1,76 & 7,12 & $2,36^{\mathrm{a}}$ \\
\hline Média & $0,81^{\mathrm{C}}$ & $0,94^{\mathrm{BC}}$ & $1,32^{\mathrm{BC}}$ & $2,14^{\mathrm{B}}$ & $2,09^{\mathrm{B}}$ & $7,81^{\mathrm{A}}$ & \\
\hline
\end{tabular}

(1) T1: irrigação com água $+520 \mathrm{~kg} \mathrm{ha}^{-1}$ ano $^{-1}$ de nitrogênio via fertilizante mineral (NFM);

(2) T2: irrigação com efluente secundário de esgoto tratado (ESET), sem NFM;

(3) T3: irrigação com ESET + 171,6 $\mathrm{kg} \mathrm{ha}^{-1} \mathrm{ano}^{-1}$ de NFM;

(4) T4: irrigação com ESET + 343,3 $\mathrm{kg} \mathrm{ha}^{-1}$ ano $^{-1}$ de NFM;

(5) T5: irrigação com ESET + $520 \mathrm{~kg} \mathrm{ha}^{-1} \mathrm{ano}^{-1}$ de NFM;

(6) Letras iguais maiúsculas ou minúsculas nas linhas e nas colunas, respectivamente, não diferem estatisticamente pelo teste de Tukey $(P<0,05)$.

(Tabela 25) e, simultaneamente, ter havido diminuição progressiva das concentrações trocáveis de $\mathrm{Ca}$ (Tabela 13) e de $\mathrm{Mg}$ (Tabela 16). Foi observado que o aumento na concentração de $\mathrm{Na}$ no complexo de troca se correlacionou negativamente com as concentrações trocáveis de (i) Ca nas camadas 40-60 ( $\left.r=-0,42^{*}\right)$ e 60-80 cm (r = $\left.0,48^{* *}\right)$; (ii) Mg nas camadas 0-10 $\left(r=-0,41^{*}\right), 10-20\left(r=-0,48^{* *}\right), 20-40\left(r=-0,46^{*}\right)$, 40-60 $\left(r=-0,63^{* *}\right), 60-80\left(r=-0,48^{* *}\right)$ e $80-100 \mathrm{~cm}\left(r=-0,54^{* *}\right)$. Isso indica que o Na, em algumas camadas, substituiu progressivamente o $\mathrm{Ca}$ e que essa substituição foi mais evidente para o $\mathrm{Mg}$, devido à menor afinidade dos sítios de adsorção por este último elemento quando comparado ao Ca (Loyola Jr. \& Pavan, 1989). Também, houve correlação positiva, para todas camadas, entre concentração de Na trocável, PST e RAS com a concentração de ADA e GDA (Tabela 24), indicando alterações nas características físicas do solo. As concentrações de Na solúvel nas camadas 40-60, 60-80 e 80-100 cm também se correlacionaram com as concentrações de ADA e GDA (Tabela 24). No entanto, maiores coeficientes de correlação foram obtidos entre as concentrações 
de Na trocável e PST com as concentraçõs de ADA e GDA, que foram, normalmente, superiores aos coeficientes de correlação entre RAS com ADA e GDA (Tabela 24).

As alterações no complexo de troca promovidas pelo aumento das concentrações de $\mathrm{Na}$, além de ter proporcionado alterações na fertilidade química do solo (Tabelas 20, 21, 23 e 25), também ocasionou mudanças na fertilidade física do solo, sobretudo, nas concentrações de ADA e, conseqüentemente, no GDA (Tabela 26). A dispersão de argilas resulta na migração destes minerais no perfil do solo e tem sido um processo importante do ponto de vista agrícola e ambiental (Goldberg et al., 1988). Esse processo provoca efeitos indesejáveis nas propriedades físicas do solo, levando à formação de crostas, obstrução de poros e diminuição na taxa de infiltração de água, resultando no escorrimento superficial de nutrientes e pesticidas (Panayiotopoulos et al., 2004). Nos solos para propósito de disposição de resíduos antrópicos, particularmente do EET, este escorrimento superficial é altamente indesejável, pois se constitui num modo indireto de disposição deste subproduto nos corpos d'água (Bond, 1998). Os processos de dispersão e flocução de argilas são regidos pela teoria da dupla camada elétrica (Singh \& Uehara, 1999). A floculação ocorre devido à compressão da dupla camada mediante aumento da concentração eletrolítica, onde as variações nas forças repulsivas são reduzidas consideravelmente. A dispersão ocorre pelo aumento da repulsão quando se dá a expansão da dupla camada (Singh \& Uehara, 1999), que ocorre mediante diminuição da concentração da solução no solo, aumento da RAS, do pH e dominância de cátion monovalente no complexo de troca (Hillel, 1998). As mudanças no pH afetam as cargas das bordas das argilas e de superfície dos minerais de carga variável, como óxidos de Fe e Al (Suarez et al., 1984). Em condição de baixo pH, podem ocorrer ligações face-borda, como por exemplo, óxidos de $\mathrm{Fe}$ e $\mathrm{Al}$ carregados positivamente que se encontram ligados às argilas silicatadas, o que resulta num ótimo de condutividade hidráulica. Com o aumento de $\mathrm{pH}$ ocorre a diminuição nas cargas negativas dos minerais de carga variável e, consequentemente, diminui a atração eletrostática face-borda, favorecendo a dispersão e reduzindo a condutividade hidráulica do solo (Suarez et al., 1984). 
Tabela 26. Efeitos da irrigação (água e efluente) e de doses de nitrogênio mineral no grau de dispersão de argilas (GDA)

\begin{tabular}{|c|c|c|c|c|c|c|c|}
\hline \multirow{2}{*}{ Tratamento } & \multicolumn{7}{|c|}{ Época de avaliação } \\
\hline & Abr/03 & Jul/03 & Out/03 & Jan/04 & Abr/04 & Jul/04 & Média \\
\hline & \multicolumn{7}{|c|}{$\%$} \\
\hline \multicolumn{8}{|c|}{ Camada 0-10 cm (CV = 22,46\%) } \\
\hline $\mathrm{T1}^{(1)}$ & 11,62 & 27,56 & 36,25 & 40,93 & 36,61 & 51,16 & $34,03^{a(6)}$ \\
\hline $\mathbf{T} 2^{(2)}$ & 23,30 & 29,19 & 33,93 & 38,11 & 39,39 & 53,56 & $36,25^{\mathrm{a}}$ \\
\hline T3 ${ }^{(3)}$ & 14,29 & 28,89 & 37,82 & 48,55 & 46,97 & 52,67 & $38,20^{\mathrm{a}}$ \\
\hline$T 4^{(4)}$ & 11,22 & 27,68 & 37,13 & 40,65 & 44,15 & 49,83 & $35,11^{\mathrm{a}}$ \\
\hline $\mathbf{T} 5^{(5)}$ & 13,97 & 23,60 & 35,27 & 44,92 & 47,10 & 73,49 & $39,73^{\mathrm{a}}$ \\
\hline Média & $14,88^{\mathrm{D}}$ & $27,39^{\mathrm{C}}$ & $36,08^{\mathrm{B}}$ & $42,63^{\mathrm{B}}$ & $42,84^{\mathrm{B}}$ & $56,14^{\mathrm{A}}$ & \\
\hline \multicolumn{8}{|c|}{ Camada $10-20 \mathrm{~cm}(C V=21,94 \%)$} \\
\hline T1 & 13,86 & 19,52 & 37,70 & 47,18 & 40,18 & 69,04 & $37,91^{\mathrm{a}}$ \\
\hline T2 & 21,65 & 21,74 & 39,86 & 45,26 & 28,68 & 72,82 & $38,34^{\mathrm{a}}$ \\
\hline T3 & 11,54 & 19,72 & 29,63 & 47,35 & 40,58 & 65,62 & $35,74^{\mathrm{a}}$ \\
\hline T4 & 10,22 & 19,27 & 41,45 & 56,17 & 40,38 & 62,74 & $38,77^{\mathrm{a}}$ \\
\hline T5 & 9,31 & 19,80 & 39,18 & 48,57 & 44,58 & 63,63 & $37,51^{\mathrm{a}}$ \\
\hline Média & $13,32^{\mathrm{D}}$ & $20,01^{\mathrm{D}}$ & $37,56^{\mathrm{C}}$ & $48,91^{\mathrm{B}}$ & $38,88^{\mathrm{C}}$ & $66,77^{\mathrm{A}}$ & \\
\hline \multicolumn{8}{|c|}{ Camada $20-40 \mathrm{~cm}(C V=25,68 \%)$} \\
\hline T1 & 19,57 & 29,98 & 46,71 & 61,27 & 51,08 & 78,93 & $47,92^{\mathrm{a}}$ \\
\hline T2 & 14,38 & 20,55 & 34,91 & 52,63 & 49,84 & 90,60 & $43,82^{a b}$ \\
\hline T3 & 7,20 & 22,18 & 24,01 & 38,88 & 38,54 & 58,52 & $31,55^{\mathrm{b}}$ \\
\hline T4 & 12,63 & 13,15 & 28,46 & 40,91 & 38,81 & 55,63 & $31,60^{\mathrm{b}}$ \\
\hline T5 & 11,72 & 18,78 & 31,59 & 41,17 & 38,11 & 45,75 & $31,18^{b}$ \\
\hline Média & $13,10^{\mathrm{D}}$ & $20,93^{\mathrm{D}}$ & $33,14^{\mathrm{C}}$ & $46,97^{\mathrm{B}}$ & $43,24^{\mathrm{B}}$ & $65,88^{\mathrm{A}}$ & \\
\hline \multicolumn{8}{|c|}{ Camada $40-60 \mathrm{~cm}(C V=28,31 \%)$} \\
\hline T1 & 15,02 & 26,92 & 35,53 & 52,08 & 48,63 & 57,25 & $39,24^{\mathrm{a}}$ \\
\hline T2 & 17,60 & 22,63 & 19,88 & 31,31 & 42,26 & 63,08 & $32,79^{a b}$ \\
\hline T3 & 12,31 & 14,68 & 20,38 & 38,00 & 38,45 & 47,88 & $28,62^{\mathrm{b}}$ \\
\hline T4 & 11,74 & 18,85 & 20,61 & 38,93 & 36,68 & 47,49 & $29,05^{\mathrm{b}}$ \\
\hline T5 & 6,53 & 13,43 & 23,06 & 38,74 & 32,63 & 44,17 & $26,43^{b}$ \\
\hline Média & $12,64^{\mathrm{D}}$ & $19,30^{\mathrm{CD}}$ & $23,89^{\mathrm{C}}$ & $39,81^{\mathrm{B}}$ & $39,73^{\mathrm{B}}$ & $51,97^{\mathrm{A}}$ & \\
\hline \multicolumn{8}{|c|}{ Camada $60-80 \mathrm{~cm}(C V=31,08 \%)$} \\
\hline $\mathrm{T1}$ & 20,45 & 21,13 & 37,89 & 17,05 & 44,66 & 62,40 & $33,93^{\mathrm{a}}$ \\
\hline T2 & 15,13 & 17,22 & 19,55 & 22,08 & 28,59 & 49,65 & $25,37^{\mathrm{a}}$ \\
\hline T3 & 7,93 & 19,03 & 11,58 & 5,76 & 38,39 & 38,28 & $20,16^{\mathrm{a}}$ \\
\hline T4 & 10,68 & 13,79 & 16,12 & 12,00 & 36,34 & 46,38 & $22,55^{\mathrm{a}}$ \\
\hline T5 & 8,62 & 15,05 & 14,79 & 22,84 & 29,59 & 47,80 & $23,12^{\mathrm{a}}$ \\
\hline Média & $12,56^{\mathrm{D}}$ & $17,24^{\mathrm{CD}}$ & $19,97^{\mathrm{C}}$ & $15,94^{\mathrm{CD}}$ & $35,52^{\mathrm{B}}$ & $48,90^{\mathrm{A}}$ & \\
\hline
\end{tabular}


Tabela 26. Efeitos da irrigação (água e efluente) e de doses de nitrogênio mineral no grau de dispersão de argilas (GDA)

\begin{tabular}{|c|c|c|c|c|c|c|c|}
\hline \multirow{2}{*}{ Tratamento } & \multicolumn{7}{|c|}{ Época de avaliação } \\
\hline & Abr/03 & Jul/03 & Out/03 & Jan/04 & Abr/04 & Jul/04 & Média \\
\hline & \multicolumn{7}{|c|}{$\%$} \\
\hline \multicolumn{8}{|c|}{ Camada $80-100 \mathrm{~cm}(C V=58,00 \%)$} \\
\hline $\mathrm{T} 1$ & 7,49 & 12,93 & 19,30 & 16,06 & 25,21 & 44,30 & $20,88^{\mathrm{a}}$ \\
\hline T2 & 3,97 & 5,42 & 11,72 & 14,05 & 19,88 & 39,29 & $15,72^{\mathrm{a}}$ \\
\hline T3 & 2,76 & 2,16 & 5,78 & 9,71 & 15,92 & 28,88 & $10,87^{\mathrm{a}}$ \\
\hline T4 & 3,82 & 4,92 & 7,30 & 1,83 & 17,36 & 45,46 & $13,45^{\mathrm{a}}$ \\
\hline T5 & 3,13 & 2,50 & 5,73 & 7,40 & 16,51 & 33,76 & $11,51^{\mathrm{a}}$ \\
\hline Média & $4,23^{\mathrm{C}}$ & $5,59^{\mathrm{C}}$ & $9,97^{\mathrm{C}}$ & $9,81^{\mathrm{C}}$ & $18,98^{\mathrm{B}}$ & $38,34^{\mathrm{A}}$ & \\
\hline
\end{tabular}

(1) T1: irrigação com água $+520 \mathrm{~kg} \mathrm{ha}^{-1}$ ano $^{-1}$ de nitrogênio via fertilizante mineral (NFM);

(2) T2: irrigação com efluente secundário de esgoto tratado (ESET), sem NFM;

(3) T3: irrigação com ESET + 171,6 $\mathrm{kg} \mathrm{ha}^{-1} \mathrm{ano}^{-1}$ de NFM;

(4) T4: irrigação com ESET + 343,3 $\mathrm{kg} \mathrm{ha}^{-1} \mathrm{ano}^{-1}$ de NFM;

(5) T5: irrigação com ESET $+520 \mathrm{~kg} \mathrm{ha}^{-1} \mathrm{ano}^{-1}$ de NFM;

(6) Letras iguais maiúsculas ou minúsculas nas linhas e nas colunas, respectivamente, não diferem estatisticamente pelo teste de Tukey $(P<0,05)$.

No presente estudo, preocupações quanto à dispersão de argilas se tornaram constantes, por se tratar de um solo caulinítico, com concentrações médias de argila, apresentando baixa CTC (Tabela 2). Para solos cauliníticos tem sido observado que (i) os efeitos da alta RAS na condutividade hidráulica são mais pronunciados quando comparados aos solos montmoriloníticos (McNeal \& Coleman, 1966); (ii) são mais sensíveis a pequenos aumentos na concentração de $\mathrm{Na}$ trocável e de $\mathrm{pH}$, devido à presença de ligantes orgânicos nos sítos de troca nas borda das argilas, onde estes ligantes revertem estas cargas de positiva para negativa, inibindo a floculação faceborda, que é dominante para caulinita (Miller et al., 1990); (iii) em alguns solos australianos com carga variável, o aporte de Na tem ocasionado comportamento sódico, mesmo em condição de PST inferior ao valor crítico de 15\% (Sumner, 1993), pelo fato de apresentarem relação $\mathrm{Ca}: \mathrm{Mg}$ menor que 0,5 no complexo de troca (Dawes \& Goonetilleke, 2003).

Portanto, o fato de ter ocorrido aumento no GDA no decorrer deste experimento e também, da água empregada na irrigação ter superado, em algumas 
camadas (20-40 e 40-60 cm), o efeito dispersante do ESET para os tratamentos T3, T4 e T5 (Tabela 26), evidencia que a manutenção da fertilidade física deste solo passa a ser um desafio.

$\mathrm{O}$ aumento das concentrações de ADA e, por consequência, incremento no GDA (Tabela 26) pode ser explicado devido ao aumento nas concentrações de $\mathrm{Na}$ trocável no solo (Tabela 20), bem como no PST (Tabela 21). Houve correlação positiva altamente significativa, para todas as camadas, entre os parâmetros Na trocável e PST com os parâmetros ADA e GDA (Tabela 24). Nota-se que os coeficientes de correlação entre os parâmetros $\mathrm{Na}$ trocável, RAS e PST com os parâmetros GDA e ADA foram maiores nas camadas subsuperficiais, na grande maioria das situações (Tabela 24). Isso evidencia que a dispersão de argilas é mais acentuada em situação de menor concentração de CT (Tabela 2). Nas camadas superficiais, devido ao fato de ter maiores concentrações de CT (Tabela 2) e de cátions floculantes, principalmente Ca (Tabela 13), os efeitos deletérios do Na podem ter sido amenizados. No entanto, Sumner (1993) em sua extensa revisão a despeito da sodicidade de solos chamou atenção para o papel do C, bem como das substâncias húmicas, nos processos de floculação e dispersão de argilas, sobretudo, em sistemas com carga variável. O autor afirmou que as informações publicadas tem sido divergentes, ora as substâncias húmicas têm promovido floculação, ora tem ocorrido dispersão dos colóides do solo.

Shainberg \& Letey (1984) e Panayiotopoulos et al. (2004) assinalaram que a concentração crítica de floculação é influenciada por (i) fatores de solução, que são RAS e $\mathrm{pH}$; (ii) fatores de solo, incluindo mineralogia, presença de agentes dipersantes (cátions monovalentes, com ênfase às concentrações de $\mathrm{Na}$ trocável e ao PST) e floculantes (óxidos de $\mathrm{Fe}$ e $\mathrm{Al}, \mathrm{CaCO}_{3}$ ), concentrações de $\mathrm{MOS}$ e de argila; (iii) distúrbios provocados pelo homem, incluindo o revolvimento do solo e o tráfego de máquinas. Portanto, no presente estudo, o elevado rendimento da capim (Tabela 5 e Figura 3) em condições de altas concentrações de $\mathrm{Na}$ (Tabelas 20, 21, 23 e 25) e de incremento no GDA (Tabela 26), pode estar relacionado, além das características intrínsicas da planta, ao fato de não ter ocorrido distúrbios mecânicos no solo decorrentes de máquinas agrícolas. 
As operações de revolvimento do solo (no mínimo duas vezes ao ano), que são comuns nos sistemas convencionais de cultivos de plantas anuais, acentuam o efeito deletério do Na na dispersão de argilas e promovem diminuição da fertilidade física do solo (Shainberg \& Letey, 1984). Balks et al. (1998) assinalaram que, em plantação florestal irrigada durante cinco anos com EET rico em $\mathrm{Na}$, foi observado apenas pequena diminuição na condutividade hidráulica do solo. Esses últimos autores assinalaram que os efeitos deletérios do $\mathrm{Na}$ foram grandemente reduzidos pelo fato de, no sistema de produção estudado, o solo não ter sofrido revolvimento e os distúrbios mecânicos terem sido os mínimos possíveis. Portanto, a partir dos resultados do presente estudo, que concordaram com as observações de Balks et al (1998), torna-se patente o potencial de uso dos EET rico em Na somente nas culturas perenes, com destaque para pastagens (Bole \& Bell, 1978; Allhands et al., 1995; Mohammad \& Ayadi, 2004), citros (Zekri \& Koo, 1994; Reboll et al., 2000), plantações florestais (Stewart et al., 1990) e florestas em fase de recuperação (Speir et al, 1999).

Analisando-se os cátions $\mathrm{Ca}^{2+}, \mathrm{Mg}^{2+}$ e $\mathrm{K}^{+}$, torna-se necessária, para que o sistema solo-pastagem se mantenha eficiente em receber irrigação com ESET, a manutenção de concentrações adequadas destes nutrientes no complexo de troca. Devido ao elevado aporte de Na-efluente (Tabela 4), bem como da alta RAS do ESET, que é bem superior à média mundial (Tabela 3), as práticas agronômicas de adubação, calagem e gessagem tornam-se fundamentais para a manutenção da qualidade do sistema solo-planta receptor de ESET. Para minimização do risco de sodicidade do solo no presente estudo, há necessidade de aumentar as concentrações de $\mathrm{Ca}$ e $\mathrm{Mg}$ no complexo de troca, mediante calagem, seguindo de gessagem. Isso porque a calagem não somente causa um efeito positivo na floculação de argilas, por aumentar as concentrações de Ca e $\mathrm{Mg}$, mas por outro lado, pode promover um aumento de $\mathrm{pH}$, que acarreta na geração de cargas elétricas negativas nos colóides do solo, aumentando as forças de repulsão e, consequentemente, incrementando a dispersão de argilas (Singh \& Uehara, 1999). A adição de gesso agrícola $\left(\mathrm{CaSO}_{4} \cdot 2 \mathrm{H}_{2} \mathrm{O}\right)$, que é um sal neutro, promove aumento na concentração de $\mathrm{Ca}$, incremento na relação $\mathrm{Ca}: \mathrm{Mg}$ no solo e, consequentemente, favorece o processo de floculação e melhoria na agregação do solo (Raij, 1988). Parte do 
gesso aplicado na superfície do solo se dissocia em $\mathrm{Ca}^{2+} \mathrm{e} \mathrm{SO}_{4}{ }^{2-}$ e parte consititui o par iônico $\mathrm{CaSO}_{4}{ }^{0}$ (aq.). $\mathrm{O} \mathrm{Ca}^{2+}$ substitui o $\mathrm{Na}^{+}$no complexo de troca, o qual pode, em solução, formar complexo com o ânion $\mathrm{SO}_{4}{ }^{2-} \mathrm{e}$, mediante irrigação abundante, promover a lixiviação de $\mathrm{Na}$ do perfil do solo. O par iônico $\mathrm{CaSO}_{4}{ }^{0}$ (aq.) pode migrar no perfil do solo, dissociando-se em profundidade e ocasionando aumento na concentração de $\mathrm{Ca}$ trocável no subsolo (Raij, 1988).

Salienta-se que, no presente estudo, o emprego de lâminas de irrigação excedente em $16 \%$ não foi o suficiente para promover a remoção de Na do perfil. Hayes et al. (1990a) observaram efeitos semelhantes em solo cultivado com capim-Bermuda e submetido à irrigação com EET. Os autores verificaram que lâminas de irrigação excedente em 20\% também ocasionaram aumento no PST. Balks et al. (1998) verificaram que a irrigação de plantações florestais com EET rico em $\mathrm{Na}$ promoveu incremento no PST de dois para 25\%, após cinco anos. Esses autores salientaram que o aumento no PST foi muito superior ao previsto pelos modelos convencionais apresentados em Ayers \& Westcot (1985). Portanto, os modelos convencionais para previsão da sodicidade e salinidade do solo não parecem ser os mais adequados às nossas condições de clima, solo e cultura e ainda, essas limitações também têm sido observadas em outros estudos (Hayes et al., 1990a; Balks et al., 1998). Isso provavelmente tem acontecido devido ao fato de Ayers \& Westcot (1985) somente levarem em consideração os parâmetros RAS e CE para avaliar o risco de sodicidade do solo.

Paliwal \& Gandhi (1976) assinalaram que (i) a RAS apresenta inexatidão por considerar que o complexo de troca possui a mesma afinidade para os íons $\mathrm{Ca}^{2+}, \mathrm{Mg}^{2+} \mathrm{e}$ $\mathrm{Na}^{+}$; (ii) em condições similares de salinidade e de RAS, há maior adsorção no sistema $\mathrm{Na}-\mathrm{Mg}$ do que no sistema Na-Ca e essas diferenças são maiores em solos de baixa CTC; (iii) o desenvolvimento da sodicidade do solo pode ser influenciado tanto pela RAS como pela relação Ca: $\mathrm{Mg}$ da água de irrigação, pois o aumento da adsorção de $\mathrm{Na}$ é favorecida pela diminuição na relação $\mathrm{Ca}: \mathrm{Mg}$, que leva, indiretamente, ao aumento no PST; (iv) a afinidade do complexo de troca pelo $\mathrm{Ca}^{2+}$ é muito superior à do $\mathrm{Mg}^{2+}$, que é superior à do $\mathrm{Na}^{+}$. Esta diferença de afinidade dos cátions $\mathrm{Ca}^{2+}, \mathrm{Mg}^{2+}$ e $\mathrm{Na}^{+}$pelo 
complexo de troca também foi verificada nos solos ácidos tropicais por Takachi \& Pavan (1995), cujos resultados concordaram com as observações de Paliwal \& Gandhi (1976). Portanto, a presença de $\mathrm{NH}_{4}^{+}, \mathrm{K}^{+}$e $\mathrm{HCO}_{3}^{-}$no EET deve ser levada em consideração nos estudos de sodicidade, devido ao fato de (i) os dois primeiros íons

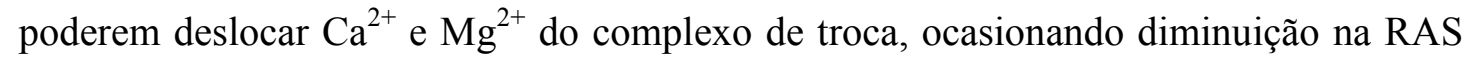
da solução no solo; (ii) a presença do $\mathrm{HCO}_{3}{ }^{-}$poder ocasionar precipitação de $\mathrm{Ca}^{2+} \mathrm{e}$ $\mathrm{Mg}^{2+}$ na solução, aumentando a RAS (Levy et al., 1985).

Apesar de o ESET apresentar menor RAS que a água potável, ambos possuem relações Ca:Mg estreitas (Tabela 3) e o emprego destas águas na irrigação do capim ocasionou aumento na sodicidade do solo (Tabelas 20, 21, 23 e 25). Portanto, os efeitos de águas residuárias sódicas nos solos necessitam ser melhores investigados e, sobretudo, previsíveis, levando-se em conta não somente os parâmetros tradicionais (RAS, CE) abordados em Ayers \& Westcot (1985), mas também incorporando outros parâmetros, tais como relação $\mathrm{Ca}: \mathrm{Mg}$ (Paliwal \& Gandhi, 1976), concentração de $\mathrm{HCO}_{3}{ }^{-}$ (Suarez, 1981), razão de adsorção de potássio e de amônio (Levy et al., 1985). A previsão destes efeitos torna-se crucial para solo tropical, de baixa CTC, rico em argilominerais do tipo $1: 1$, que são mais sensíveis a pequenos aumentos nas concentrações de Na trocável e de pH (Miller et al., 1990).

Um outro parâmetro, largamente empregado nos estudos de qualidade de solo e de água para irrigação, é a salinidade. Quando aplicado a solos, o termo "salinidade" se refere à presença de sais solúveis e prontamente dissolúveis (Rhoades, 1996), cujas concentrações totais são determinadas através de medição da CE no extrato de saturação (Maas, 1985). No presente estudo, os tratamentos empregaram ocasionaram alterações na salinidade do perfil do solo (Tabela 27). Na camada $0-10 \mathrm{~cm}$, não foram diferentes as concentrações de sais entre os tratamentos T2 e T3, que foram superiores às concentrações de sais dos demais tratamentos. Nas camadas 10-20 e 20-40 cm, a concentração de sais do tratamento T2 foi superior à do tratamento T1; no entanto, essas concentrações não diferiram das médias observadas nos demais tratamentos (Tabela 27). Na camada 40-60 cm, o tratamento T2 apresentou maior concentração de sais que os tratamentos T1 e T4 e ainda, os tratamentos T5 e T3 não diferiram dos demais 
Tabela 27. Efeitos da irrigação (água e efluente) e de doses de nitrogênio mineral na condutividade elétrica (CE) no extrato de saturação

\begin{tabular}{|c|c|c|c|c|c|c|c|}
\hline \multirow{2}{*}{ Tratamento } & \multicolumn{7}{|c|}{ Época de avaliação } \\
\hline & Abr/03 & Jul/03 & Out/03 & Jan/04 & Abr/04 & Jul/04 & Média \\
\hline & \multicolumn{7}{|c|}{$d S m^{-1}$} \\
\hline \multicolumn{8}{|c|}{ Camada 0-10 cm (CV = 14,85\%) } \\
\hline $\mathrm{T1}^{(\mathbf{1})}$ & 0,33 & 0,63 & 0,47 & 0,30 & 0,63 & 0,30 & $0,44^{\mathrm{b}(6)}$ \\
\hline $\mathbf{T}^{(2)}$ & 0,35 & 0,74 & 0,60 & 0,34 & 0,66 & 0,45 & $0,52^{\mathrm{a}}$ \\
\hline $\mathbf{T} 3^{(3)}$ & 0,38 & 0,88 & 0,63 & 0,35 & 0,53 & 0,40 & $0,53^{\mathrm{a}}$ \\
\hline$T 4^{(4)}$ & 0,25 & 0,65 & 0,54 & 0,35 & 0,49 & 0,32 & $0,43^{b}$ \\
\hline $\mathbf{T} 5^{(5)}$ & 0,29 & 0,69 & 0,43 & 0,30 & 0,54 & 0,33 & $0,43^{b}$ \\
\hline Média & $0,32^{\mathrm{C}}$ & $0,72^{\mathrm{A}}$ & $0,54^{\mathrm{B}}$ & $0,33^{\mathrm{C}}$ & $0,57^{\mathrm{B}}$ & $0,36^{\mathrm{C}}$ & \\
\hline \multicolumn{8}{|c|}{ Camada $10-20 \mathrm{~cm}(C V=17,40 \%)$} \\
\hline T1 & 0,28 & 0,42 & 0,40 & 0,27 & 0,50 & 0,20 & $0,35^{\mathrm{b}}$ \\
\hline $\mathbf{T 2}$ & 0,29 & 0,74 & 0,52 & 0,26 & 0,46 & 0,35 & $0,44^{\mathrm{a}}$ \\
\hline T3 & 0,29 & 0,63 & 0,55 & 0,25 & 0,41 & 0,27 & $0,40^{a b}$ \\
\hline T4 & 0,27 & 0,55 & 0,47 & 0,22 & 0,48 & 0,24 & $0,37^{\mathrm{ab}}$ \\
\hline T5 & 0,28 & 0,67 & 0,52 & 0,22 & 0,49 & 0,24 & $0,40^{\mathrm{ab}}$ \\
\hline Média & $0,28^{\mathrm{C}}$ & $0,60^{\mathrm{A}}$ & $0,49^{\mathrm{B}}$ & $0,24^{\mathrm{C}}$ & $0,47^{\mathrm{B}}$ & $0,26^{\mathrm{C}}$ & \\
\hline \multicolumn{8}{|c|}{ Camada $20-40 \mathrm{~cm}(\mathrm{CV}=25,94 \%)$} \\
\hline T1 & 0,21 & 0,18 & 0,41 & 0,21 & 0,42 & 0,17 & $0,26^{\mathrm{b}}$ \\
\hline T2 & 0,20 & 0,25 & 0,69 & 0,30 & 0,51 & 0,26 & $0,37^{\mathrm{a}}$ \\
\hline T3 & 0,19 & 0,23 & 0,55 & 0,26 & 0,32 & 0,25 & $0,30^{\mathrm{ab}}$ \\
\hline T4 & 0,20 & 0,20 & 0,56 & 0,25 & 0,43 & 0,22 & $0,31^{a b}$ \\
\hline T5 & 0,20 & 0,19 & 0,53 & 0,21 & 0,66 & 0,23 & $0,34^{a b}$ \\
\hline Média & $0,20^{\mathrm{C}}$ & $0,21^{\mathrm{C}}$ & $0,55^{\mathrm{A}}$ & $0,25^{\mathrm{C}}$ & $0,47^{\mathrm{B}}$ & $0,23^{\mathrm{C}}$ & \\
\hline \multicolumn{8}{|c|}{ Camada $40-60 \mathrm{~cm}(C V=21,59 \%)$} \\
\hline T1 & 0,19 & 0,10 & 0,28 & 0,17 & 0,21 & 0,18 & $0,19^{\mathrm{b}}$ \\
\hline T2 & 0,09 & 0,13 & 0,55 & 0,25 & 0,31 & 0,26 & $0,27^{\mathrm{a}}$ \\
\hline T3 & 0,09 & 0,11 & 0,38 & 0,26 & 0,29 & 0,25 & $0,23^{\mathrm{ab}}$ \\
\hline T4 & 0,09 & 0,09 & 0,33 & 0,20 & 0,29 & 0,22 & $0,20^{\mathrm{b}}$ \\
\hline T5 & 0,09 & 0,12 & 0,34 & 0,26 & 0,28 & 0,24 & $0,22^{\mathrm{ab}}$ \\
\hline Média & $0,11^{\mathrm{D}}$ & $0,11^{\mathrm{D}}$ & $0,38^{\mathrm{A}}$ & $0,23^{\mathrm{C}}$ & $0,28^{\mathrm{B}}$ & $0,23^{\mathrm{C}}$ & \\
\hline \multicolumn{8}{|c|}{ Camada $60-80 \mathrm{~cm}(C V=21,05 \%)$} \\
\hline T1 & 0,06 & 0,06 & 0,15 & 0,15 & 0,11 & 0,16 & $0,12^{b}$ \\
\hline $\mathbf{T 2}$ & 0,06 & 0,06 & 0,17 & 0,24 & 0,23 & 0,23 & $0,16^{\mathrm{a}}$ \\
\hline T3 & 0,07 & 0,05 & 0,13 & 0,34 & 0,23 & 0,21 & $0,17^{\mathrm{a}}$ \\
\hline T4 & 0,05 & 0,05 & 0,18 & 0,29 & 0,17 & 0,20 & $0,16^{\mathrm{a}}$ \\
\hline T5 & 0,05 & 0,04 & 0,13 & 0,25 & 0,21 & 0,23 & $0,15^{\mathrm{a}}$ \\
\hline Média & $0,06^{\mathrm{D}}$ & $0,05^{\mathrm{D}}$ & $0,15^{\mathrm{C}}$ & $0,25^{\mathrm{A}}$ & $0,19^{\mathrm{B}}$ & $0,21^{\mathrm{B}}$ & \\
\hline
\end{tabular}


Tabela 27. Efeitos da irrigação (água e efluente) e de doses de nitrogênio mineral na condutividade elétrica (CE) no extrato de saturação

\begin{tabular}{|c|c|c|c|c|c|c|c|}
\hline \multirow{2}{*}{ Tratamento } & \multicolumn{7}{|c|}{ Época de avaliação } \\
\hline & Abr/03 & Jul/03 & Out/03 & Jan/04 & Abr/04 & Jul/04 & Média \\
\hline & \multicolumn{7}{|c|}{$\mathrm{dS} \mathrm{m}^{-1}$} \\
\hline \multicolumn{8}{|c|}{ Camada $80-100 \mathrm{~cm}(C V=23,25 \%)$} \\
\hline T1 & 0,09 & 0,04 & 0,07 & 0,11 & 0,12 & 0,12 & $0,09^{\mathrm{c}}$ \\
\hline T2 & 0,05 & 0,04 & 0,08 & 0,31 & 0,18 & 0,22 & $0,15^{\mathrm{ab}}$ \\
\hline T3 & 0,06 & 0,06 & 0,07 & 0,28 & 0,25 & 0,22 & $0,16^{\mathrm{a}}$ \\
\hline T4 & 0,05 & 0,04 & 0,07 & 0,21 & 0,18 & 0,18 & $0,12^{\mathrm{b}}$ \\
\hline $\mathbf{T} 5$ & 0,05 & 0,05 & 0,10 & 0,20 & 0,19 & 0,23 & $0,14^{a b}$ \\
\hline Média & $0,06^{\mathrm{CD}}$ & $0,05^{\mathrm{D}}$ & $0,08^{\mathrm{C}}$ & $0,22^{\mathrm{A}}$ & $0,18^{\mathrm{B}}$ & $0,19^{\mathrm{AB}}$ & \\
\hline
\end{tabular}

(1) T1: irrigação com água $+520 \mathrm{~kg} \mathrm{ha}^{-1}$ ano $^{-1}$ de nitrogênio via fertilizante mineral (NFM);

(2) T2: irrigação com efluente secundário de esgoto tratado (ESET), sem NFM;

(3) T3: irrigação com ESET + 171,6 kg ha-1 ano $^{-1}$ de NFM;

(4) T4: irrigação com ESET + 343,3 $\mathrm{kg} \mathrm{ha}^{-1} \mathrm{ano}^{-1}$ de NFM;

(5) T5: irrigação com ESET $+520 \mathrm{~kg} \mathrm{ha}^{-1} \mathrm{ano}^{-1}$ de NFM;

(6) Letras iguais maiúsculas ou minúsculas nas linhas e nas colunas, respectivamente, não diferem estatisticamente pelo teste de Tukey $(P<0,05)$.

(Tabela 27). Na camada $60-80 \mathrm{~cm}$, o tratamento $\mathrm{T} 1$ apresentou menor salinidade que os demais tratamentos (Tabela 27). Na camada $80-100 \mathrm{~cm}$, menor e maior concentração de sais foram observadas nos tratamentos T1 e T3, respectivamente (Tabela 27). Ainda para esta camada, não foram observadas diferenças entre as concentrações de sais dos tratamentos $\mathrm{T} 2$ e $\mathrm{T} 5$ com os tratamentos $\mathrm{T} 3$ e $\mathrm{T} 4$; porém o tratamento $\mathrm{T} 1$, quando comparado aos demais, apresentou menor concentração de sais (Tabela 27). Normalmente, as maiores concentrações de sais foram observadas no tratamento T2 (Tabela 27), que teve menor rendimento de MS (Tabela 5 e Figura 3) e, assim, acumulou menor quantidade de elementos no capim (Tabelas 12 e 22), restando maior concentração de sais no solo. As concentrações de sais dos tratamentos T1 e T5, que receberam a mesma dose de NFM, não foram diferentes até $60 \mathrm{~cm}$ (Tabela 27). Portanto o ESET, em condição semelhante de fertilização, não proporcionou incremento na salinidade do solo, discordando da maioria dos estudos com plantas forrageiras submetidas à irrigação com este subproduto (Hortenstine, 1976; Hayes et al., 1990a; 
Feigin et al., 1991; Mancino \& Pepper, 1992; Bond, 1998; Shahalam et al., 1998), mas concordando com as observações realizadas por Ramirez-Fuentes et al. (2002).

A salinidade do solo deste experimento variou conforme a época de amostragem (Tabela 27), que pode ser atribuída às variações nas quantidades de sais lixiviadas e absorvidas pelas plantas, no decorrer do ano. No mês de abril/2003 a CE do solo foi menor, devido ao fato de ter ocorrido, até nesta época, predomínio da precipitação pluvial sobre as lâminas de irrigação empregadas nos tratamentos (Figura 2). No mês de julho/2003 foram observados incrementos nos valores de CE nas camadas superficiais (0-10 e 10-20 cm), decorrente do predomínio das lâminas de irrigação em relação à precipitação pluvial. Destaca-se que, neste caso, mesmo empregando lâmina de irrigação excedente de 16\%, houve acúmulo de sais no solo, sobretudo, sais de $\mathrm{Na}$, uma vez que, para esta mesma época, foi observada aumento na concentração trocável (Tabela 20) e solúvel (Tabela 23) deste elemento. Aumento na salinidade do solo, mesmo trabalhando-se com fração de lixiviação considerável, também foi observado por Mohammad \& Mazahreh (2003). Esses autores verificaram que houve aumento da CE nas camadas superficial do solo em períodose de alta evapotranspiração, devido à ascensão capilar de sais, apesar de ter sido aplicada lâmina excedente de irrigação de $26 \%$. No mês de outubro/2003 a salinidade diminuiu nas camadas superficiais em detrimento do maior requerimento de elementos pelas plantas, pois neste período as temperaturas são maiores, o que favorece o crescimento e o aumento na demanda das plantas por nutrientes e elementos benéficos. Para esta mesma época, foi observado aumento na concentração de sais em subsuperfície, que podem ter sido lixiviados de camadas superiores (Tabela 27). No mês de janeiro/2004, as chuvas abundantes (Figura 2) promoveram lixiviação de elementos das camadas superficiais para as camadas $60-80$ e 80-100 cm e ainda, o intenso crescimento do capim, nesta época do ano, também contribuiu para a diminuição na concentração dos elementos nas camadas superficiais, onde provavelmente se encontrava a maior parte do sistema radicular do capim. No mês de abril/2004 a diminuição na precipitação pluvial, associada à maior necessidade de irrigação proporcionou aumento na salinidade até $60 \mathrm{~cm}$ (Tabela 27). No mês de julho/2004, embora as lâminas de irrigação foram muito superiores à precipitação 
pluvial (Figura 2) a salinidade do solo não aumentou. Este fato pode estar associado à diminuição na concentração trocável dos elementos Ca (Tabela 13), Mg (Tabela 16) e K (Tabela 18), que normalmente estão em "equíbrio" com a solução e também exercem efeito na salinidade do solo, conforme assinalado por Rhoades (1996).

As alterações na salinidade do solo, no presente estudo, correlacionaram positivamente com as concentrações de Na solúvel nas camadas 0-10 $\left(r=0,52^{* *}\right), 10-20$ $\left(r=0,44^{*}\right), 20-40\left(r=0,60^{* *}\right), 40-60\left(r=0,61^{* *}\right), 60-80\left(r=0,81^{* *}\right)$ e $80-100 \mathrm{~cm}(r=$ $0,80^{* *}$ ). Também houve correlação positiva entre a salinidade e o PST nas camadas 40 $60\left(r=0,40^{*}\right), 60-80\left(r=0,60^{* *}\right)$ e $80-100\left(r=0,70^{* *}\right)$. O sódio, devido ao seu elevado aporte (Tabela 4), provavelmente foi o elemento que mais exerceu influência na salinidade do solo, sobretudo nas camadas subsuperficiais, onde foram obtidas melhores correlações entre $\mathrm{Na}$ e salinidade.

Do ponto de vista de fertilidade química do solo, os maiores efeitos ocorreram nas camadas superficiais (Tabelas $6,9,10,13,16,18$ e 20). Isso foi pode ser atribuído, principalmente, à fertilização mineral (Tabela 1), fonte de $\mathrm{K}^{+}, \mathrm{NH}_{4}{ }^{+}, \mathrm{NO}_{3}{ }^{-}$e outros íons, que foi realizada a lanço na superfície. No entanto, pelo fato de ter ocorrido alta concentração de íons $\mathrm{Na}^{+}$no meio (Tabelas 20 e 23), este elemento foi lixiviado para camadas subsuperficiais, através das chuvas intensas de verão (Figura 2), exercendo efeitos na salinidade em subsuperfície (Tabela 27). Todavia, as alterações na salinidade do solo ocorridas no presente estudo são de pouca importância prática, pois se encontram numa faixa abaixo de $1,0 \mathrm{dS} \mathrm{m}^{-1}$, não ocasionando, normalmente, efeitos negativo no rendimento das plantas de interesse agronômico, segundo Maas (1985).

\subsection{Fósforo, enxofre, carbono e nitrogênio}

Os tratamentos empregados ocasionaram alterações nas concentrações de $\mathrm{P}$ disponivel no solo, exceto na camada 60-80 cm (Tabela 28). Na camada 0-10 cm, o tratamento T2 apresentou maior concentração de $\mathrm{P}$ que o tratamento T3; porém, estes tratamentos não diferiram dos demais (Tabela 28). Na camada $10-20 \mathrm{~cm}$, o tratamento T5 apresentou maior concentração de $\mathrm{P}$ que o tratamento T3; mas estes tratamentos não foram diferentes dos demais (Tabela 28). Na camada 20-40 cm, o tratamento T3, que 
Tabela 28. Efeitos da irrigação (água e efluente) e de doses de nitrogênio mineral nas concentrações de P disponível no solo

\begin{tabular}{|c|c|c|c|c|c|c|c|}
\hline \multirow{2}{*}{ Tratamento } & \multicolumn{7}{|c|}{ Época de avaliação } \\
\hline & Abr/03 & Jul/03 & Out/03 & Jan/04 & Abr/04 & Jul/04 & Média \\
\hline & \multicolumn{7}{|c|}{$\mathrm{mg} \mathrm{kg}^{-1}$} \\
\hline \multicolumn{8}{|c|}{ Camada 0-10 cm (CV = 20,31\%) } \\
\hline $\mathrm{T1}^{(1)}$ & 19,64 & 13,10 & 11,52 & 17,40 & 21,76 & 14,54 & $16,33^{a b(6)}$ \\
\hline $\mathbf{T} 2^{(2)}$ & 16,84 & 18,32 & 17,20 & 14,04 & 25,75 & 19,01 & $18,53^{\mathrm{a}}$ \\
\hline $\mathbf{T} 3^{(3)}$ & 14,99 & 10,65 & 9,80 & 12,07 & 14,00 & 11,54 & $12,18^{b}$ \\
\hline$T 4^{(4)}$ & 16,87 & 14,48 & 14,00 & 16,36 & 23,61 & 9,12 & $15,74^{a b}$ \\
\hline T5 $5^{(5)}$ & 16,55 & 9,82 & 14,34 & 13,69 & 21,40 & 7,88 & $13,95^{\text {ab }}$ \\
\hline Média & $16,98^{\mathrm{B}}$ & $13,27^{\mathrm{C}}$ & $13,37^{\mathrm{C}}$ & $14,71^{\mathrm{BC}}$ & $21,30^{\mathrm{A}}$ & $12,42^{\mathrm{C}}$ & \\
\hline \multicolumn{8}{|c|}{ Camada $10-20 \mathrm{~cm}(C V=24,25 \%)$} \\
\hline T1 & 6,31 & 4,30 & 3,51 & 3,12 & 6,32 & 3,71 & $4,55^{a b}$ \\
\hline $\mathbf{T 2}$ & 5,67 & 3,78 & 5,48 & 3,53 & 5,88 & 2,69 & $4,51^{a b}$ \\
\hline T3 & 5,80 & 2,66 & 4,22 & 3,65 & 4,79 & 1,74 & $3,81^{\mathrm{b}}$ \\
\hline T4 & 5,78 & 3,60 & 5,29 & 4,24 & 5,91 & 1,78 & $4,43^{\mathrm{ab}}$ \\
\hline T5 & 5,62 & 4,22 & 5,68 & 5,55 & 7,92 & 1,57 & $5,09^{\mathrm{a}}$ \\
\hline Média & $5,84^{\mathrm{AB}}$ & $3,71^{\mathrm{D}}$ & $4,84^{\mathrm{BC}}$ & $4,02^{\mathrm{CD}}$ & $6,16^{\mathrm{A}}$ & $2,30^{\mathrm{E}}$ & \\
\hline \multicolumn{8}{|c|}{ Camada $20-40 \mathrm{~cm}(C V=22,11 \%)$} \\
\hline T1 & 2,26 & 2,04 & 1,41 & 1,42 & 3,31 & 1,48 & $1,99^{\mathrm{bc}}$ \\
\hline $\mathbf{T} 2$ & 2,44 & 1,95 & 2,66 & 0,88 & 3,11 & 1,33 & $2,06^{\mathrm{bc}}$ \\
\hline T3 & 2,47 & 1,03 & 1,33 & 1,25 & 1,85 & 1,79 & $1,62^{\mathrm{c}}$ \\
\hline T4 & 2,59 & 1,95 & 2,00 & 1,79 & 2,81 & 3,38 & $2,42^{a b}$ \\
\hline T5 & 2,54 & 2,25 & 2,55 & 1,55 & 5,49 & 1,68 & $2,68^{\mathrm{a}}$ \\
\hline Média & $2,46^{\mathrm{B}}$ & $1,85^{\mathrm{C}}$ & $1,99^{\mathrm{C}}$ & $1,38^{\mathrm{D}}$ & $3,32^{\mathrm{A}}$ & $1,93^{\mathrm{C}}$ & \\
\hline \multicolumn{8}{|c|}{ Camada $40-60 \mathrm{~cm}(\mathrm{CV}=40,26 \%)$} \\
\hline $\mathrm{T} 1$ & 1,43 & 1,31 & 1,03 & 0,79 & 1,85 & 1,19 & $1,27^{\mathrm{ab}}$ \\
\hline T2 & 1,29 & 1,59 & 1,27 & 0,47 & 2,23 & 1,85 & $1,45^{\mathrm{a}}$ \\
\hline T3 & 1,08 & 0,44 & 0,62 & 0,49 & 1,32 & 1,12 & $0,85^{\mathrm{b}}$ \\
\hline T4 & 1,49 & 0,75 & 0,92 & 0,57 & 2,46 & 1,64 & $1,31^{\mathrm{ab}}$ \\
\hline T5 & 1,32 & 1,34 & 1,35 & 0,90 & 1,83 & 2,20 & $1,49^{\mathrm{a}}$ \\
\hline Média & $1,32^{\mathrm{BC}}$ & $1,09^{\mathrm{CD}}$ & $1,04^{\mathrm{CD}}$ & $0,65^{\mathrm{D}}$ & $1,94^{\mathrm{A}}$ & $1,60^{\mathrm{AB}}$ & \\
\hline \multicolumn{8}{|c|}{ Camada $60-80 \mathrm{~cm}(C V=45,50 \%)$} \\
\hline T1 & 0,80 & 1,36 & 0,56 & 0,29 & 2,72 & 3,00 & $1,45^{\mathrm{a}}$ \\
\hline $\mathbf{T 2}$ & 0,93 & 1,09 & 1,23 & 0,39 & 1,90 & 0,43 & $0,99^{\mathrm{a}}$ \\
\hline T3 & 0,98 & 0,32 & 0,51 & 0,47 & 1,76 & 2,37 & $1,07^{\mathrm{a}}$ \\
\hline T4 & 0,78 & 0,70 & 0,77 & 0,45 & 2,19 & 1,43 & $1,05^{\mathrm{a}}$ \\
\hline T5 & 0,81 & 0,99 & 0,79 & 0,42 & 2,55 & 3,22 & $1,46^{\mathrm{a}}$ \\
\hline Média & $0,86^{\mathrm{B}}$ & $0,89^{\mathrm{B}}$ & $0,77^{\mathrm{B}}$ & $0,41^{\mathrm{B}}$ & $2,22^{\mathrm{A}}$ & $2,09^{\mathrm{A}}$ & \\
\hline
\end{tabular}


Tabela 28. Efeitos da irrigação (água e efluente) e de doses de nitrogênio mineral nas concentrações de P disponível no solo

\begin{tabular}{|c|c|c|c|c|c|c|c|}
\hline \multirow{2}{*}{ Tratamento } & \multicolumn{7}{|c|}{ Época de avaliação } \\
\hline & Abr/03 & Jul/03 & Out/03 & Jan/04 & Abr/04 & Jul/04 & Média \\
\hline & \multicolumn{7}{|c|}{$\mathrm{mg} \mathrm{kg}^{-1}$} \\
\hline \multicolumn{8}{|c|}{ Camada $80-100 \mathrm{~cm}(C V=54,63 \%)$} \\
\hline T1 & 0,89 & 0,33 & 0,60 & 0,26 & 0,81 & 1,45 & $0,72^{a b}$ \\
\hline $\mathbf{T 2}$ & 0,74 & 0,61 & 0,80 & 0,46 & 0,65 & 1,50 & $0,79^{a b}$ \\
\hline T3 & 0,96 & 0,48 & 0,35 & 0,22 & 0,97 & 1,39 & $0,73^{a b}$ \\
\hline T4 & 0,56 & 0,26 & 0,49 & 0,19 & 1,42 & 0,66 & $0,60^{\mathrm{b}}$ \\
\hline T5 & 0,75 & 0,39 & 0,77 & 0,19 & 1,37 & 2,90 & $1,06^{\mathrm{a}}$ \\
\hline Média & $0,78^{\mathrm{BC}}$ & $0,41^{\mathrm{CD}}$ & $0,60^{\mathrm{CD}}$ & $0,26^{\mathrm{D}}$ & $1,04^{\mathrm{B}}$ & $1,58^{\mathrm{A}}$ & \\
\hline
\end{tabular}

(1) T1: irrigação com água $+520 \mathrm{~kg} \mathrm{ha}^{-1}$ ano $^{-1}$ de nitrogênio via fertilizante mineral (NFM);

(2) T2: irrigação com efluente secundário de esgoto tratado (ESET), sem NFM;

(3) T3: irrigação com ESET + 171,6 $\mathrm{kg} \mathrm{ha}^{-1} \mathrm{ano}^{-1}$ de NFM;

(4) T4: irrigação com ESET + 343,3 $\mathrm{kg} \mathrm{ha}^{-1} \mathrm{ano}^{-1}$ de NFM;

(5) T5: irrigação com ESET + $520 \mathrm{~kg} \mathrm{ha}^{-1} \mathrm{ano}^{-1}$ de NFM;

(6) Letras iguais maiúsculas ou minúsculas nas linhas e nas colunas, respectivamente, não diferem estatisticamente pelo teste de Tukey $(P<0,05)$.

não diferiu dos tratamentos $\mathrm{T} 1$ e $\mathrm{T} 2$, apresentou menor concentração de $\mathrm{P}$; mas o tratamento $\mathrm{T} 5$, que não diferiu do tratamento $\mathrm{T} 4$, foi o que apresentou maior concentração deste nutriente nesta camada (Tabela 28). Na camada 40-60 cm, os tratamentos T2 e T5, que não diferiram dos tratamentos T1 e T4, apresentaram maiores concentrações de $\mathrm{P}$ que o tratamento T3 (Tabela 28). Na camada 80-100 cm, a concentração de $\mathrm{P}$ do tratamento $\mathrm{T} 5$ foi superior à do tratamento $\mathrm{T} 4$, mas não foi diferente dos tratamentos T1, T2 e T3 (Tabela 28).

O aumento no aporte médio de P-efluente do tratamento T2 para o tratamento T5 (Tabela 4) não implicou em incremento na concentração deste nutriente no solo, exceto na camada subsuperficial 20-40 cm (Tabela 28). O fato de o ESET nas maiores doses (tratamentos $\mathrm{T} 4$ e $\mathrm{T} 5$ ) ter proporcionado aumento de $\mathrm{P}$ disponível em subsuperficície (Tabela 28), concordou com as observações realizadas por Latterell et al. (1982), Al-Nakshabandi et al. (1997) e Mohammad \& Mazahreh (2003).

Comparando-se os tratamentos $\mathrm{T} 1$ e $\mathrm{T} 5$, que receberam a mesma dose de fertilizantes minerais (Tabela 1), foi observado que o P-efluente pouco afetou a dinâmica 
deste nutriente no solo, por ocasionar apenas pequeno aumento na concentração de $\mathrm{P}$ na camada 20-40 cm (Tabela 28). Efeitos mais expressivos da irrigação com EET em relação ao aumento de $\mathrm{P}$ disponível no solo, têm sido comuns nos experimentos conduzidos por períodos superiores a cinco anos (em médio e longo prazo), conforme assinalado nos estudos de Sommers et al. (1979), Zekri \& Koo (1994) e Wang et al. (2003).

Mediante comparação das médias dos tratamentos dos meses de abri1/2003 e julho/2004 foram observadas (i) diminuição nas concentrações de P nas camadas 0-10, 10-20 e 20-40 cm (Tabela 28), provavelmente, devido à elevada demanda das plantas por este nutriente (Tabela 22); (ii) aumento nas concentrações de P nas camadas 60-80 e 80-100 cm (Tabela 28), porém, sem trazer implicações práticas, por não promover mudanças significativas na fertilidade deste solo. Foi observado, no mês de abril/2004, aumento nas concentrações de $\mathrm{P}$ em quase todas camadas (Tabela 28), que pode ter sido devido à adubação mineral realizada no mês de janeiro/2004 (Tabela 1).

Apesar do rendimento de MS do tratamento T1 ter sido superior ao do tratamento T2 (Tabela 5), o acúmulo de $\mathrm{P}$ nas plantas destes tratamentos não foi diferente (Tabela 22). Os tratamentos T1, T3 e T4 não apresentaram rendimento de MS diferentes (Tabela 5), porém as plantas dos tratamentos T3 e T4 acumularam maior quantidade de $\mathrm{P}$ que as plantas do tratamento $\mathrm{T} 1$ (Tabela 22). O tratamento T5 apresentou não somente maior rendimento de MS (Tabela 5), mas também, maior acúmulo de P (Tabela 22). Portanto, maiores doses de irrigação com ESET, implicando em aportes mais elevados de P-efluente (Tabela 4), apesar de não terem proporcionado alterações expressivas nas concentrações de $\mathrm{P}$ no solo (Tabela 28), ocasionaram incremento no acúmulo deste nutriente nas plantas (Tabela 22). Aumento no conteúdo de $\mathrm{P}$ em plantas forrageiras irrigadas com EET, ocasionando melhoria de qualidade (Hayes et al., 1990b), também foi relatado nos trabalhos de Adekalu \& Okunade (2002), Mohammad \& Ayadi (2004) e Barton et al. (2005).

As observações realizadas no presente estudo, com relação ao $\mathrm{P}$, indicaram que (i) o capim-Bermuda Tifton 85 foi um dreno eficiente do P-efluente, acumulando-o na sua parte aérea (Tabela 22); (ii) a alta extração de P pelo capim levou à diminuição na 
concentração disponível deste nutriente até $40 \mathrm{~cm}$; (iii) não foi excessiva a quantidade de P-efluente adicionada no sistema solo-pastagem, pois o capim foi cortado e removido da área, promovendo exportação de nutrientes; (iv) as concentrações de $\mathrm{P}_{-}-\mathrm{H}_{2} \mathrm{PO}_{4}{ }^{-}$na solução no solo encontravam-se abaixo do limite de detecção do método empregado (25 $\mu \mathrm{g} \mathrm{L}^{-1}$ ), indicando que o sistema solo-pastagem atuou como "filtro-vivo" em relação ao P-efluente, evitando sua migração (em altas concentrações) abaixo da zona radicular. Portanto, o manejo do sistema solo-pastagem empregado neste estudo permitiu a utilização eficiente do P-efluente, promoveu aumento de qualidade do capim e ainda, não ocasionou riscos de poluição deste nutriente, concordando com os trabalhos realizados por Kardos \& Hook (1976), Ryden \& Pratt (1980), Hook (1981), Goh \& Condron (1989) e Barton et al. (2005).

Ao que parece, as concentrações de P-efluente, assim como às de $\mathrm{Ca}, \mathrm{Mg}$ e $\mathrm{K}$ não deveriam, quando se tratar de solo tropical sob pastagem com elevada demanda por nutrientes, serem consideradas no manejo da fertilidade do solo. Isso porque o ESET proporcionou pequenas alterações nas concentrações disponíveis desses nutrientes no solo (Tabelas 13, 16, 18 e 28).

Com relação ao $\mathrm{S}$ disponível, os tratamentos empregados alteraram as concentrações deste nutriente nas camadas 0-10, 20-40 e 60-80 cm (Tabela 29). Na camada 0-10 cm, foi observada maior concentração de $\mathrm{S}$ no tratamento T2 que nos tratamentos T1, T4 e T5; ainda, o tratamento T3 não foi diferente dos demais (Tabela 29). Na camada 20-40 cm, as concentrações de $\mathrm{S}$ nos tratamentos $\mathrm{T} 2$ e T4, que não foram diferentes dos tratamentos T3 e T5, foram maiores que as concentrações deste nutriente no tratamento T1 (Tabela 29). Na camada 60-80 cm, o tratamento T2, que não diferiu do tratamento T1, apresentou maior concentração de S que os tratamentos T3 e T4, que não diferiram do tratamento T5 (Tabela 29). O fato de o tratamento T2 ter, geralmente, proporcionado maiores concentrações de $\mathrm{S}$ disponível no solo, pode estar relacionado ao menor rendimento de MS (Tabela 5 e Figura 3) e, conseqüentemente, baixo acúmulo deste nutriente no capim (Tabela 22), restando maior quantidade de $\mathrm{S}$ disponível no solo (Tabela 29). 
Tabela 29. Efeitos da irrigação (água e efluente) e de doses de nitrogênio mineral nas concentrações de S disponível no solo

\begin{tabular}{|c|c|c|c|c|c|c|c|}
\hline \multirow{2}{*}{ Tratamento } & \multicolumn{7}{|c|}{ Época de avaliação } \\
\hline & Abr/03 & Jul/03 & Out/03 & Jan/04 & Abr/04 & Jul/04 & Média \\
\hline & \multicolumn{7}{|c|}{$\mathrm{mg} \mathrm{kg}^{-1}$} \\
\hline \multicolumn{8}{|c|}{ Camada 0-10 cm (CV = 22,23\%) } \\
\hline$T 1^{(1)}$ & 24,99 & 14,21 & 10,33 & 12,92 & 19,69 & 19,19 & $16,89^{b(6)}$ \\
\hline$T 2^{(2)}$ & 31,26 & 20,35 & 22,48 & 19,58 & 16,13 & 25,99 & $22,63^{\mathrm{a}}$ \\
\hline T3 ${ }^{(3)}$ & 21,18 & 19,09 & 32,30 & 13,37 & 13,43 & 18,81 & $19,70^{a b}$ \\
\hline$T 4^{(4)}$ & 25,77 & 16,18 & 15,38 & 18,53 & 15,00 & 16,69 & $17,92^{\mathrm{b}}$ \\
\hline $\mathbf{T} 5^{(5)}$ & 28,94 & 17,37 & 9,31 & 16,45 & 19,80 & 16,46 & $18,05^{b}$ \\
\hline Média & $26,43^{\mathrm{A}}$ & $17,44^{\mathrm{B}}$ & $17,96^{\mathrm{B}}$ & $16,17^{\text {B }}$ & $16,81^{\mathrm{B}}$ & $19,43^{\text {B }}$ & \\
\hline \multicolumn{8}{|c|}{ Camada $10-20 \mathrm{~cm}(C V=23,66 \%)$} \\
\hline $\mathrm{T} 1$ & 25,59 & 19,12 & 13,56 & 25,32 & 18,15 & 23,63 & $20,90^{\mathrm{a}}$ \\
\hline $\mathbf{T} 2$ & 25,58 & 21,61 & 26,74 & 17,06 & 17,55 & 21,05 & $21,60^{\mathrm{a}}$ \\
\hline T3 & 15,90 & 14,05 & 28,94 & 21,50 & 13,80 & 18,48 & $18,78^{\mathrm{a}}$ \\
\hline T4 & 26,16 & 12,79 & 12,41 & 36,81 & 15,68 & 17,58 & $20,24^{\mathrm{a}}$ \\
\hline T5 & 39,01 & 13,08 & 9,56 & 31,58 & 17,29 & 17,02 & $21,26^{\mathrm{a}}$ \\
\hline Média & $26,45^{\mathrm{A}}$ & $16,13^{\mathrm{B}}$ & $18,24^{\mathrm{B}}$ & $26,45^{\mathrm{A}}$ & $16,49^{\mathrm{B}}$ & $19,55^{\mathrm{B}}$ & \\
\hline \multicolumn{8}{|c|}{ Camada $20-40 \mathrm{~cm}(C V=25,01 \%)$} \\
\hline T1 & 32,04 & 25,09 & 23,72 & 21,32 & 14,06 & 27,44 & $23,95^{b}$ \\
\hline T2 & 38,24 & 26,79 & 47,02 & 39,60 & 30,79 & 25,42 & $34,64^{\mathrm{a}}$ \\
\hline T3 & 33,13 & 23,25 & 36,30 & 39,87 & 24,60 & 30,81 & $31,33^{a b}$ \\
\hline T4 & 42,24 & 26,64 & 43,31 & 46,70 & 21,08 & 27,52 & $34,58^{\mathrm{a}}$ \\
\hline T5 & 49,07 & 20,63 & 26,48 & 25,38 & 21,23 & 20,19 & $27,16^{\mathrm{ab}}$ \\
\hline Média & $38,95^{\mathrm{A}}$ & $24,48^{\mathrm{B}}$ & $35,37^{\mathrm{A}}$ & $34,58^{\mathrm{A}}$ & $22,35^{\mathrm{B}}$ & $26,28^{\mathrm{B}}$ & \\
\hline \multicolumn{8}{|c|}{ Camada $40-60 \mathrm{~cm}(C V=31,56 \%)$} \\
\hline $\mathrm{T} 1$ & 31,97 & 24,70 & 12,71 & 45,35 & 21,29 & 21,68 & $26,28^{\mathrm{a}}$ \\
\hline T2 & 30,74 & 21,70 & 34,49 & 51,67 & 32,36 & 30,80 & $33,63^{a}$ \\
\hline T3 & 18,99 & 12,69 & 17,57 & 50,57 & 22,43 & 40,82 & $27,18^{\mathrm{a}}$ \\
\hline T4 & 47,09 & 16,18 & 26,20 & 32,75 & 30,53 & 29,91 & $30,44^{\mathrm{a}}$ \\
\hline T5 & 40,30 & 22,86 & 33,93 & 35,27 & 25,80 & 39,44 & $32,93^{\mathrm{a}}$ \\
\hline Média & $33,82^{\mathrm{B}}$ & $19,63^{\mathrm{D}}$ & $24,98^{\mathrm{CD}}$ & $43,12^{\mathrm{A}}$ & $26,48^{\mathrm{BCD}}$ & $32,53^{\mathrm{BC}}$ & \\
\hline \multicolumn{8}{|c|}{ Camada $60-80 \mathrm{~cm}(\mathrm{CV}=43,16 \%)$} \\
\hline T1 & 29,64 & 20,79 & 12,54 & 35,46 & 27,30 & 20,04 & $28,46^{\mathrm{ab}}$ \\
\hline T2 & 17,25 & 10,95 & 33,19 & 34,33 & 50,29 & 63,99 & $35,00^{\mathrm{a}}$ \\
\hline T3 & 12,36 & 9,01 & 22,89 & 15,24 & 14,69 & 28,72 & $17,15^{\mathrm{c}}$ \\
\hline T4 & 16,53 & 9,79 & 15,50 & 18,79 & 26,09 & 33,21 & $19,99^{\mathrm{c}}$ \\
\hline T5 & 18,79 & 14,15 & 13,82 & 36,05 & 19,95 & 33,50 & $22,71^{b c}$ \\
\hline Média & $23,91^{\mathrm{B}}$ & $12,94^{\mathrm{C}}$ & $19,59^{\mathrm{BC}}$ & $27,98^{\mathrm{AB}}$ & $27,66^{\mathrm{AB}}$ & $35,89^{\mathrm{A}}$ & \\
\hline
\end{tabular}


Tabela 29. Efeitos da irrigação (água e efluente) e de doses de nitrogênio mineral nas concentrações de S disponível no solo

\begin{tabular}{|c|c|c|c|c|c|c|c|}
\hline \multirow{2}{*}{ Tratamento } & \multicolumn{7}{|c|}{ Época de avaliação } \\
\hline & Abr/03 & Jul/03 & Out/03 & Jan/04 & Abr/04 & Jul/04 & Média \\
\hline & \multicolumn{7}{|c|}{$\mathrm{mg} \mathrm{kg}^{-1}$} \\
\hline \multicolumn{8}{|c|}{ Camada $80-100 \mathrm{~cm}(C V=36,92 \%)$} \\
\hline T1 & 19,64 & 15,69 & 11,04 & 9,27 & 17,18 & 26,02 & $16,47^{\mathrm{a}}$ \\
\hline T2 & 14,92 & 15,50 & 12,53 & 13,44 & 32,70 & 32,47 & $20,26^{\mathrm{a}}$ \\
\hline T3 & 16,47 & 13,57 & 27,91 & 10,59 & 24,93 & 27,35 & $20,14^{\mathrm{a}}$ \\
\hline T4 & 14,15 & 14,28 & 18,25 & 23,25 & 20,19 & 32,71 & $20,47^{\mathrm{a}}$ \\
\hline T5 & 15,90 & 16,16 & 23,77 & 14,34 & 21,00 & 24,53 & $19,28^{\mathrm{a}}$ \\
\hline Média & $16,21^{\mathrm{CD}}$ & $15,04^{\mathrm{CD}}$ & $18,70^{\mathrm{C}}$ & $14,18^{\mathrm{D}}$ & $23,20^{\mathrm{B}}$ & $28,62^{\mathrm{A}}$ & \\
\hline \multicolumn{8}{|c|}{$\begin{array}{l}\text { (1) T1: irrigação com água }+520 \mathrm{~kg} \mathrm{ha}^{-1} \text { ano }^{-1} \text { de nitrogênio via fertilizante mineral (NFM); } \\
\text { (2) T2: irrigação com efluente secundário de esgoto tratado (ESET), sem NFM; } \\
\text { (3) T3: irrigação com ESET }+171,6 \mathrm{~kg} \mathrm{ha}^{-1} \mathrm{ano}^{-1} \text { de NFM; } \\
\text { (4) T4: irrigação com ESET }+343,3 \mathrm{~kg} \mathrm{ha}^{-1} \mathrm{ano}^{-1} \text { de NFM; } \\
\text { (5) T5: irrigação com ESET + } 520 \mathrm{~kg} \mathrm{ha}^{-1} \mathrm{ano}^{-1} \text { de NFM; } \\
\text { (6) Letras iguais maiúsculas ou minúsculas nas linhas e nas colunas, respectivamente, nã } \\
\text { diferem estatisticamente pelo teste de Tukey }(P<0,05) \text {. }\end{array}$} \\
\hline
\end{tabular}

Comparando-se os tratametos $\mathrm{T} 1$ e $\mathrm{T} 5$, que receberam as mesmas doses de fertilizantes minerais (Tabela 1), nota-se que as concentrações de S no solo não foram diferentes (Tabela 29); porém, o acúmulo deste nutriente no capim foi maior no tratamento T5 (Tabela 22). O fato de o ESET, em condições similares de fertilização mineral, não ter proprocionado alterações nas concentrações de S disponível no solo está de acordo com os resultados de Quin \& Woods (1978) e Fonseca (2001).

Analisando-se os tratamentos irrigados com ESET (T2, T3, T4 e T5), foi observado que o aporte diferenciado de S-efluente (Tabela 4) não implicou em aumento nas concentrações deste nutriente no solo (Tabela 29). No entanto, foi observado maior acúmulo de $\mathrm{S}$ nas plantas do tratamento T5 (Tabela 22), que demandaram mais irrigação, ou seja, onde o aporte de S-efluente foi mais elevado (Tabela 4). Pelo fato de as concentrações de S no ESET e na água terem sido similares (Tabela 3), a quantidade de irrigação empregada nos tratamentos (Tabela 4) foi o principal fator que governou a quantidade de $\mathrm{S}$ acumulada no capim (Tabela 22). Essa afirmação é válida, pois os tratamentos T1 e T3 receberam lâminas similares de irrigação (Figura 2) e não houve 
diferenças entre as quantidades de $\mathrm{S}$ acumulado nas plantas destes tratamentos (Tabela 22).

As concentrações de $\mathrm{S}$ disponível no decorrer do experimento foram (i) aumentando nas camadas subsuperficiais do solo, sobretudo nas de 60-80 e 80-100 cm; (ii) diminuindo nas camadas superficiais, principalmente, na de 0-10 cm (Tabela 29). Nas camadas 10-20 e 20-40 cm, as concentrações de $\mathrm{S}$ aumentaram em algumas épocas e diminuíram posteriormente (Tabela 29). Comparando-se as concentrações médias dos tratamentos nos meses de abril/2003 e julho/2004, as concentrações de S foram menores no último período, exceto nas camadas 40-60, 60-80 e 80-100 cm (Tabela 29). Essas diminuições nas concentrações de S nas camadas 0-10, 10-20 e 20-40 cm podem estar relacionadas com (i) maior absorção deste nutriente pelas plantas, principalmente, no segundo semestre (Tabela 22); (ii) interações do $\mathrm{S}_{-} \mathrm{SO}_{4}{ }^{-}$no solo, devido ao aporte de nutrientes via fertilização mineral (Tabela 1) e via irrigação (Tabela 4). A presença de maiores concentrações de P (Tabela 28) e de CT (Tabela 2) nas camadas superficiais pode ter implicado em menores e maiores concentrações de $\mathrm{S}$ nestas camadas e no subsolo, respectivamente (Tabela 29). Isso porque os ânions $\mathrm{H}_{2} \mathrm{PO}_{4}{ }^{-}$e ligantes orgânicos são mais competitivos pelos sítios de adsorção que o $\mathrm{SO}_{4}{ }^{2-}$, ocasionando incremento na dessorção deste último composto para a solução (Meurer et al., 2004). Portanto, concentrações mais elevadas de $\mathrm{SO}_{4}{ }^{2-}$ em solução implica na sua lixiação para camadas subsuperficiais, ocasionando aumento nas concentrações disponíveis deste nutriente em subsuperfície.

Com excessão da camada $80-100 \mathrm{~cm}$, nas demais camadas os tratamentos ou promoveram pequenas alterações nas concentrações de $S$ disponível (Tabela 29) ou ocasionaram mudanças nas concentrações de $\mathrm{S}$ solúvel (Tabela 30). As interações entre concentrações disponíveis e solúveis de $\mathrm{S}$ foram (i) correlação negativa para as camadas 0-10 $\left(r=-0,40^{*}\right)$ e 10-20 $\left(r=-0,38^{*}\right)$; (ii) ausência de correlação para a camada 20-40 $\mathrm{cm}\left(r=-0,12^{\mathrm{NS}}\right)$; (iii) correlação positiva para as camadas 40-60 $\left(r=0,49^{* *}\right), 60-80(r=$ $\left.0,63^{* *}\right)$ e $80-100 \mathrm{~cm}\left(r=0,66^{* *}\right)$. Os altos CV de $\mathrm{S}$ solúvel (Tabela 30$)$, associados aos baixos coeficientes de correlação entre as concentrações disponíveis e solúveis deste 
Tabela 30. Efeitos da irrigação (água e efluente) e de doses de nitrogênio mineral nas concentrações de S na solução no solo

\begin{tabular}{|c|c|c|c|c|c|c|c|}
\hline \multirow{2}{*}{ Tratamento } & \multicolumn{7}{|c|}{ Época de avaliação } \\
\hline & Abr/03 & Jul/03 & Out/03 & Jan/04 & Abr/04 & Jul/04 & Média \\
\hline & \multicolumn{7}{|c|}{$m g L^{-1}$} \\
\hline \multicolumn{8}{|c|}{ Camada 0-10 cm (CV = 34,42\%) } \\
\hline $\mathrm{T1}^{(1)}$ & 15,16 & 18,67 & 19,48 & 20,43 & 17,41 & 5,67 & $16,14^{\mathrm{a}(6)}$ \\
\hline $\mathbf{T} 2^{(2)}$ & 12,45 & 22,69 & 22,43 & 10,72 & 14,68 & 10,70 & $15,61^{\mathrm{a}}$ \\
\hline $\mathbf{T} 3^{(3)}$ & 10,33 & 19,82 & 15,44 & 8,40 & 12,71 & 4,60 & $11,88^{\mathrm{a}}$ \\
\hline$T 4^{(4)}$ & 10,64 & 20,45 & 23,20 & 6,21 & 19,36 & 6,98 & $14,47^{\mathrm{a}}$ \\
\hline $\mathbf{T} 5^{(5)}$ & 9,31 & 21,03 & 14,78 & 7,84 & 19,21 & 7,37 & $13,26^{\mathrm{a}}$ \\
\hline Média & $11,58^{\mathrm{BC}}$ & $20,53^{\mathrm{A}}$ & $19,07^{\mathrm{A}}$ & $10,72^{\mathrm{C}}$ & $16,67^{\mathrm{BC}}$ & $7,07^{\mathrm{C}}$ & \\
\hline \multicolumn{8}{|c|}{ Camada $10-20 \mathrm{~cm}(C V=33,95 \%)$} \\
\hline T1 & 24,29 & 14,96 & 11,60 & 5,65 & 7,23 & 2,60 & $11,06^{\mathrm{ab}}$ \\
\hline T2 & 12,25 & 10,64 & 22,07 & 9,19 & 10,73 & 5,78 & $11,78^{\mathrm{a}}$ \\
\hline T3 & 11,09 & 8,39 & 25,42 & 7,51 & 10,24 & 5,07 & $11,29^{a b}$ \\
\hline T4 & 11,33 & 8,02 & 20,20 & 5,06 & 10,75 & 5,14 & $10,08^{a b}$ \\
\hline T5 & 3,07 & 7,34 & 15,23 & 4,13 & 9,36 & 3,65 & $7,13^{\mathrm{b}}$ \\
\hline Média & $12,41^{\mathrm{B}}$ & $9,87^{\mathrm{BC}}$ & $18,90^{\mathrm{A}}$ & $6,31^{\mathrm{CD}}$ & $9,66^{\mathrm{BC}}$ & $4,45^{\mathrm{D}}$ & \\
\hline \multicolumn{8}{|c|}{ Camada $20-40 \mathrm{~cm}(C V=40,15 \%)$} \\
\hline $\mathrm{T1}$ & 10,45 & 4,16 & 4,38 & 13,97 & 11,25 & 6,44 & $8,44^{\mathrm{a}}$ \\
\hline T2 & 8,88 & 4,48 & 10,55 & 20,14 & 13,99 & 9,51 & $11,26^{\mathrm{a}}$ \\
\hline T3 & 7,79 & 3,86 & 7,58 & 19,26 & 13,85 & 9,14 & $10,25^{\mathrm{a}}$ \\
\hline T4 & 8,18 & 2,61 & 8,11 & 21,89 & 9,88 & 9,60 & $10,04^{\mathrm{a}}$ \\
\hline T5 & 8,67 & 4,22 & 10,00 & 13,48 & 4,09 & 9,39 & $8,31^{\mathrm{a}}$ \\
\hline Média & $8,79^{\mathrm{B}}$ & $3,86^{\mathrm{C}}$ & $8,12^{\mathrm{B}}$ & $17,75^{\mathrm{A}}$ & $10,61^{\mathrm{B}}$ & $8,81^{\mathrm{B}}$ & \\
\hline \multicolumn{8}{|c|}{ Camada $40-60 \mathrm{~cm}(C V=54,19 \%)$} \\
\hline $\mathrm{T1}$ & 2,23 & 3,18 & 1,36 & 9,38 & 7,21 & 11,74 & $5,85^{\mathrm{ab}}$ \\
\hline T2 & 1,55 & 5,02 & 1,90 & 14,05 & 8,64 & 10,27 & $6,90^{\mathrm{a}}$ \\
\hline T3 & 1,79 & 1,54 & 0,42 & 3,95 & 5,53 & 6,17 & $3,23^{c}$ \\
\hline T4 & 2,00 & 1,51 & 1,42 & 5,77 & 6,42 & 9,25 & $4,39 \mathrm{abc}$ \\
\hline T5 & 0,95 & 2,04 & 1,33 & 6,35 & 3,28 & 6,75 & $3,45^{\mathrm{bc}}$ \\
\hline Média & $1,70^{\mathrm{B}}$ & $2,66^{\mathrm{B}}$ & $1,29^{\mathrm{B}}$ & $7,90^{\mathrm{A}}$ & $6,22^{\mathrm{A}}$ & $8,83^{\mathrm{A}}$ & \\
\hline \multicolumn{8}{|c|}{ Camada $60-80 \mathrm{~cm}(C V=89,04 \%)$} \\
\hline T1 & 0,37 & 0,63 & 0,13 & 0,20 & 0,63 & 2,23 & $0,70^{\mathrm{a}}$ \\
\hline $\mathbf{T 2}$ & 0,36 & 0,49 & 1,31 & 0,87 & 0,23 & 1,19 & $0,74^{\mathrm{a}}$ \\
\hline T3 & 0,26 & 0,20 & 0,14 & 0,06 & 1,72 & 1,63 & $0,67^{\mathrm{a}}$ \\
\hline T4 & 0,24 & 0,27 & 0,32 & 0,13 & 1,16 & 2,36 & $0,74^{\mathrm{a}}$ \\
\hline T5 & 0,22 & 0,24 & 0,30 & 0,58 & 0,77 & 2,32 & $0,74^{\mathrm{a}}$ \\
\hline Média & $0,29^{\mathrm{B}}$ & $0,37^{\mathrm{B}}$ & $0,44^{\mathrm{B}}$ & $0,37^{\mathrm{B}}$ & $0,90^{\mathrm{B}}$ & $1,95^{\mathrm{A}}$ & \\
\hline
\end{tabular}


Tabela 30. Efeitos da irrigação (água e efluente) e de doses de nitrogênio mineral nas concentrações de S na solução no solo

\begin{tabular}{|c|c|c|c|c|c|c|c|}
\hline \multirow{2}{*}{ Tratamento } & \multicolumn{7}{|c|}{ Época de avaliação } \\
\hline & Abr/03 & $\mathrm{Jul} / \mathbf{0 3}$ & Out/03 & Jan/04 & Abr $/ 04$ & Jul/04 & Média \\
\hline & \multicolumn{7}{|c|}{$\mathbf{m g} \mathbf{L}^{-1}$} \\
\hline \multicolumn{8}{|c|}{ Camada $80-100 \mathrm{~cm}(C V=96,85 \%)$} \\
\hline T1 & 0,21 & 0,94 & 0,31 & 0,21 & 0,11 & 0,74 & $0,42^{\mathrm{a}}$ \\
\hline T2 & 0,15 & 0,33 & 0,44 & 0,44 & 0,51 & 0,60 & $0,41^{\mathrm{a}}$ \\
\hline T3 & 0,15 & 0,14 & 0,34 & 0,30 & 0,39 & 0,62 & $0,32^{\mathrm{a}}$ \\
\hline T4 & 0,06 & 0,20 & 0,21 & 0,12 & 0,23 & 0,56 & $0,23^{\mathrm{a}}$ \\
\hline T5 & 0,05 & 0,21 & 0,26 & 0,08 & 0,55 & 0,84 & $0,33^{\mathrm{a}}$ \\
\hline Média & $0,13^{\mathrm{B}}$ & $0,36^{\mathrm{AB}}$ & $0,31^{\mathrm{AB}}$ & $0,23^{\mathrm{B}}$ & $0,36^{\mathrm{AB}}$ & $0,67^{\mathrm{A}}$ & \\
\hline
\end{tabular}

(1) T1: irrigação com água $+520 \mathrm{~kg} \mathrm{ha}^{-1}$ ano $^{-1}$ de nitrogênio via fertilizante mineral (NFM);

(2) T2: irrigação com efluente secundário de esgoto tratado (ESET), sem NFM;

(3) T3: irrigação com ESET + 171,6 kg ha-1 $\mathrm{ano}^{-1}$ de NFM;

(4) T4: irrigação com ESET + 343,3 $\mathrm{kg} \mathrm{ha}^{-1} \mathrm{ano}^{-1}$ de NFM;

(5) T5: irrigação com ESET + $520 \mathrm{~kg} \mathrm{ha}^{-1} \mathrm{ano}^{-1}$ de NFM;

(6) Letras iguais maiúsculas ou minúsculas nas linhas e nas colunas, respectivamente, não diferem estatisticamente pelo teste de Tukey $(P<0,05)$;

${ }^{\text {(7) }} \mathrm{LD}$ : limite de detecção $\left(50 \mu \mathrm{g} \mathrm{L}{ }^{-1}\right)$.

nutriente, indicaram que resultados dos extratos de saturação também deixaram a desejar com relação ao nutriente S na solução.

As quantidades de $\mathrm{S}$ acumulado nas plantas foram diferentes tanto para os tratamentos como para as épocas de avaliação (Tabela 22). Maiores quantidades de $\mathrm{S}$ foram extraídas e acumuladas por ocasião do segundo semestre (Tabela 22), período que as plantas apresentaram maior crescimento e rendimento e, conseqüentemente, demandaram maior quantidade de nutrientes, inclusive de S (Tabela 22). O tratamento T5, que recebeu maior dose de irrigação e, portanto, aporte mais elevado de S-efluente (Tabela 4), acumulou maior quantidade deste nutriente (Tabela 22). As plantas dos tratamentos T1, T3 e T4 acumularam menor quantidade de $\mathrm{S}$ que as plantas do tratamento T5, mas superaram as plantas do tratamento T2 (Tabela 22).

Os trabalhos relacionados aos efeitos da irrigação com EET no sistema soloplanta não têm focado, normalmente, o nutriente S. Isso porque na maioria das situações as concentrações de $\mathrm{S}_{-} \mathrm{SO}_{4}{ }^{2-}$ são similares tanto na água de irrigação, que é empregada no tratamento controle, quanto no EET, que é utilizado nos demais tratamentos. Ainda, 
em um experimento conduzido em casa de vegetação por Fonseca (2001), não foram observadas diferenças tanto para as concentrações disponíveis de S no solo quanto para o acúmulo deste nutriente no milho, apesar de ter sido empregada água deionizada na irrigação do tratamento controle.

Os tratamentos não ocasionaram alterações nas concentrações de CT (Tabela 31) e NT (Tabela 32) no solo. Assim, o tipo de água empregada na irrigação, bem como as doses de NFM e o aporte de N-efluente não foram o bastante para promover alterações nas concentrações desses elementos no solo. Essas informações discordaram de vários resultados de pesquisas publicados no exterior. Quin \& Woods (1978) verificaram aumento nas concentrações de CT e NT no solo sob pastagem de azevémperene, submetida à irrigação com EET por mais de 16 anos. Latterell et al. (1982) observaram aumento nas concentrações de CT e NT no solo cultivado com milho, submetido à irrigação com EET durante cinco anos. Mancino \& Pepper (1992) verificaram aumento e manutenção das concentrações de CT no solo sob pastagem de capim-Bermuda, submetida à irrigação com EET por 3,2 anos. Zekri \& Koo (1994) observaram diminuição nas concentrações de NT nos solos arenosos (da Florida, EUA) cultivados com citrus, submetido à irrigação com EET por cinco anos. Polglase et al. (1995) e Falkiner \& Smith (1997) verificam aumento na taxa de decomposição da MOS de plantações florestais irrigadas com EET, ocasionando diminuição nas concentrações de CT e NT. Paliwal et al. (1998) observaram aumento nas concentrações de NT em solo sob plantações florestais submetidas à irrigação com EET. Agunwamba (2001) verificou incremento de aproximadamente $100 \%$ nas concentrações de NT no solo, após quatro anos de aplicação de EET nas culturas de milho, mandioca, inhame e feijão. Adekalu \& Okunade (2002) e Mohammad \& Mazahreh (2003) observaram incrementos nas concentrações de NT e CT no solo, respectivamente, após cultivo de milho submetido à irrigação com EET. Madyiwa et al. (2002) verificaram aumento de 2,6\% na concentração de CT em solo sob pastagem de capim-Kikuyu e capim-Estrela (Cynodon nlemfuensis), submetidos à irrigação com EET por 29 anos. Ramirez-Fuentes et al. (2002) observaram pequenos efeitos, que foram se somando ao longo de um, dois, 22 , 
Tabela 31. Efeitos da irrigação (água e efluente) e de doses de nitrogênio mineral nas concentrações de carbono total (CT) no solo

\begin{tabular}{|c|c|c|c|c|c|c|}
\hline \multirow{2}{*}{ Tratamento } & \multicolumn{6}{|c|}{ Época de avaliação } \\
\hline & Abr/03 & Jul/03 & Out/03 & Jan/04 & Jul/04 & Média \\
\hline & \multicolumn{6}{|c|}{$\mathbf{g ~ k g}^{-1}$} \\
\hline \multicolumn{7}{|c|}{ Camada 0-10 cm (CV = 8,44\%) } \\
\hline $\mathrm{T1}^{(1)}$ & 7,42 & 6,86 & 6,23 & 5,88 & 6,90 & $6,66^{\text {a (6) }}$ \\
\hline $\mathbf{T} 2^{(2)}$ & 7,25 & 6,66 & 6,43 & 6,00 & 6,45 & $6,56^{\mathrm{a}}$ \\
\hline T3 ${ }^{(3)}$ & 7,29 & 7,08 & 6,40 & 6,50 & 6,23 & $6,70^{\mathrm{a}}$ \\
\hline $\mathbf{T 4}{ }^{(4)}$ & 7,40 & 6,10 & 6,50 & 6,87 & 6,29 & $6,63^{\mathrm{a}}$ \\
\hline $\mathbf{T} 5^{(5)}$ & 6,80 & 6,39 & 6,03 & 5,70 & 6,03 & $6,19^{a}$ \\
\hline Média & $7,23^{\mathrm{A}}$ & $6,62^{\mathrm{B}}$ & $6,32^{\mathrm{B}}$ & $6,19^{\mathrm{B}}$ & $6,38^{\mathrm{B}}$ & \\
\hline \multicolumn{7}{|c|}{ Camada 10-20 cm (CV = 7,29\%) } \\
\hline T1 & 6,36 & 5,56 & 5,77 & 6,04 & 5,30 & $5,80^{\mathrm{a}}$ \\
\hline T2 & 6,57 & 6,22 & 6,20 & 5,95 & 5,20 & $6,03^{\mathrm{a}}$ \\
\hline T3 & 7,24 & 6,14 & 6,40 & 6,01 & 5,23 & $6,20^{\mathrm{a}}$ \\
\hline T4 & 6,45 & 5,87 & 6,13 & 5,98 & 5,48 & $5,98^{\mathrm{a}}$ \\
\hline T5 & 6,37 & 5,60 & 5,80 & 5,93 & 5,20 & $5,78^{a}$ \\
\hline Média & $6,60^{\mathrm{A}}$ & $5,88^{\mathrm{B}}$ & $6,06^{\mathrm{B}}$ & $5,98^{\mathrm{B}}$ & $5,28^{\mathrm{C}}$ & \\
\hline \multicolumn{7}{|c|}{ Camada $20-40 \mathrm{~cm}(C V=10,91 \%)$} \\
\hline T1 & 6,12 & 5,26 & 5,13 & 5,07 & 4,63 & $5,24^{\mathrm{a}}$ \\
\hline $\mathbf{T} 2$ & 6,36 & 5,36 & 5,50 & 5,33 & 4,88 & $5,48^{\mathrm{a}}$ \\
\hline T3 & 6,34 & 5,33 & 5,27 & 5,48 & 4,61 & $5,40^{\mathrm{a}}$ \\
\hline T4 & 5,96 & 5,31 & 5,33 & 5,61 & 4,73 & $5,39^{a}$ \\
\hline T5 & 6,10 & 5,30 & 5,30 & 5,55 & 3,73 & $5,20^{\mathrm{a}}$ \\
\hline Média & $6,18^{A}$ & $5,31^{\mathrm{B}}$ & $5,30^{\mathrm{B}}$ & $5,40^{\mathrm{B}}$ & $4,51^{\mathrm{C}}$ & \\
\hline \multicolumn{7}{|c|}{ Camada 40-60 cm (CV = 7,43\%) } \\
\hline T1 & 5,12 & 4,57 & 4,23 & 4,35 & 4,20 & $4,49^{\mathrm{a}}$ \\
\hline T2 & 5,53 & 4,36 & 4,60 & 4,31 & 4,08 & $4,58^{\mathrm{a}}$ \\
\hline T3 & 5,39 & 4,33 & 4,33 & 4,08 & 3,71 & $4,37^{\mathrm{a}}$ \\
\hline T4 & 4,80 & 4,61 & 4,30 & 4,64 & 3,88 & $4,45^{\mathrm{a}}$ \\
\hline T5 & 5,23 & 4,38 & 4,73 & 4,40 & 4,03 & $4,55^{\mathrm{a}}$ \\
\hline Média & $5,22^{\mathrm{A}}$ & $4,45^{\mathrm{B}}$ & $4,44^{\mathrm{B}}$ & $4,36^{\mathrm{B}}$ & $3,98^{\mathrm{C}}$ & \\
\hline \multicolumn{7}{|c|}{ Camada $60-80 \mathrm{~cm}(C V=9,30 \%)$} \\
\hline T1 & 4,03 & 3,61 & 3,43 & 3,40 & 3,40 & $3,58^{\mathrm{a}}$ \\
\hline $\mathbf{T} 2$ & 4,32 & 3,68 & 3,73 & 3,40 & 3,13 & $3,65^{\mathrm{a}}$ \\
\hline T3 & 4,12 & 3,77 & 3,25 & 3,08 & 3,13 & $3,47^{\mathrm{a}}$ \\
\hline T4 & 4,28 & 3,76 & 3,38 & 3,38 & 3,28 & $3,61^{\mathrm{a}}$ \\
\hline $\mathbf{T 5}$ & 4,03 & 3,34 & 3,53 & 3,41 & 3,25 & $3,51^{\mathrm{a}}$ \\
\hline Média & $4,16^{\mathrm{A}}$ & $3,63^{\mathrm{B}}$ & $3,46^{\mathrm{BC}}$ & $3,33^{\mathrm{C}}$ & $3,24^{\mathrm{C}}$ & \\
\hline
\end{tabular}


Tabela 31. Efeitos da irrigação (água e efluente) e de doses de nitrogênio mineral nas concentrações de carbono total (CT) no solo

\begin{tabular}{|c|c|c|c|c|c|c|}
\hline \multirow{2}{*}{ Tratamento } & \multicolumn{6}{|c|}{ Época de avaliação } \\
\hline & Abr/03 & Jul/03 & Out/03 & Jan/04 & Jul/04 & Média \\
\hline & \multicolumn{6}{|c|}{$\mathrm{g} \mathrm{kg}^{-1}$} \\
\hline \multicolumn{7}{|c|}{ Camada $80-100 \mathrm{~cm}(C V=8,10 \%)$} \\
\hline $\mathrm{T1}$ & 3,24 & 2,98 & 2,90 & 2,80 & 2,63 & $2,91^{\mathrm{a}}$ \\
\hline T2 & 3,69 & 2,64 & 2,93 & 3,00 & 2,80 & $3,01^{\mathrm{a}}$ \\
\hline T3 & 3,51 & 2,89 & 2,83 & 2,78 & 2,70 & $2,94^{\mathrm{a}}$ \\
\hline T4 & 3,30 & 2,98 & 2,75 & 2,85 & 2,83 & $2,94^{\mathrm{a}}$ \\
\hline T5 & 3,32 & 2,94 & 3,03 & 2,84 & 2,75 & $2,98^{\mathrm{a}}$ \\
\hline Média & $3,41^{\mathrm{A}}$ & $2,89^{\mathrm{B}}$ & $2,89^{\mathrm{B}}$ & $2,85^{\mathrm{B}}$ & $2,74^{\mathrm{B}}$ & \\
\hline \multicolumn{7}{|c|}{$\begin{array}{l}\text { (1) T1: irrigação com água }+520 \mathrm{~kg} \mathrm{ha}^{-1} \text { ano }^{-1} \text { de nitrogênio via fertilizante mineral (NFM); } \\
\text { (2) T2: irrigação com efluente secundário de esgoto tratado (ESET), sem NFM; } \\
\text { (3) T3: irrigação com ESET }+171,6 \mathrm{~kg} \mathrm{ha}^{-1} \mathrm{ano}^{-1} \text { de NFM; } \\
\text { (4) T4: irrigação com ESET }+343,3 \mathrm{~kg} \mathrm{ha}^{-1} \mathrm{ano}^{-1} \text { de NFM; } \\
\text { (5) T5: irrigação com ESET + } 520 \mathrm{~kg} \mathrm{ha}^{-1} \text { ano }^{-1} \text { de NFM; } \\
\text { (6) Letras iguais maiúsculas ou minúsculas nas linhas e nas colunas, respectivamente, nã } \\
\text { diferem estatisticamente pelo teste de Tukey }(P<0,05) \text {. }\end{array}$} \\
\hline
\end{tabular}

33, 73 e 86 anos de irrigação com EET, levando ao incremento nas concentrações de CT e NT no solo, para diferentes agrossistemas.

Por outro lado, o fato de o ESET não ter ocasionado alterações nas concentrações de CT (Tabela 31) e NT do solo (Tabela 32), está de acordo com os resultados de pesquisas realizadas por (i) Ross et al. (1978), que não observaram alterações nas concentrações de CT e NT em dez solos neozelandezes sob pastagens (azevém-perene, paspalum, trevo branco e capins nativos da região) submetidas à irrigação com 1700 a 2400 mm de EET durante 16 meses; (ii) Cromer et al. (1984), que não verificaram alterações nas concentrações de NT de solos florestais australianos submetidos à irrigação com EET; (iii) Agunwamba (2001), que não observou efeitos da irrigação com EET nas concentrações de CT em solos agrícolas nigerianos; (iv) Fonseca (2001), que não verificou alteração na concentração de CT em solo similar ao utilizado neste experimento, que foi cultivado com milho submetido à irrigação com ESET.

As concentrações de NT diminuiram, durante o período experimental, nas camadas 20-40 e 40-60 cm e apresentaram pequenas flutuações nas camadas 0-10, 
Tabela 32. Efeitos da irrigação (água e efluente) e de doses de nitrogênio mineral nas concentrações de nitrogênio total (NT) no solo

\begin{tabular}{|c|c|c|c|c|c|c|}
\hline \multirow{2}{*}{ Tratamento } & \multicolumn{6}{|c|}{ Época de avaliação } \\
\hline & Abr/03 & Jul/03 & Out/03 & Jan/04 & Jul/04 & Média \\
\hline & \multicolumn{6}{|c|}{$\mathrm{g} \mathrm{kg}^{-1}$} \\
\hline \multicolumn{7}{|c|}{ Camada 0-10 cm (CV = 9,41\%) } \\
\hline$T 1^{(1)}$ & 0,51 & 0,58 & 0,57 & 0,53 & 0,55 & $0,55^{\mathrm{a}(6)}$ \\
\hline $\mathbf{T 2}^{(2)}$ & 0,50 & 0,58 & 0,60 & 0,57 & 0,55 & $0,56^{\mathrm{a}}$ \\
\hline T3 ${ }^{(3)}$ & 0,53 & 0,57 & 0,58 & 0,55 & 0,58 & $0,56^{\mathrm{a}}$ \\
\hline$T 4^{(4)}$ & 0,56 & 0,51 & 0,58 & 0,55 & 0,55 & $0,55^{\mathrm{a}}$ \\
\hline $\mathbf{T} 5^{(5)}$ & 0,54 & 0,51 & 0,55 & 0,50 & 0,55 & $0,53^{\mathrm{a}}$ \\
\hline Média & $0,53^{\mathrm{B}}$ & $0,55^{\mathrm{AB}}$ & $0,57^{\mathrm{A}}$ & $0,54^{\mathrm{AB}}$ & $0,56^{\mathrm{AB}}$ & \\
\hline \multicolumn{7}{|c|}{ Camada $10-20 \mathrm{~cm}(\mathrm{CV}=9,44 \%)$} \\
\hline T1 & 0,50 & 0,51 & 0,53 & 0,50 & 0,48 & $0,50^{\mathrm{a}}$ \\
\hline T2 & 0,48 & 0,51 & 0,53 & 0,50 & 0,48 & $0,50^{\mathrm{a}}$ \\
\hline T3 & 0,49 & 0,52 & 0,55 & 0,50 & 0,50 & $0,51^{\mathrm{a}}$ \\
\hline T4 & 0,53 & 0,49 & 0,53 & 0,53 & 0,50 & $0,51^{\mathrm{a}}$ \\
\hline T5 & 0,47 & 0,47 & 0,53 & 0,53 & 0,45 & $0,49^{\mathrm{a}}$ \\
\hline Média & $0,49^{\mathrm{AB}}$ & $0,50^{\mathrm{AB}}$ & $0,53^{\mathrm{A}}$ & $0,51^{\mathrm{AB}}$ & $0,48^{\mathrm{B}}$ & \\
\hline \multicolumn{7}{|c|}{ Camada $20-40 \mathrm{~cm}(C V=9,65 \%)$} \\
\hline $\mathrm{T} 1$ & 0,49 & 0,48 & 0,48 & 0,46 & 0,43 & $0,47^{\mathrm{a}}$ \\
\hline T2 & 0,48 & 0,45 & 0,50 & 0,48 & 0,40 & $0,46^{\mathrm{a}}$ \\
\hline T3 & 0,45 & 0,46 & 0,48 & 0,47 & 0,40 & $0,45^{\mathrm{a}}$ \\
\hline T4 & 0,46 & 0,45 & 0,48 & 0,48 & 0,40 & $0,45^{\mathrm{a}}$ \\
\hline T5 & 0,48 & 0,46 & 0,48 & 0,48 & 0,43 & $0,46^{\mathrm{a}}$ \\
\hline Média & $0,47^{\mathrm{A}}$ & $0,46^{\mathrm{A}}$ & $0,48^{\mathrm{A}}$ & $0,47^{\mathrm{A}}$ & $0,41^{\mathrm{B}}$ & \\
\hline \multicolumn{7}{|c|}{ Camada $40-60 \mathrm{~cm}(C V=10,96 \%)$} \\
\hline T1 & 0,41 & 0,40 & 0,43 & 0,40 & 0,33 & $0,39^{\mathrm{a}}$ \\
\hline T2 & 0,40 & 0,38 & 0,40 & 0,40 & 0,33 & $0,38^{\mathrm{a}}$ \\
\hline T3 & 0,38 & 0,39 & 0,40 & 0,39 & 0,30 & $0,37^{\mathrm{a}}$ \\
\hline T4 & 0,37 & 0,38 & 0,38 & 0,40 & 0,33 & $0,37^{\mathrm{a}}$ \\
\hline T5 & 0,41 & 0,34 & 0,43 & 0,40 & 0,33 & $0,38^{\mathrm{a}}$ \\
\hline Média & $0,39^{\mathrm{A}}$ & $0,38^{\mathrm{A}}$ & $0,41^{\mathrm{A}}$ & $0,40^{\mathrm{A}}$ & $0,32^{\mathrm{B}}$ & \\
\hline \multicolumn{7}{|c|}{ Camada $60-80 \mathrm{~cm}(\mathrm{CV}=10,10 \%)$} \\
\hline $\mathrm{T} 1$ & 0,31 & 0,31 & 0,33 & 0,30 & 0,26 & $0,30^{\mathrm{a}}$ \\
\hline T2 & 0,29 & 0,32 & 0,35 & 0,30 & 0,28 & $0,31^{\mathrm{a}}$ \\
\hline T3 & 0,29 & 0,33 & 0,30 & 0,30 & 0,30 & $0,30^{\mathrm{a}}$ \\
\hline T4 & 0,29 & 0,32 & 0,30 & 0,30 & 0,30 & $0,30^{\mathrm{a}}$ \\
\hline T5 & 0,29 & 0,29 & 0,30 & 0,30 & 0,30 & $0,30^{\mathrm{a}}$ \\
\hline Média & $0,30^{\mathrm{AB}}$ & $0,32^{\mathrm{A}}$ & $0,32^{\mathrm{A}}$ & $0,30^{\mathrm{AB}}$ & $0,29^{\mathrm{B}}$ & \\
\hline
\end{tabular}


Tabela 32. Efeitos de fontes de água para irrigação (água e efluente) e de doses de nitrogênio mineral nas concentrações de nitrogênio total (NT) no solo

\begin{tabular}{|c|c|c|c|c|c|c|}
\hline \multirow{2}{*}{ Tratamento } & \multicolumn{6}{|c|}{ Época de avaliação } \\
\hline & Abr/03 & Jul/03 & Out/03 & Jan/04 & Jul/04 & Média \\
\hline & \multicolumn{6}{|c|}{$\mathrm{g} \mathrm{kg}^{-1}$} \\
\hline \multicolumn{7}{|c|}{ Camada $80-100 \mathrm{~cm}(C V=13,04 \%)$} \\
\hline T1 & 0,28 & 0,27 & 0,30 & 0,28 & 0,21 & $0,27^{\mathrm{a}}$ \\
\hline T2 & 0,26 & 0,26 & 0,28 & 0,33 & 0,25 & $0,27^{\mathrm{a}}$ \\
\hline T3 & 0,23 & 0,30 & 0,30 & 0,30 & 0,20 & $0,27^{\mathrm{a}}$ \\
\hline T4 & 0,25 & 0,26 & 0,30 & 0,30 & 0,25 & $0,27^{\mathrm{a}}$ \\
\hline T5 & 0,26 & 0,25 & 0,30 & 0,30 & 0,23 & $0,27^{\mathrm{a}}$ \\
\hline Média & $0,26^{\mathrm{CD}}$ & $0,27^{\mathrm{BC}}$ & $0,29^{\mathrm{AB}}$ & $0,30^{\mathrm{A}}$ & $0,23^{\mathrm{D}}$ & \\
\hline
\end{tabular}

(1) T1: irrigação com água $+520 \mathrm{~kg} \mathrm{ha}^{-1}$ ano $^{-1}$ de nitrogênio via fertilizante mineral (NFM);

(2) T2: irrigação com efluente secundário de esgoto tratado (ESET), sem NFM;

(3) T3: irrigação com ESET + 171,6 $\mathrm{kg} \mathrm{ha}^{-1} \mathrm{ano}^{-1}$ de NFM;

(4) T4: irrigação com ESET + 343,3 $\mathrm{kg} \mathrm{ha}^{-1} \mathrm{ano}^{-1}$ de NFM;

(5) T5: irrigação com ESET $+520 \mathrm{~kg} \mathrm{ha}^{-1}$ ano $^{-1}$ de NFM;

(6) Letras iguais maiúsculas ou minúsculas nas linhas e nas colunas, respectivamente, não diferem estatisticamente pelo teste de Tukey $(P<0,05)$.

10-20, 60-80 e 80-100 cm (Tabela 32). Com relação às concentrações de CT, estas diminuiram no perfil do solo no decorrer do experimento (Tabela 31). A relação $\mathrm{C} / \mathrm{N}$ do solo não foi diferente para os tratamentos (variando de 10,99 a 12,27), mas diminiu com o tempo de experimentação nas camadas $0-10$ (de 13,94 para 11,53), 10-20 (de 13,51 para 11,06), 20-40 (de 13,31 para 11,05), 40-60 (de 13,52 para 12,53), 60-80 (de 14,45 para 11,37) e 80-100 cm (de 13,64 para 12,32). Esses resultados indicaram que o efeito da adição de NFM associada à irrigação, apesar de ter promovido maior rendimento de MS do capim (Tabela 5), não proporcionou aporte de resíduos orgânicos no solo em quantidade e qualidade suficiente para promover incremento nas concentrações de MOS. Zekri \& Koo (1994) observaram, num estudo comparando fontes de água para irrigação (água convencional e EET), que as concentrações de NT no solo foram diminuídas com o tempo de experimentação, independentemente do tipo de água empregada. A mineralização da MOS é altamente dependente do potencial de água no solo (Stanford \& Epstein, 1974; Myers et al., 1982) associado aos fatores de temperatura, $\mathrm{O}_{2}, \mathrm{pH}$, quantidade e qualidade do material orgânico (Stanford \& Smith, 1972). Desse modo, a 
irrigação pode ocasionar alterações na ciclagem de nutrientes, sobretudo, nos agrossistemas de pastagens, por promover modificações na atividade microbiana, alterando a mineralização da MOS (Dubeux Jr. et al., 2004) e, consequentemente, diminuindo as concentrações de CT e NT no solo.

Ainda, o fato de ter ocorrido, no decorrer período experimental, diminuição nas concentrações de CT (Tabela 31) e NT no solo (Tabela 32), pode ter sido devido aos fatores (i) aporte de NFM e de N-efluente, ocasionando incremento na mineralização do $\mathrm{N}$ presente no húmus nativo do solo, através do efeito "priming"; (ii) aporte externo de $\mathrm{N}$ no sistema (N-efluente e/ou NFM), promovendo condições favoráveis para melhor crescimento e desenvolvimento da parte aérea das plantas, bem como do sistema radicular das mesmas, permitindo melhor utilização do N, sobretudo, aquele que ora não era acessível às raízes (Stevenson, 1986). O efeito "priming" consite num estímulo, normalmente positivo, que ocasiona incremento na taxa de decomposição da MOS, devido ao crescimento extenso e vigoroso da população microbiana quando material rico em energia é adicionado no sistema e, subseqüentemente, microrganismos produzem enzimas que atacam a MOS. A magnitude de diminuição da concentração de MOS depende, principalmente, do tamanho e da atividade da microflora (Stevenson, 1986).

Barton et al. (2005) estudaram quatro solos neozelandezes cultivados com azevém-perene consorciado com trevo branco (Trifolium repens L.) submetidos à irrigação com EET por dois anos. Os autores verificaram que (i) ocorreu efeito "priming" para dois solos (sendo um rico em alofana e outro de textura arenosa); (ii) a quantidade de $\mathrm{N}$ recuperado ( $\mathrm{N}$ lixiviado e $\mathrm{N}$ acumulado na pastagem) durante $\mathrm{o}$ experimento superou em $180 \mathrm{~kg} \mathrm{ha}^{-1}$ o aporte de $\mathrm{N}$ (via fertilizante e via efluente), indicando que houve mineralização do $\mathrm{N}$ nativo do solo. Portanto, essas informações permitem inferir que foi significativo o efeito "priming" no presente estudo, pois a eficiência de conversão do $\mathrm{N}$ aplicado (NFM e N-efluente), foi muito superior aos valores médios apresentados na revisão de Martha Júnior et al. (2004), sobretudo, para o tratamento T2 (Tabela 5). A eficiência de conversão do $\mathrm{N}$ em forragem, em pastagens de gramíneas tropicais (sem irrigação), normalmente varia de 15 a $45 \mathrm{~kg}$ de MS por $\mathrm{kg}$ de $\mathrm{N}$, podendo atingir até $83 \mathrm{~kg}$ de $\mathrm{MS}$ por $\mathrm{kg}$ de $\mathrm{N}$ (Martha Júnior et al., 2004). 
Evidentemente, a irrigação pode proporcionar aumento na eficiência de absorção e utilização do N pelo capim (Marcelino et al., 2003), porém, não o suficiente para explicar os efeitos ocorridos neste trabalho.

Nos agrossistemas irrigados com EET, as alterações nas concentrações de CT e NT podem ser distintas ao longo do perfil do solo. Sommers et al. (1979) verificaram, em solos sob pastagens, que houve aumento e diminuição nas concentrações de CT nas camadas 0-15 cm e 15-60 cm, respectivamente, mediante irrigação com EET por 11 anos. Allhands et al. (1995) observaram, em vários solos da Florida (EUA) sometidos à irrigação com EET por oito anos, incluindo aqueles sob pastagens com capim-Bermuda, que as concentrações de MOS diminuiram e aumentaram nas camadas 0-15 e 15-120 $\mathrm{cm}$, respectivamente. Speir (2002) assinalou que, em solos florestais neozelandeses submetidos à irrigação com EET, normalmente não têm sido observadas alterações nas concentrações de CT e NT na camada $0-5 \mathrm{~cm}$; porém, aumentos nas concentrações destes elementos na camada $5-15 \mathrm{~cm}$ têm sido constantes. Portanto, a partir dos resultados do presente estudo e das observações realizadas por Sommers et al. (1979), Allhands et al. (1995) e Speir (2002), conclui-se que, para trabalhos futuros, seria interessante modificar a metodologia de amostragem de solos, fracionando a camada 0 $10 \mathrm{~cm}$ em 0-5 e 5-10 cm. Esse fracionamento da camada 0-10 $\mathrm{cm}$ poderia facilitar a identificação dos efeitos da irrigação com EET na dinâmica dos elementos $\mathrm{C}$ e $\mathrm{N}$ no solo.

Os efeitos dos tratamentos empregados, bem como dos resultados das concentrações de CT e NT no decorrer do experimento (Tabelas 31 e 32), foram discordantes da maioria dos trabalhos publicados, por causa de pelo menos um dos seguintes fatores:

a) $\mathrm{O}$ solo em questão apresentou características distintas da maioria dos solos destinados, no exterior, à colocação de EET. Pois, trata-se de solo com baixa fertilidade natural, pobre em MOS (Tabela 2), localizado numa latitude que recebe grande quantidade de energia solar ao longo do ano, que associada às condições adequadas de umidade e aeração, promove rápida mineralização da MOS (Mielniczuk et al., 2003). 
b) A contribuição do EET com $\mathrm{C}$ orgânico e $\mathrm{N}$ orgânico se resume em algas mortas presentes neste subproduto, que possuem rápida velocidade de decomposição (Snow et al., 1999). Em solos de baixa fertilidade natural, o aporte de nutrientes, (principalmente, $\mathrm{N}$ e $\mathrm{P}$ ) devido à irrigação com EET, associado às baixas concentrações de C-efluente, pode promover incremento dos processos de mineralização e nitrificação (Speir et al., 1999) e, em longo prazo, pode diminuir as concentrações de CT no solo (Speir, 2002).

c) Apesar de o ESET ter ocasionado, neste estudo, aporte elevado de N-efluente no sistema solo-planta (Tabela 4), não foi observado aumento nas concentrações de NT no solo (Tabela 32), devido à elevada capacidade de extração de N pelo capim (Tabela 22), conforme assinado anteriormente por Mancino \& Pepper (1992) e Barton et al. (2005).

d) $\mathrm{O}$ aumento nas concentrações de CT e/ou NT devido à irrigação com EET tem sido acompanhado, em muitos experimentos de longo prazo, do incremento nas concentrações de metais pesados no solo, conforme observado nos estudos de Quin \& Syers (1978), Quin \& Woods (1978), Madyiwa et al. (2002) e Ramirez-Fuentes (2002). O acúmulo de metais pesados no solo pode alterar as atividades enzimáticas e dos microrganismos, promovendo mudanças, sobretudo, na ciclagem de C, N, P e S (Kandeler et al., 1996) e, consequentemente, ocasionando incremento nas concentrações de CT no solo (Valsecchi et al., 1995), não necessariamente de C humificado (Stevenson, 1986). Isso porque os metais pesados, em altas concentrações, afetam o crescimento, a morfologia e o metabolismo dos microganismos atuantes na MOS, ocasionando distúrbios funcionais, desnaturação de proteínas e destruição da integridade das membranas celulares (Leita et al., 1995).

Com relação ao $\mathrm{N}$ na solução no solo, os tratamentos empregados promoveram alterações nas concentrações de (i) $\mathrm{N}^{-\mathrm{NO}_{3}}{ }^{-}+\mathrm{N}_{-} \mathrm{NO}_{2}{ }^{-}$nas camadas 0-10 e

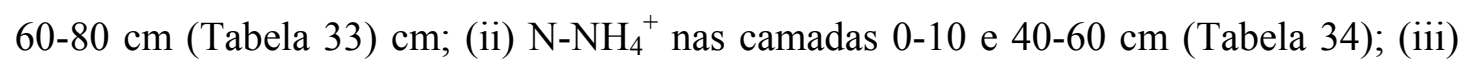
$\mathrm{N}-$ mineral $\left(\mathrm{N}_{-} \mathrm{NO}_{3}{ }^{-}+\mathrm{N}^{-\mathrm{NO}_{2}}{ }^{-}+\mathrm{N}^{-} \mathrm{NH}_{4}{ }^{+}\right)$nas camadas 0-10 e 60-80 cm (Tabela 35). As concentrações de $\mathrm{N}_{-} \mathrm{NO}_{2}{ }^{-}$, para a maioria das amostras, encontravam-se abaixo do limite de detecção do método empregado $\left(5 \mu \mathrm{g} \mathrm{L}^{-1}\right)$ e raramente atingiu concentrações 
Tabela 33. Efeitos da irrigação (água e efluente) e de doses de nitrogênio mineral nas concentrações de $\mathrm{N}_{-} \mathrm{NO}_{3}{ }^{-}+\mathrm{N}^{-} \mathrm{NO}_{2}{ }^{-}$na solução no solo

\begin{tabular}{|c|c|c|c|c|c|c|c|}
\hline \multirow{2}{*}{ Tratamento } & \multicolumn{7}{|c|}{ Época de avaliação } \\
\hline & Abr/03 & Jul/03 & Out/03 & Jan/04 & Abr/04 & Jul/04 & Média \\
\hline & \multicolumn{7}{|c|}{$\mathrm{mg} \mathrm{L}^{-1}$} \\
\hline \multicolumn{8}{|c|}{ Camada 0-10 cm (CV = 32,78\%) } \\
\hline $\mathrm{T1}^{(1)}$ & 5,77 & 7,86 & 4,85 & 6,09 & 0,96 & 2,12 & $4,61^{\mathrm{c}(6)}$ \\
\hline $\mathbf{T} 2^{(2)}$ & 4,23 & 8,25 & 0,69 & 5,27 & 1,79 & 2,14 & $3,73^{\mathrm{c}}$ \\
\hline T3 ${ }^{(3)}$ & 7,00 & 9,58 & 1,82 & 3,62 & 3,96 & 3,84 & $4,97^{\mathrm{bc}}$ \\
\hline T4 ${ }^{(4)}$ & 5,63 & 12,47 & 6,16 & 6,51 & 1,23 & 7,96 & $6,66^{\mathrm{a}}$ \\
\hline $\mathbf{T} 5^{(5)}$ & 6,02 & 10,75 & 4,91 & 7,81 & 1,24 & 6,74 & $6,24^{a b}$ \\
\hline Média & $5,73^{\mathrm{B}}$ & $9,78^{\mathrm{A}}$ & $3,69^{\mathrm{C}}$ & $5,86^{\mathrm{B}}$ & $1,84^{\mathrm{D}}$ & $4,56^{\mathrm{BC}}$ & \\
\hline \multicolumn{8}{|c|}{ Camada $10-20 \mathrm{~cm}(C V=35,96 \%)$} \\
\hline T1 & 5,82 & 8,01 & 2,82 & 3,85 & 6,70 & 5,35 & $5,42^{\mathrm{a}}$ \\
\hline T2 & 4,78 & 8,02 & 1,37 & 4,09 & 8,52 & 6,82 & $5,60^{\mathrm{a}}$ \\
\hline T3 & 5,47 & 5,76 & 1,70 & 3,07 & 8,63 & 10,03 & $5,78^{\mathrm{a}}$ \\
\hline T4 & 5,21 & 6,11 & 3,81 & 4,86 & 9,54 & 9,78 & $6,55^{\mathrm{a}}$ \\
\hline T5 & 6,09 & 8,06 & 2,06 & 4,50 & 9,12 & 8,92 & $6,46^{\mathrm{a}}$ \\
\hline Média & $5,47^{\mathrm{BC}}$ & $7,19^{\mathrm{AB}}$ & $2,35^{\mathrm{D}}$ & $4,07^{\mathrm{CD}}$ & $8,50^{\mathrm{A}}$ & $8,18^{\mathrm{A}}$ & \\
\hline \multicolumn{8}{|c|}{ Camada $20-40 \mathrm{~cm}(C V=87,39 \%)$} \\
\hline T1 & 5,31 & 2,16 & 0,96 & 2,00 & 4,07 & 7,75 & $3,71^{\mathrm{a}}$ \\
\hline $\mathbf{T 2}$ & 4,00 & 1,97 & 0,55 & 2,17 & 8,37 & 5,90 & $3,83^{\mathrm{a}}$ \\
\hline T3 & 4,65 & 0,74 & 0,55 & 1,04 & 1,84 & 0,95 & $1,63^{\mathrm{a}}$ \\
\hline T4 & 3,84 & 0,62 & 1,57 & 2,04 & 3,65 & 4,04 & $2,63^{\mathrm{a}}$ \\
\hline T5 & 4,44 & 1,02 & 2,14 & 2,25 & 4,29 & 4,57 & $3,12^{\mathrm{a}}$ \\
\hline Média & $4,45^{\mathrm{A}}$ & $1,30^{\mathrm{B}}$ & $1,16^{\mathrm{B}}$ & $1,90^{\mathrm{B}}$ & $4,44^{\mathrm{A}}$ & $4,64^{\mathrm{A}}$ & \\
\hline \multicolumn{8}{|c|}{ Camada $40-60 \mathrm{~cm}(C V=90,09 \%)$} \\
\hline T1 & 3,69 & 1,28 & 0,61 & 0,81 & 6,91 & 2,55 & $2,64^{\mathrm{a}}$ \\
\hline $\mathbf{T} 2$ & 1,17 & 0,78 & 0,85 & 0,56 & 5,69 & 0,24 & $1,55^{\mathrm{a}}$ \\
\hline T3 & 1,87 & 0,53 & 0,25 & 0,51 & 2,74 & 1,17 & $1,18^{\mathrm{a}}$ \\
\hline T4 & 1,55 & 0,66 & 0,38 & 0,62 & 2,32 & 1,74 & $1,21^{\mathrm{a}}$ \\
\hline T5 & 1,98 & 1,47 & 0,57 & 0,92 & 5,65 & 2,42 & $2,17^{\mathrm{a}}$ \\
\hline Média & $2,05^{\mathrm{B}}$ & $0,94^{\mathrm{BC}}$ & $0,53^{\mathrm{C}}$ & $0,68^{\mathrm{BC}}$ & $4,66^{\mathrm{A}}$ & $1,62^{\mathrm{BC}}$ & \\
\hline \multicolumn{8}{|c|}{ Camada $60-80 \mathrm{~cm}(\mathrm{CV}=82,76 \%)$} \\
\hline T1 & 2,43 & 0,76 & 0,34 & 0,49 & 7,63 & 3,89 & $2,59^{\mathrm{a}}$ \\
\hline $\mathbf{T 2}$ & 0,88 & 0,53 & 0,54 & 0,32 & 1,65 & 1,51 & $0,90^{\mathrm{b}}$ \\
\hline T3 & 0,88 & 0,45 & 0,21 & 0,23 & 1,65 & 1,50 & $0,82^{b}$ \\
\hline T4 & 0,63 & 0,55 & 0,26 & 0,40 & 5,44 & 2,20 & $1,58^{\mathrm{ab}}$ \\
\hline T5 & 1,23 & 0,68 & 0,51 & 0,64 & 4,98 & 4,73 & $2,13^{\mathrm{a}}$ \\
\hline Média & $1,21^{\mathrm{C}}$ & $0,59^{\mathrm{C}}$ & $0,37^{\mathrm{C}}$ & $0,42^{\mathrm{C}}$ & $4,27^{\mathrm{A}}$ & $2,76^{\mathrm{B}}$ & \\
\hline
\end{tabular}


Tabela 33. Efeitos da irrigação (água e efluente) e de doses de nitrogênio mineral nas concentrações de $\mathrm{N}^{-\mathrm{NO}_{3}}{ }^{-}+\mathrm{N}^{-} \mathrm{NO}_{2}{ }^{-}$na solução no solo

\begin{tabular}{cccccccc}
\hline \multirow{2}{*}{ Tratamento } & \multicolumn{7}{c}{ Época de avaliação } \\
& Abr/03 & Jul/03 & Out/03 & Jan/04 & Abr/04 & Jul/04 & Média \\
\hline \multicolumn{7}{c}{ Camada 80-100 } \\
cm $\mathbf{( C V}=\mathbf{8 5 , 7 4 \% )}$ & & $\mathbf{~ m g ~ L ~}^{-1}$ & & & \\
T1 & 1,35 & 0,57 & 0,17 & 0,66 & 3,25 & 1,14 & $1,19^{\text {a }}$ \\
T2 & 1,01 & 0,39 & 0,42 & 0,37 & 1,22 & 2,11 & $0,92^{\text {a }}$ \\
T3 & 0,59 & 0,49 & 0,12 & 0,16 & 2,40 & 1,81 & $0,93^{\text {a }}$ \\
T4 & 0,59 & 0,43 & 0,12 & 0,22 & 3,05 & 2,58 & $1,16^{\text {a }}$ \\
T5 & 0,59 & 0,51 & 0,46 & 0,39 & 5,46 & 1,99 & $1,57^{\text {a }}$ \\
Média & $0,82^{\mathrm{C}}$ & $0,48^{\mathrm{C}}$ & $0,26^{\mathrm{C}}$ & $0,36^{\mathrm{C}}$ & $3,08^{\mathrm{A}}$ & $1,93^{\mathrm{B}}$ & \\
\hline
\end{tabular}

(1) T1: irrigação com água $+520 \mathrm{~kg} \mathrm{ha}^{-1}$ ano $^{-1}$ de nitrogênio via fertilizante mineral (NFM);

(2) T2: irrigação com efluente secundário de esgoto tratado (ESET), sem NFM;

(3) T3: irrigação com ESET + 171,6 $\mathrm{kg} \mathrm{ha}^{-1} \mathrm{ano}^{-1}$ de NFM;

(4) T4: irrigação com ESET + 343,3 $\mathrm{kg} \mathrm{ha}^{-1} \mathrm{ano}^{-1}$ de NFM;

(5) T5: irrigação com ESET $+520 \mathrm{~kg} \mathrm{ha}^{-1} \mathrm{ano}^{-1}$ de NFM;

(6) Letras iguais maiúsculas ou minúsculas nas linhas e nas colunas, respectivamente, não diferem estatisticamente pelo teste de Tukey $(P<0,05)$;

superiores a dez vezes ao limite de detecção. Portanto, os compostos representativos do $\mathrm{N}$-mineral na solução no solo foram $\mathrm{N}-\mathrm{NO}_{3}{ }^{-}$e N-NH${ }_{4}^{+}$.

Na camada 0-10 cm, os tratamentos $\mathrm{T} 1$ e $\mathrm{T} 2$, que não diferiram de $\mathrm{T} 3$, apresentaram menores concentrações de $\mathrm{N}^{-\mathrm{NO}_{3}}{ }^{-}$, enquanto os tratamentos $\mathrm{T} 4$ e T5 apresentaram maiores concentrações deste composto (Tabela 33). Na camada $60-80 \mathrm{~cm}$ foram observadas menores e maiores concentrações de $\mathrm{N}_{-} \mathrm{NO}_{3}{ }^{-}$nos tratamentos $\mathrm{T} 2$ e T3 e T1 e T5, respectivamente; o tratamento T4 não foi diferente dos demais (Tabela 33). Assim, maiores concentrações de $\mathrm{N}^{-\mathrm{NO}_{3}}{ }^{-}$foram observadas nos tratamentos que receberam doses mais elevadas de $\mathrm{N}$, sobretudo, associadas à irrigação com ESET (Tabela 33). O fato de o EET promover aumento nas concentrações de $\mathrm{N}^{-\mathrm{NO}_{3}}{ }^{-}$na solução no solo tem sido amplamente relatado, independentemente se em sistemas agrícolas (Feigin et al., 1978; Johns \& McConchie, 1994b), pastagens (Quin \& Forsythe, 1978; Linden et al., 1981; Lund et al., 1981; Hayes et al., 1990a) ou florestas (Polglase et al., 1995; Magesan et al., 1998; Smith \& Bond, 1999; Speir et al., 1999). No entanto, os incrementos nas concentrações de $\mathrm{N}_{-} \mathrm{NO}_{3}{ }^{-}$observados no presente estudo não foram 
Tabela 34. Efeitos da irrigação (água e efluente) e de doses de nitrogênio mineral nas concentrações de $\mathrm{N}-\mathrm{NH}_{4}{ }^{+}$na solução no solo

\begin{tabular}{|c|c|c|c|c|c|c|c|}
\hline \multirow{2}{*}{ Tratamento } & \multicolumn{7}{|c|}{ Época de avaliação } \\
\hline & Abr/03 & Jul/03 & Out/03 & Jan/04 & Abr/04 & Jul/04 & Média \\
\hline & \multicolumn{7}{|c|}{$\mathrm{mg} \mathrm{L}^{-1}$} \\
\hline \multicolumn{8}{|c|}{ Camada 0-10 cm (CV = 25,50\%) } \\
\hline $\mathrm{T1}^{(1)}$ & 1,94 & 3,66 & 1,61 & 1,63 & 1,37 & 1,26 & $1,91^{\mathrm{b}(6)}$ \\
\hline$T 2^{(2)}$ & 2,26 & 3,58 & 2,19 & 2,53 & 1,48 & 2,25 & $2,38^{\mathrm{a}}$ \\
\hline T3 ${ }^{(3)}$ & 2,29 & 4,18 & 1,83 & 1,37 & 1,34 & 1,81 & $2,14^{a b}$ \\
\hline$T 4^{(4)}$ & 2,42 & 3,78 & 1,62 & 1,85 & 1,24 & 1,27 & $2,03^{\mathrm{b}}$ \\
\hline $\mathbf{T} 5^{(5)}$ & 2,31 & 3,72 & 0,93 & 1,84 & 1,35 & 2,00 & $2,03^{b}$ \\
\hline Média & $2,24^{\mathrm{B}}$ & $3,78^{\mathrm{A}}$ & $1,63^{\mathrm{C}}$ & $1,84^{\mathrm{BC}}$ & $1,36^{\mathrm{C}}$ & $1,72^{\mathrm{C}}$ & \\
\hline \multicolumn{8}{|c|}{ Camada $10-20 \mathrm{~cm}(C V=27,64 \%)$} \\
\hline $\mathrm{T} 1$ & 2,53 & 2,14 & 1,58 & 1,18 & 2,18 & 0,78 & $1,73^{\mathrm{a}}$ \\
\hline T2 & 1,95 & 3,62 & 2,16 & 1,31 & 0,91 & 2,15 & $2,02^{\mathrm{a}}$ \\
\hline T3 & 2,18 & 3,15 & 1,90 & 1,05 & 1,06 & 0,93 & $1,71^{\mathrm{a}}$ \\
\hline T4 & 2,17 & 3,25 & 1,98 & 1,12 & 1,34 & 1,23 & $1,85^{\mathrm{a}}$ \\
\hline T5 & 2,82 & 3,37 & 1,72 & 1,24 & 1,85 & 1,33 & $2,05^{\mathrm{a}}$ \\
\hline Média & $2,33^{\mathrm{B}}$ & $3,11^{\mathrm{A}}$ & $1,87^{\mathrm{BC}}$ & $1,18^{\mathrm{D}}$ & $1,47^{\mathrm{CD}}$ & $1,29^{\mathrm{D}}$ & \\
\hline \multicolumn{8}{|c|}{ Camada $20-40 \mathrm{~cm}(\mathrm{CV}=27,85 \%)$} \\
\hline $\mathrm{T} 1$ & 1,59 & 2,44 & 2,10 & 1,03 & 2,54 & 1,15 & $1,81^{\mathrm{a}}$ \\
\hline T2 & 2,13 & 2,49 & 2,84 & 1,60 & 1,34 & 1,59 & $2,00^{\mathrm{a}}$ \\
\hline T3 & 2,19 & 2,69 & 2,73 & 1,30 & 1,73 & 1,55 & $2,03^{\mathrm{a}}$ \\
\hline T4 & 2,04 & 2,69 & 2,61 & 0,95 & 1,47 & 1,37 & $1,86^{\mathrm{a}}$ \\
\hline T5 & 2,10 & 2,21 & 2,19 & 1,62 & 2,53 & 1,19 & $1,97^{\mathrm{a}}$ \\
\hline Média & $2,01^{\mathrm{AB}}$ & $2,50^{\mathrm{A}}$ & $2,49^{\mathrm{A}}$ & $1,30^{\mathrm{C}}$ & $1,92^{\mathrm{B}}$ & $1,37^{\mathrm{C}}$ & \\
\hline \multicolumn{8}{|c|}{ Camada $40-60 \mathrm{~cm}(\mathrm{CV}=25,19 \%)$} \\
\hline $\mathrm{T} 1$ & 1,36 & 1,72 & 2,20 & 1,34 & 2,20 & 0,92 & $1,62^{\mathrm{ab}}$ \\
\hline T2 & 1,37 & 1,70 & 2,71 & 1,18 & 2,14 & 1,59 & $1,78^{\mathrm{a}}$ \\
\hline T3 & 1,32 & 1,53 & 2,84 & 1,43 & 1,69 & 1,14 & $1,66^{\mathrm{ab}}$ \\
\hline T4 & 1,59 & 1,32 & 2,56 & 1,18 & 1,96 & 0,88 & $1,58^{a b}$ \\
\hline T5 & 1,55 & 1,62 & 2,04 & 1,26 & 1,11 & 0,86 & $1,41^{\mathrm{b}}$ \\
\hline Média & $1,44^{\mathrm{CD}}$ & $1,58^{\mathrm{BC}}$ & $2,47^{\mathrm{A}}$ & $1,28^{\mathrm{CD}}$ & $1,82^{\mathrm{B}}$ & $1,08^{\mathrm{D}}$ & \\
\hline \multicolumn{8}{|c|}{ Camada $60-80 \mathrm{~cm}(\mathrm{CV}=24,07 \%)$} \\
\hline T1 & 0,97 & 1,05 & 1,39 & 1,06 & 1,20 & 0,57 & $1,04^{\mathrm{a}}$ \\
\hline T2 & 0,87 & 0,75 & 1,32 & 1,41 & 1,78 & 1,68 & $1,30^{\mathrm{a}}$ \\
\hline T3 & 1,26 & 0,86 & 1,42 & 1,50 & 2,16 & 0,57 & $1,29^{\mathrm{a}}$ \\
\hline T4 & 1,05 & 0,89 & 1,60 & 1,32 & 1,62 & 1,14 & $1,27^{\mathrm{a}}$ \\
\hline T5 & 1,05 & 1,07 & 1,30 & 1,27 & 1,66 & 1,08 & $1,24^{\mathrm{a}}$ \\
\hline Média & $1,04^{\mathrm{CD}}$ & $0,92^{\mathrm{D}}$ & $1,41^{\mathrm{B}}$ & $1,31^{\mathrm{BC}}$ & $1,68^{\mathrm{A}}$ & $1,01^{\mathrm{D}}$ & \\
\hline
\end{tabular}


Tabela 34. Efeitos da irrigação (água e efluente) e de doses de nitrogênio mineral nas concentrações de $\mathrm{N}^{-\mathrm{NH}_{4}}{ }^{+}$na solução no solo

\begin{tabular}{|c|c|c|c|c|c|c|c|}
\hline \multirow{2}{*}{ Tratamento } & \multicolumn{7}{|c|}{ Época de avaliação } \\
\hline & Abr/03 & Jul/03 & Out/03 & Jan/04 & Abr/04 & Jul/04 & Média \\
\hline & \multicolumn{7}{|c|}{$\mathrm{mg} \mathrm{L}^{-1}$} \\
\hline \multicolumn{8}{|c|}{ Camada $80-100 \mathrm{~cm}(C V=27,60 \%)$} \\
\hline T1 & 1,39 & 0,74 & 1,08 & 1,16 & 1,08 & 0,43 & $0,98^{\mathrm{a}}$ \\
\hline T2 & 0,75 & 0,99 & 1,18 & 1,29 & 1,57 & 0,92 & $1,12^{\mathrm{a}}$ \\
\hline T3 & 0,96 & 0,97 & 0,96 & 1,23 & 1,18 & 0,75 & $1,01^{\mathrm{a}}$ \\
\hline T4 & 0,92 & 1,16 & 1,05 & 1,04 & 1,12 & 0,80 & $1,01^{\mathrm{a}}$ \\
\hline T5 & 0,65 & 0,90 & 1,12 & 1,13 & 1,13 & 1,16 & $1,01^{\mathrm{a}}$ \\
\hline Média & $0,93^{\mathrm{BC}}$ & $0,95^{\mathrm{BC}}$ & $1,08^{\mathrm{AB}}$ & $1,17^{\mathrm{AB}}$ & $1,22^{\mathrm{A}}$ & $0,81^{\mathrm{C}}$ & \\
\hline
\end{tabular}

(1) T1: irrigação com água $+520 \mathrm{~kg} \mathrm{ha}^{-1}$ ano $^{-1}$ de nitrogênio via fertilizante mineral (NFM);

(2) T2: irrigação com efluente secundário de esgoto tratado (ESET), sem NFM;

(3) T3: irrigação com ESET + 171,6 $\mathrm{kg} \mathrm{ha}^{-1} \mathrm{ano}^{-1}$ de NFM;

(4) T4: irrigação com ESET + 343,3 $\mathrm{kg} \mathrm{ha}^{-1} \mathrm{ano}^{-1}$ de NFM;

(5) T5: irrigação com ESET $+520 \mathrm{~kg} \mathrm{ha}^{-1} \mathrm{ano}^{-1}$ de NFM;

(6) Letras iguais maiúsculas ou minúsculas nas linhas e nas colunas, respectivamente, não diferem estatisticamente pelo teste de Tukey $(P<0,05)$;

limitantes, pelo fato de terem ocorrido numa faixa de concentração inferior a $10 \mathrm{mg} \mathrm{L}^{-1}$

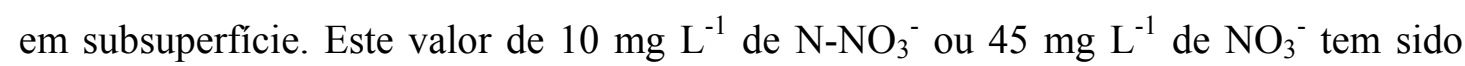
tomado como referência, pois é o máximo permitido na água potável no Brasil (Resolução Conama n. ${ }^{\circ}$ 357, 17/03/2005) e nos EUA (Stevenson, 1986). O excesso de $\mathrm{NO}_{3}{ }^{-}$na água potável (e em alimentos) pode ocasionar metaemoglobinemia (síndrome do bebê azul), que consiste na redução do $\mathrm{NO}_{3}{ }^{-}$para $\mathrm{NO}_{2}{ }^{-}$por microrganismos presentes no estômago de crianças e no rúmem de animais. $\mathrm{Na}$ corrente sangüínea, o $\mathrm{NO}_{2}^{-}$é oxidado pela oxiemoglobina, tornando-a metaemeglobina, que é impapaz de transportar $\mathrm{O}_{2}$ (Stevenson, 1986).

Na camada 0-10 cm, o tratamento T2 apresentou maior concentração de N$\mathrm{NH}_{4}^{+}$que os tratamentos T1, T4 e T5; porém, o tratamento T3 não foi diferente dos demais (Tabela 34). Na camada 40-60 cm, o tratamento $\mathrm{T} 2$ apresentou maior concentração de $\mathrm{N}^{-N_{4}}{ }_{4}^{+}$que o tratamento T5; no entanto, esses tratamentos não diferiram dos demais (Tabela 34). Menores concentrações de $\mathrm{N}_{-} \mathrm{NH}_{4}{ }^{+}$foram observadas nos tratamentos que receberam maiores doses de irrigação e/ou de NFM, indicando que 
Tabela 35. Efeitos da irrigação (água e efluente) e de doses de nitrogênio mineral nas concentrações de N-mineral $\left(\mathrm{N}-\mathrm{NO}_{3}{ }^{-}+\mathrm{N}^{-} \mathrm{NO}_{2}{ }^{-}+\mathrm{N}^{-\mathrm{NH}_{4}}{ }^{+}\right)$na solução no solo

\begin{tabular}{|c|c|c|c|c|c|c|c|}
\hline \multirow{2}{*}{ Tratamento } & \multicolumn{7}{|c|}{ Época de avaliação } \\
\hline & Abr/03 & Jul/03 & Out/03 & Jan/04 & Abr $/ 04$ & Jul/04 & Média \\
\hline & \multicolumn{7}{|c|}{$\mathrm{mg} \mathrm{L}^{-1}$} \\
\hline \multicolumn{8}{|c|}{ Camada 0-10 cm (CV = 27,02\%) } \\
\hline$T 1^{(1)}$ & 7,71 & 11,52 & 6,46 & 7,72 & 2,33 & 3,37 & $6,52^{\mathrm{c}(6)}$ \\
\hline $\mathbf{T} 2^{(2)}$ & 6,49 & 11,84 & 2,87 & 7,80 & 3,27 & 4,39 & $6,11^{\mathrm{c}}$ \\
\hline T3 ${ }^{(3)}$ & 9,29 & 13,76 & 3,65 & 4,99 & 5,30 & 5,65 & $7,10^{b c}$ \\
\hline T4 ${ }^{(4)}$ & 8,05 & 16,25 & 7,78 & 8,36 & 2,47 & 9,23 & $8,69^{\mathrm{a}}$ \\
\hline $\mathbf{T} 5^{(5)}$ & 8,33 & 14,48 & 5,85 & 9,65 & 2,60 & 8,74 & $8,27^{a b}$ \\
\hline Média & $7,97^{\mathrm{B}}$ & $13,57^{\mathrm{A}}$ & $5,32^{\mathrm{C}}$ & $7,70^{\mathrm{B}}$ & $3,19^{\mathrm{D}}$ & $6,28^{\mathrm{BC}}$ & \\
\hline \multicolumn{8}{|c|}{ Camada $10-20 \mathrm{~cm}(C V=27,51 \%)$} \\
\hline $\mathrm{T1}$ & 8,35 & 10,15 & 4,40 & 5,03 & 8,88 & 6,13 & $7,16^{\mathrm{a}}$ \\
\hline $\mathbf{T} 2$ & 6,73 & 11,65 & 3,53 & 5,41 & 9,43 & 8,97 & $7,62^{\mathrm{a}}$ \\
\hline T3 & 7,65 & 8,91 & 3,60 & 4,12 & 9,69 & 10,96 & $7,49^{\mathrm{a}}$ \\
\hline T4 & 7,38 & 9,36 & 5,79 & 5,98 & 10,88 & 11,02 & $8,40^{\mathrm{a}}$ \\
\hline T5 & 8,90 & 11,43 & 3,78 & 5,74 & 10,97 & 10,25 & $8,51^{\text {a }}$ \\
\hline Média & $7,80^{\mathrm{B}}$ & $10,30^{\mathrm{A}}$ & $4,22^{\mathrm{C}}$ & $5,25^{\mathrm{C}}$ & $9,97^{\mathrm{A}}$ & $9,47^{\mathrm{AB}}$ & \\
\hline \multicolumn{8}{|c|}{ Camada $20-40 \mathrm{~cm}(\mathrm{CV}=54,50 \%)$} \\
\hline T1 & 6,90 & 4,60 & 3,06 & 3,03 & 6,61 & 8,90 & $5,52^{\text {a }}$ \\
\hline $\mathbf{T} 2$ & 6,13 & 4,46 & 3,39 & 3,77 & 9,72 & 7,49 & $5,83^{\mathrm{a}}$ \\
\hline T3 & 6,83 & 3,43 & 3,28 & 2,34 & 3,57 & 2,50 & $3,66^{\mathrm{a}}$ \\
\hline T4 & 5,88 & 3,32 & 4,17 & 2,99 & 5,12 & 5,41 & $4,48^{a}$ \\
\hline T5 & 6,54 & 3,23 & 4,33 & 3,87 & 6,82 & 5,76 & $5,09^{\mathrm{a}}$ \\
\hline Média & $6,46^{\mathrm{A}}$ & $3,81^{\mathrm{BC}}$ & $3,65^{\mathrm{BC}}$ & $3,20^{\mathrm{C}}$ & $6,37^{\mathrm{A}}$ & $6,01^{\mathrm{AB}}$ & \\
\hline \multicolumn{8}{|c|}{ Camada $40-60 \mathrm{~cm}(C V=46,47 \%)$} \\
\hline T1 & 5,05 & 3,00 & 2,81 & 2,15 & 9,11 & 3,47 & $4,26^{\mathrm{a}}$ \\
\hline $\mathbf{T} 2$ & 2,54 & 2,47 & 3,56 & 1,74 & 7,82 & 1,83 & $3,33^{\mathrm{a}}$ \\
\hline T3 & 3,19 & 2,06 & 3,09 & 1,94 & 4,43 & 2,31 & $2,84^{\mathrm{a}}$ \\
\hline T4 & 3,14 & 1,98 & 2,94 & 1,79 & 4,28 & 2,62 & $2,79^{\mathrm{a}}$ \\
\hline $\mathbf{T 5}$ & 3,54 & 3,09 & 2,60 & 2,17 & 6,76 & 3,28 & $3,57^{\mathrm{a}}$ \\
\hline Média & $3,49^{\mathrm{B}}$ & $2,52^{\mathrm{BC}}$ & $3,00^{\mathrm{BC}}$ & $1,96^{\mathrm{C}}$ & $6,48^{\mathrm{A}}$ & $2,70^{\mathrm{BC}}$ & \\
\hline \multicolumn{8}{|c|}{ Camada $60-80 \mathrm{~cm}(\mathrm{CV}=47,29 \%)$} \\
\hline T1 & 3,40 & 1,81 & 1,73 & 1,55 & 8,83 & 4,46 & $3,63^{\mathrm{a}}$ \\
\hline $\mathbf{T} 2$ & 1,75 & 1,28 & 1,86 & 1,73 & 3,43 & 3,19 & $2,21^{\mathrm{b}}$ \\
\hline T3 & 2,14 & 1,31 & 1,63 & 1,73 & 3,80 & 2,07 & $2,11^{b}$ \\
\hline T4 & 1,68 & 1,44 & 1,87 & 1,72 & 7,06 & 3,34 & $2,85^{\mathrm{ab}}$ \\
\hline T5 & 2,28 & 1,75 & 1,81 & 1,91 & 6,64 & 5,80 & $3,37^{\mathrm{a}}$ \\
\hline Média & $2,25^{\mathrm{C}}$ & $1,52^{\mathrm{C}}$ & $1,78^{\mathrm{C}}$ & $1,73^{\mathrm{C}}$ & $5,95^{\mathrm{A}}$ & $3,77^{\mathrm{B}}$ & \\
\hline
\end{tabular}


Tabela 35. Efeitos da irrigação (água e efluente) e de doses de nitrogênio mineral nas concentrações de $\mathrm{N}$-mineral $\left(\mathrm{N}_{-} \mathrm{NO}_{3}{ }^{-}+\mathrm{N}^{-} \mathrm{NO}_{2}{ }^{-}+\mathrm{N}^{-\mathrm{NH}_{4}}{ }^{+}\right)$na solução no solo

\begin{tabular}{|c|c|c|c|c|c|c|c|}
\hline \multirow{2}{*}{ Tratamento } & \multicolumn{7}{|c|}{ Época de avaliação } \\
\hline & Abr/03 & Jul/03 & Out/03 & Jan/04 & Abr $/ 04$ & Jul/04 & Média \\
\hline & \multicolumn{7}{|c|}{$\mathbf{m g ~ L ^ { - 1 }}$} \\
\hline \multicolumn{8}{|c|}{ Camada $80-100 \mathrm{~cm}(C V=48,93 \%)$} \\
\hline $\mathrm{T1}$ & 2,74 & 1,31 & 1,25 & 1,82 & 4,33 & 1,57 & $2,17^{\mathrm{a}}$ \\
\hline T2 & 1,75 & 1,38 & 1,59 & 1,66 & 2,79 & 3,03 & $2,04^{\mathrm{a}}$ \\
\hline T3 & 1,55 & 1,46 & 1,08 & 1,39 & 3,58 & 2,56 & $1,94^{\mathrm{a}}$ \\
\hline T4 & 1,50 & 1,58 & 1,17 & 1,26 & 4,18 & 3,37 & $2,18^{\mathrm{a}}$ \\
\hline T5 & 1,24 & 1,41 & 1,58 & 1,52 & 6,58 & 3,15 & $2,58^{\mathrm{a}}$ \\
\hline Média & $1,76^{\mathrm{BC}}$ & $1,43^{\mathrm{C}}$ & $1,34^{\mathrm{C}}$ & $1,53^{\mathrm{C}}$ & $4,29^{\mathrm{A}}$ & $2,74^{\mathrm{B}}$ & \\
\hline
\end{tabular}

(1) T1: irrigação com água $+520 \mathrm{~kg} \mathrm{ha}^{-1}$ ano $^{-1}$ de nitrogênio via fertilizante mineral (NFM);

(2) T2: irrigação com efluente secundário de esgoto tratado (ESET), sem NFM;

(3) T3: irrigação com ESET + 171,6 $\mathrm{kg} \mathrm{ha}^{-1} \mathrm{ano}^{-1}$ de NFM;

(4) T4: irrigação com ESET + 343,3 $\mathrm{kg} \mathrm{ha}^{-1} \mathrm{ano}^{-1}$ de NFM;

(5) T5: irrigação com ESET $+520 \mathrm{~kg} \mathrm{ha}^{-1} \mathrm{ano}^{-1}$ de NFM;

(6) Letras iguais maiúsculas ou minúsculas nas linhas e nas colunas, respectivamente, não diferem estatisticamente pelo teste de Tukey $(P<0,05)$;

não houve relação positiva entre doses de NFM ou N-efluente com concentrações de N$\mathrm{NH}_{4}{ }^{+}$na solução no solo. Isso certamente ocorreu, pois o N-NH${ }_{4}^{+}$uma vez presente no sistema pode ser (i) absorvido pelas plantas; (ii) adsorvido no complexo de troca; (iii) utilizado para o crescimento da microbiota do solo, pois se constitui na forma preferencial de imobilização microbiana; (iv) fixado nos espaços interlamelar das argilas (somente em alguns argilominerais do tipo 2:1, deslocando o íon $\mathrm{K}^{+}$), tornando-se numa forma de $\mathrm{NH}_{4}{ }^{+}$não trocável; (v) utilizado para formar complexos quinona- $\mathrm{NH}_{2}$, constituindo-se numa importante reação de estabilização da MOS; (vi) volatilizado como $\mathrm{NH}_{3}$; (vii) utilizado como fonte de energia por bactérias quimioautotróficas durante processo de nitrificação (Paul \& Clark, 1989).

Os efeitos dos tratamentos nas concentrações de N-mineral na solução no solo (Tabela 35) foram, precisamente, os mesmos observados para as concentrações de N$\mathrm{NO}_{3}^{-}$(Tabela 33), devido ao predomínio deste último composto na solução. $\mathrm{O}$ predomínio de $\mathrm{N}^{-\mathrm{NO}_{3}}{ }^{-}$na solução no solo tem sido comum nos ambientes oxidantes que 
não apresentam limitações das condições de temperatura, umidade, aeração e substrato $\mathrm{NH}_{4}{ }^{+}$(Stevenson, 1986), particularmente nos sistemas receptores de EET (Hortenstine, 1976; Quin \& Forsythe, 1978; Feigin et al., 1978; Polglase et al., 1995; Schipper et al., 1996).

As concentrações de $\mathrm{N}_{-} \mathrm{NH}_{4}^{+}$(Tabela 34), $\mathrm{N}^{+} \mathrm{NO}_{3}^{-}$(Tabela 33) e, conseqüentemente, de N-mineral na solução no solo (Tabela 35), variaram no decorrer do experimento, para todas camadas estudas. Essas flutuações podem estar relacionadas com períodos de maior ou menor demanda de $\mathrm{N}$ pelas das plantas, que foi menor no primeiro semestre e maior no terceiro semestre (Tabela 22). Os principais fatores que controlam a transformação do $\mathrm{NH}_{4}{ }^{+}$em $\mathrm{NO}_{3}{ }^{-}$no solo são temperatura, umidade, $\mathrm{pH}$, concentração de $\mathrm{NH}_{4}{ }^{+}$no meio, $\mathrm{O}_{2}$ e $\mathrm{CO}_{2}$ (Stevenson, 1986). Com excessão de umidade e aeração, todos os demais fatores principais que governam a nitrificação não são controlados nos experimentos de campo, implicando na ocorrência de períodos de maior ou menor favorecimento no acúmulo de $\mathrm{N}_{-\mathrm{NO}_{3}}^{-}$. Ainda, os íons $\mathrm{NH}_{4}{ }^{+}$e $\mathrm{NO}_{3}^{-}$são grandemente influenciados pela intensidade de precipitação pluvial (Stevenson, 1986). O $\mathrm{NH}_{4}{ }^{+}$, apesar de ser um cátion trocável, apresenta baixa afinidade no complexo de troca; quanto ao $\mathrm{NO}_{3}^{-}$, este ânion sofre repulsão, sobretudo nas camadas superficiais do solo, favorecendo seu deslocamento no perfil (Meurer et al., 2004).

Os tratamentos empregados promoveram alterações no acúmulo de $\mathrm{N}$ no capim (Tabela 22). As plantas do tratamento T2 não somente apresentaram menor rendimento de MS (Tabela 5 e Figura 3), mas também acumularam menor quantidade de N (Tabela 22). O acúmulo de N (Tabela 32), bem como o rendimento de MS do capim (Tabela 5) aumentou do tratamento T2 para o tratamento T5. Nos tratamentos T1, T3 e T4 não foram observadas diferenças tanto no rendimento de MS (Tabela 5) quanto no acúmulo de $\mathrm{N}$ no capim (Tabela 32). Isso indicou que a economia de NFM mediante a substituição da água convencional pelo ESET (discutido no item 4.3), não afetou o acúmulo de $\mathrm{N}$ no capim. Ainda, o aumento de $\mathrm{N}$ acumulado nas plantas devido à irrigação com ESET, sobretudo, no tratamento T5 (Tabela 32), promoveu melhoria de qualidade da forragem (Hayes et al., 1990b), concordando com os resultados de 
Vazquez-Montiel et al. (1996), Adekalu \& Okunade (2002) e Mohammad \& Ayadi (2004) e Barton et al. (2005).

Portanto, os resultados deste trabalho permitem indicar duas possibilidades de manejo do sistema receptor de ESET cultivado com capim-Bermuda Tifton 85: (a) considerar a economia de NFM promovida pela irrigação com este subproduto, mantendo altos rendimentos de MS (Tabela 5 e Figura 3) e boa qualidade do capim, sobre a ótica de conteúdo de nutrientes nas plantas (Tabelas 12 e 22); (b) desconsiderar o aporte de N-efluente, bem como os demais elementos presentes neste subproduto, permitindo maior rendimento de MS (Tabela 5 e Figura 3) e melhor qualidade da forragem (Tabelas 12 e 22). Ainda, a preocupação com excesso de $\mathrm{N}$ no sistema soloplanta fertilizado e irrigado com efluente, relatado em diversos trabalhos (Overman, 1981; Polglase et al., 1995; Magesan et al., 1998; Smith \& Bond, 1999), não ocorreu no

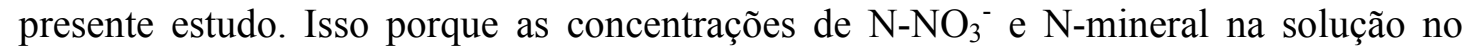
solo, apesar de terem sido mais elevadas nas camadas 0-10 e 10-20 cm, não atingiram concentrações críticas nas camadas subsuperficiais em nenhuma ocasião de avaliação (Tabelas 33 e 35). Essas informações concordam com as observações de Quin \& Forsythe (1978), num estudo com pastagem de azevém-perene irrigada anualmente com $840 \mathrm{~mm}$ de EET (contendo concentrações de N-total de 13,8-41,0 $\mathrm{mg} \mathrm{L}^{-1}$ ). Os autores

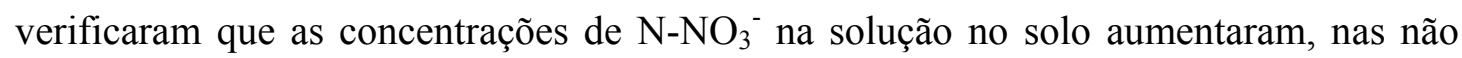
atingiram valores críticos (Quin \& Woods, 1978).

$\mathrm{O}$ capim utilizado neste experimento governou as concentrações de $\mathrm{N}$-mineral no sistema solo-solução e, mediante o corte e exportação de MS e de nutrientes, foi mantido a capacidade do sistema solo-planta em promover o polimento (tratamento terciário) do ESET. Essas observações concordam com as afirmações de Barton et al. (2005), os quais assinalaram que (i) a cultura é o principal fator que governa as perdas de $\mathrm{N}$ e que evita a lixiviação deste nutriente do sistema solo-planta irrigado com EET; (ii) a dose de efluente a ser aplicada deve estar relacionada às necessidades hídricas das plantas, bem como às diferenças sazonais da produção; (iii) as perdas de N-efluente por volatilização, denitrificação, bem como o incremento no estoque de $\mathrm{N}$ do solo são variáveis, difíceis de serem previsíveis e mensuráveis em curto prazo; (iv) as 
necessidades das plantas (notadamente, das gramíneas forrageiras) quanto ao nutriente $\mathrm{N}$, são "conhecidas" e mais fáceis de serem monitoradas.

\subsection{Micronutrientes e elementos tóxicos}

As concentrações de B disponível no solo somente foram influenciadas pelos tratamentos na camada $0-10 \mathrm{~cm}$ (Tabela 36). Os tratamentos T1 e T5, que não diferiram dos tratamentos T3 e T4, apresentaram maiores concentrações de B que o tratamento T2 (Tabela 36). Maiores concentrações de B foram observadas nos tratamentos que demandaram por doses mais elevadas de irrigação, implicando no aporte de maior quantidade deste micronutriente no sistema solo-planta (Tabela 4). Comparando-se os tratamentos $\mathrm{T} 1$ e $\mathrm{T} 5$, que receberam as mesmas doses de fertilizantes minerais (Tabela 1), torna-se evidente que o tipo de água empregada na irrigação do experimento não promoveu alterações nas concentrações de B no solo (Tabela 36). Isso foi devido ao fato de a água e o ESET terem apresentado baixas concentrações deste micronutriente (Tabela 3), numa faixa de concentração abaixo de $0,7 \mathrm{mg} \mathrm{L}^{-1}$, não implicando em restrição de uso, segundo Ayers \& Westcot (1985). Essas observações concordam com os trabalhos de Shahalam et al. (1998) e Fonseca (2001).

As concentrações de B no solo diminuiram no decorrer do experimento, exceto na camada 0-10 cm (Tabela 36). Essa diminuição pode estar relacionada, pelo menos em parte, com o aumento na quantidade de B acumulada no capim (Tabela 37), devido ao incremento no rendimento de MS durante o período experimental (Tabela 5), ocasionando menor quantidade deste micronutriente no solo (Tabela 36). Foi observada correlação negativa entre as concentrações de B na camada $20-40 \mathrm{~cm}$ e o acúmulo deste micronutriente no capim $\left(r=-0,53^{*}\right)$; para as demais camadas não foram observadas correlações. Essa diminuição nas concentrações disponíveis de B não foi observada por El-Nennah et al. (1982), mas está de acordo com os resultados de Reboll et al. (2000).

Na camada 0-10 cm, as concentrações de B ora aumentaram ora diminuíram durante o período experimental (Tabela 36). Essas flutuações podem estar relacionadas com (i) baixo poder tampão do solo; (ii) alta absorção de nutrientes pelas plantas, inclusive de B (Tabela 37); (iii) liberação de B oriundo da MOS. Devido ao fato de o 
Tabela 36. Efeitos da irrigação (água e efluente) e de doses de nitrogênio mineral nas concentrações de B disponível no solo

\begin{tabular}{|c|c|c|c|c|c|c|c|}
\hline \multirow{2}{*}{ Tratamento } & \multicolumn{7}{|c|}{ Época de avaliação } \\
\hline & Abr/03 & Jul/03 & Out/03 & Jan/04 & Abr/04 & Jul/04 & Média \\
\hline & \multicolumn{7}{|c|}{$\mathrm{mg} \mathrm{kg}^{-1}$} \\
\hline \multicolumn{8}{|c|}{ Camada 0-10 cm (CV = 19,26\%) } \\
\hline $\mathrm{T1}^{(1)}$ & 0,37 & 0,33 & 0,34 & 0,48 & 0,36 & 0,42 & $0,38^{a(6)}$ \\
\hline $\mathbf{T} 2^{(2)}$ & 0,33 & 0,26 & 0,35 & 0,38 & 0,26 & 0,41 & $0,33^{\mathrm{b}}$ \\
\hline T3 ${ }^{(3)}$ & 0,48 & 0,35 & 0,32 & 0,31 & 0,30 & 0,40 & $0,36^{\mathrm{ab}}$ \\
\hline$T 4^{(4)}$ & 0,37 & 0,36 & 0,33 & 0,38 & 0,33 & 0,43 & $0,37^{\mathrm{ab}}$ \\
\hline $\mathbf{T} 5^{(5)}$ & 0,39 & 0,33 & 0,29 & 0,50 & 0,33 & 0,44 & $0,38^{\mathrm{a}}$ \\
\hline Média & $0,39^{\mathrm{AB}}$ & $0,33^{\mathrm{BC}}$ & $0,33^{\mathrm{BC}}$ & $0,41^{\mathrm{A}}$ & $0,32^{\mathrm{C}}$ & $0,42^{\mathrm{A}}$ & \\
\hline \multicolumn{8}{|c|}{ Camada $10-20 \mathrm{~cm}(C V=20,75 \%)$} \\
\hline T1 & 0,29 & 0,24 & 0,22 & 0,29 & 0,23 & 0,31 & $0,26^{\mathrm{a}}$ \\
\hline T2 & 0,31 & 0,27 & 0,21 & 0,26 & 0,22 & 0,26 & $0,25^{\mathrm{a}}$ \\
\hline T3 & 0,37 & 0,31 & 0,19 & 0,25 & 0,24 & 0,24 & $0,27^{\mathrm{a}}$ \\
\hline T4 & 0,36 & 0,32 & 0,26 & 0,28 & 0,22 & 0,28 & $0,29^{\mathrm{a}}$ \\
\hline T5 & 0,37 & 0,28 & 0,21 & 0,29 & 0,17 & 0,26 & $0,26^{\mathrm{a}}$ \\
\hline Média & $0,34^{\mathrm{A}}$ & $0,28^{\mathrm{B}}$ & $0,22^{\mathrm{C}}$ & $0,27^{\mathrm{B}}$ & $0,22^{\mathrm{C}}$ & $0,27^{\mathrm{B}}$ & \\
\hline \multicolumn{8}{|c|}{ Camada $20-40 \mathrm{~cm}(C V=23,18 \%)$} \\
\hline T1 & 0,39 & 0,31 & 0,20 & 0,15 & 0,16 & 0,27 & $0,25^{\mathrm{a}}$ \\
\hline T2 & 0,34 & 0,32 & 0,22 & 0,27 & 0,15 & 0,19 & $0,25^{\mathrm{a}}$ \\
\hline T3 & 0,42 & 0,31 & 0,18 & 0,26 & 0,12 & 0,21 & $0,25^{\mathrm{a}}$ \\
\hline T4 & 0,39 & 0,37 & 0,28 & 0,20 & 0,20 & 0,26 & $0,28^{\mathrm{a}}$ \\
\hline T5 & 0,44 & 0,33 & 0,28 & 0,18 & 0,15 & 0,19 & $0,26^{\mathrm{a}}$ \\
\hline Média & $0,39^{\mathrm{A}}$ & $0,33^{\mathrm{B}}$ & $0,23^{\mathrm{C}}$ & $0,21^{\mathrm{CD}}$ & $0,16^{\mathrm{D}}$ & $0,22^{\mathrm{C}}$ & \\
\hline \multicolumn{8}{|c|}{ Camada $40-60 \mathrm{~cm}(\mathrm{CV}=23,39 \%)$} \\
\hline $\mathrm{T1}$ & 0,38 & 0,27 & 0,25 & 0,16 & 0,14 & 0,18 & $0,23^{\mathrm{a}}$ \\
\hline T2 & 0,35 & 0,32 & 0,25 & 0,31 & 0,14 & 0,19 & $0,26^{\mathrm{a}}$ \\
\hline T3 & 0,41 & 0,28 & 0,20 & 0,18 & 0,16 & 0,16 & $0,23^{\mathrm{a}}$ \\
\hline T4 & 0,39 & 0,33 & 0,24 & 0,25 & 0,20 & 0,23 & $0,27^{\mathrm{a}}$ \\
\hline T5 & 0,41 & 0,32 & 0,20 & 0,25 & 0,13 & 0,22 & $0,26^{\mathrm{a}}$ \\
\hline Média & $0,39^{\mathrm{A}}$ & $0,30^{\mathrm{B}}$ & $0,23^{\mathrm{C}}$ & $0,23^{\mathrm{C}}$ & $0,15^{\mathrm{D}}$ & $0,20^{\mathrm{CD}}$ & \\
\hline \multicolumn{8}{|c|}{ Camada $60-80 \mathrm{~cm}(C V=26,29 \%)$} \\
\hline $\mathrm{T1}$ & 0,38 & 0,26 & 0,25 & 0,19 & 0,11 & 0,17 & $0,23^{\mathrm{a}}$ \\
\hline $\mathbf{T 2}$ & 0,29 & 0,34 & 0,20 & 0,28 & 0,07 & 0,21 & $0,23^{\mathrm{a}}$ \\
\hline T3 & 0,33 & 0,32 & 0,20 & 0,18 & 0,15 & 0,19 & $0,23^{\mathrm{a}}$ \\
\hline T4 & 0,36 & 0,32 & 0,19 & 0,27 & 0,15 & 0,21 & $0,25^{\mathrm{a}}$ \\
\hline T5 & 0,32 & 0,30 & 0,24 & 0,22 & 0,18 & 0,17 & $0,24^{\mathrm{a}}$ \\
\hline Média & $0,33^{\mathrm{A}}$ & $0,31^{\mathrm{A}}$ & $0,22^{\mathrm{B}}$ & $0,23^{\mathrm{B}}$ & $0,13^{\mathrm{C}}$ & $0,19^{\mathrm{BC}}$ & \\
\hline
\end{tabular}


Tabela 36. Efeitos da irrigação (água e efluente) e de doses de nitrogênio mineral nas concentrações de B disponível no solo

\begin{tabular}{|c|c|c|c|c|c|c|c|}
\hline \multirow{2}{*}{ Tratamento } & \multicolumn{7}{|c|}{ Época de avaliação } \\
\hline & Abr/03 & Jul/03 & Out/03 & Jan/04 & Abr/04 & Jul/04 & Média \\
\hline & \multicolumn{7}{|c|}{$\mathrm{mg} \mathrm{kg}^{-1}$} \\
\hline \multicolumn{8}{|c|}{ Camada $80-100 \mathrm{~cm}(\mathrm{CV}=24,02 \%)$} \\
\hline T1 & 0,35 & 0,33 & 0,23 & 0,22 & 0,10 & 0,16 & $0,23^{\mathrm{a}}$ \\
\hline T2 & 0,31 & 0,33 & 0,23 & 0,30 & 0,05 & 0,17 & $0,23^{\mathrm{a}}$ \\
\hline T3 & 0,29 & 0,31 & 0,20 & 0,15 & 0,18 & 0,24 & $0,23^{\mathrm{a}}$ \\
\hline T4 & 0,40 & 0,30 & 0,22 & 0,18 & 0,13 & 0,15 & $0,23^{\mathrm{a}}$ \\
\hline T5 & 0,35 & 0,29 & 0,25 & 0,18 & 0,15 & 0,18 & $0,24^{\mathrm{a}}$ \\
\hline Média & $0,34^{\mathrm{A}}$ & $0,31^{\mathrm{A}}$ & $0,23^{\mathrm{B}}$ & $0,21^{\mathrm{B}}$ & $0,12^{\mathrm{C}}$ & $0,18^{\mathrm{B}}$ & \\
\hline
\end{tabular}

(1) T1: irrigação com água $+520 \mathrm{~kg} \mathrm{ha}^{-1}$ ano $^{-1}$ de nitrogênio via fertilizante mineral (NFM);

(2) T2: irrigação com efluente secundário de esgoto tratado (ESET), sem NFM;

(3) T3: irrigação com ESET + 171,6 $\mathrm{kg} \mathrm{ha}^{-1} \mathrm{ano}^{-1}$ de NFM;

(4) T4: irrigação com ESET + 343,3 $\mathrm{kg} \mathrm{ha}^{-1} \mathrm{ano}^{-1}$ de NFM;

(5) T5: irrigação com ESET $+520 \mathrm{~kg} \mathrm{ha}^{-1} \mathrm{ano}^{-1}$ de NFM;

(6) Letras iguais maiúsculas ou minúsculas nas linhas e nas colunas, respectivamente, não diferem estatisticamente pelo teste de Tukey $(P<0,05)$.

solo deste experimento apresentar baixo poder tampão (Tabela 2), períodos de elevada demanda por nutrientes podem ter ocasionado diminuição nas concentrações de B no solo. O aumento na concentração de B na camada 0-10 cm, no mês de janeiro/2004 (Tabela 36), pode ter sido devido à coincidência com condições favoráveis para a mineralização da MOS (temperatura, umidade, aeração e atividade microbina), que tem estreita relação com o aumento na biodisponibilidade de B (Mortvedt, 2000). Mas o incremento na concentração de B na camada 0-10 cm, no mês de julho/2004 (Tabela 36), pode ter sido devido aos fatores (i) aumento da quantidade de irrigação (Figura 2), ocasionando maior aporte deste micronutriente; (ii) diminuição na quantidade de B extraída pelas plantas durante este período (terceiro semestre) (Tabela 37), implicando em maior quantidade deste micronutriente no solo.

Maior e menor acúmulo de $\mathrm{B}$ no capim foram observados nos tratamentos T5 e T2, respectivamente (Tabela 37). A quantidade de B acumulada nas plantas dos tratamentos T1 e T4 não foram diferentes das observadas para as plantas dos tratamentos T3 e T5 (Tabela 37). Houve relação entre emprego de maiores doses de irrigação com 
Tabela 37. Efeitos da irrigação (água e efluente) e de doses de nitrogênio mineral no acúmulo semestral (somatório de três cortes bimestrais) dos micronutrientes $\mathrm{B}, \mathrm{Cu}, \mathrm{Zn}, \mathrm{Fe}$ e $\mathrm{Mn}$ na parte aérea (folhas + colmos + bainhas) do capim-Bermuda Tifton 85

\begin{tabular}{|c|c|c|c|c|}
\hline Tratamento & $1^{\circ}$ semestre & $\begin{array}{c}\text { Época } \\
2^{\circ} \text { semestre } \\
\end{array}$ & $3^{\circ}$ semestre & Média \\
\hline & \multicolumn{4}{|c|}{ g ha $^{-1}$} \\
\hline \multicolumn{5}{|c|}{ Acúmulo de B (CV = 13,78\%) } \\
\hline $\mathrm{T} 1^{(1)}$ & 77,50 & 150,73 & 83,07 & $103,77^{a b(6)}$ \\
\hline$T 2^{(2)}$ & 64,58 & 73,48 & 50,25 & $62,77^{\mathrm{c}}$ \\
\hline T3 ${ }^{(3)}$ & 69,33 & 137,04 & 83,23 & $96,54^{\mathrm{b}}$ \\
\hline T4 ${ }^{(4)}$ & 74,64 & 156,34 & 74,84 & $101,94^{a b}$ \\
\hline$T 5^{(5)}$ & 84,05 & 174,37 & 80,53 & $112,99^{\mathrm{a}}$ \\
\hline Média & $74,02^{\mathrm{B}}$ & $138,39^{\mathrm{A}}$ & $74,38^{\mathrm{B}}$ & \\
\hline \multicolumn{5}{|c|}{ Acúmulo de $\mathrm{Cu}(\mathrm{CV}=30,09 \%)$} \\
\hline T1 & 175,52 & 113,83 & 71,12 & $120,16^{\mathrm{a}}$ \\
\hline T2 & 144,15 & 63,76 & 65,41 & $91,11^{b}$ \\
\hline T3 & 129,69 & 106,01 & 76,50 & $104,07^{\mathrm{ab}}$ \\
\hline T4 & 132,84 & 118,46 & 66,58 & $105,96^{\mathrm{ab}}$ \\
\hline T5 & 96,17 & 127,53 & 68,63 & $97,44^{\mathrm{ab}}$ \\
\hline Média & $135,67^{\mathrm{A}}$ & $105,92^{\mathrm{B}}$ & $69,65^{\mathrm{C}}$ & \\
\hline \multicolumn{5}{|c|}{ Acúmulo de $\mathrm{Zn}(\mathrm{CV}=11,97 \%)$} \\
\hline T1 & 205,83 & 227,21 & 243,27 & $225,44^{\mathrm{a}}$ \\
\hline T2 & 146,79 & 145,60 & 225,73 & $172,70^{\mathrm{b}}$ \\
\hline T3 & 177,98 & 237,95 & 248,40 & $221,44^{\mathrm{a}}$ \\
\hline T4 & 175,99 & 245,91 & 225,96 & $215,96^{\mathrm{a}}$ \\
\hline T5 & 207,37 & 290,10 & 260,05 & $252,51^{\mathrm{a}}$ \\
\hline \multirow[t]{2}{*}{ Média } & $182,79^{\mathrm{B}}$ & $229,35^{\mathrm{A}}$ & $240,68^{A}$ & \\
\hline & \multicolumn{4}{|c|}{ kg ha $^{-1}$} \\
\hline \multicolumn{5}{|c|}{ Acúmulo de Fe $(C V=12,53)$} \\
\hline $\mathbf{T 1}$ & 1,19 & 1,26 & 0,86 & $1,10^{\mathrm{c}}$ \\
\hline $\mathbf{T} 2$ & 1,51 & 0,73 & 0,80 & $1,01^{\mathrm{c}}$ \\
\hline T3 & 1,45 & 1,36 & 1,22 & $1,34^{\mathrm{b}}$ \\
\hline T4 & 1,35 & 1,84 & 1,20 & $1,46^{\mathrm{ab}}$ \\
\hline T5 & 1,40 & 1,98 & 1,23 & $1,54^{\mathrm{a}}$ \\
\hline Média & $1,38^{\mathrm{A}}$ & $1,43^{\mathrm{A}}$ & $1,06^{\mathrm{B}}$ & \\
\hline
\end{tabular}


Tabela 37. Efeitos da irrigação (água e efluente) e de doses de nitrogênio mineral no acúmulo semestral (somatório de três cortes bimestrais) dos micronutrientes $\mathrm{B}, \mathrm{Cu}, \mathrm{Zn}, \mathrm{Fe}$ e $\mathrm{Mn}$ na parte aérea (folhas + colmos + bainhas) do capim-Bermuda Tifton 85

\begin{tabular}{|c|c|c|c|c|}
\hline Tratamento & $1^{\circ}$ semestre & $\begin{array}{c}\text { Época } \\
2^{\circ} \text { semestre } \\
\end{array}$ & $3^{\circ}$ semestre & Média \\
\hline & \multicolumn{4}{|c|}{ kg ha $^{-1}$} \\
\hline \multicolumn{5}{|c|}{ Acúmulo de Mn (CV = 11,77\%) } \\
\hline $\mathrm{T} 1$ & 1,45 & 1,75 & 1,15 & $1,45^{\mathrm{a}}$ \\
\hline $\mathbf{T} 2$ & 0,96 & 1,07 & 0,96 & $0,99^{\mathrm{b}}$ \\
\hline T3 & 1,19 & 1,70 & 1,49 & $1,46^{\mathrm{a}}$ \\
\hline T4 & 1,48 & 2,17 & 1,57 & $1,74^{\mathrm{a}}$ \\
\hline T5 & 1,61 & 2,00 & 1,22 & $1,61^{\mathrm{a}}$ \\
\hline Média & $1,34^{\mathrm{B}}$ & $1,74^{\mathrm{A}}$ & $1,28^{\mathrm{B}}$ & \\
\hline
\end{tabular}

(1) T1: irrigação com água $+520 \mathrm{~kg} \mathrm{ha}^{-1}$ ano $^{-1}$ de nitrogênio via fertilizante mineral (NFM);

(2) T2: irrigação com efluente secundário de esgoto tratado (ESET), sem NFM;

(3) T3: irrigação com ESET + 171,6 $\mathrm{kg} \mathrm{ha}^{-1} \mathrm{ano}^{-1}$ de NFM;

(4) T4: irrigação com ESET + 343,3 kg ha ${ }^{-1} \mathrm{ano}^{-1}$ de NFM;

(5) T5: irrigação com ESET $+520 \mathrm{~kg} \mathrm{ha}^{-1} \mathrm{ano}^{-1}$ de NFM;

(6) Letras iguais maiúsculas ou minúsculas nas linhas e nas colunas, respectivamente, não diferem estatisticamente pelo teste de Tukey $(P<0,05)$.

aumento no acúmulo de B no capim. Isso porque o tratamento T5 recebeu maior dose de irrigação que os tratamentos T2 e T3 (Figura 2) e, consequentemente, apresentou acúmulo mais elevado de B nas plantas (Tabela 37). Ainda, os tratamentos T1 e T3 receberam doses similares de irrigação com água e ESET (Figura 2) e, desse modo, as quantidades de B acumuladas nas plantas desses tratamentos não foram diferentes (Tabela 37). Portanto, o tipo de água empregada na irrigação não alterou o acúmulo de $\mathrm{B}$ nas plantas (Tabela 37), discordando das observações realizadas por Johns \& McConchie (1994b), mas concordando com os resultados de Fonseca (2001).

$\mathrm{Na}$ solução no solo (extrato aquoso), os tratamentos somente ocasionam alterações nas concentrações de $\mathrm{B}$ solúvel na camada 40-60 cm (Tabela 38). O tratamento T4 apresentou maior concentração de B solúvel que os tratamentos T1 e T2; porém, estes tratamentos não apresentaram concentraçõs deste micronutriente diferentes das observadas nos tratamentos T3 e T5 (Tabela 38). No decorrer do experimento as 
Tabela 38. Efeitos da irrigação (água e efluente) e de doses de nitrogênio mineral nas concentrações de B na solução no solo

\begin{tabular}{|c|c|c|c|c|c|c|c|}
\hline \multirow{2}{*}{ Tratamento } & \multicolumn{7}{|c|}{ Época de avaliação } \\
\hline & Abr/03 & Jul/03 & Out/03 & Jan/04 & Abr/04 & Jul/04 & Média \\
\hline & \multicolumn{7}{|c|}{$\mu g L^{-1}$} \\
\hline \multicolumn{8}{|c|}{ Camada 0-10 cm (CV = 45,99\%) } \\
\hline $\mathrm{T1}^{(1)}$ & 64 & 22 & 69 & 82 & 65 & 111 & $69^{\mathrm{a}(7)}$ \\
\hline $\mathbf{T} 2^{(2)}$ & 99 & 73 & 48 & 79 & 58 & 81 & $73^{a}$ \\
\hline T3 ${ }^{(3)}$ & 75 & 142 & 20 & 74 & 89 & 119 & $87^{\mathrm{a}}$ \\
\hline$T 4^{(4)}$ & 47 & 107 & 70 & 99 & 103 & 222 & $108^{\mathrm{a}}$ \\
\hline$T 5^{(5)}$ & 43 & 57 & $<\mathrm{LD}^{(6)}$ & 120 & 72 & 191 & $81^{\mathrm{a}}$ \\
\hline Média & $66^{\mathrm{BC}}$ & $80^{\mathrm{B}}$ & $41^{\mathrm{C}}$ & $91^{\mathrm{B}}$ & $77^{\mathrm{B}}$ & $145^{\mathrm{A}}$ & \\
\hline \multicolumn{8}{|c|}{ Camada $10-20 \mathrm{~cm}(C V=77,16 \%)$} \\
\hline T1 & 63 & $<\mathrm{LD}$ & 16 & 67 & 27 & 149 & $54^{\mathrm{a}}$ \\
\hline $\mathbf{T 2}$ & 109 & $<\mathrm{LD}$ & 50 & 48 & 104 & 313 & $104^{\mathrm{a}}$ \\
\hline T3 & 68 & 31 & 144 & 64 & 82 & 219 & $101^{\mathrm{a}}$ \\
\hline T4 & 62 & 68 & 40 & 94 & 48 & 116 & $71^{\mathrm{a}}$ \\
\hline T5 & 134 & $<\mathrm{LD}$ & $<\mathrm{LD}$ & 57 & 18 & 47 & $43^{\mathrm{a}}$ \\
\hline Média & $87^{\mathrm{B}}$ & $20^{\mathrm{C}}$ & $50^{\mathrm{BC}}$ & $66^{\mathrm{BC}}$ & $56^{\mathrm{BC}}$ & $169^{\mathrm{A}}$ & \\
\hline \multicolumn{8}{|c|}{ Camada $20-40 \mathrm{~cm}(C V=84,63 \%)$} \\
\hline T1 & 107 & 85 & $<\mathrm{LD}$ & 36 & 45 & 46 & $53^{\mathrm{a}}$ \\
\hline T2 & 169 & $<\mathrm{LD}$ & $<\mathrm{LD}$ & 24 & $<\mathrm{LD}$ & 54 & $41^{\mathrm{a}}$ \\
\hline T3 & 62 & 59 & 75 & 32 & 10 & 47 & $48^{\mathrm{a}}$ \\
\hline T4 & 45 & 19 & $<\mathrm{LD}$ & 60 & 77 & 21 & $37^{\mathrm{a}}$ \\
\hline T5 & 55 & 102 & $<\mathrm{LD}$ & 29 & 8 & 21 & $36^{\mathrm{a}}$ \\
\hline Média & $88^{\mathrm{A}}$ & $53^{\mathrm{B}}$ & $15^{\mathrm{C}}$ & $36^{\mathrm{BC}}$ & $28^{\mathrm{BC}}$ & $38^{\mathrm{BC}}$ & \\
\hline \multicolumn{8}{|c|}{ Camada $40-60 \mathrm{~cm}(C V=110,93 \%)$} \\
\hline $\mathrm{T1}$ & 54 & $<\mathrm{LD}$ & $<\mathrm{LD}$ & 20 & 77 & 37 & $31^{\mathrm{b}}$ \\
\hline T2 & 75 & $<\mathrm{LD}$ & $<\mathrm{LD}$ & 19 & 21 & 40 & $26^{\mathrm{b}}$ \\
\hline T3 & 84 & 21 & $<\mathrm{LD}$ & 27 & 53 & 68 & $42^{\mathrm{ab}}$ \\
\hline T4 & 125 & 123 & 46 & 23 & $<\mathrm{LD}$ & 62 & $63^{\mathrm{a}}$ \\
\hline T5 & 46 & 53 & $<\mathrm{LD}$ & 68 & 50 & 16 & $39^{\mathrm{ab}}$ \\
\hline Média & $77^{\mathrm{A}}$ & $39^{\mathrm{AB}}$ & $9^{\mathrm{B}}$ & $31^{\mathrm{B}}$ & $40^{\mathrm{AB}}$ & $45^{\mathrm{AB}}$ & \\
\hline \multicolumn{8}{|c|}{ Camada $60-80 \mathrm{~cm}(\mathrm{CV}=105,69 \%)$} \\
\hline $\mathrm{T1}$ & 49 & 37 & $<\mathrm{LD}$ & 17 & 10 & 87 & $33^{a}$ \\
\hline $\mathbf{T 2}$ & 161 & 146 & $<\mathrm{LD}$ & 23 & $<\mathrm{LD}$ & 13 & $57^{\text {a }}$ \\
\hline T3 & 74 & $<\mathrm{LD}$ & 41 & 33 & $<\mathrm{LD}$ & 126 & $46^{\mathrm{a}}$ \\
\hline T4 & 63 & $<\mathrm{LD}$ & 72 & 61 & 21 & 52 & $45^{\mathrm{a}}$ \\
\hline T5 & 92 & 49 & $<\mathrm{LD}$ & 27 & 53 & 70 & $49^{\mathrm{a}}$ \\
\hline Média & $88^{\mathrm{A}}$ & $46^{\mathrm{ABC}}$ & $23^{\mathrm{C}}$ & $32^{\mathrm{BC}}$ & $17^{\mathrm{C}}$ & $70^{\mathrm{AB}}$ & \\
\hline
\end{tabular}


Tabela 38. Efeitos da irrigação (água e efluente) e de doses de nitrogênio mineral nas concentrações de B na solução no solo

\begin{tabular}{|c|c|c|c|c|c|c|c|}
\hline \multirow{2}{*}{ Tratamento } & \multicolumn{7}{|c|}{ Época de avaliação } \\
\hline & Abr/03 & Jul/03 & Out/03 & Jan/04 & Abr/04 & Jul/04 & Média \\
\hline & \multicolumn{7}{|c|}{$\mu g L^{-1}$} \\
\hline \multicolumn{8}{|c|}{ Camada $80-100 \mathrm{~cm}(C V=77,82 \%)$} \\
\hline T1 & 81 & $<\mathrm{LD}$ & $<\mathrm{LD}$ & 23 & $<\mathrm{LD}$ & 40 & $24^{\mathrm{a}}$ \\
\hline T2 & 85 & 44 & $<\mathrm{LD}$ & 16 & $<\mathrm{LD}$ & 105 & $42^{\mathrm{a}}$ \\
\hline T3 & 40 & 17 & $<\mathrm{LD}$ & 14 & 35 & 82 & $31^{\mathrm{a}}$ \\
\hline T4 & 59 & 36 & $<\mathrm{LD}$ & 25 & 19 & 50 & $32^{\mathrm{a}}$ \\
\hline T5 & 50 & 26 & $<\mathrm{LD}$ & 17 & 21 & 45 & $27^{\mathrm{a}}$ \\
\hline Média & $63^{\mathrm{A}}$ & $25^{\mathrm{B}}$ & $<\mathrm{LD}$ & $19^{\mathrm{BC}}$ & $15^{\mathrm{BC}}$ & $65^{\mathrm{A}}$ & \\
\hline
\end{tabular}

(1) T1: irrigação com água $+520 \mathrm{~kg} \mathrm{ha}^{-1}$ ano $^{-1}$ de nitrogênio via fertilizante mineral (NFM).

(2) T2: irrigação com efluente secundário de esgoto tratado (ESET), sem NFM.

(3) T3: irrigação com ESET + 171,6 kg ha-1 ano-1 de NFM.

(4) T4: irrigação com ESET + 343,3 $\mathrm{kg} \mathrm{ha}^{-1} \mathrm{ano}^{-1}$ de NFM.

(5) T5: irrigação com ESET $+520 \mathrm{~kg} \mathrm{ha}^{-1} \mathrm{ano}^{-1}$ de NFM.

(6) LD: limite de detecção $\left(8 \mu \mathrm{g} \mathrm{L}^{-1}\right)$. Para fins de análises estatísticas esses valores foram considerados iguais a zero.

(7) Letras iguais maiúsculas ou minúsculas nas linhas e nas colunas, respectivamente, não diferem estatisticamente pelo teste de Tukey $(P<0,05)$.

concentrações de B solúvel (i) aumentaram nas camadas 0-10 e 10-20 cm; (ii) diminuíram na camada 20-40 cm; (iii) diminuíram e tornaram a aumentar nas camadas 40-60, 60-80 e 80-100 cm (Tabela 38). O aumento e a diminuição nas concentrações de B solúvel nas camadas 0-10 e 20-40 cm, respectivamente, pode ser reflexo das alterações nas concentrações disponíveis deste micronutriente no solo (Tabela 36). Apesar dos coeficientes de correlação terem sido baixos, houve correlação positiva entre as concentrações solúveis e disponíveis de B para as camadas 0-10 cm. $\left(r=0,47^{* *}\right)$ e 20 $40 \mathrm{~cm}\left(r=0,38^{*}\right)$. Para as demais camadas, nenhuma correlação foi observada entre as concentrações de $\mathrm{B}$ disponíveis no solo e solúveis no extrato aquoso. A falta de correlação e/ou a obtenção de baixos coeficientes de correlação entre as concentrações solúveis e disponíveis de $\mathrm{B}$ pode ser devido à maior variabilidade dos resultados na solução no solo. Assim, os CV do B na solução no solo (Tabela 38), que foi obtida conforme Rhoades (1996), foram superiores aos observados para as concentrações disponíveis deste micronutriente no solo (Tabela 36), cuja determinação foi realizada 
conforme Abreu et al. (1994). Portanto, os extratos de saturação também não se mostraram eficientes para estudos do micronutriente B no presente trabalho.

$\mathrm{O}$ micronutriente $\mathrm{B}$, semelhantemente ao que aconteceu com o nutriente $\mathrm{P}$, promoveu pequenas alterações no solo (Tabela 36) e na solução no solo (Tabela 38), uma vez que o capim-Bermuda Tifton 85 atuou como um dreno eficiente para este micronutriente. Os resultados obtidos no presente trabalho permitem inferir que, nos estudos envolvendo irrigação com ESET contendo baixa concentração de $\mathrm{B}$, o monitoramento deste micronutriente no solo somente será justificado para fins de avaliação da fertilidade, que pode ser realizada com base na amostragem da camada 0$10 \mathrm{~cm}$ (Raij, 1991).

Os tratamentos empregados somente ocasionaram alterações nas concentrações de $\mathrm{Cu}$ disponível na camada 40-60 cm (Tabela 39). Maior e menor concentração de $\mathrm{Cu}$ no solo foi observada no tratamento T2 e E3, respectivamente, porém esses tratamentos não foram diferentes dos demais (Tabela 39). Os tratamentos T1 e T5, que receberam as mesmas doses de fertilizantes minerais (Tabela 1), não apresentaram concentrações de $\mathrm{Cu}$ disponível diferentes (Tabela 39). Pelo fato de o ESET ter apresentado baixíssima concentração de $\mathrm{Cu}$ (Tabela 3), a irrigação com este subproduto ocasionou aporte insignificante deste micronutriente no sistema (Tabela 4), não alterando sua biodisponibilidade (Tabela 39). O fato de o ESET não ter proporcionado alterações nas concentrações de $\mathrm{Cu}$ disponível no solo concorda com os trabalhos de Hayes et al. (1990a), Inglés et al. (1992), Mancino \& Pepper (1992), Johns \& McConchie (1994b), Adekalu \& Okunade (2002) e Mohammad \& Mazahreh (2003). Normalmente, o uso de EET de origem predominantemente doméstico na irrigação de agrossistemas não tem ocasionado aumento nas concentrações de $\mathrm{Cu}$ no solo (Bouwer and Chaney, 1974; Feigin et al., 1991). Em médio e longo prazo, as concentrações de $\mathrm{Cu}$ biodisponível e total no solo podem (Quin \& Syers, 1978; Siebe, 1995; Madyiwa et al., 2002) ou não (Wang et al., 2003) serem aumentadas devido à irrigação de pastagens com EET. Isso é dependente, evidentemente, da concentração de $\mathrm{Cu}$ no EET (Al-Nakshabandi et al., 1997), sobretudo, ao longo do tempo (Ramirez-Fuentes et al., 2002). 
Tabela 39. Efeitos da irrigação (água e efluente) e de doses de nitrogênio mineral nas concentrações de $\mathrm{Cu}$ disponível no solo

\begin{tabular}{|c|c|c|c|c|c|c|c|}
\hline \multirow{2}{*}{ Tratamento } & \multicolumn{7}{|c|}{ Época de avaliação } \\
\hline & Abr/03 & Jul/03 & Out/03 & Jan/04 & Abr/04 & Jul/04 & Média \\
\hline & \multicolumn{7}{|c|}{$\mathrm{mg} \mathrm{kg}^{-1}$} \\
\hline \multicolumn{8}{|c|}{ Camada 0-10 cm (CV = 23,63\%) } \\
\hline $\mathrm{T1}^{(1)}$ & 0,26 & 0,28 & 0,36 & 0,31 & 0,74 & 0,36 & $0,38^{a(6)}$ \\
\hline$T 2^{(2)}$ & 0,43 & 0,27 & 0,43 & 0,30 & 0,66 & 0,29 & $0,39^{\mathrm{a}}$ \\
\hline T3 ${ }^{(3)}$ & 0,48 & 0,25 & 0,43 & 0,30 & 0,71 & 0,37 & $0,42^{\mathrm{a}}$ \\
\hline$T 4^{(4)}$ & 0,44 & 0,25 & 0,38 & 0,31 & 0,65 & 0,50 & $0,42^{\mathrm{a}}$ \\
\hline $\mathbf{T} 5^{(5)}$ & 0,50 & 0,26 & 0,35 & 0,29 & 0,65 & 0,36 & $0,41^{\mathrm{a}}$ \\
\hline Média & $0,42^{\mathrm{B}}$ & $0,26^{\mathrm{D}}$ & $0,39^{\mathrm{BC}}$ & $0,30^{\mathrm{CD}}$ & $0,68^{\mathrm{A}}$ & $0,37^{\mathrm{BC}}$ & \\
\hline \multicolumn{8}{|c|}{ Camada $10-20 \mathrm{~cm}(C V=23,58 \%)$} \\
\hline T1 & 0,26 & 0,24 & 0,32 & 0,23 & 0,71 & 0,34 & $0,35^{\mathrm{a}}$ \\
\hline T2 & 0,58 & 0,24 & 0,41 & 0,33 & 0,64 & 0,42 & $0,44^{\mathrm{a}}$ \\
\hline T3 & 0,38 & 0,26 & 0,41 & 0,34 & 0,82 & 0,42 & $0,44^{\mathrm{a}}$ \\
\hline T4 & 0,40 & 0,26 & 0,38 & 0,35 & 0,72 & 0,46 & $0,43^{\mathrm{a}}$ \\
\hline T5 & 0,47 & 0,25 & 0,40 & 0,24 & 0,68 & 0,34 & $0,40^{\mathrm{a}}$ \\
\hline Média & $0,42^{\mathrm{B}}$ & $0,25^{\mathrm{D}}$ & $0,38^{\mathrm{BC}}$ & $0,30^{\mathrm{CD}}$ & $0,71^{\mathrm{A}}$ & $0,39^{\mathrm{B}}$ & \\
\hline \multicolumn{8}{|c|}{ Camada $20-40 \mathrm{~cm}(\mathrm{CV}=22,59 \%)$} \\
\hline $\mathrm{T} 1$ & 0,45 & 0,30 & 0,46 & 0,31 & 0,79 & 0,47 & $0,46^{\mathrm{a}}$ \\
\hline T2 & 0,44 & 0,27 & 0,49 & 0,32 & 0,79 & 0,46 & $0,46^{\mathrm{a}}$ \\
\hline T3 & 0,33 & 0,28 & 0,49 & 0,37 & 0,76 & 0,36 & $0,43^{\mathrm{a}}$ \\
\hline T4 & 0,43 & 0,31 & 0,46 & 0,40 & 0,78 & 0,47 & $0,47^{\mathrm{a}}$ \\
\hline T5 & 0,48 & 0,30 & 0,45 & 0,36 & 0,76 & 0,41 & $0,46^{\mathrm{a}}$ \\
\hline Média & $0,43^{\mathrm{BC}}$ & $0,29^{\mathrm{D}}$ & $0,47^{\mathrm{B}}$ & $0,35^{\mathrm{CD}}$ & $0,78^{\mathrm{A}}$ & $0,43^{\mathrm{BC}}$ & \\
\hline \multicolumn{8}{|c|}{ Camada $40-60 \mathrm{~cm}(\mathrm{CV}=18,77 \%)$} \\
\hline $\mathrm{T} 1$ & 0,42 & 0,29 & 0,44 & 0,38 & 0,77 & 0,38 & $0,45^{\mathrm{ab}}$ \\
\hline T2 & 0,53 & 0,31 & 0,46 & 0,39 & 0,84 & 0,35 & $0,48^{\mathrm{a}}$ \\
\hline T3 & 0,29 & 0,27 & 0,40 & 0,37 & 0,66 & 0,40 & $0,40^{\mathrm{b}}$ \\
\hline T4 & 0,45 & 0,30 & 0,50 & 0,42 & 0,76 & 0,35 & $0,46^{\mathrm{ab}}$ \\
\hline T5 & 0,49 & 0,29 & 0,43 & 0,33 & 0,77 & 0,27 & $0,43^{a b}$ \\
\hline Média & $0,44^{\mathrm{B}}$ & $0,29^{\mathrm{D}}$ & $0,45^{\mathrm{B}}$ & $0,38^{\mathrm{BC}}$ & $0,76^{\mathrm{A}}$ & $0,35^{\mathrm{CD}}$ & \\
\hline \multicolumn{8}{|c|}{ Camada $60-80 \mathrm{~cm}(\mathrm{CV}=22,33 \%)$} \\
\hline T1 & 0,34 & 0,24 & 0,33 & 0,25 & 0,61 & 0,30 & $0,34^{\mathrm{a}}$ \\
\hline T2 & 0,34 & 0,26 & 0,39 & 0,34 & 0,69 & 0,29 & $0,39^{\mathrm{a}}$ \\
\hline T3 & 0,47 & 0,22 & 0,41 & 0,24 & 0,75 & 0,25 & $0,39^{\mathrm{a}}$ \\
\hline T4 & 0,40 & 0,22 & 0,37 & 0,45 & 0,69 & 0,31 & $0,40^{\mathrm{a}}$ \\
\hline T5 & 0,42 & 0,26 & 0,42 & 0,31 & 0,71 & 0,32 & $0,41^{\mathrm{a}}$ \\
\hline Média & $0,39^{\mathrm{B}}$ & $0,24^{\mathrm{C}}$ & $0,38^{\mathrm{B}}$ & $0,32^{\mathrm{BC}}$ & $0,69^{\mathrm{A}}$ & $0,30^{\mathrm{C}}$ & \\
\hline
\end{tabular}


Tabela 39. Efeitos da irrigação (água e efluente) e de doses de nitrogênio mineral nas concentrações de $\mathrm{Cu}$ disponível no solo

\begin{tabular}{|c|c|c|c|c|c|c|c|}
\hline \multirow{2}{*}{ Tratamento } & \multicolumn{7}{|c|}{ Época de avaliação } \\
\hline & Abr/03 & Jul/03 & Out/03 & Jan/04 & Abr/04 & Jul/04 & Média \\
\hline & \multicolumn{7}{|c|}{$\mathrm{mg} \mathrm{kg}^{-1}$} \\
\hline \multicolumn{8}{|c|}{ Camada $80-100 \mathrm{~cm}(C V=30,50 \%)$} \\
\hline T1 & 0,28 & 0,21 & 0,33 & 0,23 & 0,66 & 0,25 & $0,32^{\mathrm{a}}$ \\
\hline T2 & 0,25 & 0,22 & 0,39 & 0,24 & 0,74 & 0,27 & $0,35^{\mathrm{a}}$ \\
\hline T3 & 0,49 & 0,17 & 0,31 & 0,17 & 0,67 & 0,23 & $0,34^{\mathrm{a}}$ \\
\hline T4 & 0,34 & 0,19 & 0,34 & 0,32 & 0,71 & 0,25 & $0,36^{\mathrm{a}}$ \\
\hline T5 & 0,48 & 0,21 & 0,38 & 0,22 & 0,61 & 0,27 & $0,36^{\mathrm{a}}$ \\
\hline Média & $0,37^{\mathrm{B}}$ & $0,20^{\mathrm{D}}$ & $0,35^{\mathrm{BC}}$ & $0,24^{\mathrm{D}}$ & $0,68^{\mathrm{A}}$ & $0,25^{\mathrm{CD}}$ & \\
\hline
\end{tabular}

(1) T1: irrigação com água $+520 \mathrm{~kg} \mathrm{ha}^{-1}$ ano $^{-1}$ de nitrogênio via fertilizante mineral (NFM);

(2) T2: irrigação com efluente secundário de esgoto tratado (ESET), sem NFM;

(3) T3: irrigação com ESET + 171,6 $\mathrm{kg} \mathrm{ha}^{-1} \mathrm{ano}^{-1}$ de NFM;

(4) T4: irrigação com ESET + 343,3 $\mathrm{kg} \mathrm{ha}^{-1} \mathrm{ano}^{-1}$ de NFM;

(5) T5: irrigação com ESET $+520 \mathrm{~kg} \mathrm{ha}^{-1} \mathrm{ano}^{-1}$ de NFM;

(6) Letras iguais maiúsculas ou minúsculas nas linhas e nas colunas, respectivamente, não diferem estatisticamente pelo teste de Tukey $(P<0,05)$.

No decorrer do experimento as concentrações de $\mathrm{Cu}$ no solo diminuíram até o mês de janeiro/2004, aumentaram em abril/2004 e diminuíram em julho/2004 (Tabela 39). Essas flutuações nas concentrações de $\mathrm{Cu}$ no solo podem estar relacionadas ao aumento na absorção e no acúmulo deste micronutriente nas plantas, que foi maior nos dois primeiros semestres (Tabela 37), período onde foram observadas menores concentrações de $\mathrm{Cu}$ no solo (Tabela 39). Também foi observado que o acúmulo de $\mathrm{Cu}$ no capim se correlacionou negativamente com as concentrações deste micronutriente nas camadas $0-10\left(r=-0,59^{*}\right), 10-20\left(r=-0,75^{* *}\right)$ e $20-40 \mathrm{~cm}\left(r=-0,68^{* *}\right)$, indicando que a diminuição nas concentrações de $\mathrm{Cu}$ no solo foi devido, principalmente, à maior extração pelas plantas. Ainda, a MOS tem importante papel no controle da disponibilidade de micronutrientes no solo (Stevenson, 1986). Pelo fato de ter ocorrido diminuição nas concentrações de CT no solo (Tabela 31), no decorrer do experimento, pode ter ocorrido liberação do $\mathrm{Cu}$ ligado à $\mathrm{MOS}$, ocasionando aumento nas concentrações deste micronutriente, pelo menos em determinados períodos. 
A disponibilidade de $\mathrm{Cu}$ no solo é grandemente influenciada pelo $\mathrm{pH}$ (Lindsay, 1979; Mortvedt, 2000). Apesar de não ter sido observadas correlações entre as concentrações de $\mathrm{Cu}$ (disponível e solúvel) com o pH (do solo e da solução no solo), foram obtidas correlações negativas entre a quantidade de $\mathrm{Cu}$ acumulada no capim e o pH da solução no solo nas camadas 0-10 $\left(r=-0,70^{* *}\right), 10-20\left(r=-0,61^{*}\right), 20-40(r=-$ $\left.0,72^{* *}\right)$ e 40-60 $\left(r=-0,55^{*}\right) \mathrm{cm}$. Isso evidenciou que, em condições de menor $\mathrm{pH}$ da solução, o acúmulo de $\mathrm{Cu}$ nas plantas foi favorecido, concordando com as afirmações de Mengel \& Kirkby (2001).

$\mathrm{O}$ acúmulo de $\mathrm{Cu}$ no capim foi mais elevado no tratamento $\mathrm{T} 1$ quando comparado ao tratamento T2, porém esses tratamentos não diferiram dos demais (Tabela 37). $\mathrm{O}$ menor acúmulo de $\mathrm{Cu}$ no tratamento $\mathrm{T} 2$ pode estar relacionado ao fato deste tratamento ter tido menor rendimento de MS (Tabela 5), implicando em menor acúmulo de nutrientes, inclusive de $\mathrm{Cu}$ (Tabela 37). Comparando-se os tratamentos $\mathrm{T} 1 \mathrm{com}$ os demais tratamentos irrigados com ESET, conclui-se que este subproduto não alterou o acúmulo de $\mathrm{Cu}$ no capim, discordando das observações realizadas por Inglés et al. (1992), Adekalu \& Okunade (2002) e Mohammad \& Ayadi (2004), mas concordando com os resultados de Fonseca (2001). Ainda, o acúmulo de $\mathrm{Cu}$ no capim foi maior no primeiro semestre e menor no terceiro semestre (Tabela 37).

$\mathrm{Na}$ solução no solo, as concentrações de Cu solúvel não foram diferentes para os tratamentos empregados, sendo somente observadas alterações nas concentrações deste micronutriente para as épocas de avaliação (Tabela 40). Nos meses de abril/2003 e julho/2004 as concentrações de $\mathrm{Cu}$ encontravam-se abaixo do limite de detecção (Tabela 40), justamente no período de maior acúmulo deste micronutriente (Tabela 37). Após esse período, as concentrações de $\mathrm{Cu}$ foram detectadas e continuaram mais elevadas, com algumas flutuações sazonais (Tabela 40). O acúmulo de $\mathrm{Cu}$ no capim se correlacionou negativamente com as concentrações de $\mathrm{Cu}$ na solução nas camadas 0-10 $\left(r=-0,70^{* *}\right), 10-20\left(r=-0,64^{* *}\right)$ e $40-60 \mathrm{~cm}\left(r=-0,62^{*}\right)$. Portanto, as concentrações de $\mathrm{Cu}$ solúvel foram menores por ocasião de maior demanda deste micronutriente pelas plantas. 
Tabela 40. Efeitos da irrigação (água e efluente) e de doses de nitrogênio mineral nas concentrações de $\mathrm{Cu}$ na solução no solo

\begin{tabular}{|c|c|c|c|c|c|c|c|}
\hline \multirow{2}{*}{ Tratamento } & \multicolumn{7}{|c|}{ Época de avaliação } \\
\hline & Abr/03 & Jul/03 & Out/03 & Jan/04 & Abr/04 & Jul/04 & Média \\
\hline & \multicolumn{7}{|c|}{$\mu g L^{-1}$} \\
\hline \multicolumn{8}{|c|}{ Camada 0-10 cm (CV =60,66 \%) } \\
\hline $\mathrm{T1}^{(1)}$ & $<\mathrm{LD}$ & $<\mathrm{LD}^{(6)}$ & 5 & 26 & 32 & 24 & $14^{\text {a (7) }}$ \\
\hline$T 2^{(2)}$ & $<\mathrm{LD}$ & $<\mathrm{LD}$ & 6 & 43 & 30 & 25 & $17^{\mathrm{a}}$ \\
\hline T3 ${ }^{(3)}$ & $<\mathrm{LD}$ & $<\mathrm{LD}$ & 14 & 35 & 39 & 44 & $22^{\mathrm{a}}$ \\
\hline$T 4^{(4)}$ & $<\mathrm{LD}$ & $<\mathrm{LD}$ & 12 & 34 & 28 & 48 & $20^{\mathrm{a}}$ \\
\hline $\mathbf{T} 5^{(5)}$ & $<\mathrm{LD}$ & $<\mathrm{LD}$ & 12 & 30 & 27 & 39 & $18^{\mathrm{a}}$ \\
\hline Média & $<\mathrm{LD}$ & $<\mathrm{LD}$ & $10^{\mathrm{B}}$ & $34^{\mathrm{A}}$ & $31^{\mathrm{A}}$ & $36^{\mathrm{A}}$ & \\
\hline \multicolumn{8}{|c|}{ Camada $10-20 \mathrm{~cm}(C V=65,54 \%)$} \\
\hline $\mathrm{T1}$ & $<\mathrm{LD}$ & $<\mathrm{LD}$ & $<\mathrm{LD}$ & 36 & 22 & 45 & $17^{\mathrm{a}}$ \\
\hline T2 & $<\mathrm{LD}$ & $<\mathrm{LD}$ & $<\mathrm{LD}$ & 32 & 25 & 46 & $17^{\mathrm{a}}$ \\
\hline T3 & $<\mathrm{LD}$ & $<\mathrm{LD}$ & $<\mathrm{LD}$ & 38 & 47 & 33 & $20^{\mathrm{a}}$ \\
\hline T4 & $<\mathrm{LD}$ & $<\mathrm{LD}$ & $<\mathrm{LD}$ & 34 & 17 & 26 & $13^{\mathrm{a}}$ \\
\hline T5 & $<\mathrm{LD}$ & $<\mathrm{LD}$ & $<\mathrm{LD}$ & 39 & 20 & 35 & $16^{\mathrm{a}}$ \\
\hline Média & $<\mathrm{LD}$ & $<\mathrm{LD}$ & $<\mathrm{LD}$ & $36^{\mathrm{A}}$ & $26^{\mathrm{B}}$ & $37^{\mathrm{A}}$ & \\
\hline \multicolumn{8}{|c|}{ Camada $20-40 \mathrm{~cm}(\mathrm{CV}=66,04 \%)$} \\
\hline $\mathrm{T1}$ & $<\mathrm{LD}$ & $<\mathrm{LD}$ & $<\mathrm{LD}$ & 21 & 16 & 14 & $9^{\text {a }}$ \\
\hline T2 & $<\mathrm{LD}$ & $<\mathrm{LD}$ & $<\mathrm{LD}$ & 23 & 11 & 18 & $9^{\mathrm{a}}$ \\
\hline T3 & $<\mathrm{LD}$ & $<\mathrm{LD}$ & $<\mathrm{LD}$ & 12 & 7 & 11 & $5^{\mathrm{a}}$ \\
\hline T4 & $<\mathrm{LD}$ & $<\mathrm{LD}$ & $<\mathrm{LD}$ & 21 & 12 & 6 & $7^{\text {a }}$ \\
\hline T5 & $<\mathrm{LD}$ & $<\mathrm{LD}$ & $<\mathrm{LD}$ & 18 & 19 & 16 & $9^{\mathrm{a}}$ \\
\hline Média & $<\mathrm{LD}$ & $<\mathrm{LD}$ & $<\mathrm{LD}$ & $19^{\mathrm{A}}$ & $13^{\mathrm{B}}$ & $13^{\mathrm{B}}$ & \\
\hline \multicolumn{8}{|c|}{ Camada $40-60 \mathrm{~cm}(C V=159,70 \%)$} \\
\hline $\mathrm{T1}$ & $<\mathrm{LD}$ & $<\mathrm{LD}$ & $<\mathrm{LD}$ & 11 & 8 & 9 & $5^{\mathrm{a}}$ \\
\hline T2 & $<\mathrm{LD}$ & $<\mathrm{LD}$ & $<\mathrm{LD}$ & 11 & 3 & 14 & $5^{\mathrm{a}}$ \\
\hline T3 & $<\mathrm{LD}$ & $<\mathrm{LD}$ & $<\mathrm{LD}$ & 9 & 18 & 17 & $7^{\mathrm{a}}$ \\
\hline T4 & $<\mathrm{LD}$ & $<\mathrm{LD}$ & $<\mathrm{LD}$ & 14 & 7 & 9 & $5^{\mathrm{a}}$ \\
\hline T5 & $<\mathrm{LD}$ & $<\mathrm{LD}$ & $<\mathrm{LD}$ & 8 & 13 & 7 & $5^{\mathrm{a}}$ \\
\hline Média & $<\mathrm{LD}$ & $<\mathrm{LD}$ & $<\mathrm{LD}$ & $11^{\mathrm{A}}$ & $10^{\mathrm{A}}$ & $11^{\mathrm{A}}$ & \\
\hline \multicolumn{8}{|c|}{ Camada $60-80 \mathrm{~cm}(\mathrm{CV}=121,06 \%)$} \\
\hline $\mathrm{T} 1$ & $<\mathrm{LD}$ & $<\mathrm{LD}$ & $<\mathrm{LD}$ & 11 & 2 & $<\mathrm{LD}$ & $2^{\mathrm{a}}$ \\
\hline T2 & $<\mathrm{LD}$ & $<\mathrm{LD}$ & $<\mathrm{LD}$ & 10 & 4 & 1 & $3^{a}$ \\
\hline T3 & $<\mathrm{LD}$ & $<\mathrm{LD}$ & $<\mathrm{LD}$ & 15 & 7 & 4 & $4^{\mathrm{a}}$ \\
\hline T4 & $<\mathrm{LD}$ & $<\mathrm{LD}$ & $<\mathrm{LD}$ & 19 & 2 & 3 & $4^{\mathrm{a}}$ \\
\hline T5 & $<\mathrm{LD}$ & $<\mathrm{LD}$ & $<\mathrm{LD}$ & 8 & 3 & 5 & $3^{a}$ \\
\hline Média & $<\mathrm{LD}$ & $<\mathrm{LD}$ & $<\mathrm{LD}$ & $13^{\mathrm{A}}$ & $4^{\mathrm{B}}$ & $3^{\mathrm{B}}$ & \\
\hline
\end{tabular}


Tabela 40. Efeitos da irrigação (água e efluente) e de doses de nitrogênio mineral nas concentrações de $\mathrm{Cu}$ na solução no solo

\begin{tabular}{cccccccc}
\hline \multirow{2}{*}{ Tratamento } & \multicolumn{7}{c}{ Época de avaliação } \\
& Abr/03 & Jul/03 & Out/03 & Jan/04 & Abr/04 & Jul/04 & Média \\
\hline \multicolumn{7}{c}{ Camada 80-100 } \\
cm (CV $=\mathbf{1 7 8 , 3 5 \% )}$ & & Hg L $^{-1}$ & & & \\
T1 & $<$ LD & $<$ LD & $<$ LD & 20 & 2 & $<$ LD & $4^{\text {a }}$ \\
T2 & $<$ LD & $<$ LD & $<$ LD & 10 & 4 & 3 & $3^{\text {a }}$ \\
T3 & $<$ LD & $<$ LD & $<$ LD & 9 & 4 & 3 & $3^{\text {a }}$ \\
T4 & $<$ LD & $<$ LD & $<$ LD & 8 & 5 & 2 & $3^{\text {a }}$ \\
T5 & $<$ LD & $<$ LD & $<$ LD & $<$ LD & 7 & 4 & $2^{\text {a }}$ \\
Média & $<$ LD & $<$ LD & $<$ LD & $9^{\mathrm{A}}$ & $4^{\mathrm{B}}$ & $3^{\mathrm{B}}$ & \\
\hline
\end{tabular}

(1) T1: irrigação com água $+520 \mathrm{~kg} \mathrm{ha}^{-1}$ ano $^{-1}$ de nitrogênio via fertilizante mineral (NFM).

(2) T2: irrigação com efluente secundário de esgoto tratado (ESET), sem NFM.

(3) T3: irrigação com ESET + 171,6 $\mathrm{kg} \mathrm{ha}^{-1} \mathrm{ano}^{-1}$ de NFM.

(4) T4: irrigação com ESET + 343,3 $\mathrm{kg} \mathrm{ha}^{-1} \mathrm{ano}^{-1}$ de NFM.

(5) T5: irrigação com ESET $+520 \mathrm{~kg} \mathrm{ha}^{-1} \mathrm{ano}^{-1}$ de NFM.

(6) LD: limite de detecção $\left(1 \mu \mathrm{g} \mathrm{L}^{-1}\right)$. Para fins de análises estatísticas esses valores foram considerados iguais a zero.

(7) Letras iguais maiúsculas ou minúsculas nas linhas e nas colunas, respectivamente, não diferem estatisticamente pelo teste de Tukey $(P<0,05)$.

Comparando-se os resultados das concentrações disponíveis (Tabela 39) e solúveis de $\mathrm{Cu}$ (Tabela 40), foi verificada maior variabilidade na solução no solo, pois os CV foram mais elevados. Ainda, não houve correlação entre as concentrações de $\mathrm{Cu}$ disponível e solúvel no extrato aquoso, indicando a falta de sustentabilidade dos extratos aquosos para estudo deste micronutriente.

As concentrações de Fe disponível foram diferentes para os tratamentos apenas nas camadas $0-10,10-20$ e $20-40 \mathrm{~cm}$ (Tabela 41 ). Na camada $0-10 \mathrm{~cm}$ menor e maior concentração de Fe foi observada no tratamento T2 e T5, respectivamente; porém, estes tratamentos não foram diferentes dos demais (Tabela 41). Essa diferença entre os tratamentos $\mathrm{T} 2$ e $\mathrm{T} 5$ pode ser devido ao fato deste último tratamento ter recebido maior dose de irrigação, implicando em aporte mais elevado de Fe-efluente (Tabela 4), que ocasionou aumento na quantidade disponível deste micronutriente no solo (Tabela 41). Na camada 10-20 o tratamento T3 apresentou maior concentração de Fe que os demais tratamentos (Tabela 41 ). Na camada $20-40 \mathrm{~cm}$ a concentração de Fe no tratamento T2 
Tabela 41. Efeitos da irrigação (água e efluente) e de doses de nitrogênio mineral nas concentrações de Fe disponível no solo

\begin{tabular}{|c|c|c|c|c|c|c|c|}
\hline \multirow{2}{*}{ Tratamento } & \multicolumn{7}{|c|}{ Época de avaliação } \\
\hline & Abr/03 & Jul/03 & Out/03 & Jan/04 & Abr/04 & Jul/04 & Média \\
\hline & \multicolumn{7}{|c|}{$\mathrm{mg} \mathrm{kg}^{-1}$} \\
\hline \multicolumn{8}{|c|}{ Camada $0-10 \mathrm{~cm}(\mathrm{CV}=22,82 \%)$} \\
\hline $\mathrm{T1}^{(1)}$ & 15,67 & 14,68 & 14,87 & 15,89 & 17,73 & 70,02 & $24,81^{\mathrm{ab}(6)}$ \\
\hline $\mathbf{T} 2^{(2)}$ & 10,78 & 14,81 & 10,34 & 11,50 & 22,55 & 59,71 & $21,61^{\mathrm{b}}$ \\
\hline T3 ${ }^{(3)}$ & 13,98 & 14,15 & 14,88 & 12,01 & 31,06 & 57,36 & $23,91^{\text {ab }}$ \\
\hline$T 4^{(4)}$ & 14,40 & 13,89 & 15,08 & 15,03 & 23,00 & 83,33 & $27,45^{\mathrm{ab}}$ \\
\hline $\mathbf{T} 5^{(5)}$ & 15,64 & 12,50 & 18,35 & 15,97 & 32,11 & 75,20 & $28,30^{\text {a }}$ \\
\hline Média & $14,09^{\mathrm{C}}$ & $14,00^{\mathrm{C}}$ & $14,70^{\mathrm{C}}$ & $14,08^{\mathrm{C}}$ & $25,29^{\mathrm{B}}$ & $69,12^{\mathrm{A}}$ & \\
\hline \multicolumn{8}{|c|}{ Camada $10-20 \mathrm{~cm}(C V=20,63 \%)$} \\
\hline $\mathrm{T} 1$ & 14,01 & 12,06 & 15,04 & 15,59 & 14,47 & 57,68 & $21,47^{b}$ \\
\hline T2 & 10,61 & 10,12 & 10,97 & 11,72 & 22,26 & 47,73 & $18,90^{\mathrm{b}}$ \\
\hline T3 & 13,65 & 13,12 & 13,75 & 14,84 & 27,15 & 76,99 & $26,59^{\mathrm{a}}$ \\
\hline T4 & 12,21 & 12,26 & 12,74 & 12,24 & 15,14 & 54,06 & $19,78^{\mathrm{b}}$ \\
\hline T5 & 14,94 & 11,57 & 14,16 & 12,96 & 14,01 & 54,48 & $20,35^{b}$ \\
\hline Média & $13,08^{\mathrm{C}}$ & $11,83^{\mathrm{C}}$ & $13,33^{\mathrm{C}}$ & $13,47^{\mathrm{C}}$ & $18,61^{\mathrm{B}}$ & $58,19^{\mathrm{A}}$ & \\
\hline \multicolumn{8}{|c|}{ Camada $20-40 \mathrm{~cm}(\mathrm{CV}=12,80 \%)$} \\
\hline $\mathrm{T} 1$ & 14,24 & 11,79 & 14,40 & 12,40 & 10,94 & 15,74 & $13,25^{\mathrm{a}}$ \\
\hline T2 & 10,63 & 9,08 & 12,15 & 9,85 & 10,11 & 12,24 & $10,68^{\mathrm{b}}$ \\
\hline T3 & 12,03 & 11,33 & 13,51 & 12,80 & 14,91 & 22,20 & $14,46^{\mathrm{a}}$ \\
\hline T4 & 11,40 & 12,31 & 13,60 & 14,37 & 12,33 & 17,24 & $13,54^{\mathrm{a}}$ \\
\hline T5 & 11,63 & 10,65 & 14,39 & 13,33 & 12,18 & 11,93 & $12,35^{\mathrm{ab}}$ \\
\hline Média & $11,99^{\mathrm{C}}$ & $11,03^{\mathrm{C}}$ & $12,61^{\mathrm{B}}$ & $12,55^{\mathrm{BC}}$ & $12,09^{\mathrm{BC}}$ & $15,87^{\mathrm{A}}$ & \\
\hline \multicolumn{8}{|c|}{ Camada $40-60 \mathrm{~cm}(\mathrm{CV}=17,20 \%)$} \\
\hline $\mathrm{T} 1$ & 10,47 & 9,05 & 11,06 & 10,58 & 8,44 & 12,25 & $10,31^{\mathrm{a}}$ \\
\hline T2 & 8,67 & 8,17 & 9,88 & 9,39 & 7,71 & 7,94 & $8,63^{\mathrm{a}}$ \\
\hline T3 & 8,43 & 7,62 & 9,03 & 9,59 & 9,92 & 9,32 & $8,98^{\mathrm{a}}$ \\
\hline T4 & 8,61 & 8,47 & 7,65 & 11,33 & 8,66 & 9,20 & $8,99^{\mathrm{a}}$ \\
\hline T5 & 8,28 & 7,70 & 10,35 & 10,27 & 8,16 & 7,16 & $8,65^{\mathrm{a}}$ \\
\hline Média & $8,89^{\mathrm{AB}}$ & $8,20^{\mathrm{B}}$ & $9,59^{\mathrm{AB}}$ & $10,23^{\mathrm{A}}$ & $8,58^{\mathrm{B}}$ & $9,17^{\mathrm{AB}}$ & \\
\hline \multicolumn{8}{|c|}{ Camada $60-80 \mathrm{~cm}(\mathrm{CV}=16,78 \%)$} \\
\hline T1 & 6,16 & 5,28 & 7,10 & 6,63 & 5,64 & 6,61 & $6,24^{\mathrm{a}}$ \\
\hline $\mathbf{T 2}$ & 5,23 & 5,91 & 6,76 & 6,83 & 5,50 & 5,57 & $5,97^{\mathrm{a}}$ \\
\hline T3 & 5,13 & 4,61 & 6,06 & 5,88 & 6,84 & 6,41 & $5,81^{\mathrm{a}}$ \\
\hline T4 & 5,83 & 4,86 & 5,31 & 7,64 & 5,46 & 5,97 & $5,85^{\mathrm{a}}$ \\
\hline T5 & 6,01 & 4,72 & 6,41 & 5,88 & 5,30 & 6,14 & $5,74^{\mathrm{a}}$ \\
\hline Média & $5,67^{\mathrm{AB}}$ & $5,07^{\mathrm{B}}$ & $6,33^{\mathrm{A}}$ & $6,57^{\mathrm{A}}$ & $5,75^{\mathrm{AB}}$ & $6,14^{\mathrm{A}}$ & \\
\hline
\end{tabular}


Tabela 41. Efeitos da irrigação (água e efluente) e de doses de nitrogênio mineral nas concentrações de Fe disponível no solo

\begin{tabular}{|c|c|c|c|c|c|c|c|}
\hline \multirow{2}{*}{ Tratamento } & \multicolumn{7}{|c|}{ Época de avaliação } \\
\hline & Abr/03 & Jul/03 & Out/03 & Jan/04 & Abr/04 & Jul/04 & Média \\
\hline & \multicolumn{7}{|c|}{$\mathrm{mg} \mathrm{kg}^{-1}$} \\
\hline \multicolumn{8}{|c|}{ Camada $80-100 \mathrm{~cm}(C V=20,41 \%)$} \\
\hline T1 & 5,16 & 4,14 & 5,62 & 4,10 & 4,22 & 4,68 & $4,65^{\mathrm{a}}$ \\
\hline T2 & 4,21 & 5,35 & 5,67 & 5,95 & 3,81 & 4,31 & $4,88^{\mathrm{a}}$ \\
\hline T3 & 3,80 & 3,02 & 4,54 & 4,30 & 3,34 & 4,73 & $4,96^{\mathrm{a}}$ \\
\hline T4 & 3,78 & 3,42 & 4,52 & 4,25 & 4,17 & 4,19 & $4,06^{\mathrm{a}}$ \\
\hline T5 & 3,25 & 3,79 & 5,08 & 4,72 & 4,30 & 4,38 & $4,25^{\mathrm{a}}$ \\
\hline Média & $4,04^{\mathrm{B}}$ & $3,94^{\mathrm{B}}$ & $5,09^{\mathrm{A}}$ & $4,66^{\mathrm{AB}}$ & $3,97^{\mathrm{B}}$ & $4,46^{\mathrm{AB}}$ & \\
\hline
\end{tabular}

(1) T1: irrigação com água $+520 \mathrm{~kg} \mathrm{ha}^{-1}$ ano $^{-1}$ de nitrogênio via fertilizante mineral (NFM);

(2) T2: irrigação com efluente secundário de esgoto tratado (ESET), sem NFM;

(3) T3: irrigação com ESET + 171,6 $\mathrm{kg} \mathrm{ha}^{-1} \mathrm{ano}^{-1}$ de NFM;

(4) T4: irrigação com ESET + 343,3 $\mathrm{kg} \mathrm{ha}^{-1} \mathrm{ano}^{-1}$ de NFM;

(5) T5: irrigação com ESET + $520 \mathrm{~kg} \mathrm{ha}^{-1} \mathrm{ano}^{-1}$ de NFM;

(6) Letras iguais maiúsculas ou minúsculas nas linhas e nas colunas, respectivamente, não diferem estatisticamente pelo teste de Tukey $(P<0,05)$.

foi menor que às observadas nos tratamentos $\mathrm{T} 1, \mathrm{~T} 3$ e T4; porém, estes tratamentos não foram diferentes do tratamento T5 (Tabela 41). Explicações para alterações nas concentrações de Fe disponível nas camadas 10-20 e 20-40 cm podem estar relacionadas às diferenças nas quantidades de Fe acumuladas no capim (Tabela 37) ou ao aporte distinto de Fe-efluente nos tratamentos T2, T3, T4 e T5 (Tabela 4).

Comparando-se os tratamentos $\mathrm{T} 1$ e $\mathrm{T} 5$, cujas diferenças foram o tipo e a quantidade de água empregada na irrigação do capim, conclui-se que o ESET não proporcionou alterações nas concentrações de Fe no solo, discordando das observações de Mancino \& Pepper (1992), Al-Nakshabandi et al. (1997), Fonseca (2001), Adekalu \& Okunade (2002), Mohammad \& Mazahreh (2003), mas concordando com os resultados de Ramirez-Fuentes et al. (2002). Aumento na disponibilidade de Fe no solo, devido à irrigação com ESET, normalmente tem ocorrido em pelo menos uma das seguintes situações (i) subproduto cuja concentração deste micronutriente é alta, como relatado no estudo de Al-Nakshabandi et al. (1997); (ii) condição de solo neutro ou ligeiramente alcalino, onde o ESET proporcionou diminuição no pH do solo, ocasionando incremento 
na disponibilidade de micronutrientes catiônicos (inclusive de $\mathrm{Fe}$ ), conforme observações realizadas por Mancino \& Pepper (1992) e Mohammad \& Mazahreh (2003).

Foram observados, no decorrer do período experimental, aumentos nas concentrações disponíveis de Fe nas camadas 0-10, 10-20 e 20-40 cm; nas demais camadas ocorreram variações sazonais, porém, de pequena magnitude (Tabela 41). As menores concentrações de Fe disponível até $40 \mathrm{~cm}$, nos dois primeiros semestres, podem estar relacionadas ao maior acúmulo e exportação, neste período, deste micronutriente pelas plantas (Tabela 37). No terceiro semestre ocorreu o inverso, ou seja, as plantas acumularam menor quantidade de Fe (Tabela 37), restando maior concentração deste micronutriente no solo (Tabela 41). Esse incremento nas concentrações de Fe disponível no solo, no decorrer do experimento, também foi observado por Hayes et al. (1990a) num experimento com capim-Bermuda. Os autores relataram que, independentemente do tipo de água (EET e água convencional) empregada na irrigação da pastagem, as concentrações de Fe no solo aumentaram. Ainda, a diminuição nas concentrações de CT no solo (Tabela 31), que reflete mineralização da MOS, pode ter favorecido à liberação de Fe ligado à MOS, promovendo aumento nas concentrações disponíveis deste micronutriente.

Os tratamentos T1 e T2 apresentaram menor acúmulo de Fe no capim quando comparados aos demais tratamentos (Tabela 37). Pode ser observado que o emprego de doses mais elevadas de NFM, promovendo incremento no rendimento de MS (Tabela 5 e Figura 3), proporcionou maior acúmulo de nutrientes (Tabelas 12, 22 e 37), inclusive do micronutriente Fe. Ainda, plantas submetidas às maiores doses de NFM necessitaram de mais irrigação, implicando em incremento no aporte de Fe-efluente (Tabela 4), que favoreceu a ocorrência de maior acúmulo deste micronutriente no capim (Tabela 37). Esses resultados discordaram das observações de Fonseca (2001) e Adekalu \& Okunade (2002), mas estão de acordo com os trabalhos realizados por Inglés et al. (1992), Gadallah (1994) e Mohammad \& Ayadi (2004).

Apesar do $\mathrm{pH}$ controlar grandemente as variações na biodisponibilidade do $\mathrm{Fe}$ (Lindsay, 1979; Mortvedt, 2000), ao que parece, as plantas se constituíram, neste 
experimento, o fator preponderante no controle das concentrações deste micronutriente no solo e na solução no solo. Isso porque as alterações no pH do solo e da solução no solo somente auxiliam nas explicações das concentrações de Fe disponível nas camadas superficiais (0-10 e 10-20 cm). Foram observados baixos coeficientes de correlação entre acúmulo de Fe no capim com pH da solução no solo na camada 0-10 cm $(r=$ $\left.0,60^{*}\right)$ e com o $\mathrm{pH}$ do solo na camada $10-20 \mathrm{~cm}\left(r=-0,54^{*}\right)$; para as demais camadas não foram observadas correlações entre estes parâmetros.

As concentrações de Fe solúvel no extrato de saturação não foram alteradas pelos tratamentos empregados; porém, ocorreram variações nas concentrações médias dos tratamentos nos períodos de avaliação (Tabela 42). No primeiro semestre, período correspondente com elevado acúmulo de Fe no capim (Tabela 37), as concentrações de Fe na solução no solo, para maioria das situações, encontravam-se abaixo do limite de detecção (Tabela 42). No último semestre, período correspondente com menor acúmulo de Fe no capim (Tabela 37), as concentrações de Fe solúvel, apesar de não serem as mais elevadas, foram detectadas em quase todas amostras (Tabela 42). Porém, somente foram observadas correlações negativas entre o acúmulo de $\mathrm{Fe}$ no capim e as concentrações solúveis deste micronutriente nas camadas 10-20 ( $\left.r=-0,53^{*}\right)$ e 80-100 cm $\left(r=-0,56^{*}\right)$. Para as demais camadas não houve correlações, provavelmente, devido à obtenção de altos CV para os resultados de Fe solúvel (Tabela 42). A variabilidade das concentrações de Fe no extrato de saturação levou à obtenção de correlação significativa somente com as concentrações de Fe disponível em solução DTPA-TEA a pH 7,3 nas camadas $0-10\left(r=0,91^{* *}\right)$ e $10-20 \mathrm{~cm}\left(r=0,45^{*}\right)$. Na camada $0-10 \mathrm{~cm}$, onde houve menor CV dos resultados de Fe solúvel, o coeficiente de correlação entre as concentrações solúveis e disponíveis deste micronutriente foi maior; o inverso ocorreu na camada 10-20 cm, onde o $\mathrm{CV}$ das concentrações de Fe solúvel foi mais elevado (Tabela 42).

As concentrações de $\mathrm{Mn}$ disponível no solo foram influenciadas pelos tratamentos apenas nas camadas 0-10 e 10-20 cm (Tabela 43). Na camada 0-10 cm, o tratamento T5 apresentou maior concentração de Mn que o tratamento T3, no entanto, ambos tratamentos não diferiram dos demais (Tabela 43). Na camada 10-20 cm, 
Tabela 42. Efeitos da irrigação (água e efluente) e de doses de nitrogênio mineral nas concentrações de Fe na solução no solo

\begin{tabular}{|c|c|c|c|c|c|c|c|}
\hline \multirow{2}{*}{ Tratamento } & \multicolumn{7}{|c|}{ Época de avaliação } \\
\hline & Abr/03 & Jul/03 & Out/03 & Jan/04 & Abr/04 & Jul/04 & Média \\
\hline & \multicolumn{7}{|c|}{$\mu g L^{-1}$} \\
\hline \multicolumn{8}{|c|}{ Camada $0-10 \mathrm{~cm}(C V=66,02 \%)$} \\
\hline $\mathrm{T1}^{(1)}$ & $<\mathrm{LD}^{(6)}$ & 205 & 6600 & 2750 & 107 & 2561 & $2037^{\text {a (7) }}$ \\
\hline$T 2^{(2)}$ & 32 & 28 & 5554 & 2846 & 37 & 1685 & $1697^{\mathrm{a}}$ \\
\hline T3 ${ }^{(3)}$ & 36 & 55 & 4144 & 4686 & 3637 & 2038 & $2433^{\mathrm{a}}$ \\
\hline$T 4^{(4)}$ & $<\mathrm{LD}$ & 148 & 6202 & 3695 & 1712 & 2474 & $2372^{\mathrm{a}}$ \\
\hline $\mathbf{T} 5^{(5)}$ & 12 & 108 & 6508 & 3217 & 192 & 1406 & $1907^{\mathrm{a}}$ \\
\hline Média & $16^{\mathrm{D}}$ & $109^{\mathrm{D}}$ & $5802^{\mathrm{A}}$ & $3839^{\mathrm{B}}$ & $1137^{\mathrm{CD}}$ & $2033^{C}$ & \\
\hline \multicolumn{8}{|c|}{ Camada $10-20 \mathrm{~cm}(\mathrm{CV}=98,97 \%)$} \\
\hline $\mathrm{T} 1$ & $<\mathrm{LD}$ & $<\mathrm{LD}$ & 1187 & 3182 & 47 & 1259 & $946^{\mathrm{a}}$ \\
\hline T2 & 90 & $<\mathrm{LD}$ & 793 & 2108 & 1399 & 3302 & $1282^{\mathrm{a}}$ \\
\hline T3 & 9 & $<\mathrm{LD}$ & 126 & 3798 & 1535 & 2638 & $1351^{\mathrm{a}}$ \\
\hline T4 & 13 & $<\mathrm{LD}$ & 1301 & 2468 & 218 & 703 & $784^{\mathrm{a}}$ \\
\hline T5 & 33 & $<\mathrm{LD}$ & 777 & 2112 & 676 & 1149 & $791^{\mathrm{a}}$ \\
\hline Média & $29^{\mathrm{B}}$ & $<\mathrm{LD}$ & $837^{\mathrm{B}}$ & $2734^{\mathrm{A}}$ & $775^{\mathrm{B}}$ & $1810^{\mathrm{A}}$ & \\
\hline \multicolumn{8}{|c|}{ Camada $20-40 \mathrm{~cm}(C V=170,85 \%)$} \\
\hline $\mathrm{T} 1$ & $<\mathrm{LD}$ & $<\mathrm{LD}$ & $<\mathrm{LD}$ & 611 & 69 & 739 & $237^{\mathrm{a}}$ \\
\hline T2 & $<\mathrm{LD}$ & $<\mathrm{LD}$ & $<\mathrm{LD}$ & 981 & 108 & 472 & $260^{\mathrm{a}}$ \\
\hline T3 & $<\mathrm{LD}$ & $<\mathrm{LD}$ & $<\mathrm{LD}$ & 104 & 55 & 201 & $60^{\mathrm{a}}$ \\
\hline T4 & $<\mathrm{LD}$ & $<\mathrm{LD}$ & $<\mathrm{LD}$ & 160 & 42 & 590 & $132^{\mathrm{a}}$ \\
\hline T5 & $<\mathrm{LD}$ & $<\mathrm{LD}$ & $<\mathrm{LD}$ & 445 & 27 & 305 & $130^{\mathrm{a}}$ \\
\hline Média & $<\mathrm{LD}$ & $<\mathrm{LD}$ & $<\mathrm{LD}$ & $460^{\mathrm{A}}$ & $60^{\mathrm{B}}$ & $461^{\mathrm{A}}$ & \\
\hline \multicolumn{8}{|c|}{ Camada $40-60 \mathrm{~cm}(C V=310,72 \%)$} \\
\hline $\mathrm{T} 1$ & $<\mathrm{LD}$ & $<\mathrm{LD}$ & $<\mathrm{LD}$ & 60 & 125 & 104 & $48^{\mathrm{a}}$ \\
\hline T2 & $<\mathrm{LD}$ & $<\mathrm{LD}$ & $<\mathrm{LD}$ & 22 & 10 & 153 & $31^{\mathrm{a}}$ \\
\hline T3 & $<\mathrm{LD}$ & $<\mathrm{LD}$ & $<\mathrm{LD}$ & 10 & 40 & 74 & $21^{\mathrm{a}}$ \\
\hline T4 & $<\mathrm{LD}$ & $<\mathrm{LD}$ & $<\mathrm{LD}$ & 25 & 23 & 222 & $45^{\text {a }}$ \\
\hline T5 & $<\mathrm{LD}$ & $<\mathrm{LD}$ & $<\mathrm{LD}$ & 21 & 31 & 10 & $10^{\mathrm{a}}$ \\
\hline Média & $<\mathrm{LD}$ & $<\mathrm{LD}$ & $<\mathrm{LD}$ & $28^{\mathrm{A}}$ & $46^{\mathrm{A}}$ & $113^{\mathrm{A}}$ & \\
\hline \multicolumn{8}{|c|}{ Camada $60-80 \mathrm{~cm}(C V=200,33 \%)$} \\
\hline $\mathrm{T} 1$ & $<\mathrm{LD}$ & $<\mathrm{LD}$ & $<\mathrm{LD}$ & 38 & 11 & 12 & $10^{\mathrm{a}}$ \\
\hline T2 & $<\mathrm{LD}$ & $<\mathrm{LD}$ & $<\mathrm{LD}$ & 8 & 20 & 5 & $6^{\mathrm{a}}$ \\
\hline T3 & 10 & $<\mathrm{LD}$ & $<\mathrm{LD}$ & 10 & 39 & 2 & $10^{\mathrm{a}}$ \\
\hline T4 & $<\mathrm{LD}$ & $<\mathrm{LD}$ & $<\mathrm{LD}$ & $<\mathrm{LD}$ & 12 & 31 & $7^{\mathrm{a}}$ \\
\hline T5 & 2 & $<\mathrm{LD}$ & $<\mathrm{LD}$ & 15 & 35 & 7 & $10^{\mathrm{a}}$ \\
\hline Média & 2 & $<\mathrm{LD}$ & $<\mathrm{LD}$ & $14^{\mathrm{A}}$ & $23^{\mathrm{A}}$ & $11^{\mathrm{A}}$ & \\
\hline
\end{tabular}


Tabela 42. Efeitos da irrigação (água e efluente) e de doses de nitrogênio mineral nas concentrações de Fe na solução no solo

\begin{tabular}{|c|c|c|c|c|c|c|c|}
\hline \multirow{2}{*}{ Tratamento } & \multicolumn{7}{|c|}{ Época de avaliação } \\
\hline & Abr/03 & Jul/03 & Out/03 & Jan/04 & Abr/04 & Jul/04 & Média \\
\hline & \multicolumn{7}{|c|}{$\mu g L^{-1}$} \\
\hline \multicolumn{8}{|c|}{ Camada $80-100 \mathrm{~cm}(C V=76,19 \%)$} \\
\hline T1 & $<\mathrm{LD}$ & $<\mathrm{LD}$ & $<\mathrm{LD}$ & 11 & 8 & $<\mathrm{LD}$ & $3^{\mathrm{a}}$ \\
\hline T2 & $<\mathrm{LD}$ & $<\mathrm{LD}$ & $<\mathrm{LD}$ & 10 & 10 & 9 & $5^{\mathrm{a}}$ \\
\hline T3 & $<\mathrm{LD}$ & $<\mathrm{LD}$ & $<\mathrm{LD}$ & 6 & 10 & $<\mathrm{LD}$ & $3^{\mathrm{a}}$ \\
\hline T4 & $<\mathrm{LD}$ & $<\mathrm{LD}$ & $<\mathrm{LD}$ & $<\mathrm{LD}$ & 10 & 5 & $3^{\mathrm{a}}$ \\
\hline T5 & $<\mathrm{LD}$ & $<\mathrm{LD}$ & $<\mathrm{LD}$ & $<\mathrm{LD}$ & 17 & 3 & $3^{\mathrm{a}}$ \\
\hline Média & $<\mathrm{LD}$ & $<\mathrm{LD}$ & $<\mathrm{LD}$ & $5^{\mathrm{A}}$ & $11^{\mathrm{A}}$ & $4^{\mathrm{A}}$ & \\
\hline
\end{tabular}

(1) T1: irrigação com água $+520 \mathrm{~kg} \mathrm{ha}^{-1}$ ano $^{-1}$ de nitrogênio via fertilizante mineral (NFM).

(2) T2: irrigação com efluente secundário de esgoto tratado (ESET), sem NFM.

(3) T3: irrigação com ESET + 171,6 $\mathrm{kg} \mathrm{ha}^{-1} \mathrm{ano}^{-1}$ de NFM.

(4) T4: irrigação com ESET + 343,3 $\mathrm{kg} \mathrm{ha}^{-1} \mathrm{ano}^{-1}$ de NFM.

(5) T5: irrigação com ESET $+520 \mathrm{~kg} \mathrm{ha}^{-1} \mathrm{ano}^{-1}$ de NFM.

(6) LD: limite de detecção $\left(3 \mu \mathrm{g} \mathrm{L}^{-1}\right)$. Para fins de análises estatísticas esses valores foram considerados iguais a zero.

(7) Letras iguais maiúsculas ou minúsculas nas linhas e nas colunas, respectivamente, não diferem estatisticamente pelo teste de Tukey $(P<0,05)$.

o tratamento T4 apresentou maior concentração de Mn que o tratamento T3 (Tabela 43), porém, estes tratamentos não foram diferentes dos demais (Tabela 43). Não foram observadas diferenças entre as concentrações de Mn disponível nos tratamentos T1 e T5 (Tabela 43), que receberam a mesma fertilização mineral (Tabela 1). Portanto, o emprego de ESET, quando comparado à água potável, não proporcionou alterações na disponibilidade de Mn no solo, fato que discorda da maioria dos trabalhos publicados (Quin \& Syers, 1978; Mancino \& Pepper, 1992; Al-Jaloud et al., 1995; Al-Nakshabandi et al., 1997; Adekalu \& Okunade, 2002; Falkiner \& Smith, 1997; Mohammad \& Mazahreh, 2003), mas concorda com estudos anteriores conduzidos por Fonseca (2001), com solo de características similares ao empregado neste experimento. Portanto, a baixa concentração de Mn no ESET e na água, que foram utilizados na irrigação do capim (Tabela 3), implicou no aporte de baixíssimas quantidades deste micronutriente no sistema solo-planta (Tabela 4), não levando à ocorrência de alterações importantes na sua biodisponibilidade (Tabela 43). 
Tabela 43. Efeitos da irrigação (água e efluente) e de doses de nitrogênio mineral nas concentrações de Mn disponível no solo

\begin{tabular}{|c|c|c|c|c|c|c|c|}
\hline \multirow{2}{*}{ Tratamento } & \multicolumn{7}{|c|}{ Época de avaliação } \\
\hline & Abr/03 & Jul/03 & Out/03 & Jan/04 & Abr/04 & Jul/04 & Média \\
\hline & \multicolumn{7}{|c|}{$\mathrm{mg} \mathrm{kg}^{-1}$} \\
\hline \multicolumn{8}{|c|}{ Camada 0-10 cm (CV = 24,34\%) } \\
\hline $\mathrm{T1}^{(1)}$ & 4,10 & 3,20 & 2,54 & 1,61 & 2,10 & 6,51 & $3,34^{\mathrm{ab}(6)}$ \\
\hline$T 2^{(2)}$ & 3,99 & 3,05 & 2,77 & 1,44 & 3,33 & 3,33 & $2,98^{a b}$ \\
\hline T3 ${ }^{(3)}$ & 2,94 & 2,54 & 2,35 & 1,27 & 1,76 & 4,84 & $2,62^{b}$ \\
\hline$T 4^{(4)}$ & 3,72 & 3,12 & 3,37 & 1,81 & 2,30 & 5,92 & $3,37^{\mathrm{ab}}$ \\
\hline $\mathbf{T} 5^{(5)}$ & 4,36 & 3,72 & 3,23 & 2,81 & 2,24 & 6,08 & $3,74^{\mathrm{a}}$ \\
\hline Média & $3,82^{\mathrm{B}}$ & $3,12^{\mathrm{BC}}$ & $2,85^{\mathrm{CD}}$ & $1,79^{\mathrm{E}}$ & $2,35^{\mathrm{DE}}$ & $5,34^{\mathrm{A}}$ & \\
\hline \multicolumn{8}{|c|}{ Camada $10-20 \mathrm{~cm}(C V=30,21 \%)$} \\
\hline $\mathrm{T} 1$ & 3,84 & 2,13 & 1,97 & 1,73 & 1,77 & 5,95 & $2,90^{\mathrm{ab}}$ \\
\hline T2 & 3,46 & 2,60 & 2,25 & 1,38 & 2,50 & 5,06 & $2,87^{\mathrm{ab}}$ \\
\hline T3 & 3,04 & 2,59 & 2,22 & 1,26 & 1,08 & 6,26 & $2,74^{\mathrm{b}}$ \\
\hline T4 & 3,69 & 2,83 & 2,80 & 1,51 & 4,24 & 8,48 & $3,93^{\mathrm{a}}$ \\
\hline T5 & 3,67 & 2,30 & 2,38 & 1,50 & 3,36 & 5,41 & $3,10^{\mathrm{ab}}$ \\
\hline Média & $3,54^{\mathrm{B}}$ & $2,49^{\mathrm{C}}$ & $2,32^{\mathrm{C}}$ & $1,47^{\mathrm{D}}$ & $2,59^{\mathrm{C}}$ & $6,23^{\mathrm{A}}$ & \\
\hline \multicolumn{8}{|c|}{ Camada $20-40 \mathrm{~cm}(\mathrm{CV}=27,46 \%)$} \\
\hline $\mathrm{T} 1$ & 3,94 & 1,82 & 2,89 & 1,51 & 1,53 & 2,55 & $2,37^{\mathrm{a}}$ \\
\hline T2 & 2,67 & 1,85 & 2,49 & 0,89 & 1,90 & 2,71 & $2,08^{\mathrm{a}}$ \\
\hline T3 & 2,96 & 2,06 & 2,74 & 1,41 & 2,05 & 2,93 & $2,36^{\mathrm{a}}$ \\
\hline T4 & 3,16 & 2,46 & 2,72 & 2,06 & 2,15 & 3,67 & $2,71^{\mathrm{a}}$ \\
\hline T5 & 2,81 & 2,15 & 2,34 & 1,27 & 1,91 & 2,35 & $2,14^{\mathrm{a}}$ \\
\hline Média & $3,11^{\mathrm{A}}$ & $2,07^{\mathrm{BC}}$ & $2,64^{\mathrm{AB}}$ & $1,43^{\mathrm{D}}$ & $1,91^{\mathrm{CD}}$ & $2,84^{\mathrm{A}}$ & \\
\hline \multicolumn{8}{|c|}{ Camada $40-60 \mathrm{~cm}(\mathrm{CV}=22,77 \%)$} \\
\hline $\mathrm{T} 1$ & 2,87 & 1,78 & 2,78 & 1,52 & 0,90 & 1,83 & $1,95^{\mathrm{a}}$ \\
\hline T2 & 2,59 & 2,25 & 2,18 & 1,06 & 1,42 & 1,51 & $1,83^{\mathrm{a}}$ \\
\hline T3 & 2,45 & 1,86 & 2,57 & 1,63 & 1,36 & 1,41 & $1,88^{\mathrm{a}}$ \\
\hline T4 & 2,81 & 2,55 & 2,25 & 2,03 & 1,31 & 1,65 & $2,10^{\mathrm{a}}$ \\
\hline T5 & 2,34 & 1,81 & 2,35 & 1,65 & 1,36 & 1,34 & $1,81^{\mathrm{a}}$ \\
\hline Média & $2,61^{\mathrm{A}}$ & $2,05^{\mathrm{B}}$ & $2,43^{\mathrm{AB}}$ & $1,58^{\mathrm{C}}$ & $1,27^{\mathrm{C}}$ & $1,55^{\mathrm{C}}$ & \\
\hline \multicolumn{8}{|c|}{ Camada $60-80 \mathrm{~cm}(C \mathrm{C}=21,66 \%)$} \\
\hline T1 & 2,47 & 1,60 & 1,78 & 1,39 & 1,04 & 1,37 & $1,61^{\mathrm{a}}$ \\
\hline T2 & 2,05 & 1,57 & 2,04 & 1,29 & 0,85 & 1,13 & $1,49^{\mathrm{a}}$ \\
\hline T3 & 1,95 & 1,56 & 2,02 & 1,45 & 1,38 & 1,37 & $1,62^{\mathrm{a}}$ \\
\hline T4 & 2,53 & 1,87 & 1,86 & 1,73 & 0,88 & 1,49 & $1,73^{\mathrm{a}}$ \\
\hline T5 & 1,92 & 1,41 & 1,98 & 1,55 & 0,96 & 1,40 & $1,54^{\mathrm{a}}$ \\
\hline Média & $2,18^{\mathrm{A}}$ & $1,60^{\mathrm{B}}$ & $1,94^{\mathrm{A}}$ & $1,48^{\mathrm{B}}$ & $1,02^{\mathrm{C}}$ & $1,35^{\mathrm{B}}$ & \\
\hline
\end{tabular}


Tabela 43. Efeitos da irrigação (água e efluente) e de doses de nitrogênio mineral nas concentrações de Mn disponível no solo

\begin{tabular}{|c|c|c|c|c|c|c|c|}
\hline \multirow{2}{*}{ Tratamento } & \multicolumn{7}{|c|}{ Época de avaliação } \\
\hline & Abr/03 & $\mathbf{J u l} / \mathbf{0 3}$ & Out/03 & Jan/04 & Abr/04 & Jul/04 & Média \\
\hline & \multicolumn{7}{|c|}{$\mathrm{mg} \mathrm{kg}^{-1}$} \\
\hline \multicolumn{8}{|c|}{ Camada $80-100 \mathrm{~cm}(C V=18,82 \%)$} \\
\hline T1 & 2,08 & 1,48 & 2,17 & 1,54 & 0,82 & 1,27 & $1,56^{\mathrm{a}}$ \\
\hline T2 & 1,90 & 1,59 & 1,71 & 1,41 & 0,81 & 0,93 & $1,39^{\mathrm{a}}$ \\
\hline T3 & 2,10 & 1,55 & 1,90 & 1,53 & 1,05 & 1,27 & $1,57^{\mathrm{a}}$ \\
\hline T4 & 2,19 & 1,59 & 1,84 & 1,29 & 1,11 & 1,22 & $1,54^{\mathrm{a}}$ \\
\hline T5 & 1,91 & 1,33 & 1,76 & 1,05 & 1,30 & 1,20 & $1,42^{\mathrm{a}}$ \\
\hline Média & $2,03^{\mathrm{A}}$ & $1,51^{\mathrm{B}}$ & $1,88^{\mathrm{A}}$ & $1,36^{\mathrm{BC}}$ & $1,02^{\mathrm{D}}$ & $1,18^{\mathrm{CD}}$ & \\
\hline
\end{tabular}

(1) T1: irrigação com água $+520 \mathrm{~kg} \mathrm{ha}^{-1}$ ano $^{-1}$ de nitrogênio via fertilizante mineral (NFM);

(2) T2: irrigação com efluente secundário de esgoto tratado (ESET), sem NFM;

(3) T3: irrigação com ESET + 171,6 $\mathrm{kg} \mathrm{ha}^{-1} \mathrm{ano}^{-1}$ de NFM;

(4) T4: irrigação com ESET + 343,3 $\mathrm{kg} \mathrm{ha}^{-1} \mathrm{ano}^{-1}$ de NFM;

(5) T5: irrigação com ESET $+520 \mathrm{~kg} \mathrm{ha}^{-1} \mathrm{ano}^{-1}$ de NFM;

(6) Letras iguais maiúsculas ou minúsculas nas linhas e nas colunas, respectivamente, não diferem estatisticamente pelo teste de Tukey $(P<0,05)$.

No decorrer do período experimental, as concentrações de Mn nas camadas 010, 10-20 e 20-40 cm diminuíram, principalmente, no mês de janeiro/2004 (Tabela 43), perído onde houve maior acúmulo e exportação de Mn pelas plantas (Tabela 37). A partir de janeiro/2004 as concentrações de Mn disponíveis nessas camadas (0-10, 10-20 e 20-40 cm) aumentaram, sobretudo no mês de julho/2004, período coincidente com diminuição no acúmulo de Mn no capim (Tabela 37), restando maior concentração deste micronutriente no solo (Tabela 43). Para as demais camadas as concentrações de Mn foram menores no mês de julho/2004 que no mês de abril/2003. Portanto, essa diminuição nas concentrações de $\mathrm{Mn}$ no decorrer do experimento discorda das observações de Hayes et al. (1990a), mas concorda com o trabalho de Ramirez-Fuentes et al (2002). A diminuição nas concentrações de CT do solo (Tabela 31), que indica mineralização da MOS, pode ter proporcionado, durante o período experimental, aumento na disponibilidade de Mn, sobretudo, nas camadas superficiais.

Menor acúmulo de Mn no capim foi observado no tratamento T2 (Tabela 37), provavelmente, devido ao fato de as plantas deste tratamento ter tido menor rendimento 
de MS (Tabela 5 e Figura 3), implicando no menor acúmulo de nutrientes (Tabelas 12, 22 e 37), inclusive de Mn. Para os demais tratamentos as quantidades de Mn acumuladas no capim não foram diferentes, porém, superiores às do tratamento T2 (Tabela 37). Inglés et al. (1992) observaram resultados similares em plantas de tomateiro irrigadas com EET. Os autores verificaram que o tomateiro irrigado com EET apresentou maior crescimento, absorção e acúmulo de Mn. No entanto, Inglés et al. (1992) não atribuíram esses efeitos ao aporte de Mn-efluente, mas sim, a outros fatores que favoreceram o crescimento das plantas e a absorção e assimilação de nutrientes. Comparando-se os tratamentos T1 e T5, pode-se concluir que o tipo de água de irrigação não afetou o acúmulo de Mn nas plantas (Tabela 37), discordando das observações realizadas por Gadallah (1994) e Mohammad \& Ayadi (2004), mas concordando com os trabalhos de Fonseca (2001). Os efluentes utilizados por Al-Jaloud et al. (1995) e Mohammad \&

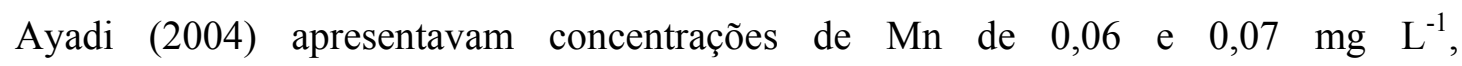
respectivamente, ou seja, concentrações bem mais elevadas que às observadas no ESET empregado no presente estudo (Tabela 3).

As concentrações de $\mathrm{Mn}$ solúvel no extrato de saturação variaram grandemente, com CV de 72,27 a 145,24\% (Tabela 44). Os tratamentos somente exerceram influência nas concentrações de Mn solúvel nas camadas 60-80 e 80-100 cm (Tabela). Na camada 60-80 o tratamento T3, que não diferiu dos tratamentos T2 e T4, apresentou maior concentração de Mn solúvel que os tratamentos T1 e T5 (Tabela 44). Para essa mesma camada, não foram diferentes as concentrações de Mn solúvel entre os tratamentos T1, T2 e T5 (Tabela 44). Para a camada 80-100 cm, a concentração de Mn solúvel no tratamento T3 não diferiu da observada no tratamento T2, mas foi superior às concentrações deste micronutriente nos tratamentos T1, T4 e T5 (Tabela 44). No entanto, essas alterações não se correlacionaram com o acúmulo de Mn no capim, pH do solo e da solução no solo, bem como com as concentrações disponíveis no solo mediante o emprego do extrator DTPA-TEA a $\mathrm{pH} 7,3$ para a maioria das camadas estudas. Somente houve correlações entre as concentrações disponíveis e solúveis de Mn nas camadas 20-40 $\left(r=0,45^{*}\right)$ e 40-60 cm $\left(r=0,59^{* *}\right)$ e ainda, os coeficientes de correlação foram baixos. Portanto, essas diferenças entre os tratamentos nas camadas 60-80 e 
Tabela 44. Efeitos da irrigação (água e efluente) e de doses de nitrogênio mineral nas concentrações de Mn na solução no solo

\begin{tabular}{|c|c|c|c|c|c|c|c|}
\hline \multirow{2}{*}{ Tratamento } & \multicolumn{7}{|c|}{ Época de avaliação } \\
\hline & Abr/03 & Jul/03 & Out/03 & Jan/04 & Abr/04 & Jul/04 & Média \\
\hline & \multicolumn{7}{|c|}{$\mu g L^{-1}$} \\
\hline \multicolumn{8}{|c|}{ Camada 0-10 cm (CV = 72,27\%) } \\
\hline $\mathrm{T1}^{(1)}$ & 72 & 114 & $<\mathrm{LD}^{(6)}$ & 9 & 10 & 19 & $37^{\text {a (7) }}$ \\
\hline $\mathbf{T} 2^{(2)}$ & 74 & 119 & $<\mathrm{LD}$ & 13 & $<\mathrm{LD}$ & 10 & $36^{\mathrm{a}}$ \\
\hline T3 ${ }^{(3)}$ & 89 & 125 & 9 & 22 & 20 & 11 & $46^{\mathrm{a}}$ \\
\hline$T 4^{(4)}$ & 71 & 180 & 4 & 19 & 9 & 10 & $49^{\mathrm{a}}$ \\
\hline $\mathbf{T} 5^{(5)}$ & 86 & 184 & $<\mathrm{LD}$ & 15 & 70 & 26 & $64^{\mathrm{a}}$ \\
\hline Média & $78^{\mathrm{B}}$ & $144^{\mathrm{A}}$ & $3^{\mathrm{C}}$ & $16^{\mathrm{C}}$ & $22^{\mathrm{C}}$ & $15^{\mathrm{C}}$ & \\
\hline \multicolumn{8}{|c|}{ Camada $10-20 \mathrm{~cm}(C V=86,97 \%)$} \\
\hline T1 & 148 & 41 & $<\mathrm{LD}$ & 17 & 67 & 16 & $48^{\mathrm{a}}$ \\
\hline T2 & 70 & 359 & $<\mathrm{LD}$ & 8 & 7 & 20 & $77^{\mathrm{a}}$ \\
\hline T3 & 127 & 471 & $<\mathrm{LD}$ & 16 & 26 & 16 & $109^{\mathrm{a}}$ \\
\hline T4 & 214 & 390 & $<\mathrm{LD}$ & 19 & 23 & 18 & $111^{\mathrm{a}}$ \\
\hline T5 & 197 & 222 & $<\mathrm{LD}$ & 13 & 38 & 18 & $81^{\mathrm{a}}$ \\
\hline Média & $151^{\mathrm{B}}$ & $297^{\mathrm{A}}$ & $<\mathrm{LD}$ & $15^{\mathrm{C}}$ & $32^{\mathrm{C}}$ & $18^{\mathrm{C}}$ & \\
\hline \multicolumn{8}{|c|}{ Camada $20-40 \mathrm{~cm}(C V=74,82 \%)$} \\
\hline T1 & 222 & 117 & 109 & 10 & 17 & 12 & $81^{\mathrm{a}}$ \\
\hline T2 & 177 & 115 & 96 & 11 & 8 & 8 & $69^{\mathrm{a}}$ \\
\hline T3 & 182 & 198 & 144 & 14 & 22 & 10 & $95^{\mathrm{a}}$ \\
\hline T4 & 216 & 239 & 121 & 10 & 28 & 7 & $104^{\mathrm{a}}$ \\
\hline T5 & 167 & 189 & 67 & 6 & 39 & 11 & $80^{\mathrm{a}}$ \\
\hline Média & $193^{\mathrm{A}}$ & $172^{\mathrm{A}}$ & $107^{\mathrm{B}}$ & $10^{\mathrm{C}}$ & $23^{\mathrm{C}}$ & $10^{\mathrm{C}}$ & \\
\hline \multicolumn{8}{|c|}{ Camada $40-60 \mathrm{~cm}(\mathrm{CV}=91,36 \%)$} \\
\hline T1 & 132 & 65 & 147 & 11 & 2 & 13 & $62^{\mathrm{a}}$ \\
\hline T2 & 72 & 92 & 262 & 29 & 28 & 7 & $82^{\mathrm{a}}$ \\
\hline T3 & 66 & 54 & 251 & 60 & 13 & 14 & $76^{\mathrm{a}}$ \\
\hline T4 & 50 & 68 & 192 & 47 & 28 & 9 & $66^{\mathrm{a}}$ \\
\hline T5 & 37 & 42 & 55 & 37 & 40 & 7 & $36^{\mathrm{a}}$ \\
\hline Média & $71^{\mathrm{B}}$ & $64^{\mathrm{BC}}$ & $181^{\mathrm{A}}$ & $37^{\mathrm{BC}}$ & $22^{\mathrm{BC}}$ & $10^{\mathrm{C}}$ & \\
\hline \multicolumn{8}{|c|}{ Camada $60-80 \mathrm{~cm}(C V=101,59 \%)$} \\
\hline $\mathrm{T1}$ & 7 & 20 & $<\mathrm{LD}$ & 29 & 1 & 3 & $10^{\mathrm{c}}$ \\
\hline T2 & $<\mathrm{LD}$ & $<\mathrm{LD}$ & 51 & 90 & 10 & 6 & $26^{\mathrm{abc}}$ \\
\hline T3 & $<\mathrm{LD}$ & $<\mathrm{LD}$ & 40 & 180 & 18 & 12 & $42^{\mathrm{a}}$ \\
\hline T4 & 9 & $<\mathrm{LD}$ & 45 & 119 & 4 & 5 & $30^{a b}$ \\
\hline T5 & $<\mathrm{LD}$ & $<\mathrm{LD}$ & 8 & 66 & 29 & 13 & $19^{\mathrm{bc}}$ \\
\hline Média & $3^{\mathrm{C}}$ & $4^{\mathrm{C}}$ & $29^{\mathrm{B}}$ & $97^{\mathrm{A}}$ & $12^{\mathrm{BC}}$ & $8^{\mathrm{BC}}$ & \\
\hline
\end{tabular}


Tabela 44. Efeitos da irrigação (água e efluente) e de doses de nitrogênio mineral nas concentrações de Mn na solução no solo

\begin{tabular}{|c|c|c|c|c|c|c|c|}
\hline \multirow{2}{*}{ Tratamento } & \multicolumn{7}{|c|}{ Época de avaliação } \\
\hline & Abr/03 & Jul/03 & Out/03 & Jan/04 & Abr/04 & Jul/04 & Média \\
\hline & \multicolumn{7}{|c|}{$\mu g L^{-1}$} \\
\hline \multicolumn{8}{|c|}{ Camada $80-100 \mathrm{~cm}(C V=145,24 \%)$} \\
\hline T1 & 25 & $<\mathrm{LD}$ & $<\mathrm{LD}$ & 27 & 2 & 3 & $10^{\mathrm{b}}$ \\
\hline T2 & $<\mathrm{LD}$ & $<\mathrm{LD}$ & $<\mathrm{LD}$ & 103 & 4 & 7 & $19^{\mathrm{ab}}$ \\
\hline T3 & $<\mathrm{LD}$ & $<\mathrm{LD}$ & $<\mathrm{LD}$ & 167 & 30 & 19 & $36^{\mathrm{a}}$ \\
\hline T4 & 2 & $<\mathrm{LD}$ & $<\mathrm{LD}$ & 74 & 14 & 6 & $16^{\mathrm{b}}$ \\
\hline T5 & $<\mathrm{LD}$ & $<\mathrm{LD}$ & $<\mathrm{LD}$ & 48 & 19 & 18 & $14^{\mathrm{b}}$ \\
\hline Média & $5^{\mathrm{B}}$ & $<\mathrm{LD}$ & $<\mathrm{LD}$ & $84^{\mathrm{A}}$ & $14^{\mathrm{B}}$ & $11^{\mathrm{B}}$ & \\
\hline \multicolumn{8}{|c|}{$\begin{array}{l}\text { (1) T1: irrigação com água + } 520 \mathrm{~kg} \mathrm{ha}^{-1} \text { ano }^{-1} \text { de nitrogênio via fertilizante mineral (NFM). } \\
\text { (2) T2: irrigação com efluente secundário de esgoto tratado (ESET), sem NFM. } \\
\text { (3) T3: irrigação com ESET }+171,6 \mathrm{~kg} \mathrm{ha}^{-1} \text { ano }^{-1} \text { de NFM. } \\
\text { (4) T4: irrigação com ESET }+343,3 \mathrm{~kg} \mathrm{ha}^{-1} \mathrm{ano}^{-1} \text { de NFM. } \\
\text { (5) T5: irrigação com ESET }+520 \mathrm{~kg} \mathrm{ha}^{-1} \mathrm{ano}^{-1} \text { de NFM. } \\
\text { (6) LD: limite de detecção }\left(1 \mu \mathrm{g} \mathrm{L}^{-1}\right) \text {. Para fins de análises estatísticas esses valores foran } \\
\text { considerados iguais a zero. } \\
\text { (7) Letras iguais maiúsculas ou minúsculas nas linhas e nas colunas, respectivamente, nã } \\
\text { diferem estatisticamente pelo teste de Tukev }(P<0,05) \text {. }\end{array}$} \\
\hline
\end{tabular}

80-100 cm, bem como as flutuações sazonais nas concentrações médias dos tratamentos em todas as camadas, no decorrer do experimento, podem estar relacionadas às limitações do método de obtenção do extrato de saturação. Resultados favoráveis ao uso de extratos de saturação, visando discriminar as espécies iônicas dos metais em solução, têm sido observados em situação de solo contendo elevada concentração de metais (Abreu et al., 2002). Portanto, o solo do presente experimento não se enquadra nessa situação e pode ser devido às suas baixas concentrações de metais disponíveis (Tabelas $39,41,43$ e 45) que os resultados dos extratos aquosos não foram satisfatórios (Tabelas 40, 42, 44 e 46), inclusive para Mn.

As concentrações de $\mathrm{Zn}$ disponível no solo não foram alteradas pelos tratamentos empregados (Tabela 45). Isso porque o ESET e a água, que foram utilizados na irrigação do capim, apresentaram baixíssimas concentrações deste micronutriente (Tabela 3), ocasionando aporte insignificante no sistema solo-planta (Tabela 4). O fato de o ESET não ter promovido alteração nas concentrações de $\mathrm{Zn}$ disponível no solo 
Tabela 45. Efeitos da irrigação (água e efluente) e de doses de nitrogênio mineral nas concentrações de Zn disponível no solo

\begin{tabular}{|c|c|c|c|c|c|c|c|}
\hline \multirow{2}{*}{ Tratamento } & \multicolumn{7}{|c|}{ Época de avaliação } \\
\hline & Abr/03 & $\mathrm{Jul} / 03$ & Out/03 & Jan/04 & Abr/04 & Jul/04 & Média \\
\hline & \multicolumn{7}{|c|}{$\mathrm{mg} \mathrm{kg}^{-1}$} \\
\hline \multicolumn{8}{|c|}{ Camada 0-10 cm (CV =62,28\%) } \\
\hline $\mathrm{T1}^{(1)}$ & 0,29 & 0,22 & 0,21 & 0,24 & 0,17 & 0,14 & $0,21^{a(6)}$ \\
\hline$T 2^{(2)}$ & 0,25 & 0,20 & 0,19 & 0,16 & 0,22 & 0,16 & $0,20^{\mathrm{a}}$ \\
\hline T3 ${ }^{(3)}$ & 0,17 & 0,14 & 0,16 & 0,15 & 0,21 & 0,15 & $0,16^{\mathrm{a}}$ \\
\hline$T 4^{(4)}$ & 0,47 & 0,29 & 0,22 & 0,15 & 0,16 & 0,16 & $0,24^{\mathrm{a}}$ \\
\hline $\mathbf{T} 5^{(5)}$ & 0,47 & 0,27 & 0,25 & 0,22 & 0,19 & 0,14 & $0,25^{\mathrm{a}}$ \\
\hline Média & $0,33^{\mathrm{A}}$ & $0,22^{\mathrm{AB}}$ & $0,21^{\mathrm{B}}$ & $0,18^{\mathrm{B}}$ & $0,19^{\mathrm{B}}$ & $0,15^{\mathrm{B}}$ & \\
\hline \multicolumn{8}{|c|}{ Camada $10-20 \mathrm{~cm}(C V=35,44 \%)$} \\
\hline $\mathrm{T} 1$ & 0,21 & 0,14 & 0,21 & 0,23 & 0,14 & 0,08 & $0,17^{\mathrm{a}}$ \\
\hline T2 & 0,32 & 0,12 & 0,13 & 0,12 & 0,21 & 0,12 & $0,17^{\mathrm{a}}$ \\
\hline T3 & 0,17 & 0,17 & 0,18 & 0,17 & 0,20 & 0,07 & $0,16^{\mathrm{a}}$ \\
\hline T4 & 0,19 & 0,13 & 0,16 & 0,13 & 0,16 & 0,09 & $0,14^{\mathrm{a}}$ \\
\hline T5 & 0,21 & 0,09 & 0,15 & 0,15 & 0,16 & 0,08 & $0,14^{\mathrm{a}}$ \\
\hline Média & $0,22^{\mathrm{A}}$ & $0,13^{\mathrm{BC}}$ & $0,16^{\mathrm{B}}$ & $0,16^{\mathrm{B}}$ & $0,17^{\mathrm{AB}}$ & $0,09^{\mathrm{C}}$ & \\
\hline \multicolumn{8}{|c|}{ Camada $20-40 \mathrm{~cm}(\mathrm{CV}=39,87 \%)$} \\
\hline $\mathrm{T} 1$ & 0,14 & 0,20 & 0,16 & 0,18 & 0,13 & 0,11 & $0,15^{\mathrm{a}}$ \\
\hline T2 & 0,24 & 0,11 & 0,12 & 0,12 & 0,21 & 0,11 & $0,15^{\mathrm{a}}$ \\
\hline T3 & 0,14 & 0,08 & 0,16 & 0,20 & 0,15 & 0,10 & $0,14^{\mathrm{a}}$ \\
\hline T4 & 0,13 & 0,07 & 0,17 & 0,18 & 0,13 & 0,08 & $0,13^{\mathrm{a}}$ \\
\hline T5 & 0,20 & 0,10 & 0,15 & 0,20 & 0,14 & 0,07 & $0,14^{\mathrm{a}}$ \\
\hline Média & $0,17^{\mathrm{A}}$ & $0,11^{\mathrm{BC}}$ & $0,15^{\mathrm{AB}}$ & $0,17^{\mathrm{A}}$ & $0,15^{\mathrm{AB}}$ & $0,09^{\mathrm{C}}$ & \\
\hline \multicolumn{8}{|c|}{ Camada $40-60 \mathrm{~cm}(\mathrm{CV}=59,78 \%)$} \\
\hline $\mathrm{T} 1$ & 0,13 & 0,10 & 0,14 & 0,25 & 0,12 & 0,14 & $0,15^{\mathrm{a}}$ \\
\hline T2 & 0,15 & 0,09 & 0,11 & 0,11 & 0,14 & 0,08 & $0,11^{\mathrm{a}}$ \\
\hline T3 & 0,14 & 0,24 & 0,11 & 0,13 & 0,13 & 0,09 & $0,14^{\mathrm{a}}$ \\
\hline T4 & 0,10 & 0,05 & 0,14 & 0,12 & 0,15 & 0,09 & $0,11^{\mathrm{a}}$ \\
\hline T5 & 0,19 & 0,09 & 0,13 & 0,13 & 0,12 & 0,07 & $0,12^{\mathrm{a}}$ \\
\hline Média & $0,14^{\mathrm{A}}$ & $0,12^{\mathrm{A}}$ & $0,13^{\mathrm{A}}$ & $0,15^{\mathrm{A}}$ & $0,13^{\mathrm{A}}$ & $0,09^{\mathrm{A}}$ & \\
\hline \multicolumn{8}{|c|}{ Camada $60-80 \mathrm{~cm}(\mathrm{CV}=47,62 \%)$} \\
\hline T1 & 0,08 & 0,06 & 0,14 & 0,18 & 0,11 & 0,10 & $0,11^{\mathrm{a}}$ \\
\hline T2 & 0,15 & 0,06 & 0,15 & 0,12 & 0,13 & 0,11 & $0,12^{\mathrm{a}}$ \\
\hline T3 & 0,20 & 0,12 & 0,15 & 0,13 & 0,14 & 0,05 & $0,13^{\mathrm{a}}$ \\
\hline T4 & 0,13 & 0,09 & 0,11 & 0,14 & 0,13 & 0,07 & $0,11^{\mathrm{a}}$ \\
\hline T5 & 0,22 & 0,11 & 0,14 & 0,18 & 0,14 & 0,05 & $0,14^{\mathrm{a}}$ \\
\hline Média & $0,15^{\mathrm{A}}$ & $0,09^{\mathrm{BC}}$ & $0,14^{\mathrm{AB}}$ & $0,15^{\mathrm{A}}$ & $0,13^{\mathrm{ABC}}$ & $0,08^{\mathrm{C}}$ & \\
\hline
\end{tabular}


Tabela 45. Efeitos da irrigação (água e efluente) e de doses de nitrogênio mineral nas concentrações de Zn disponível no solo

\begin{tabular}{|c|c|c|c|c|c|c|c|}
\hline \multirow{2}{*}{ Tratamento } & \multicolumn{7}{|c|}{ Época de avaliação } \\
\hline & Abr/03 & Jul/03 & Out/03 & Jan/04 & Abr/04 & Jul/04 & Média \\
\hline & \multicolumn{7}{|c|}{$\mathrm{mg} \mathrm{kg}^{-1}$} \\
\hline \multicolumn{8}{|c|}{ Camada $80-100 \mathrm{~cm}(C V=54,84 \%)$} \\
\hline T1 & 0,16 & 0,06 & 0,14 & 0,13 & 0,12 & 0,06 & $0,11^{\mathrm{a}}$ \\
\hline T2 & 0,31 & 0,08 & 0,12 & 0,17 & 0,13 & 0,09 & $0,14^{\mathrm{a}}$ \\
\hline T3 & 0,23 & 0,15 & 0,11 & 0,12 & 0,13 & 0,05 & $0,13^{\mathrm{a}}$ \\
\hline T4 & 0,10 & 0,08 & 0,16 & 0,11 & 0,12 & 0,07 & $0,11^{\mathrm{a}}$ \\
\hline T5 & 0,17 & 0,08 & 0,11 & 0,15 & 0,11 & 0,08 & $0,12^{\mathrm{a}}$ \\
\hline Média & $0,19^{\mathrm{A}}$ & $0,09^{\mathrm{BC}}$ & $0,13^{\mathrm{BC}}$ & $0,14^{\mathrm{AB}}$ & $0,12^{\mathrm{BC}}$ & $0,07^{\mathrm{C}}$ & \\
\hline
\end{tabular}

(1) T1: irrigação com água $+520 \mathrm{~kg} \mathrm{ha}^{-1}$ ano $^{-1}$ de nitrogênio via fertilizante mineral (NFM);

(2) T2: irrigação com efluente secundário de esgoto tratado (ESET), sem NFM;

(3) T3: irrigação com ESET + 171,6 $\mathrm{kg} \mathrm{ha}^{-1} \mathrm{ano}^{-1}$ de NFM;

(4) T4: irrigação com ESET + 343,3 $\mathrm{kg} \mathrm{ha}^{-1} \mathrm{ano}^{-1}$ de NFM;

(5) T5: irrigação com ESET + $520 \mathrm{~kg} \mathrm{ha}^{-1}$ ano $^{-1}$ de NFM;

(6) Letras iguais maiúsculas ou minúsculas nas linhas e nas colunas, respectivamente, não diferem estatisticamente pelo teste de Tukey $(P<0,05)$.

discordou das observações realizadas por (i) Quin \& Syers (1978) e Siebe (1995), que verificaram pequeno incremento nas concentrações de $\mathrm{Zn}$ disponível no solo sob pastagem de azevém-perene (submetida à irrigação com EET por 16 anos) e alfafa (irrigada com este subproduto por mais de 80 anos), respectivamente; (ii) Al-Jaloud et al. (1995) e Paliwal et al. (1998), que observaram diminuição na concentração de Zn disponível no solo devido ao aumento de $\mathrm{pH}$ promovido pelo EET; (iii) Al-Nakshabandi et al. (1997) e Adekalu \& Okunade (2002), que observaram aumento em curto prazo nas concentrações de Zn disponível em solo cultivado com beringela (submetida à irrigação com EET contendo $0,035 \mathrm{mg} \mathrm{L}^{-1}$ de $\mathrm{Zn}$ ) e milho (submetido à irrigação com este subproduto contendo $0,24 \mathrm{mg} \mathrm{L}^{-1}$ deste metal), respectivamente. No entanto, os resultados do presente trabalho concordaram com as observações realizadas por Smith et al. (1996), Fonseca (2001), Mohammad \& Mazahreh (2003) e Wang et al. (2003).

As concentrações de $\mathrm{Zn}$ no perfil do solo diminuíram no decorrer do experimento, exceto na camada 40-60 cm (Tabela 45). As maiores diminuições nas concentrações de Zn no solo ocorreram nas camadas 0-10 e 10-20 cm, certamente onde 
há maior concentração do sistema radicular do capim, promovendo maior extração de nutrientes, sobretudo de $\mathrm{Zn}$. O crescimento vigoroso do capim, devido à irrigação (independentemente do tipo de água empregada) promoveu altos rendimentos de MS (Tabela 5) e aumento na extração de nutrientes, inclusive de Zn (Tabela 37), diminuindo, com o tempo, a concentração deste micronutriente no solo (Tabela 45). Hayes et al. (1990a) e Mancino \& Pepper (1992) obtiveram resultados similares em pastagem de capim-Bermuda submetida à irrigação com água e EET.

$\mathrm{O}$ acúmulo de $\mathrm{Zn}$ no capim foi menor no tratamento T2, pelo fato de a ausência de NFM ter promovido menor crescimento e desenvolvimento das plantas deste tratamento, implicando em menor acúmulo de nutrientes (Tabelas 12, 22 e 37), inclusive de Zn. A quantidade de Zn acumulada nas plantas dos tratamentos T1, T3, T4 e T5 não foram diferentes (Tabela 37). Portanto, o tipo de água empregada na irrigação não afetou o acúmulo de Zn nas plantas, contrastando com as observações realizadas por (i) Gadallah (1994), Al-Jaloud et al. (1995) e Mohammad \& Ayadi (2004), que observaram aumento no conteúdo de Zn nas plantas (girassol e milho) mediante irrigação com EET; (i) Fonseca (2001), que verificou menor acúmulo de Zn no milho submetido à irrigação com ESET.

As concentrações de $\mathrm{Zn}$ na solução no solo se encontravam abaixo do limite de detecção, exceto para as avaliações realizadas nos meses de abril/2004 e julho/2004 (Tabela 46). Para essas épocas, as concentrações de Zn solúvel não diferiram e ainda, os tratamentos não ocasionaram alterações nas concentrações deste micronutriente no extrato de saturação (Tabela 46). O fato de ter ocorrido baixíssimas concentrações de Zn solúvel (Tabela 46) pode estar relacionado às baixas concentrações disponíveis deste micronutriente por ocasião da instalação do experimento (Tabela 2) e durante o período experimental (Tabela 45). Os CV para Zn disponível foram elevados (Tabela 45), no entanto, foram ainda maiores para Zn solúvel (Tabela 46). Ao que parece, determinações das concentrações de $\mathrm{Zn}$ solúvel, assim como às de $\mathrm{Mn}$, $\mathrm{Fe}$ e $\mathrm{Cu}$, não são sustentáveis mediante o emprego do método de Rhoades (1996) para solos contendo baixa concentração disponível destes micronutrientes. Portanto, a obtenção de extratos de saturação a partir da pasta de saturação (Rhoades, 1996), apesar de ser um método 
Tabela 46. Efeitos da irrigação (água e efluente) e de doses de nitrogênio mineral nas concentrações de Zn na solução no solo

\begin{tabular}{|c|c|c|c|c|c|c|c|}
\hline \multirow{2}{*}{ Tratamento } & \multicolumn{7}{|c|}{ Época de avaliação } \\
\hline & Abr/03 & Jul/03 & Out/03 & Jan/04 & Abr/04 & Jul/04 & Média \\
\hline & \multicolumn{7}{|c|}{$\mu g L^{-1}$} \\
\hline \multicolumn{8}{|c|}{ Camada 0-10 cm (CV = 193,77\%) } \\
\hline $\mathrm{T1}^{(1)}$ & $<\mathrm{LD}^{(7)}$ & $<\mathrm{LD}$ & $<\mathrm{LD}$ & $<\mathrm{LD}$ & 8 & 20 & $5^{\mathrm{a}(6)}$ \\
\hline $\mathbf{T 2}^{(2)}$ & $<\mathrm{LD}$ & $<\mathrm{LD}$ & $<\mathrm{LD}$ & $<\mathrm{LD}$ & 19 & 3 & $4^{\mathrm{a}}$ \\
\hline T3 ${ }^{(3)}$ & $<\mathrm{LD}$ & $<\mathrm{LD}$ & $<\mathrm{LD}$ & $<\mathrm{LD}$ & 25 & 17 & $7^{\mathrm{a}}$ \\
\hline T4 ${ }^{(4)}$ & $<\mathrm{LD}$ & $<\mathrm{LD}$ & $<\mathrm{LD}$ & $<\mathrm{LD}$ & 22 & 8 & $5^{\mathrm{a}}$ \\
\hline T5 ${ }^{(5)}$ & $<\mathrm{LD}$ & $<\mathrm{LD}$ & $<\mathrm{LD}$ & $<\mathrm{LD}$ & 25 & 15 & $7^{\mathrm{a}}$ \\
\hline Média & $<\mathrm{LD}$ & $<\mathrm{LD}$ & $<\mathrm{LD}$ & $<\mathrm{LD}$ & $20^{\mathrm{A}}$ & $13^{\mathrm{A}}$ & \\
\hline \multicolumn{8}{|c|}{ Camada $10-20 \mathrm{~cm}(C V=206,66 \%)$} \\
\hline T1 & $<\mathrm{LD}$ & $<\mathrm{LD}$ & $<\mathrm{LD}$ & $<\mathrm{LD}$ & 10 & 38 & $8^{\mathrm{a}}$ \\
\hline T2 & $<\mathrm{LD}$ & $<\mathrm{LD}$ & $<\mathrm{LD}$ & $<\mathrm{LD}$ & 81 & 33 & $19^{\mathrm{a}}$ \\
\hline T3 & $<\mathrm{LD}$ & $<\mathrm{LD}$ & $<\mathrm{LD}$ & $<\mathrm{LD}$ & 12 & 17 & $5^{a}$ \\
\hline T4 & $<\mathrm{LD}$ & $<\mathrm{LD}$ & $<\mathrm{LD}$ & $<\mathrm{LD}$ & 31 & 18 & $8^{\mathrm{a}}$ \\
\hline T5 & $<\mathrm{LD}$ & $<\mathrm{LD}$ & $<\mathrm{LD}$ & $<\mathrm{LD}$ & 33 & 11 & $7^{\mathrm{a}}$ \\
\hline Média & $<\mathrm{LD}$ & $<\mathrm{LD}$ & $<\mathrm{LD}$ & $<\mathrm{LD}$ & $33^{\mathrm{A}}$ & $23^{\mathrm{A}}$ & \\
\hline \multicolumn{8}{|c|}{ Camada $20-40 \mathrm{~cm}(C V=164,29 \%)$} \\
\hline $\mathrm{T} 1$ & $<\mathrm{LD}$ & $<\mathrm{LD}$ & $<\mathrm{LD}$ & $<\mathrm{LD}$ & 6 & 18 & $4^{\mathrm{a}}$ \\
\hline T2 & $<\mathrm{LD}$ & $<\mathrm{LD}$ & $<\mathrm{LD}$ & $<\mathrm{LD}$ & 58 & 42 & $17^{\mathrm{a}}$ \\
\hline T3 & $<\mathrm{LD}$ & $<\mathrm{LD}$ & $<\mathrm{LD}$ & $<\mathrm{LD}$ & 20 & 5 & $4^{\mathrm{a}}$ \\
\hline T4 & $<\mathrm{LD}$ & $<\mathrm{LD}$ & $<\mathrm{LD}$ & $<\mathrm{LD}$ & 21 & 9 & $5^{a}$ \\
\hline T5 & $<\mathrm{LD}$ & $<\mathrm{LD}$ & $<\mathrm{LD}$ & $<\mathrm{LD}$ & 20 & 11 & $5^{\mathrm{a}}$ \\
\hline Média & $<\mathrm{LD}$ & $<\mathrm{LD}$ & $<\mathrm{LD}$ & $<\mathrm{LD}$ & $25^{\mathrm{A}}$ & $17^{\mathrm{A}}$ & \\
\hline \multicolumn{8}{|c|}{ Camada $40-60 \mathrm{~cm}(C V=187,17 \%)$} \\
\hline $\mathrm{T} 1$ & $<\mathrm{LD}$ & $<\mathrm{LD}$ & $<\mathrm{LD}$ & $<\mathrm{LD}$ & 26 & 54 & $13^{\mathrm{a}}$ \\
\hline T2 & $<\mathrm{LD}$ & $<\mathrm{LD}$ & $<\mathrm{LD}$ & $<\mathrm{LD}$ & 13 & 38 & $9^{a}$ \\
\hline T3 & $<\mathrm{LD}$ & $<\mathrm{LD}$ & $<\mathrm{LD}$ & $<\mathrm{LD}$ & 58 & 31 & $15^{\mathrm{a}}$ \\
\hline T4 & $<\mathrm{LD}$ & $<\mathrm{LD}$ & $<\mathrm{LD}$ & $<\mathrm{LD}$ & 20 & 16 & $6^{a}$ \\
\hline T5 & $<\mathrm{LD}$ & $<\mathrm{LD}$ & $<\mathrm{LD}$ & $<\mathrm{LD}$ & 15 & 9 & $4^{\mathrm{a}}$ \\
\hline Média & $<\mathrm{LD}$ & $<\mathrm{LD}$ & $<\mathrm{LD}$ & $<\mathrm{LD}$ & $26^{\mathrm{A}}$ & $30^{\mathrm{A}}$ & \\
\hline \multicolumn{8}{|c|}{ Camada $60-80 \mathrm{~cm}(\mathrm{CV}=210,45 \%)$} \\
\hline T1 & $<\mathrm{LD}$ & $<\mathrm{LD}$ & $<\mathrm{LD}$ & $<\mathrm{LD}$ & 25 & 18 & $7^{\mathrm{a}}$ \\
\hline T2 & $<\mathrm{LD}$ & $<\mathrm{LD}$ & $<\mathrm{LD}$ & $<\mathrm{LD}$ & 18 & 38 & $9^{\mathrm{a}}$ \\
\hline T3 & $<\mathrm{LD}$ & $<\mathrm{LD}$ & $<\mathrm{LD}$ & $<\mathrm{LD}$ & 44 & 18 & $10^{\mathrm{a}}$ \\
\hline T4 & $<\mathrm{LD}$ & $<\mathrm{LD}$ & $<\mathrm{LD}$ & $<\mathrm{LD}$ & 18 & 12 & $5^{\mathrm{a}}$ \\
\hline T5 & $<\mathrm{LD}$ & $<\mathrm{LD}$ & $<\mathrm{LD}$ & $<\mathrm{LD}$ & 12 & 21 & $6^{\mathrm{a}}$ \\
\hline Média & $<\mathrm{LD}$ & $<\mathrm{LD}$ & $<\mathrm{LD}$ & $<\mathrm{LD}$ & $23^{\mathrm{A}}$ & $21^{\mathrm{A}}$ & \\
\hline
\end{tabular}


Tabela 46. Efeitos da irrigação (água e efluente) e de doses de nitrogênio mineral nas concentrações de Zn na solução no solo

\begin{tabular}{|c|c|c|c|c|c|c|c|}
\hline \multirow{2}{*}{ Tratamento } & \multicolumn{7}{|c|}{ Época de avaliação } \\
\hline & Abr/03 & Jul/03 & Out/03 & Jan/04 & Abr/04 & Jul/04 & Média \\
\hline & \multicolumn{7}{|c|}{$\mu g L^{-1}$} \\
\hline \multicolumn{8}{|c|}{ Camada $80-100 \mathrm{~cm}(C V=155,87 \%)$} \\
\hline T1 & $<\mathrm{LD}$ & $<\mathrm{LD}$ & $<\mathrm{LD}$ & $<\mathrm{LD}$ & 52 & 20 & $12^{\mathrm{a}}$ \\
\hline T2 & $<\mathrm{LD}$ & $<\mathrm{LD}$ & $<\mathrm{LD}$ & $<\mathrm{LD}$ & 28 & 23 & $9^{\mathrm{a}}$ \\
\hline T3 & $<\mathrm{LD}$ & $<\mathrm{LD}$ & $<\mathrm{LD}$ & $<\mathrm{LD}$ & 28 & 19 & $8^{\mathrm{a}}$ \\
\hline T4 & $<\mathrm{LD}$ & $<\mathrm{LD}$ & $<\mathrm{LD}$ & $<\mathrm{LD}$ & 16 & 18 & $6^{\mathrm{a}}$ \\
\hline T5 & $<\mathrm{LD}$ & $<\mathrm{LD}$ & $<\mathrm{LD}$ & $<\mathrm{LD}$ & 13 & 31 & $7^{\text {a }}$ \\
\hline Média & $<\mathrm{LD}$ & $<\mathrm{LD}$ & $<\mathrm{LD}$ & $<\mathrm{LD}$ & $27^{\mathrm{A}}$ & $22^{\mathrm{A}}$ & \\
\hline
\end{tabular}

(1) T1: irrigação com água $+520 \mathrm{~kg} \mathrm{ha}^{-1}$ ano $^{-1}$ de nitrogênio via fertilizante mineral (NFM).

(2) T2: irrigação com efluente secundário de esgoto tratado (ESET), sem NFM.

(3) T3: irrigação com ESET + 171,6 $\mathrm{kg} \mathrm{ha}^{-1} \mathrm{ano}^{-1}$ de NFM.

(4) T4: irrigação com ESET + 343,3 $\mathrm{kg} \mathrm{ha}^{-1} \mathrm{ano}^{-1}$ de NFM.

(5) T5: irrigação com ESET $+520 \mathrm{~kg} \mathrm{ha}^{-1} \mathrm{ano}^{-1}$ de NFM.

(6) LD: limite de detecção $\left(12 \mu \mathrm{g} \mathrm{L}^{-1}\right)$. Para fins de análises estatísticas esses valores foram considerados iguais a zero.

(7) Letras iguais maiúsculas ou minúsculas nas linhas e nas colunas, respectivamente, não diferem estatisticamente pelo teste de Tukey $(P<0,05)$.

amplamente utilizado nos estudos de química da solução no solo (Wolt, 1994), não forneceu, para este trabalho, informações necessárias para prever o comportamento dos metais pesados em solução, devido aos elevados CV dos resultados (Tabelas 40, 42, 44 e 46).

As concentrações de $\mathrm{Cr}$ disponíveis no solo para os tratamentos e para as épocas de avaliação não foram diferentes nas camadas 0-10 e 10-20 cm. Para as demais camadas $(20-40,40-60,60-80$ e 80-100 cm), as concentrações deste elemento se encontravam abaixo do limite de detecção do método empregado $\left(0,01 \mathrm{mg} \mathrm{kg}^{-1}\right)$. Na camada 0-10 cm as concentrações de Cr disponível foram 0,$05 ; 0,05 ; 0,07 ; 0,07$ e 0,05 $\mathrm{mg} \mathrm{kg}^{-1}$ para os tratamentos T1, T2, T3, T4 e T5, respectivamente. Na camada 10-20 cm as concentrações de $\mathrm{Cr}$ disponível foram 0,05; 0,05;0,06; 0,06 e $0,04 \mathrm{mg} \mathrm{kg}^{-1}$ para os tratamentos T1, T2, T3, T4 e T5, respectivamente. As concentrações de Cr disponível nas diferentes épocas de avaliação para as camadas 0-10 e 10-20 cm variaram de 0,05 a 0,06 e de 0,05 a $0,07 \mathrm{mg} \mathrm{kg}^{-1}$, respectivamente. As concentrações disponíveis de $\mathrm{Cd}, \mathrm{Ni}$ 
e $\mathrm{Pb}$ se encontravam abaixo do limite de detecção do método empregado, cujos valores foram 0,$03 ; 0,06$ e $0,13 \mathrm{mg} \mathrm{kg}^{-1}$, respectivamente.

Ainda, foram observadas que as concentrações dos metais pesados $\mathrm{Cd}, \mathrm{Cr}$, Ni e $\mathrm{Pb}$ se encontravam abaixo do limite de detecção nas amostras de (i) solução no solo (extrato de saturação), cujos limites de detecção foram 7, 3, 18 e $92 \mu \mathrm{g} \mathrm{L} \mathrm{L}^{-1}$, respectivamente; (ii) plantas, cujos limites de detecção foram $10,3,18$ e $58 \mu \mathrm{g} \mathrm{L}^{-1}$, respectivamente e que correspondiam a uma concentração (na MS) de 0,50;0,15;0,90 e 2,90 $\mathrm{mg} \mathrm{kg}^{1}$ para $\mathrm{Cd}, \mathrm{Cr}, \mathrm{Ni}$ e $\mathrm{Pb}$, respectivamente.

As doses de irrigação utilizadas no presente estudo não ocasionaram aportes significativos de $\mathrm{Cd}, \mathrm{Cr}$, $\mathrm{Ni}$ e $\mathrm{Pb}$ no sistema, devido às baixas concentrações destes metais no ESET (Tabela 3). Desse modo, o ESET de Lins não apresentou potencial de poluição com os metais $\mathrm{Cd}, \mathrm{Cr}$, $\mathrm{Ni}$ e $\mathrm{Pb}$, uma vez que as concentrações destes metais no sistema solo-planta-solução não foram afetadas pelos tratamentos e/ou encontravam-se abaixo do limite de detecção do método empregado. Esses resultados estão de acordo com as observações de (i) Inglés et al. (1992) para $\mathrm{Cd}$ e $\mathrm{Pb}$; (ii) Johns \& McConchie (1994a e 1994b) para Cd, Cr e Pb; (iii) Al-Jaloud et al. (1995) para Ni; (iv) Smith et al. (1996) para Cr, Ni e Pb; (v) Ramirez-Fuentes et al. (2002) para Cr e Ni; (vi) Wang et al. (2003) para Cd, Cr e Ni; (vii) Mohammad \& Mazahreh (2003) para Cd, Cr, Ni e Pb.

A partir dos resultados do presente trabalho pode-se inferir que (i) a aplicação de 1200 a 1500 anuais mm de ESET (com características similares ao empregado neste experimento) em pastagens produtivas não promoverá, em curto prazo, alterações na dinâmica dos metais pesados no sistema solo-planta-solução; (ii) as possíveis alterações nas concentrações de metais pesados neste sistema, em médio e longo prazo, não necessariamente terão aspectos negativos do ponto de vista agronômico-ambiental; (iii) o monitoramento anual da fertilidade do solo permitirá inferir as possíveis mudanças no agrossitema, mediante análise dos resultados de $\mathrm{pH}, \mathrm{CT}, \mathrm{Cu}, \mathrm{Fe}, \mathrm{Mn}$ e $\mathrm{Zn}$; (iv) podem ser viáveis determinações bianuais ou qüinqüenuais das concentrações totais (ou das obtidas em água-régia) de metais pesados no solo, visando monitorar o potencial de poluição do sistema receptor de ESET. Essas inferências são suportadas a partir das 
observações levantadas no presente estudo e de análises de resultados de longo prazo, apresentados em:

a) Siebe (1995), que observou pequeno aumento nas concentrações de $\mathrm{Cd}, \mathrm{Cu}$ e $\mathrm{Zn}$ (extraídos em água-régia) em solos de Hidalgo (México), sob pastagens de alfafa submetida à irrigação com EET por mais de 80 anos.

b) Cajuste et al. (2001). Esses autores verificaram aumento, com o tempo de irrigação, nas concentrações de $\mathrm{Cd}, \mathrm{Ni}$ e $\mathrm{Pb}$ em solos do Vale de Mezquital (México), que foram irrigados com EET durante 5 a 20, 24 a 64 e 76 a 84 anos. Neste caso, foram recomendadas medidas para diminuição na concentração de metais no EET, visando sua utilização sustentável na agricultura.

c) Madyiwa et al. (2002) e Madyiwa et al. (2003). Os autores observaram aumento nas concentrações de $\mathrm{Cd}, \mathrm{Cu}, \mathrm{Pb}$ e $\mathrm{Zn}$ no solo (extraídos em água-régia) e nos capins Kikuyu e Estrela, que foram submetidos à irrigação com EET por aproximadamente 30 anos, no Zimbabué. Porém, esses autores assinalaram que não foram observadas concentrações tóxicas desses metais às plantas, bem como ao ambiente.

d) Ramirez-Fuentes et al. (2002). Esses autores verificaram, em solos do Vale de Mezquital (México), aumento nas concentrações totais de $\mathrm{Cr}$ e $\mathrm{Cu}$ e nas concentrações disponíveis de $\mathrm{Cd}, \mathrm{Cu}$ e $\mathrm{Pb}$ devido aos períodos de irrigação com EET (um, dois, 22, 33, 73 e 86 anos). Essas alterações, segundo os autores, ocorreram por causa do incremento nas concentrações de metais pesados nos esgotos durante os últimos 50 anos.

e) Wang et al. (2003), que não observaram alterações significativas na qualidade de solos da California (EUA) cultivados com alfafa, algodão, cevada, milho e sorgo, submetidos à irrigação com $1400 \mathrm{~mm}$ anuais de EET por mais de 80 anos. 


\section{CONCLUSÕES}

O efluente secundário de esgoto tratado (ESET), um problema ambiental atual, constitui-se numa água residuária (marginal), que pode substituir eficientemente a água convencional (potável) de irrigação em sistema de produção de feno de capim-Bermuda Tifton 85. Essa substituição pode proporcionar benefícios econômicos e aumento de qualidade do capim. Ainda, o ESET pode atuar como amenizador da acidez do solo.

A magnitude de resposta do capim ao ESET, bem como da economia de nitrogênio via fertilizante mineral (NFM) é dependente da precipitação pluvial e da lâmina de irrigação empregada. Assim, a substituição da água potável pelo ESET, na irrigação do capim, pode levar à economia de 32,2 a 81,0\% na dose de NFM necessária à obtenção de altos rendimentos, sem ocasionar alterações negativas no conteúdo de nutrientes nas plantas e na fertilidade do solo.

Por outro lado, se os nutrientes presentes no ESET não forem computados no manejo da fertilização da pastagem, podem ocorrer incrementos no rendimento de MS e no acúmulo de elementos, inclusive de sódio, promovendo aumento de qualidade da forragem sem ocasionar efeitos deletérios no ambiente.

As altas concentrações de sódio na água potável (utilizada no tratamento controle), bem como no ESET indicam que o sistema solo-pastagem não suportará o elevado aporte (média de 1000 a $2000 \mathrm{~kg} \mathrm{ha}^{-1} \mathrm{ano}^{-1}$ ) deste elemento e pode ser necessário o uso de condicionador de solo, como gesso agrícola.

O aporte de nutrientes no sistema (via fertilização mineral e via irrigação) associado à manutenção de tensão hídrica adequada ao capim, pode promover mineralização da matéria orgânica do solo, reduzindo os estoques de carbono e nitrogênio. 
Ao que parece, a irrigação com ESET de origem doméstico não proporcionará, em curto e médio prazo, excesso de boro e de metais pesados no sistema solo-pastagem. Ainda, apesar dos resultados promissores deste trabalho terem indicado para o uso de ESET em pastagem, outros estudos ainda são necessários para a recomendação extensiva e sustentável deste subproduto. 
ANEXO 


\section{A1 - Comparação dos métodos de obtenção da solução no solo}

Solução no solo é a fase aquosa do solo que interage com as fases sólida e gasosa através de trocas de energia e matéria (Suarez, 1999). A composição da solução no solo é dependente, acima de tudo, do equilíbrio dinâmico entre fatores ambientais, propriedades (químicas, físicas e biológicas) do solo, bem como de seus componentes orgânicos e minerais (Menéndez et al., 2003).

No estudo da solução no solo, a etapa mais crítica é a amostragem, seja esta realizada in situ ou obtida mediante emprego de métodos laboratoriais, pois os resultados normalmente não são concordantes (Suarez, 1999). Isso ocorre devido ao fato de a composição química da solução variar grandemente com o teor de umidade dos solos, principalmente, aqueles de baixo poder tampão (Wolt, 1994). A sustentabilidade de um método de amostragem de solução no solo depende, principalmente, do tipo de solo, condição de umidade e disponibilidade de recursos (Ahmed et al., 2001). Apesar das dificuldades anteriormente relatadas (itens 4.4, 4.5, 4.6, 4.7 e 4.8), torna-se necessário o monitoramento da solução nos solos destinados à reciclagem de resíduos antrópicos (Cameron et al., 1997), sobretudo, aqueles submetidos à irrigação com EET (Bond, 1998).

No presente trabalho, o emprego de cápsulas de cerâmica porosa foi o método proposto inicialmente para extração da solução no solo. $\mathrm{O}$ vácuo foi realizado aos $14 \mathrm{e}$ sete dias antes da data prevista para amostragem, que foi executada nas ocasições de corte do capim. Pretendeu-se realizar a amostragem da solução nas ocasiões de menor e maior demanda das plantas por nutrientes e água, respectivamente, visando conhecer a máxima quantidade de compostos livres presentes na solução no solo do experimento. A opção pelas cápsulas foi devido ao fato deste método de extração fornecer resultados 
satisfatórios para íons livres na solução, como $\mathrm{Cl}^{-}$e $\mathrm{NO}_{3}{ }^{-}$(Reichardt et al., 1977) e apesar de ser muito criticado (Schwab, 2000), seu uso nos estudos agronômicoambientais tem sido extensivo (Ahmed et al., 2001), incluindo sistemas de disposição de águas residuárias (Reeve \& Doering, 1965).

Porém, neste trabalho, foi verificado que, as cápsulas não se mostraram sustentáveis pois (i) ocorreram grandes variações no volume de solução extraída ao longo do período experimental; (ii) para uma mesma ocasião de amostragem, o volume de solução extraída foi inconstante, apesar de o solo de todas parcelas ter sido mantido num mesmo $\psi_{m}$; (iii) não foi observado correlação entre $\psi_{m}$ e volume de solução coletada $\left(r=0,33^{\mathrm{NS}}\right)$. Dificuldades similares também foram observadas nos experimentos conduzidos por Dawes \& Goonetilleke (2003) e Menéndez et al. (2003). As explicações para esses empecilhos são:

a) Pode ocorrer falta de correlação entre o $\psi_{m}$ da camada onde a cápsula se encontra instalada com o volume de solução coletada, sobretudo, em situação onde a água está sendo redistribuída para camadas adjacentes inferiores. Portanto, as camadas adjacentes à da cápsula exercem papel regulador no volume de solução amostrada, devido à extensão das forças mátricas (Wagner, 1965).

b) Wu et al. (1995) assinalaram que não há correlação entre a tensão $(\tau)$ aplicada nas cápsulas e o volume de solução coletada.

c) Os poros das cápsulas estão sujeitos a frequentes obstruções, principalmente, por silte, óxidos de Fe e MOS, que tendem a aumentar no decorrer do período experimental (Moraes \& Dynia, 1990). Para contornar esse problema, normalmente tem sido aumentada a $\tau$ aplicada nas cápsulas, bem como o período de vácuo, o que leva à ocorrência de alterações indesejáveis na qualidade da solução amostrada (Hansen \& Harris, 1975).

d) Altas concentrações de $\mathrm{Na}$, particularmente em condição de baixa concentração eletrolítica da solução, podem promover efeitos adversos na qualidade física do solo e, conseqüentemente, afetar o caminhamento da solução no sentido solo-cápsula (Reeve \& Doering, 1965). Este fato certamente ocorreu no presente estudo, pois foi observada baixa concentração de sais (Tabela 27) e houve incremento nas 
concentrações de Na trocável no decorrer do experimento (Tabela 20), promovendo aumento no GDA (Tabela 26).

Visando contornar os problemas metodológicos inerentes ao uso das cápsulas, foi utilizado o método de Rhoades (1996) para obtenção de extratos aquosos a partir da pasta de saturação, que tem sido amplamente empregado nos estudos de salinidade (Maas, 1985) e de química da solução no solo (Wolt, 1994; Abreu et al., 2002). Porém, os extratos de saturação estão sujeitos às críticas relacionadas à completa destruição do arranjo natural do sistema solo-solução no solo (Reichardt et al., 1977).

Foi verificado que os extratos de saturação (i) foram eficientes para determinação da salinidade; (ii) podem ser empregados, com limitações, nos estudos de $\mathrm{Mg}, \mathrm{K}, \mathrm{Na}, \mathrm{N}-\mathrm{NH}_{4}{ }^{+}, \mathrm{N}_{-} \mathrm{NO}_{3}{ }^{-}$e Fe; (iii) não foram eficientes nos estudos dos elementos $\mathrm{Al}, \mathrm{Ca}, \mathrm{S}, \mathrm{B}, \mathrm{Cu}, \mathrm{Mn}$ e $\mathrm{Zn}$, bem como na determinação do $\mathrm{pH}$, devido aos efeitos dos sais na acidez ativa. Essas afirmações foram baseadas nos resultados dos (a) CV das concentrações dos analitos (apresentados nos ítens 4.4, 4.5. 4.6, 4.7 e 4.8) na solução; (b) coeficientes de correlação entre concentrações solúveis e disponíveis (ou trocáveis) dos elementos no solo. Ainda, o incremento na concentração de Na no solo, no decorrer do experimento (Tabela 20), ocasionou dispersão de argilas (Tabela 26), aumentando extensivamente o tempo de vácuo empregado para obtenção dos extratos de saturação, principalmente daqueles oriundos das camadas 0-10 e 10-20 cm. Devido à textura média-arenosa e média-argilosa (Tabela 2) e às baixas concentrações de CT no solo estudado (Tabelas 2 e 31), a capacidade de retenção de água do solo era baixa (Tabela 2). Assim, pequena quantidade de água adicionada foi o suficiente para atingir o ponto de pasta de saturação. Houve necessidade de 500 g de TFSA para viabilizar a otenção de aproximadamente $30-40 \mathrm{~mL}$ de extrato de saturação.

Como não foi possível realizar os procedimentos estatísticos padrão para os resultados das cápsulas, foram realizadas análises de correlação entre os parâmetros (i) solução no solo mediante o emprego de cápsulas; (ii) extrato de saturação; (iii) resultados de análises químicas de solo para fins de fertilidade. Os coeficientes de correlação observados são apresentados na Tabela 47. 
Tabela 47. Coeficientes de correlação entre os resultados de análises químicas das soluções extraídas pelas cápsulas de cerâmica porosa e das pastas de saturação (extratos de saturação) com os resultados de análises químicas de solo para fins de fertilidade $\left.{ }^{(}\right)$

\begin{tabular}{llllll}
\hline \multirow{2}{*}{ Parâmetro } & \multicolumn{7}{c}{ Camada (cm) } \\
& $0-20$ & $20-40$ & $40-60$ & $60-80$ & $80-100$ \\
\hline
\end{tabular}

Solução no solo coletada pelas cápsulas de cerâmica porosa

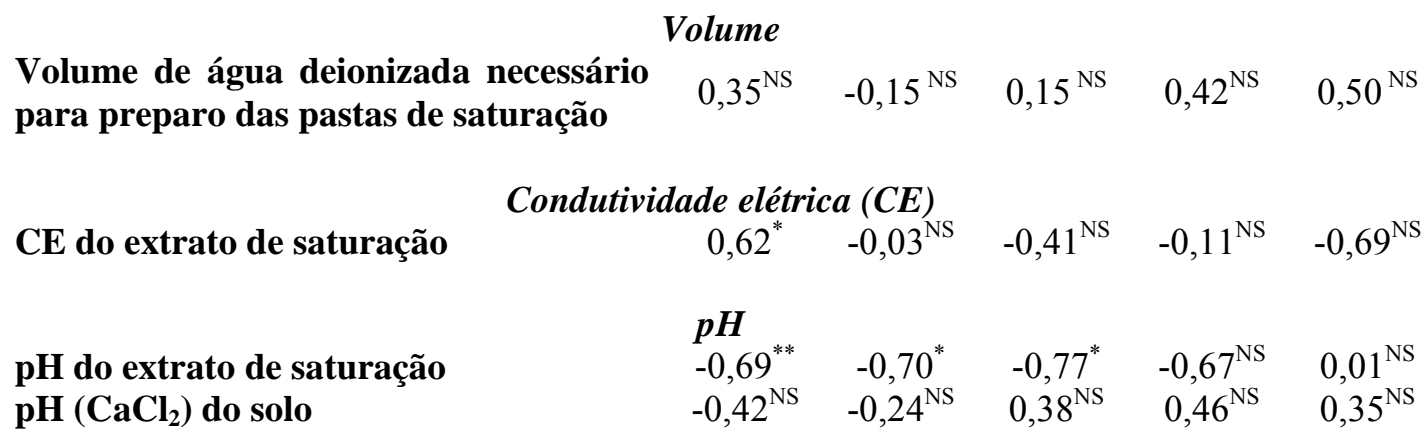

Al solúvel no extrato de saturação Al trocável no solo

$\begin{array}{ccccc}\text { Al solúvel } & & & & \\ 0,53^{*} & -0,12^{\mathrm{NS}} & 0,71^{*} & -0,16^{\mathrm{NS}} & -0,51^{\mathrm{NS}} \\ -0,21^{\mathrm{NS}} & 0,03^{\mathrm{NS}} & -0,01^{\mathrm{NS}} & 0,01^{\mathrm{NS}} & 0,15^{\mathrm{NS}} \\ & & & & \\ \text { Ca solúvel } & & & & \\ 0,33^{\mathrm{NS}} & -0,13^{\mathrm{NS}} & -0,29^{\mathrm{NS}} & 0,71^{\mathrm{NS}} & -0,44^{\mathrm{NS}} \\ 0,53^{*} & 0,49^{\mathrm{NS}} & 0,18^{\mathrm{NS}} & -0,01^{\mathrm{NS}} & -0,19^{\mathrm{NS}}\end{array}$

Ca solúvel no extrato de saturação Ca trocável no solo

Mg solúvel

$\begin{array}{ccccc}0,06^{\mathrm{NS}} & -0,14^{\mathrm{NS}} & 0,08^{\mathrm{NS}} & 0,89^{*} & -0,70^{\mathrm{NS}} \\ 0,15^{\mathrm{NS}} & 0,11^{\mathrm{NS}} & 0,34^{\mathrm{NS}} & 0,24^{\mathrm{NS}} & 0,32^{\mathrm{NS}}\end{array}$

Mg solúvel no extrato de saturação Mg trocável no solo

\section{K solúvel}

$\begin{array}{ccccc}0,86^{* *} & 0,79^{* *} & 0,70^{*} & 0,51^{\mathrm{NS}} & -0,18^{\mathrm{NS}} \\ 0,49^{\mathrm{NS}} & 0,64^{*} & 0,85^{* *} & 0,51^{\mathrm{NS}} & 0,38^{\mathrm{NS}}\end{array}$

K solúvel no extrato de saturação

K trocável no solo

\section{Na solúvel}

\begin{tabular}{|c|c|c|c|c|}
\hline $0,22^{\mathrm{NS}}$ & $-0,02^{\mathrm{NS}}$ & $0,69^{\mathrm{NS}}$ & $0,09^{\mathrm{NS}}$ & $-0,56^{\mathrm{NS}}$ \\
\hline$-0,39^{\mathrm{NS}}$ & $-0,10^{\mathrm{NS}}$ & $-0,61^{\mathrm{NS}}$ & $0,08^{\mathrm{NS}}$ & $0,59^{\mathrm{NS}}$ \\
\hline
\end{tabular}

Na solúvel no extrato de saturação Na trocável no solo

Razão de adsorção de sódio (RAS)

$\begin{array}{llllll}\text { RAS no extrato de saturação } & -0,24^{\mathrm{NS}} & 0,07^{\mathrm{NS}} & -0,89^{\mathrm{NS}} & 0,33^{\mathrm{NS}} & 0,79^{\mathrm{NS}}\end{array}$

$$
\mathrm{N}-\mathrm{NO}_{3}^{-} \text {solúvel }
$$

$\begin{array}{llllll}\mathbf{N}-\mathrm{NO}_{3}{ }^{-} \text {solúvel no extrato de saturação } & 0,28^{\mathrm{NS}} & 0,12^{\mathrm{NS}} & -0,34^{\mathrm{NS}} & -0,31^{\mathrm{NS}} & 0,69^{\mathrm{NS}}\end{array}$ 
Tabela 47. Coeficientes de correlação entre os resultados de análises químicas das soluções extraídas pelas cápsulas de cerâmica porosa e das pastas de saturação (extratos de saturação) com os resultados de análises químicas de solo para fins de fertilidade ${ }^{()}$

\begin{tabular}{|c|c|c|c|c|c|}
\hline \multirow{2}{*}{ Parâmetro } & \multicolumn{5}{|c|}{ Camada $(\mathrm{cm})$} \\
\hline & 0-20 & $20-40$ & 40-60 & $60-80$ & 80-100 \\
\hline \multicolumn{6}{|c|}{ Solução no solo coletada pelas cápsulas de cerâmica porosa } \\
\hline \multicolumn{6}{|c|}{$\mathrm{N}-\mathrm{NO}_{2}^{-}$na solução coletada pelas cápsulas } \\
\hline $\mathrm{N}-\mathrm{NO}_{2}^{-}$no extrato de saturação & $-0,23^{\mathrm{NS}}$ & $-0,26^{\mathrm{NS}}$ & $0,46^{\mathrm{NS}}$ & $-0,33^{\mathrm{NS}}$ & $0,01^{\mathrm{NS}}$ \\
\hline \multicolumn{6}{|c|}{$\mathrm{N}-\mathrm{NH}_{4}^{+}$solúvel } \\
\hline $\mathrm{N}-\mathrm{NH}_{4}{ }^{+}$solúvel no extrato de saturaçãc & $0,27^{\mathrm{NS}}$ & $-0,28^{\mathrm{NS}}$ & $0,36^{\mathrm{NS}}$ & $0,69^{\mathrm{NS}}$ & $0,42^{\mathrm{NS}}$ \\
\hline \multicolumn{6}{|c|}{$\mathrm{N}$-mineral $\left(\mathrm{N}-\mathrm{NO}_{3}^{-}+\mathrm{N}-\mathrm{NO}_{2}^{-}+\mathrm{NH}_{4}^{+}\right)$solúvel } \\
\hline $\begin{array}{l}\text { N-mineral solúvel no extrato de } \\
\text { saturação }\end{array}$ & $0,39^{\mathrm{NS}}$ & $0,32^{\mathrm{NS}}$ & $-0,41^{\mathrm{NS}}$ & $-0,42^{\mathrm{NS}}$ & $0,32^{\mathrm{NS}}$ \\
\hline \multicolumn{6}{|c|}{ S solúvel } \\
\hline S solúvel no extrato de saturação & $0,69^{* *}$ & $0,05^{\mathrm{NS}}$ & $0,07^{\mathrm{NS}}$ & $0,11^{\mathrm{NS}}$ & $0,29^{\mathrm{NS}}$ \\
\hline S disponível no solo & $0,30^{\mathrm{NS}}$ & $-0,40^{\mathrm{NS}}$ & $-0,40^{\mathrm{NS}}$ & $-0,09^{\mathrm{NS}}$ & $0,15^{\mathrm{NS}}$ \\
\hline \multicolumn{6}{|c|}{ B solúvel } \\
\hline B solúvel no extrato de saturação & $0,13^{\mathrm{NS}}$ & $0,09^{\mathrm{NS}}$ & $-0,62^{\mathrm{NS}}$ & $-0,02^{\mathrm{NS}}$ & $-0,20^{\mathrm{NS}}$ \\
\hline B solúvel no solo & $0,14^{\mathrm{NS}}$ & $0,24^{\mathrm{NS}}$ & $0,46^{\mathrm{NS}}$ & $-0,03^{\mathrm{NS}}$ & $0,25^{\mathrm{NS}}$ \\
\hline \multicolumn{6}{|c|}{ Cu solúvel } \\
\hline Cu solúvel no extrato de saturação & $0,57^{*}$ & $0,61^{*}$ & $0,20^{\mathrm{NS}}$ & $0,96^{* *}$ & $0,93^{*}$ \\
\hline Cu trocável no solo & $0,04^{\mathrm{NS}}$ & $-0,18^{\mathrm{NS}}$ & $0,06^{\mathrm{NS}}$ & $0,37^{\mathrm{NS}}$ & $-0,97^{* *}$ \\
\hline \multicolumn{6}{|c|}{ Fe solúvel } \\
\hline Fe solúvel no extrato de saturação & $0,64^{*}$ & $-0,24^{\mathrm{NS}}$ & $0,15^{\mathrm{NS}}$ & $0,71^{\mathrm{NS}}$ & $-0,76^{\mathrm{NS}}$ \\
\hline Fe trocável no solo & $0,25^{\mathrm{NS}}$ & $-0,02^{\mathrm{NS}}$ & $0,15^{\mathrm{NS}}$ & $0,40^{\mathrm{NS}}$ & $0,94^{*}$ \\
\hline \multicolumn{6}{|c|}{ Mn solúvel } \\
\hline Mn solúvel no extrato de saturação & $-0,29^{\mathrm{NS}}$ & $-0,44^{\mathrm{NS}}$ & $-0,06^{\mathrm{NS}}$ & $0,66^{\mathrm{NS}}$ & $0,99^{*}$ \\
\hline Mn trocável no solo & $0,41^{\mathrm{NS}}$ & $-0,58^{*}$ & $-0,24^{\mathrm{NS}}$ & $-0,12^{\mathrm{NS}}$ & $0,77^{\mathrm{NS}}$ \\
\hline \multicolumn{6}{|c|}{ Zn solúvel } \\
\hline Zn solúvel no extrato de saturação & $0,64^{* *}$ & $0,56^{\mathrm{NS}}$ & $0,48^{\mathrm{NS}}$ & $0,86^{*}$ & $0,15^{\mathrm{NS}}$ \\
\hline Zn trocável no solo & $-0,49^{\mathrm{NS}}$ & $-0,41^{\mathrm{NS}}$ & $-0,46^{\mathrm{NS}}$ & $-0,31^{\mathrm{NS}}$ & $-0,62^{\mathrm{NS}}$ \\
\hline
\end{tabular}

(§) Volume (mL); CE (dS m ${ }^{-1}$ ); $\mathrm{Al}, \mathrm{Ca}, \mathrm{Mg}, \mathrm{K}$ e Na na solução (mmol L $\left.{ }^{-1}\right) ; \mathrm{Al}, \mathrm{Ca}, \mathrm{Mg}, \mathrm{K} \mathrm{e} \mathrm{Na}$ no complexo de troca $\left(\mathrm{mmol}_{\mathrm{c}} \mathrm{kg}^{-1}\right)$; RAS $\left(\left(\mathrm{mmol} \mathrm{L}^{-1}\right)^{0,5}\right) ; \mathrm{N}^{-\mathrm{NO}_{3}}, \mathrm{~N}^{-} \mathrm{NO}_{2}^{-}, \mathrm{N}-\mathrm{NH}_{4}{ }^{+}, \mathrm{N}-$ mineral, $\mathrm{P}, \mathrm{S}, \mathrm{B}, \mathrm{Cu}, \mathrm{Fe}, \mathrm{Mn}$ e Zn na solução (mg L $\left.{ }^{-1}\right)$; P, S, B, Cu, Fe, Mn e Zn no solo (mg kg $\left.{ }^{-1}\right)$. 
Foi observado, mediante comparação dos resultados das soluções extraídas pelas cápsulas com os resultados dos extratos de saturação, que:

a) Não houve correlação entre o volume de solução amostrada pelas cápsulas e o volume de água deionizada necessário para preparo das pastas de saturação.

b) Houve correlações negativas para pH (camadas 0-20, 20-40 e 40-60 cm).

c) Foram observadas correlações positivas para CE (camada 0-20 cm), Al (camadas 020 e 40-60 cm), Mg (camada 60-80 cm), K (camadas 0-20, 20-40 e 40-60), S (camada 0-20 cm), Cu (camadas 0-20, 20-40, 60-80 e 80-100 cm), Fe (camada 0-10 $\mathrm{cm}$ ), Mn (camada 80-100 cm) e Zn (camada 0-10 e 60-80 cm).

d) Não houve correlações para os demais elementos e/ou camadas, inclusive para a RAS (Tabela 47).

Comparando os resultados das cápsulas com os das análises químicas de solo para fins de fertilidade, foram observadas:

a) Correlação positiva para Ca (camada 0-20 cm), K (camadas 20-40 e 40-60 cm) e Fe (camada $80-100 \mathrm{~cm}$ ).

b) Correlação negativa para $\mathrm{Cu}$ (camada $80-100 \mathrm{~cm}$ ) e $\mathrm{Mn}$ (camada 20-40 cm).

c) Nenhuma correlação para os demais elementos e/ou camadas (Tabela 47).

A falta de correlações entre parâmetros avaliados no solo e no extrato aquoso foi discutida anteriormente (itens 4.4, 4.5, 4.6, 4.7 e 4.8) e aqui será dada ênfase nos resultados das cápsulas. Portanto, quando se procede a aplição de vácuo na cápsula, ocorre diminuição na pressão parcial de $\mathrm{CO}_{2}$ proporcionalmente à redução da pressão total. Ainda, há desgaseificação da solução mediante sua entrada na cápsula, ocasionando liberação de $\mathrm{CO}_{2}$, perda de $\mathrm{H}_{2} \mathrm{CO}_{3}$ dissolvido e, conseqüentemente, favorece ao aumento de $\mathrm{pH}$, bem como do potencial de precipitação de carbonatos, fosfatos e óxidos (Suarez, 1987).

A inexistência de correlação para a maioria das camadas estudadas, no tocante aos nutrientes $\mathrm{Ca}, \mathrm{Mg}, \mathrm{K}, \mathrm{Cu}, \mathrm{Fe}, \mathrm{Mn}$ e $\mathrm{Zn}$ pode ser devido às possibilidades de (i) adsorção dos metais pesados nas paredes das cápsulas; (ii) liberação de $\mathrm{Ca}$ e $\mathrm{Mg}$ do material constituinte das cápsulas (Hansen \& Harris, 1975; Menéndez et al., 2003). Apesar de o $\mathrm{pH}$ da solução coletada pela cápsula ter sido alto, ocorreu numa faixa 
inferior a 8,0 e, desse modo, os elementos $\mathrm{Ca}, \mathrm{Mg}$ e $\mathrm{K}$ podem ter permanecido em solução, segundo Lindsay (1979).

Os métodos de estudo de solução no solo utilizados neste trabalho não se correlacionaram, pois acessaram íons e soluções em situações distintas (Tabela 47) e ainda, apresentaram limitações práticas significativas, quer seja no campo (volume inconstante de amostragem), quer seja no laboratório (extração tediosa das pastas de saturação contendo altas concentrações de $\mathrm{Na}$ ). Ao que parece, as cápsulas necessitam ser calibradas às nossas condições de solo, conforme assinalado por Ahmed et al. (2001), visando sua ampla utilização nos experimentos com EET.

Quanto aos extratos saturação, o período de repouso (uma noite) requerido pela metodologia de Rhoades (1996), não parece ser o suficiente para permitir equilítrio entre as fases sólida e líquida, implicando na obtenção de altos CV. Ainda, as pastas de saturação são preparadas a partir de TFSA, implicando nos resultados de $\mathrm{N}$ mineral. Os processos de secagem e armazenamento do solo afetam grandemente a dinâmica do $\mathrm{N}$, levando a obtenção de resultados que ora subestimam ora superestimam as concentrações de N-mineral (Mattos Júnior et al., 1995).

Portanto, o emprego dos extratos de saturação somente foi seguro nas determinações de salinidade do solo. Outras avaliações, como as de cátions solúveis e Nmineral não necessáriamente estavam totalmente equivocadas, mas seus respectivos valores absolutos provavelmente não são os fornecidos pelos extratos de saturação. Wolt (1994) apontou para a utilização de pasta de saturação imediatamente após a coleta do solo. $\mathrm{O}$ autor considerou que este método poderia, após correção da umidade, fornecer informações seguras e mais próximas da "verdadeira" solução no solo. Portanto, é um método que necessita ser adaptado e testado às nossas condições e poderia ser uma maneira de avaliar as concentrações de sais, $\mathrm{N}$-mineral e os principais elementos de interesse para química e fertilidade do solo, com custo bem inferior ao necessário para procedimentos de coleta de solução in situ. 


\section{REFERÊNCIAS BIBLIOGRÁFICAS}

ABREU, C.A.; ABREU, M.F.; BERTON, R.S. Análise química de solo para metais pesados. In: ALVAREZ V., V.H.; SCHAEFER, C.E.G.R.; BARROS, N.F.; MELLO, J.W.V.; COSTA, L.M. (Ed.). Tópicos em ciência do solo. Viçosa: Sociedade Brasileira de Ciência do Solo, 2002. v.2. p.645-692.

ABREU, C.A.; ABREU, M.F.; RAIJ, B.van; BATAGLIA, O.C.; ANDRADE, J.C. Extraction of boron from soil by microwave heating for ICP-AES determination. Communications in Soil Science and Plant Analysis, v.25, p.3321-3333, 1994.

ADEKALU, K.O.; OKUNADE, D.A. Effects of pond water and sewage effluent treatments on yield and nutrient uptake of maize (Zea mays L.). Tropical Agriculture, v.79, p.120-124, 2002.

AGENDA 21. Conferência das Nações Unidas sobre Meio Ambiente e Desenvolvimento, 1992, Rio de Janeiro. Brasília: Senado Federal, 1996. 585p.

AGUNWAMBA, J.C. Analysis of socioeconomic and environmental impacts of waste stabilization pond and unrestricted wastewater irrigation: interface with maintenance. Environmental Management, v.27, p.463-476, 2001.

AHMED, M.; SHARMA, M.L.; RICHARDS, Q.D.; AL-KALBANI, M.S. Sampling soil water in sandy soils: comparative analysis of some common methods. Communications in Soil Science and Plant Analysis, v.32, p.1677-1686, 2001.

AL-JALOUD, A.A.; HUSSAIN, G.; AL-SAATI, A.J.; KARIMULLA, S. Effect of wastewater irrigation on mineral composition of corn and sorghum plants in a pot experiment. Journal of Plant Nutrition, v.18, p.1677-1692, 1995. 
ALLHANDS, M.N.; ALLICK, S.A.; OVERMAN, A.R.; LESEMAN, W.G.; VIDAK, W. Municipal water reuse at Tallahassee, Florida. Transactions of the American Society of Agricultural Engineers, v.38, p.411-418, 1995

AL-NAKSHABANDI, G.A.; SAQQAR, M.M.; SHATANAWI, M.R.; FAYYAD, M.; AL-HORANI, H. Some environmental problems associated with the use of treated wastewater for irrigation in Jordan. Agricultural Water Management, v.34, p.8194, 1997.

ALVIM, M.J.; XAVIER, D.F.; BOTREL, M.A.; MARTINS, C.E Resposta do coastcross (Cynodon dactylon (L.) Pers.) a diferentes doses de nitrogênio e intervalos de cortes. Revista Brasileira de Zootecnia, v.27, p.833-840, 1998.

ALVIM, M.J.; XAVIER, D.F.; VERNEQUE, R.S.; BOTREL, M.A. Resposta do Tifton 85 a doses de nitrogênio e intervalos de cortes. Pesquisa Agropecuária Brasileira, v.34, p.2345-2352, 1999.

ALVIM, M.J.; XAVIER, D.F.; VERNEQUE, R.S.; BOTREL, M.A. Resposta do Tifton 68 a doses de nitrogênio e intervalos de cortes. Pesquisa Agropecuária Brasileira, v.35, p.1875-1882, 2000.

AMERICAN PUBLIC HEALTH ASSOCIATION. Standard methods for the examination for water and wastewater. 18.ed. Washington, 1992. 70p.

ARTIOLA, J.F.; PEPPER, I.L. Longterm influence of liquid sewage sludge on the organic carbon and nitrogen content of a furrow-irrigated desert soil. Biology and Fertility of Soils, v.14, p.30-36, 1992.

ASANO, T.; PETTYGROVE, G.S. Using reclaimed municipal wastewater for irrigation. California Agriculture, v.41, n.3/4, p.15-18, 1987.

ASANO, T.; MAEDA, M.; TAKAKI, M. Wastewater reclamation and reuse in Japan: overview and implementation examples. Water Science and Technology, v.34, p.219-226, 1996.

AYERS, R.S.; WESTCOT, D.S. Water quality for agriculture. Rome: Food and Agriculture Organization, 1985. 174p. (Irrigation and Drainage Paper, 29). 
BALKS, M.R.; BOND, W.J.; SMITH, C.J. Effects of sodium accumulation on soil physical properties under an effluent-irrigated plantation. Australian Journal of Soil Research, v.36, p.821-830, 1998.

BARTON, L.; SCHIPPER, L.A.; BARKLE, G.F.; McLEOD, M.; SPEIR, T.W.; TAYLOR, M.D.; McGILL, A.C.; VAN SCHAIK, A.P.; FITZGERALD, N.B.; PANDEY, S.P. Land application of domestic effluent onto four soil types: plant uptake and nutrient leachig. Journal of Environmental Quality, v.34, p.635-643, 2005 .

BIELORAI, H.; VAISMAN, I.; FEIGIN, A. Drip irrigation of cotton with treated municipal effluents: I. Yield response. Journal of Environmental Quality, v.13, p.231-234, 1984.

BOLAN, N.S; HEDLEY, M.J.; WHITE, R.E. Processes of soil acidification during nitrogen cycling with emphasis on legume based pastures. Plant and Soil, v.134, p.53-63, 1991.

BOLE, J.B.; BELL, R.G. Land application of municipal sewage waste water: yield and chemical composition of forage crops. Journal of Environmental Quality, v.7, p.222-226, 1978.

BOND, W.J. Effluent irrigation - an environmental challenge for soil science. Australian Journal of Soil Research, v.36, p.543-555, 1998.

BOUWER, H. Integrated water management: emerging issues and challenges. Agricultural Water Management, v.45, p.217-228, 2000.

BOUWER, H.; CHANEY, R.L. Land treatment of wastewater. Advances in Agronomy, v.26, p.133-176, 1974.

BOUWER, H.; IDELOVITCH, E. Quality requirements for irrigation with sewage water. Journal of Irrigation and Drainage Engineering, v.113, p.516-535, 1987.

BRASIL. CONSELHO NACIONAL DO MEIO AMBIENTE. Resolução n 357, de 17 de março de 2005. Diário Oficial da União - Executivo, 18 mar. 2005. Dispõe sobre a classificação dos corpos de água e diretrizes ambientais para o seu enquadramento, bem como estabelece as condições e padrões de lançamento de efluentes, e dá outras providências. 
BRASIL. MINISTÉRIO DO PLANEJAMENTO E ORÇAMENTO. Censo agropecuário: 1995-1996. Rio de Janeiro: Instituto Brasileiro de Geografia e Estatística, 1998. 383p.

BRASIL. MINISTÉRIO DO PLANEJAMENTO, ORÇAMENTO E GESTÃO. Censo demográfico 2000: características da população e dos domicílios: resultados do universo. Rio de Janeiro: Instituto Brasileiro de Geografia e Estatística, 2001. $519 \mathrm{p}$.

BURTON, G.W. Tifton 85 Bermudagrass - early history of its creation, selection, and evaluation. Crop Science, v.41, p.5-6, 2001.

CAJUSTE, L.J.; VAZQUEZ-A., A.; MIRANDA-C., E. Long-term changes in the extractability and availability of lead, cadmium, and nickel in soils under wastewater irrigation. Communications in Soil Science and Plant Analysis, v.33, p.3325-3333, 2001.

CAMARGO, O.A.; MONIZ, A.C.; JORGE, J.A.; VALADARES, J.M.A.S. Métodos de análise química, mineralógica e física de solos do Instituto Agronômico de Campinas. Campinas: Instituto Agronômico, 1986. 94p. (Boletim Técnico, 106).

CAMERON, K.C.; DI, H.J.; McLAREN, R.G. Is soil an appropriate dumping ground for our wastes? Australian Journal of Soil Research, v.35, p.995-1035, 1997.

CHANG, A.C.; PAN, G.; PAGE, A.L.; ASANO, T. Developing human health-related chemical guidelines for reclaimed water and sewage sludge applications in agriculture. Geneva: World Health Organization, 2002. 94p.

COUTINHO, E.L.M.; SILVA, A.R.; MONTEIRO, F.A.; RODRIGUES, L.R.A. Adubação potássica em forrageiras. In: SIMPÓSIO SOBRE MANEJO DA PASTAGEM, 21., Piracicaba, 2004. Anais. Piracicaba: Fundação de Estudos Agrários Luiz de Queiroz, 2004. p.219-277.

CROMER, R.N.; TOMPKINS, D.; BARR, N.J.; HOPMANS, P. Irrigation of Monterey pine with wastewater: effect on soil chemistry and groundwater composition. Journal of Environmental Quality, v.13, p.539-542, 1984. 
DARWISH, M.R.; EL-AWAR, F.A.; SHARARA, M.; HAMDAR, B. Economicenvironmental approach for optimum wastewater utilization in irrigation: a case study in Lebanon. Applied Engineering in Agriculture, v.15, p.41-48, 1999.

DAWES, L.; GOONETILLEKE, A. An investigation into the role of site and soil characteristics in onsite sewage treatment. Environmental Geology, v.44, p.467477, 2003.

DAY, A.D.; McFADYEN, J.A.; TUCKER,T.C.; CLUFF, C.B. Effects of municipal waste water on the yield and quality of cotton. Journal of Environmental Quality, v.10, p.47-49, 1981.

DAY, A.D.; SWINGLE, R.S.; TUCKER, T.C.; CLUFF, C.B. Alfalfa hay grown with municipal waste water and pump water. Journal of Environmental Quality, v.11, p.23-24, 1982.

DUBEUX JUNIOR., J.C.; SANTOS, H.Q.; SOLLENBERGER, L.E. Ciclagem de nutrientes: perspectivas de aumento da sustentabilidade da pastagem manejada intensivamente. In: SIMPÓSIO SOBRE MANEJO DA PASTAGEM, 21., Piracicaba, 2004. Anais. Piracicaba: Fundação de Estudos Agrários Luiz de Queiroz, 2004. p.357-400.

EL-NENNAH, M.; EL-KOBBIA, T.; SHEHATA, A.; EL-GAMAL, I. Effect of irrigation loamy sand soil by sewage effluents on its content of some nutrients and heavy metals. Plant and Soil, v.65, p.289-292, 1982.

EMPRESA BRASILEIRA DE PESQUISA AGROPECUÁRIA. Manual de métodos de análise de solo. 2.ed. Rio de Janeiro: Centro Nacional de Pesquisa de Solos, 1997. 212p.

EMPRESA BRASILEIRA DE PESQUISA AGROPECUÁRIA. Sistema brasileiro de classificação de solos. Rio de Janeiro: Centro Nacional de Pesquisa de Solos, 1999. $412 \mathrm{p}$.

FAGERIA, N.K.; BALIGAR, V.C.; JONES, C.A. Growth and mineral nutrition of field crops. 2.ed. New York: Marcel Dekker, 1997. 624p. 
FALKINER, R.A.; POLGLASE, P.J. Transport of phosphorus through soil in an effluent-irrigated tree plantation. Australian Journal of Soil Research, v.35, p.385-397, 1997a.

FALKINER, R.A.; SMITH, C.J. Changes in soil chemistry in effluent-irrigated Pinus radiata and Eucalyptus grandis. Australian Journal of Soil Research, v.35, p.131-147, 1997b.

FASSBENDER, H.W.; BORNEMISZA, E. Química de suelos con énfasis en suelos de América Latina. 2.ed. San José: Instituto Interamericano de Cooperación para la Agricultura, 1987. 420p.

FEIGIN, A.; BIELORAI, H.; DAG, Y.; KIPNIS, T.; GISKIN, M. The nitrogen factor in the management of effluent-irrigated soils. Soil Science, v.125, p.248-254, 1978.

FEIGIN, A.; RAVINA, I.; SHALHEVET, J. Irrigation with treated sewage effluent: management for environmental protection. Berlin: Springer-Verlag, 1991. 224p.

FONSECA, A.F. Disponibilidade de nitrogênio, alterações nas características químicas do solo e do milho pela aplicação de efluente de esgoto tratado. Piracicaba, 2001. 110p. Dissertação (Mestrado) - Escola Superior de Agricultura Luiz de Queiroz, Universidade de São Paulo.

FOX, R.L.; HUE, N.V.; PARRA, A.J. A turbidimetric method for determining phosphate-extractable sulfates in tropical soils. Communications in Soil Science and Plant Analysis, v.18, p.343-357, 1987.

FRIEDEL, J.K.; LANGER, T.; SIEBE, C.; STAHR, K. Effects of long-term waste water irrigation on soil organic matter, soil microbial biomass and its activities in central Mexico. Biology and Fertility Soils, v.31, p.414-421, 2000.

GADALLAH, M.A.A. Effects of industrial and sewage waste water on the concentration of soluble carbon, nitrogen, and some mineral elements in sunflower plants. Journal of Plant Nutrition, v.17, p.1369-1384, 1994.

GOH, K.M.; CONDRON, L.M. Plant availability of phosphorus accumulated from long-term applications of superphosphate and effluent to irrigated pastures. New Zealand of Agricultural Research, v.32, p.45-51, 1989. 
GOLDBERG, S.; SUAREZ, D.L.; GLAUBIG, R.A. Factors affecting clay dispersion and aggregate stability of arid-zone soils. Soil Science, v.146, p.317-325, 1988.

GRATTAN, S.R.; GRIEVE, C.M.; POSS, J.A.; ROBINSON, P.H.; SUAREZ, D.L.; BENES, S.E. Evaluation of salt-tolerant forages for sequential water reuse systems. I. Biomass production. Agricultural Water Management, v.70, p.109-120, 2004.

GRIEVE, C.M.; POSS, J.A.; GRATTAN, S.R.; SUAREZ, D.L.; BENES, S.E.; ROBINSON, P.H. Evaluation of salt-tolerant forages for sequential water reuse systems. II. Plant-ion relations. Agricultural Water Management, v.70, p.121$135,2004$.

HANSEN, E.A.; HARRIS, A.R. Validity of soil-water samples collected with porous ceramic cups. Soil Science Society of America Proceedings, v.39, p.528-536, 1975.

HAYES, A.R.; MANCINO, C.F.; PEPPER, I.L. Irrigation of turfgrass with secondary sewage effluent. I. Soil and leachate water quality. Agronomy Journal, v.82, p.939-943, 1990a.

HAYES, A.R.; MANCINO, C.F.; FORDEN, W.Y.; KOPEC, D.M.; PEPPER, I.L. Irrigation of turfgrass with secondary sewage effluent. II. Turf quality. Agronomy Journal, v.82, p.943-946, 1990 b.

HILL, G.M.; GATES, R.N.; BURTON, G.W. Forage quality and grazing steer performance from Tifton 85 and Tifton 78 Bermudagrass pastures. Journal of Animal Science, v.71, p.3219-3225, 1993.

HILLEL, D. Environmental soil physics. San Diego: Academic Press, 1998. 771p.

HOOK, J.E. Movement of phosphorus and nitrogen in soil following application of municipal wastewater. In: NELSON, D.W.; ELRICK, D.E.; TANJI, K.K. (Ed.) Chemical mobility and reactivity in soil systems. Madison: Soil Science Society of America, 1981. p.241-255.

HORTENSTINE, C.C. Chemical changes in the soil solution from a Spodosol irrigated with secondary-treated sewage effluent. Journal of Environmental Quality, v.5, p.335-338, 1976. 
HUSSAIN, G.; AL-JALOUD, A.A. Effect of irrigation and nitrogen on yield, yield components and water use efficiency of barley in Saudi Arabia. Agricultural Water Management, v.36, p.55-70, 1998.

IBRAHIM, L. Caracterização física, química, mineralógica e morfológica de uma seqüência de solos em Lins/SP. Piracicaba, 2002. 86p. Dissertação (Mestrado) Escola Superior de Agricultura Luiz de Queiroz, Universidade de São Paulo.

INGLÉS, A.; GÓMEZ, M.; NOGALES, R. Efecto del riego con aguas residuales urbanas depuradas sobre la disponibilidad de metales pesados para la planta. Suelo y Planta, v.2, p.703-712, 1992.

JEYARAMAN, S. Influence of $\mathrm{N}$ levels of crude protein yield of hybrid napier under sewage effluent irrigation. Indian Journal of Agronomy, v.33, p.326-327, 1988.

JOHNS, G.G.; McCONCHIE, D.M. Irrigation of bananas with secondary treated sewage effluent. I. Field evaluation of effect on plant nutrients and additional elements in leaf, pulp and soil. Australian Journal of Agricultural Research, v.45, p.1601-1617, 1994a.

JOHNS, G.G.; McCONCHIE, D.M. Irrigation of bananas with secondary treated sewage effluent. II. Effect on plant nutrients, additional elements and pesticide residues in plants, soil and leachate using drainage lysimeters. Australian Journal of Agricultural Research, v.45, p.1619-1638, 1994 b.

JORDAN, M.J.; NADELHOFFER, K.J.; FRY, B. Nitrogen cycling in forest and grass ecosystems irrigated with ${ }^{15} \mathrm{~N}$-enriched wastewater. Ecological Applications, v.7, p.864-881, 1997.

KANDELER, E.; KAMPICHLER, C.; HORAK, O. Influence of heavy metals on the functional diversity of soil microbial communities. Biology and Fertility Soils, v.23, p.299-306, 1996.

KARDOS, L.T.; HOOK, J.E. Phosphorus balance in sewage effluent treated soils. Journal of Environmental Quality, v.5, p.87-90, 1976.

KARLEN, D.L.; VITOSH, M.L.; KUNZE, R.J. Irrigation of corn with simulated municipal sewage effluent. Journal of Environmental Quality, v.5, p.269-273, 1976. 
LAMBAIS, M.R. Poluição orgânica e seu controle. In: CARDOSO, E.J.B.N; TSAI, S.M.; NEVES, M.C.P. (Ed.). Microbiologia do Solo. Campinas: Sociedade Brasileira de Ciência do Solo, 1992. p.91-103.

LATTERELL, J.J.; DOWDY, R.H.; CLAPP, C.E.; LARSON, W.E.; LINDEN, D.R. Distribution of phosphorus in soils irrigated with municipal waste-water effluent: a 5-year study. Journal of Environmental Quality, v.11, p.124-128, 1982.

LEITA, L.; DE NOBILI, M.; MUHLBACHOVA, G.; MONDINI, C.; MARCHIOL, L.; ZERBI, G. Bioavailatility and effects of heavy metals on soil microbial biomass survival during laboratory incubation. Biology and Fertility Soils, v.19, p.103-108, 1995.

LEVY, R.; FINE, P.; FEIGIN, A. Sodicity levels of soils equilibrated with wastewaters. Soil Science Society of America Journal, v.50, p.35-39, 1986.

LIBARDI, P.L. Dinâmica da água no solo. 2.ed. Piracicaba: Paulo Leonel Libardi, 2000. 509p.

LINDEN, D.R.; CLAPP, C.E.; GILLEY, J.R. Effects of scheduling municipal wastewater effluent irrigation of reed canarygrass on nitrogen renovation and grass production. Journal of Environmental Quality, v.10, p.507-510, 1981.

LINDSAY, W.L. Chemical equilibria in soils. New York: John Wiley, 1979. 449p.

LINDSAY, W.L.; NORVELL, W.A. Development of a DTPA soil test for zinc, iron, manganese, and copper. Soil Science Society of America Journal, v.42, p.421$428,1978$.

LOYOLA JUNIOR., E.; PAVAN, M.A. Seletividade de troca de cátions em solos ácidos. Revista Brasileira de Ciência do Solo, v.13, p.131-138, 1989.

LUND, L.J.; PAGE, A.L.; NELSON, C.O.; ELLIOTT, R.A. Nitrogen balances for an effluent irrigation area. Journal of Environmental Quality, v.10, p.349-352, 1981.

MAAS, E.V. Crop tolerance to saline sprinkling water. Plant and soil, v.89, p.273$284,1985$. 
MADYIWA, S.; CHIMBARI, M.; NYAMANGARA, J.; BANGIRA, C. Cumulative effects of sewage sludge and effluent mixture application on soil properties of a sandy soil under a mixture of star and kikuyu grasses in Zimbabwe. Physics and Chemistry of the Earth, v.27, p.747-753, 2002.

MADYIWA, S.; CHIMBARI, M.J.; SCHUTTE, C.F.; NYAMANGARA, J. Greenhouse studies on the phyto-extraction capacity of Cynodon nlemfuensis for lead and cadmium under irrigation with treated wastewater. Physics and Chemistry of the Earth, v.28, p.859-867, 2003.

MAGESAN, G.N.; MCLAY, C.D.A.; LAL, V.V. Nitrate leaching from a free-draining volcanic soil irrigated with municipal sewage effluent in New Zealand. Agriculture, Ecosystems and Environment, v.70, p.181-187, 1998.

MALAVOLTA, E.; VITTI, G.C.; OLIVEIRA, S.A. Avaliação do estado nutricional das plantas: princípios e aplicações. 2.ed. Piracicaba: Potafos, 1997. 319p.

MANCINO, C.F.; PEPPER, I.L. Irrigation of turfgrass with secondary sewage effluent: soil quality. Agronomy Journal, v.84, p.650-654, 1992.

MARCELINO, K.R.A.; VILELA, L.; LEITE, G.G.; GUERRA, A.F.; DIOGO, J.M.S. Manejo da adubação nitrogenada de tensões hídricas sobre a produção de matéria seca e índice de área foliar de Tifton 85 cultivado no Cerrado. Revista Brasileira de Zootecnia, v.32, p.268-275, 2003.

MARTHA JÚNIOR, G.B.; VILELA, L.; BARIONI, L.G.; SOUSA, D.M.G.; BARCELOS, A.O. Manejo da adubação nitrogenada em pastagens. In: SIMPÓSIO SOBRE MANEJO DA PASTAGEM, 21., Piracicaba, 2004. Anais. Piracicaba: Fundação de Estudos Agrários Luiz de Queiroz, 2004. p.155-215.

MATTOS JÚNIOR, D.; CANTARELLA, H.; RAIJ, B.VAN. Manuseio e conservação de amostras de solo para preservação do nitrogênio inorgânico. Revista Brasileira de Ciência do Solo, v.19, p.423-431, 1995.

McBRIDE, M.B. Reactions controlling heavy metal solubility in soils. Advances in Soil Science, v.10, p.1-57, 1989. 
McNEAL, B.L.; COLEMAN, N.T. Effect of solution composition on soil hydraulic conductivity. Soil Science Society of America Proceedings, v.30, p.308-312, 1966.

MENÉNDEZ, I.; GALLARDO, J.F.; VICENTE, M.A. Functional and chemical calibrates of ceramic cup water samplers in forest soils. Communications in Soil Science and Plant Analysis, v.34, p.1153-1175, 2003.

MENGEL, K. Turnover of organic nitrogen in soils and its availability to crops. Plant and Soil, v.181, p.83-93, 1996.

MENGEL, K.; KIRKBY, E.A. Principles of plant nutrition. 5.ed. Dordrecht: Kluwer Academic Publishers, 2001. 849p.

MEURER, E.J.; ANGHINONI, I. A solução no solo. In: MEURER, E.J. (Ed.). Fundamentos de química do solo. 2.ed. Porto Alegre: Genesis, 2004. p.101-129.

MEURER, E.J.; RHENHEIMER, D. ; BISSANI, C.A. Fenômenos de sorção em solos. In: MEURER, E.J. (Ed.). Fundamentos de química do solo. 2.ed. Porto Alegre: Genesis, 2004. p.131-179.

MIELNICZUK, J.; BAYER, C.; VEZZANI, F.M.; LOVATO, T.; FERNANDES, F.F.; DEBARBA, L. Manejo de solo e culturas e sua relação com os estoques de carbono e nitrogênio do solo. In: CURI, N.; MARQUES,. J.J.; GUILHERME, L.R.G.; LIMA, J.M.; LOPES, A.S.; ALVAREZ V.; V.H. (Ed.). Tópicos em ciência do solo. Viçosa: Sociedade Brasileira de Ciência do Solo, 2003. v.3. p.209-248.

MILLER, W.P.; FRENKEL, H.; NEWMAN, K.D. Flocculation concentration and sodium/calcium exchange of kaolinitc soil clays. Soil Science Society of America Journal, v.54, p.346-351, 1990.

MOHAMMAD, M.J.; MAZAHREH, N. Changes in soil fertility parameters in response to irrigation of forage crops with secondary treated wastewater. Communications in Soil Science and Plant Analysis, v.34, 1281-1294, 2003.

MOHAMMAD, M.J.; AYADI, M. Forage yield and nutrient uptake as influenced by secondary treated wastewater. Journal of Plant Nutrition, v.27, p.351-364, 2004.

MORAES, J.F.V.; DYNIA, J.F. Uso de cápsulas porosas para extrair solução do solo. Pesquisa Agropecuária Brasileira, v.25, p.1523-1528, 1990. 
MORTVEDT, J.J. Bioavailability of micronutrients. In: SUMNER, M.E. (Ed.). Handbook of soil science. Boca Raton: CRC Press, 2000. p.D71-D88.

MOSS, P. Some aspects of the cation status of soil moisture. I. The ratio law and soil moisture content. Plant and Soil, v.18, p.99-113, 1963.

MYERS, R.J.K.; CAMPBELL, C.A.; WEIER, K.L. Quantitative relationship between net nitrogen mineralization and moisture content of soils. Canadian Journal of Soil Science, v.62, p.111-124, 1982.

NELSON, D.W.; SOMMERS, L.E. Total carbon, organic carbon, and organic matter. In: SPARKS, D.L. (Ed.). Methods of soil analysis: chemical methods. pt. 3. Madison: Soil Science Society of America/American Society of Agronomy, 1996. p.961-1010.

OVERMAN, A.R. Irrigation of corn with municipal effluent. Transactions of the American Society of Agricultural Engineers, v.24, p.74-80, 1981.

OVERMAN, A.R.; NGUY, A. Growth response and nutrient uptake by forage crops under effluent irrigation. Communication in Soil Science and Plant Analysis, v.6, p.81-93, 1975.

PALIWAL, K.V.; GANDHI, A.P. Effect of salinity, SAR, Ca:Mg ratio in irrigation water, and soil texture on the predictability of exchangeable sodium percentage. Soil Science, v.122, p.85-90, 1976.

PALIWAL, K. KARUNAICHAMY, K.S.T.K.; ANANTHAVALLI, M. Effect of sewage water irrigation on growth performance, biomass and nutrient accumulation in Hardwickia binata under nursery conditions. Bioresource Technology, v.66, p.105-111, 1998.

PANAYIOTOPOULOS, K.P.; BARBAYIANNIS, N.; PAPATOLIOS, K. Influence of electrolyte concentration, sodium adsorption ratio, and mechanical disturbance on dispersed clay particle size and critical flocculation concentration in Alfisols. Communications in Soil Science and Plant Analysis, v.35, p.1415-1434, 2004.

PAUL, E.A.; CLARK, F.E. Soil microbiology and biochemistry. San Diego: Academic Press, 1989. 275p. 
PESCOD, M.B. Wastewater treatment and use in agriculture. Rome: Food and Agriculture Organization, 1992. 125p. (Irrigation and Drainage Paper, 47).

POLGLASE, P.J.; TOMPKINS, D.; STEWART, L.G.; FALKINER, R.A. Mineralization and leaching of nitrogen in an effluent-irrigated pine plantation. Journal of Environmental Quality, v.24, p.911-920, 1995.

POLLICE, A.; LOPEZ, A.; LAERA, G.; RUBINO, P.; LONIGRO, A. Tertiary filtered municipal wastewater as alternative water source in agriculture: a field investigation in Southern Italy. Science of the Total Environment, v.324, p.201-210, 2004.

PREMAZZI, L.M.; MONTEIRO, F.A.; CORRENTE, J.E. Tillering of Tifton 85 Bermudagrass in response to nitrogen rates and time of application after cutting. Scientia Agricola, v.60, p.565-571, 2003.

PRIMAVESI, A.C.; PRIMAVESI, O.; CORREAA, L.A.; CANTARELLA, H.; SILVA, A.G.; FREITAS, A.R.; VIVALDI, L.J. Adubação nitrogenada em capimCoastcross: efeitos na extração de nutrientes e recuperação aparente do nitrogênio. Revista Brasileira de Zootecnia, v.33, p.68-78, 2004.

QUIN, B.F.; FORSYTHE, L.J. Surface irrigation of pasture with treated sewage effluent. II. Drainage losses of nitrate and other nutrients. New Zealand Journal of Agricultural Research, v.21, p.427-434, 1978a.

QUIN, B.F.; SYERS, J.K. Surface irrigation of pasture with treated sewage effluent. III. Heavy metal content of sewage effluent, sludge, soil, and pasture. New Zealand Journal of Agricultural Research, v.21, p.435-442, 1978b.

QUIN, B.F.; WOODS, P.H. Surface irrigation of pasture with treated sewage effluent. I. Nutrient status of soil and pastures. New Zealand Journal of Agricultural Research, v.21, p.419-426, $1978 \mathrm{c}$.

QUIRK, J.P.; SCHOFIELD, R.K. The effect of electrolyte concentration on soil permeability. Journal of Soil Science, v.6, p.163-178, 1955.

RAIJ, B.van. Gesso agrícola na melhoria do ambiente radicular no subsolo. São Paulo: Associação Nacional para Difusão de Adubos, 1988. 88p.

RAIJ, B.van. Fertilidade do solo e adubação. Piracicaba: Potafos, 1991. 343p. 
RAMIREZ-FUENTES, E.; LUCHO-CONSTANTINO, C; ESCAMILLA-SILVA, E.; DENDOOVEN, L. Characteristics, and carbon and nitrogen dynamics in soil irrigated with wastewater for different lengths of time. Bioresource Technology, v.85, 179-187, 2002.

RAYDEN, J.C.; PRATT, P.F. Phosphorus removal from wastewater applied to land. Hilgardia, v.48, p.1-36, 1980.

REBOLL, V.; CEREZO, M.; ROIG, A.; FLORS, V.; LAPEÑA, L.; GARCÍAAGUSTÍN, P. Influence of wastewater vs groundwater on young Citrus trees. Journal of the Science of Food and Agriculture, v.80, p.1441-1446, 2000.

REEVE, R.C.; DOERING, E.J. Sampling the soil solution for salinty appraisal. Soil Science, v.99, p.339-344, 1965.

REICHARDT, K.; LIBARDI, P.L.; MEIRELLES, N.M.F.; FERREYRA H., F.F.; ZAGATTO, E.A.G.; MATSUI, E. Extração e análise de nitratos em solução de solo. Revista Brasileira de Ciência do solo, v.1, p.130-132, 1977.

RHOADES, J.D. Salinity: electrical conductivity and total dissolved solids. In: SPARKS, D.L. (Ed.). Methods of soil analysis: chemical methods. pt. 3. Madison: Soil Science Society of America/American Society of Agronomy, 1996. p.417-435.

ROSS, D.J.; CAIRNS, A.; SPEIR, T.W. Effect of irrigation with municipal water or sewage effluent on the biology of soil cores. IV. Respiratory and enzyme activities. New Zealand Journal of Agricultural Research, v. 21, p.411-417, 1978.

RUZICKA, J.; HANSEN, E.H. Flow injection analysis. I. The concept of a new, simple, ultrafast continuous flow analyser. Analytica Chimica Acta, v.78, p.145-157, 1975.

SANTAMARÍA, J.; TORANZOS, G.A. Enteric pathogens and soil: a short review. International Microbiology, v.6, p.5-9, 2003.

SCHIPPER, L.A.; WILLIAMSON, J.C.; KETTLES, H.A; SPEIR, T.W. Impact of landapplied tertiary-treated effluent on soil biochemical properties. Journal of Environmental Quality, v.25, p.1073-1077, 1996. 
SCHWAB, A.P. The soil solution. In: SUMNER, M.E. (Ed.). Handbook of soil science. Boca Raton: CRC Press, 2000. p.B85-B122.

SEGARRA, E.; DARWISH, M.R.; ETHRIDGE, D.E. Returns to municipalities from integrating crop production with wastewater disposal. Resources, Conservation and Recycling, v.17, p.97-107, 1996.

SHAHALAM, A.; ZAHRA, B.M.A.; JARADAT, A. Wastewater irrigation effect on soil, crop and environment: a pilot scale study at Irbid, Jordan. Water, Air, and Soil Pollution, v.106, p.425-445, 1998.

SHAINGERG, I.; LETEY, J. Response of soils to sodic and saline conditions. Hilgardia, v.52, p.1-57, 1984.

SIEBE, C. Heavy metal availability to plants in soils irrigated with wastewater from Mexico City. Water Science and Technology, v.32, p.29-34, 1995.

SINGH, G.; BHATI, M. Growth, biomass production, and nutrient composition of eucalyptus seedlings irrigated with municipal effluent in loamy sand soil of Indian desert. Journal of Plant Nutrition, v.26, p.2469-2488, 2003.

SINGH, U.; UEHARA, G. Electrochemistry of the double layer: principles and applications to soils. In: SPARKS, D.L.. (Ed.). Soil physical chemistry. 2.ed. Boca Raton: CRC Press, 1999. p.1-46.

SMITH, C.J.; BOND, W.J. Losses of nitrogen from an effluent-irrigated plantation. Australian Journal of Soil Research, v.37, p.371-389, 1999.

SMITH, C.J.; HOPMANS, P.; COOK, F.J. Accumulation of $\mathrm{Cr}, \mathrm{Pb}, \mathrm{Cu}, \mathrm{Ni}, \mathrm{Zn}$ and $\mathrm{Cd}$ in soil following irrigation with treated urban effluent in Australia. Environmental Pollution, v.94, p.317-323, 1996.

SMITH, F.W. The effect of sodium on potassium nutrition and ionic relations in Rhodes grass. Australian Journal of Agricultural Research, v.25, p.407-414, 1974.

SMITH, J.H.; PETERSON, J.R. Recycling of nitrogen through land application of agricultural, food processing, and municipal wastes. In: STEVENSON, F.J. (Ed.). Nitrogen in agricultural soils. 2.ed. Madison: American Society of Agronomy/Soil Science Society of America, 1982. p.791-831. 
SNOW, V.O.; SMITH, C.J.; POLGLASE, P.J.; PROBERT, M.E. Nitrogen dynamics in a eucalypt plantation irrigated with sewage effluent or bore water. Australian Journal of Soil Research, v.37, p.527-544, 1999.

SOMMERS, L.E.; NELSON, D.W.; OWENS, L.B. Status of inorganic phophorus in soils irrigated with municipal wastewater. Soil Science, v.127, p.340-350, 1979.

SONNEVEND, C.; VAN DEN ENDE, J.; DE BES, S.S. Estimating the chemical compositions of soil solutions by obtaining saturation extracts or specific 1:2 by volume extracts. Plant and Soil, v.122, p.169-175, 1990.

SPEIR, T.W. Soil biochemical properties as indices of performance and sustainability of effluent irrigation systems in New Zealand: a review. Journal of The Royal Society of New Zealand, v.32, p.535-553, 2002.

SPEIR, T.W.; VAN SCHAIK, A.P.; KETTLES, H.A.; VICENT, K.W.; CAMPBELL, D.J. Soil and stream-water impacts of sewage effluent irrigation onto steeply sloping land. Journal of Environmental Quality, v.28, p.1105-1114, 1999.

STANFORD, G.; SMITH, S.J. Nitrogen mineralization potentials of soils. Soil Science Society of America Proceedings, v.36, p.465-472, 1972.

STANFORD, G.; EPSTEIN, E. Nitrogen mineralization-water relations in soils. Soil Science Society of America Proceedings, v.38, p.99-102, 1974.

STEVENSON, F.J. Cycles of soil: carbon, nitrogen, phosphorus, sulfur, micronutrients. New York: John Wiley, 1986. 380p.

STEWART, H.T.L.; HOPMANS, P.; FLINN, D.W. Nutrient accumulation in trees and soil following irrigation with municipal effluent in Australia. Environmental Pollution, v.63, p.155-177, 1990.

SUAREZ, D.L. Relation between $\mathrm{pH}_{\mathrm{c}}$ and sodium adsorption ratio (SAR) and an alternative method of estimating SAR of soil or drainage waters. Soil Science Society of America Journal, v.45, p.469-475, 1981.

SUAREZ, D.L. Prediction of $\mathrm{pH}$ errors in soil-water extractors due to degassing. Soil Science Society of America Journal, v.51, p.64-67, 1987.

SUAREZ, D.L. Thermodynamics of the soil solution. In: SPARKS, D.L.. (Ed.). Soil physical chemistry. 2.ed. Boca Raton: CRC Press, 1999. p.97-134. 
SUAREZ, D.L.; RHOADES, J.D.; LAVADO, R.; GRIEVE, C.M. Effect of pH on saturated hydraulic conductivity and soil dispersion. Soil Science Society of America Journal, v.48, p.50-55, 1984.

SUMNER, M.E. Sodic soils: new perspectives. Australian Journal of Soil Research, v.31, p.683-750, 1993.

SUMNER, M.E. Beneficial use of effluents, wastes, and biosolids. Communications in Soil Science and Plant Analysis, v.31, p.1701-1715, 2000.

TAKACHI, C.Y.; PAVAN, M.A. Efeito da natureza e da força iônica do cátion na acidez da solução do solo. Revista Brasileira de Ciência do Solo, v.19, p.15-18, 1995.

TANJI, K.K. Irrigation with marginal quality waters: issues. Journal of Irrigation and Drainage Engineering, v.123, p.165-169, 1997.

THE SAS SYSTEM. SAS Institute Inc. Release 8.02. Cary: The SAS Institute, 1999.

TISDALE, S.L.; NELSON, W.L.; BEATON, J.D. Soil fertility and fertilizers. 4.ed. New York: Macmillan, 1985. 754p.

VAISMAN, I.; SHALHEVET, J.; KIPNIS, T.; FEIGIN, A. Reducing ground-water pollution from municipal waste-water irrigation of Rhodes grass grown on sand dunes. Journal of Environmental Quality, v.10, p.434-439, 1981.

VALSECCHI, G.; GIGLIOTTI, C.; FARINI, A. Microbial biomass, activity, and organic matter accumulation in soils contaminated with heavy metals. Biology and Fertility Soils, v.20, p.253-259, 1995.

VAN GENUCHTEN, M.T. A closed-form equation for predicting the hydraulic conductivity of unsaturated soils. Soil Science Society of America Journal, v.44, p.892-898, 1980.

VAZQUEZ-MONTIEL, O.; HORAN, N.J.; MARA, D.D. Management of domestic wastewater for reuse in irrigation. Water Science and Technology, v.33, p.355$362,1996$.

VON SPERLING, M. Introdução à qualidade das águas e ao tratamento de esgoto. Belo Horizonte: Departamento de Engenharia Sanitária e Ambiental - Universidade Federal de Minas Gerais, 1995. 243p. 
VON SPERLING, M. Lagoas de estabilização. Belo Horizonte: Departamento de Engenharia Sanitária e Ambiental - Universidade Federal de Minas Gerais, 1996. $134 \mathrm{p}$.

WAGNER, G.H. Use of porous ceramic cups to sample soil water within the profile. Soil Science, v.94, p.379-386, 1962.

WANG, Z.; CHANG, A.C.; WU, L.; CROWLEY, D. Assessing the soil quality of longterm reclaimed wastewater-irrigated cropland. Geoderma, v.114, p.261-278, 2003.

WERNER, J.C.; PAULINO, V.T.; CANTARELLA, H.; ANDRADE, N.O.; QUAGGIO, J.A. Forrageiras. In: RAIJ, B.van; CANTARELLA, H.; QUAGGIO, J.A.; FURLANI, A.M.C. (Ed.). Recomendações de adubação e calagem para o Estado de São Paulo. 2.ed. Campinas: Instituto Agronômico, 1996. p.263-273. (Boletim Técnico, 100).

WESTCOT, D.W. Quality control of wastewater for irrigated crop production. Rome: Food and Agriculture Organization, 1997. (Water Reports, 10).

WOLT, J.D. Soil solution chemistry: applications to environmental science and agriculture. New York: John Wiley, 1994. 345p.

WU, L.; BAKER, J.M.; ALLMARAS, R.R. Numerical and field evaluation of soil water sampled by suction lysimeters. Journal of Environmental Quality, v.24, p.147-152, 1995.

YADAV, R.K.; GOYAL, B.; SHARMA, R.K.; DUBEY, S.K.; MINHAS, P.S. Postirrigation impact of domestic sewage effluent on composition of soils, crops and ground water. A case study. Environment International, v.28, p.481-486, 2002.

ZEKRI, M.; KOO, R.C.J. Treated municipal wastewater for citrus irrigation. Journal of Plant Nutrition, v.17, p.693-708, 1994. 